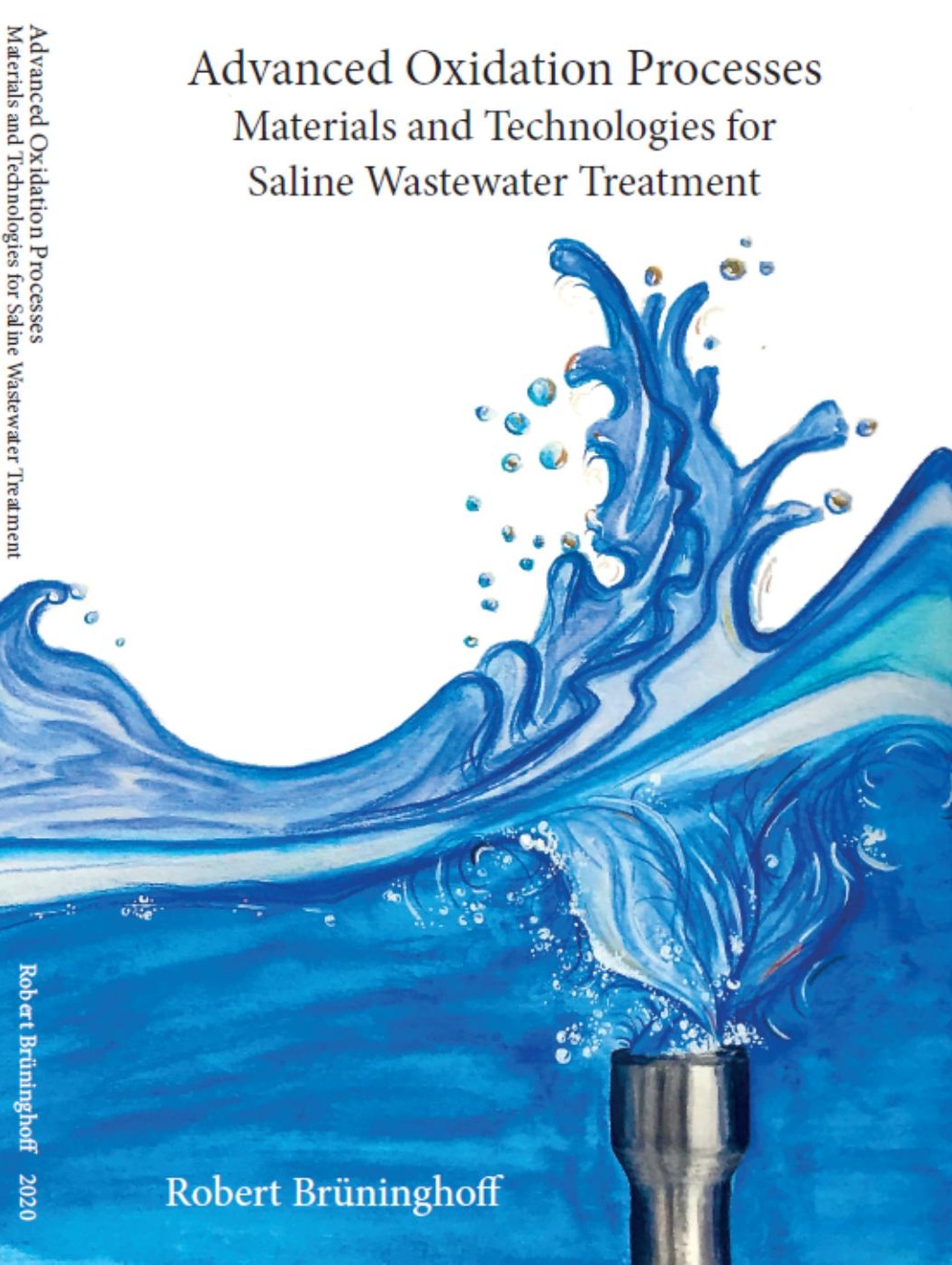




\title{
ADVANCED OXIDATION PROCESSES MATERIALS AND TECHNOLOGIES FOR SALINE WASTEWATER TREATMENT
}

\author{
Robert Brüninghoff
}





\section{ADVANCED OXIDATION PROCESSES \\ MATERIALS AND TECHNOLOGIES FOR SALINE WASTEWATER TREATMENT}

\section{DISSERTATION}

to obtain

the degree of doctor at the University of Twente, on the authority of the rector magnificus, prof.dr. T.T.M. Palstra, on the account of the decision of the Doctorate Board, to be publicly defended on Friday the $18^{\text {th }}$ of September 2020 at 16:45 hours

$$
\text { by }
$$

\section{Robert Brüninghoff}

born on the $22^{\text {nd }}$ September 1988

in Stadtlohn, Germany 
This dissertation has been approved by:

Supervisor:

prof.dr. G. Mul University of Twente

Co-supervisor:

dr. B. T. Mei University of Twente

The research described in this thesis was performed in the PhotoCatalytic Synthesis group within the faculty of Science and Technology, and the MESA+ Institute for Nanotechnology at the University of Twente. This research was funded by the Netherlands Organization for Scientific Research (NWO), which is partly funded by the Ministry of Economic Affairs and Climate Policy, and co-financed by the Netherlands Ministry of Infrastructure and Water Management and partners of the Dutch Water Nexus consortium (project number 14301)

\section{Advanced Oxidation Processes}

Materials and Technologies for Saline Wastewater Treatment

$\mathrm{PhD}$ thesis, University of Twente, Enschede, The Netherlands

Cover design: Surrealistic depiction of a water flame emerging from a Bunsen burner, symbolizing both hot and cold oxidation processes; Melissa Gile

Printed by: Gildeprint, Enschede, The Netherlands

ISBN: $\quad$ 978-90-365-5031-4

DOI: $\quad 10.3990 / 1.9789036550314$

(C) 2020 Robert Brüninghoff, The Netherlands. All rights reserved. No parts of this thesis may be reproduced, stored in a retrieval system or transmitted in any form or by any means without permission of the author. Alle rechten voorbehouden. Niets uit deze uitgave mag worden vermenigvuldigd, in enige vorm of op enige wijze, zonder voorafgaande schriftelijke toestemming van de auteur. 


\section{Graduation Committee:}

\section{Chairman/secretary}

prof.dr. J. L. Herek

University of Twente

\section{Supervisor}

prof.dr. G. Mul

University of Twente

\section{Co-supervisor}

dr. B. T. Mei

University of Twente

Committee Members:

prof.dr. W. Choi

Pohang University of Science and Technology

prof.dr.ir. D.C. Nijmeijer

Eindhoven University of Technology

prof.dr. S.J.G. Lemay

University of Twente

prof.dr. J.G.E. Gardeniers

University of Twente

dr. A.W. Jeremiasse

Magneto special anodes B.V. (an Evoqua brand) 



\section{Table of Contents}

Chapter 1: General introduction

Chapter 2: Comparative analysis of photocatalytic and electrochemical degradation of 4-ethylphenol in saline conditions

Chapter 3: Photocatalytic and electrochemical degradation treatment of cooling tower blowdown water - a case study

Chapter 4: Electrochemical defect engineering of titania 85

Chapter 5: Influence of Niobium on the charge transfer properties, lifetime and recovery of electrochemically reduced $\mathrm{TiO}_{\mathrm{x}}$

Chapter 6: Cathodic reduction of oxychlorides in electrooxidized saline water

Chapter 7: $\quad$ Summary and perspective

Samenvatting

Acknowledgements

List of Publications 



\section{Chapter 1}

General introduction 


\subsection{Sustainable development}

Sustainable development is of outmost importance to enable a better future. A future with less people suffering from poverty and hunger. A future where more people have access to a (good) health system, education and infrastructure. A future allowing for responsible production, clean energy, a healthy ecosystem and peace. Currently, for many people on our planet this future is only hope. Therefore, in 2015 the United Nations have released a resolution "Transforming our world: the 2030 Agenda for Sustainable Development", which is an action plan defining 17 sustainable development goals and 169 targets for all countries, their people and our planet (see Figure 1.1). Clean water and sanitation is one of these sustainable development goals (Figure 1.1 goal 6). ${ }^{1}$ For example, in 2016/2017 about 785 million people and one out of four health-care facilities lack access to basic drinking water services. Around 2 billion people live in countries experiencing high water stress and by 2030 about 700 million people might have to relocate because of intense water scarcity. ${ }^{2}$ In order to face these problems, prevention and reduction of water pollution, reducing or optimization of water consumption (e.g. by smart usage), or reuse of wastewater for certain applications by recycling are required targets for a sustainable development. ${ }^{3,4}$ In particular, wastewater nowadays is considered as a potential resource to lower fresh water consumption. ${ }^{5,6}$

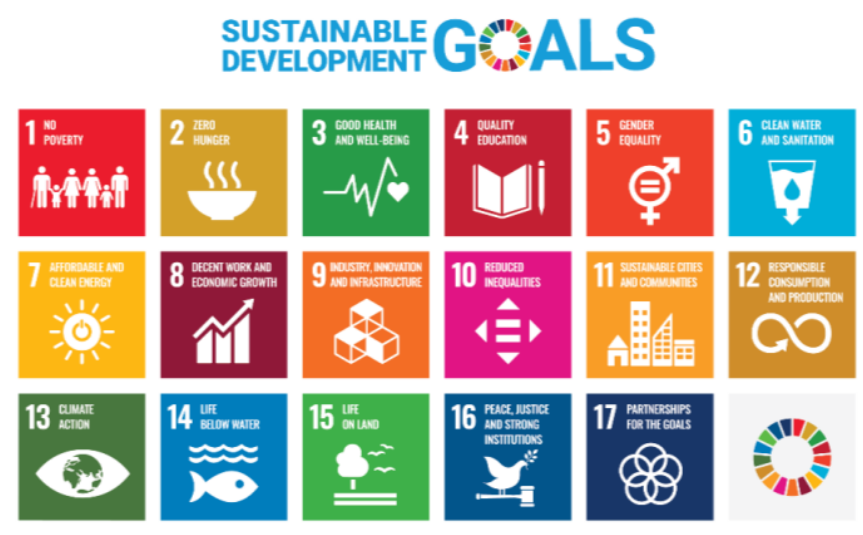

Figure 1.1. Sustainable Development Goals, The 2030 Agenda for Sustainable Development, United Nations. [Reproduced from reference ${ }^{7}$ ] 


\subsection{Water scarcity and pollution}

Without water there is no life. The water molecule consists of the elements hydrogen and oxygen and it exists in all three states of aggregation on earth: the solid state as ice $\left(<0{ }^{\circ} \mathrm{C}\right)$, the liquid state as liquid water $\left(0{ }^{\circ} \mathrm{C}-100^{\circ} \mathrm{C}\right)$ and the gaseous state as vapour $\left(>100^{\circ} \mathrm{C}\right)$. This is actually very unique for substances found on earth under "ambient conditions".

Water can be found nearly on all places on earth; however, with a very inhomogeneous distribution, varying from huge excess in the gigantic oceans to very tiny amounts of moisture in dry deserts. Around $70 \%$ of the surface of the earth is covered by water, but most of the earth's water (96.5\%) is saline in oceans and only $2.5 \%$ is fresh water. ${ }^{8}$

Water has several essential functions on earth. Among others, it is a solvent for salts and nutrients, serving as habitat for many living creatures, e.g. for tiny organisms such as plankton or whales as the biggest mammals on earth, or as an important liquid to keep animals and humans alive. The human body consists out of approximately $60 \mathrm{w} \%$ water ${ }^{9}$ and a daily fresh water supply is mandatory to prevent women and men from dehydration.

Next to these vital functions, humanity developed distinctive utilization and consumption of water. Three major sectors of water usage can be classified: the domestic, the agricultural and the industrial sector. Currently, the total annual withdrawal is estimated to be more than $4,000 \mathrm{~km}^{3}$ worldwide, and is expected to grow further in the future. ${ }^{10-12}$ This is problematic, since fresh water resources are finite and saline water is only of limited use. For example, the salt in the water supports corrosion of technical equipment or can lead to a hazardous distortion of the osmotic balance in living organisms. Moreover, increasing fresh water scarcity along with water pollution induces additional stress. Figure 1.2 shows a map of countries and their water stress levels, revealing that water stress is a global problem.

Many regions on earth suffer from fresh water scarcity, examples are parts of Africa or southern Europe. However, regions in which fresh water is scarce, are not only limited to dry areas. For instance, a large part of the world's population lives in large urbanized areas along coastlines and in delta regions. Extensive groundwater use 
leads to salt water intrusion, thus limiting or even reducing the availability of fresh water. Salt water intrusion is not only restricted to the commonly known regions of water scarcity such as on the African continent, but also relevant to countries as the Netherlands or the United States. ${ }^{13-16}$ Additionally, the increasing climate change results in extreme weather conditions such as droughts, inducing further stress on the availability of fresh water. ${ }^{12,17}$

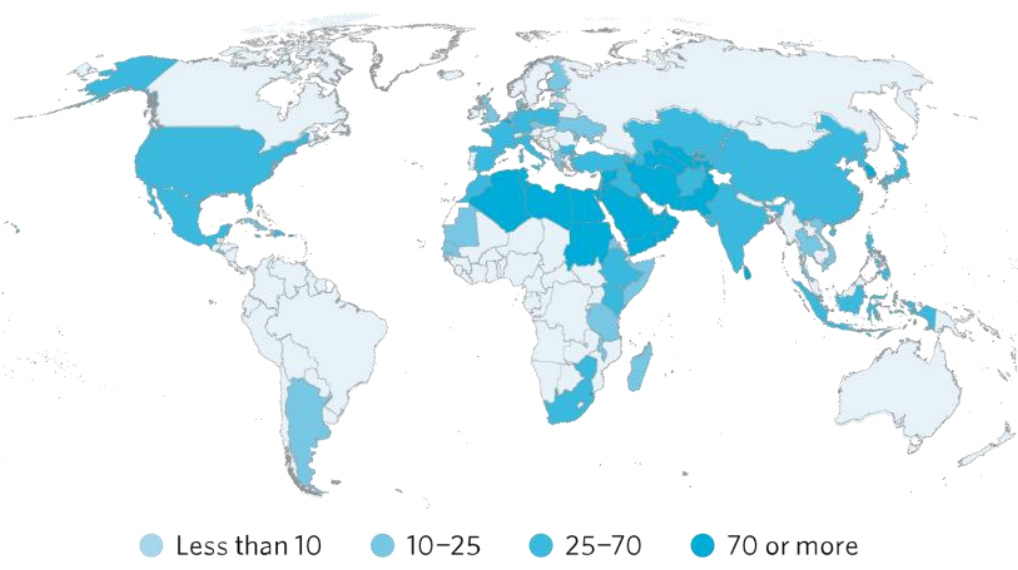

Figure 1.2. Levels of water stress (freshwater withdrawal as proportion of total renewable freshwater resources) shown as percentage. [Reproduced from reference ${ }^{2}$ ]

The usage and consumption of water is often accompanied by water pollution and generation of wastewater, thus related to the problem of limited fresh water availability. Globally around $80 \%$ of the wastewater is estimated to be discharged without any treatment, ${ }^{6}$ obviously contributing to pollution of (fresh) water resources. In general, the release of (high) organic loads into aquatic systems leads to eutrophication and oxygen consumption in the water, having a negative impact on the aquatic ecosystem. ${ }^{18,19}$ Moreover, the release of toxic compounds contributes further to an unhealthy (aquatic) environment. Furthermore, insufficient treatment also contributes to fresh water pollution. In fact, many chemical compounds can be found in natural waters and sometimes even in drinking water due to inadequate water treatment. Those (micro)pollutants are considered to have negative effects on human's health and the ecosystem. ${ }^{6,20-22}$

In addition to human's health and severe environmental issues, water scarcity and pollution, together with an increasing demand in fresh water significantly increase 
the risk of political and socioeconomic conflicts. In the absence of sufficient amounts of fresh and clean water, ecosystems might collapse and animals lose their habitat, humans are forced to leave their homeland, and industry has to lower or even stop production, negatively influencing the local/national economy. Therefore, sufficient availability of fresh and clean water belongs to the top challenges for a sustainable future. ${ }^{4,12,23}$

\subsubsection{Water Nexus project}

In order to lower the water footprint for a sustainable development in the industrial sector, several national and international research projects have been initiated. Among others, the Water Nexus project was initiated by several Dutch universities and companies and granted by the Netherlands Organisation for Scientific Research (NWO). The project started in 2015 as a strong multidisciplinary consortium of universities, research and governmental institutions, partners of industry and service providers working together towards the common goal "salt water when possible, fresh water when needed". Three research lines including several work packages working on i) resource management and control, ii) treatment technologies and iii) technology and natural system integration and governance were realized in order to contribute to a sustainable water development. A general overview of the research lines and their interdisciplinary connection is shown in Figure 1.3.

The work presented in this thesis is related to research line 2. In this research line several technologies are investigated to further understand, develop and apply the technologies and related materials for saline water treatment. Technologies of considerations are aerobic and anaerobic treatment, electrochemical oxidation and other oxidative treatment technologies, membrane filtration, plant-microbial fuel cells, and the integration of these systems for application.

In addition, two different case studies are inherent to the Water Nexus project. One case study is dealing with produced water from oil and gas production usually containing high salt loads (considered as salt water), presented by Shell. The other case study is focussed on cooling tower blowdown (CTBD) water with a medium salinity (considered as brackish water) presented by DOW Benelux B.V. Both companies suffer from fresh water scarcity, since their production facilities operate in water stressed areas. Therefore, improvements in water purification technologies are to their specific interest. 


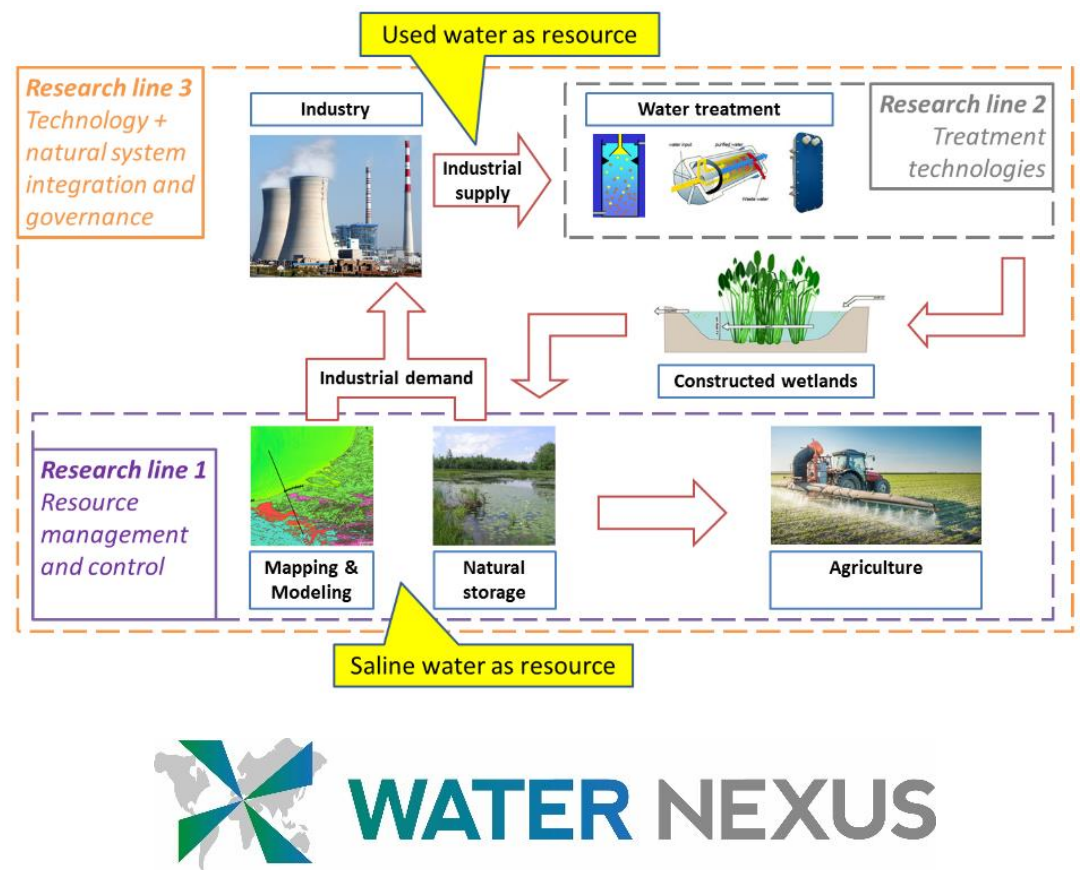

Figure 1.3. Overview of the research lines and their connection of the Water Nexus project. [Reproduced from reference ${ }^{24}$ ]

\subsubsection{Conventional wastewater treatment}

Wastewater generated in the domestic and industrial sectors contains a variety of organic and inorganic compounds, and is usually treated (if at all) in wastewater treatment plants (WWTP) using physico-mechanical, biological and chemical treatment stages, as shown in Figure 1.4. During a pre- and primary treatment stage large solids and smaller particles as well as oil are separated from the sewage streams by rakes, sedimentation and floatation. Afterwards, the water is treated in secondary biological treatment stages. Here, microorganisms degrade organic compounds and remove other nutrients such as nitrogen compounds. In a tertiary treatment step, inorganic compounds such as phosphorus can be removed by chemical precipitation, or the water can be disinfected. ${ }^{22,25}$ 


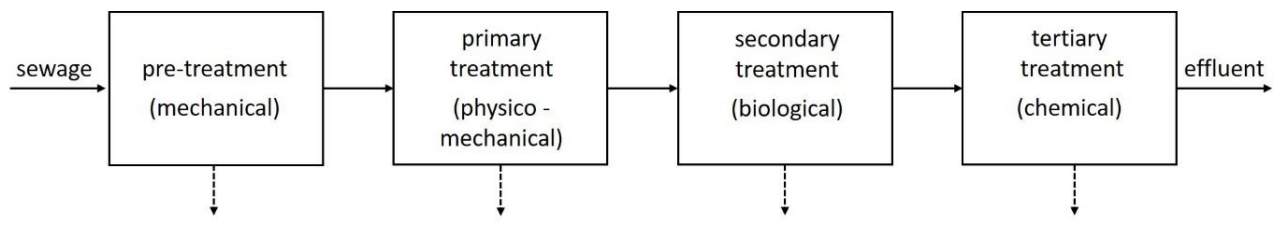

Figure 1.4. Basic scheme of wastewater treatment in a conventional WWTP. The solid arrows indicate the water flow in the process. The vertically dashed arrows indicate solid and sludge waste.

Despite this treatment procedure, common WWTP face problems with toxic compounds, non-biodegradable compounds and/or high salt loads. Toxic compounds and high salt loads in the wastewater inhibit the microorganism and nonbiodegradable compounds are recalcitrant to break-down by biological treatment. Thus, insufficient removal has been observed leading to discharge of water containing unaffected or partially degraded organic compounds into the environment. ${ }^{20-22,26}$ In order to face this problem, additional technologies are either already applied in a fourth treatment stage or under consideration. For example, activated carbon for adsorption of compounds, or membrane filtration emerged as attractive technologies. Still, disadvantages such as high costs, generation of additional sludge (e.g. when using carbon adsorber materials) or generation of a concentrated retentate stream (when using membrane filtration processes) require additional technological solutions. Advanced oxidation processes, which are introduced in the following, are believed to contribute to an effective wastewater treatment.

\subsection{Advanced Oxidation Processes}

Advanced oxidation processes (AOP) are defined as a group of technologies for aqueous phase oxidation. Generally, AOP technologies utilize highly reactive species such as hydroxyl radicals for the degradation of pollutants. ${ }^{5,27,28}$ The aim of the processes is the complete mineralization (full destruction) of the organic pollutants to "less harmful" products such as $\mathrm{CO}_{2}$, water and salts. The formation of hydroxyl radicals $\left({ }^{\circ} \mathrm{OH}\right)$ is of primary relevance in AOP. With a standard redox potential of $\mathrm{E}^{0}=2.7 \mathrm{~V}\left[\mathrm{E}^{0}\right.$ ' $\left.(\mathrm{pH} 7)=2.3 \mathrm{~V}\right] \mathrm{OH}$ radicals are considered to be the most powerful oxidizing reagents converting many organic pollutants instantaneously. ${ }^{27,29,30}$ Moreover, AOP are especially suited for the removal of non- 
or hardly biodegradable compounds, the removal of organic micropollutants, the treatment of industrial effluents as well as hazardous or toxic sewage. Furthermore, generation of $\mathrm{OH}$-radicals is also used for disinfection purposes (e.g. destruction of pathogens). ${ }^{5,27,28,31}$ Various technologies that are capable of generating ${ }^{\circ} \mathrm{OH}$ (and other reactive species) are described in the literature; for example, $\mathrm{H}_{2} \mathrm{O}_{2}$ in combination with ultraviolet light (UV) and ozonation (or combinations); Fenton's reagent-based methods; ultrasonication; photocatalysis; electrolysis and photoelectrocatalysis. ${ }^{27,28}$ The technologies can be applied either as single stage, simultaneously, sequential or in combination with other technologies. For example, pre-treatment to enhance biodegradability or post-treatment to improve the overall removal efficiency can be applied. Besides the advantages, disadvantages are for example the high costs of the (additional) treatment, consumption and potential safety aspects of required chemicals (e.g. $\mathrm{O}_{3}, \mathrm{H}_{2} \mathrm{O}_{2}$ ). ${ }^{5,27,28,31}$ Additionally, the formation of mostly unknown intermediates or by-products, which might be more harmful than the parent compounds, is a general inherent disadvantage of AOP. ${ }^{28,31-}$ ${ }^{34}$ Thus, it is of importance to understand the technologies and related mechanisms and to develop the techniques further to allow for their safe implementation. In the following photocatalysis and electrochemical oxidation, two AOPs which are studied in this thesis, are described in more detail.

\subsubsection{Photocatalytic degradation}

Photocatalytic degradation (PCD) using suspended semiconductor particles subjected to illumination with ultraviolet (UV) light has been studied for many years. Especially, titanium dioxide $\left(\mathrm{TiO}_{2}\right)$ has been widely applied as photocatalyst. $\mathrm{TiO}_{2}$ and in particular P25 (Evonik Industries) offer promising performance for degradation of organics. In addition, it is of interest due to (relatively) low material costs, abundance, non-toxicity, and (chemical) material stability. Several review papers already appeared discussing $\mathrm{TiO}_{2}$ based PCD and the principles and mechanism for water treatment in detail (the list is not exclusive). ${ }^{32,35-44}$

The principle of photocatalysis (here $\mathrm{TiO}_{2}$ is used to exemplify the processes) is shown in a scheme in Figure 1.5 along with standard potentials of various redox processes of interest for wastewater treatment. In brief $\mathrm{TiO}_{2}$, suspended in water or immobilized on a fixed bed, is exposed to UV light. If the energy of the light absorbed is larger than the band gap of the semiconductor $\left(E_{\lambda}>E_{g}=3.0-3.2 \mathrm{eV}\right.$ for Rutile or Anatase $\mathrm{TiO}_{2}$ respectively) photoexcited charge carriers are generated by 
excitation of electrons ( $\left.\mathrm{e}^{-}\right)$from the valence band (VB) into the conduction band (CB); leaving holes (unoccupied states, $\mathrm{h}^{+}$) in the VB according to equation 1.1. Depending on the extinction coefficient (and the particle size) of the semiconductor electron excitation will be limited to the near-surface region or also occur in the bulk of the semiconductor. Generated charge carriers either recombine (energy dissipation via phonon generation), move towards the solid/liquid (or solid/gas) interface triggering surface redox reactions, or are simply trapped. Importantly, formed $\mathrm{h}^{+}\left(+2.53 \mathrm{~V}\right.$ vs. SHE [pH 7] in $\left.\mathrm{TiO}_{2}\right)$ can either directly oxidize organic molecules adsorbed at the $\mathrm{TiO}_{2}$ surface (equation 1.2) or generate highly reactive ${ }^{\circ} \mathrm{OH}$ (from adsorbed water molecules or hydroxide ions, equation 1.3) leading to the oxidation of organic molecules (equation 1.4). In addition, excited CB e- (-0.52 vs. $\mathrm{SHE}$ [pH 7]) can generate reactive oxygen species (ROS) such as superoxide radicals $\left(\mathrm{O}_{2}^{-\bullet}\right.$ ) or $\mathrm{H}_{2} \mathrm{O}_{2}$ (equation $\left.1.5,1.6,1.7\right) .^{32,37}$ The generation of reactive singlet oxygen $\left({ }^{1} \mathrm{O}_{2}\right.$, equation 1.8$)$ has also been reported. ${ }^{45}$ The high activity for degradation of most organic pollutants has been attributed to the formation of various ROS species from photogenerated charge carriers at the $\mathrm{TiO}_{2}$ surface (equation 1.9). ${ }^{32,42,45}$

$$
\begin{aligned}
& \mathrm{TiO}_{2} \stackrel{h v}{\rightarrow} \mathrm{e}^{-}+\mathrm{h}^{-} \\
& \mathrm{R}+\mathrm{h}^{+} \rightarrow \mathrm{R}^{+\bullet} \rightarrow \text { intermediate(s) and final products } \\
& \mathrm{h}^{+}+\mathrm{OH}_{(\text {ads. }}^{-} \rightarrow^{\cdot} \mathrm{OH} \quad \text { or } \quad \mathrm{h}^{+}+\mathrm{H}_{2} \mathrm{O}_{\text {(ads. }} \rightarrow^{\bullet} \mathrm{OH}+\mathrm{H}^{+} \\
& \mathrm{R}-\mathrm{H}+{ }^{\circ} \mathrm{OH} \rightarrow \mathrm{R}^{\bullet}+\mathrm{H}_{2} \mathrm{O} \\
& \mathrm{e}^{-}+\mathrm{O}_{2} \rightarrow \mathrm{O}_{2}^{*} \\
& \mathrm{O}_{2}{ }^{-}+\mathrm{H}^{+} \rightarrow \mathrm{HOO}^{*} \\
& \mathrm{HOO}^{\bullet}+\mathrm{e}^{-} \rightarrow \mathrm{HO}_{2}{ }^{-} \stackrel{H^{+}}{\longrightarrow} \mathrm{H}_{2} \mathrm{O}_{2} \\
& \mathrm{O}_{2}{ }^{\cdot-} \rightarrow{ }^{1} \mathrm{O}_{2}+\mathrm{e}^{-}
\end{aligned}
$$

$$
\operatorname{Organics}_{(\mathrm{aq})} \stackrel{\mathrm{TiO}_{2}, \mathrm{hv}}{\longrightarrow} \text { Intermediate }(\mathrm{s}) \rightarrow \mathrm{CO}_{2} \uparrow+\mathrm{H}_{2} \mathrm{O}
$$




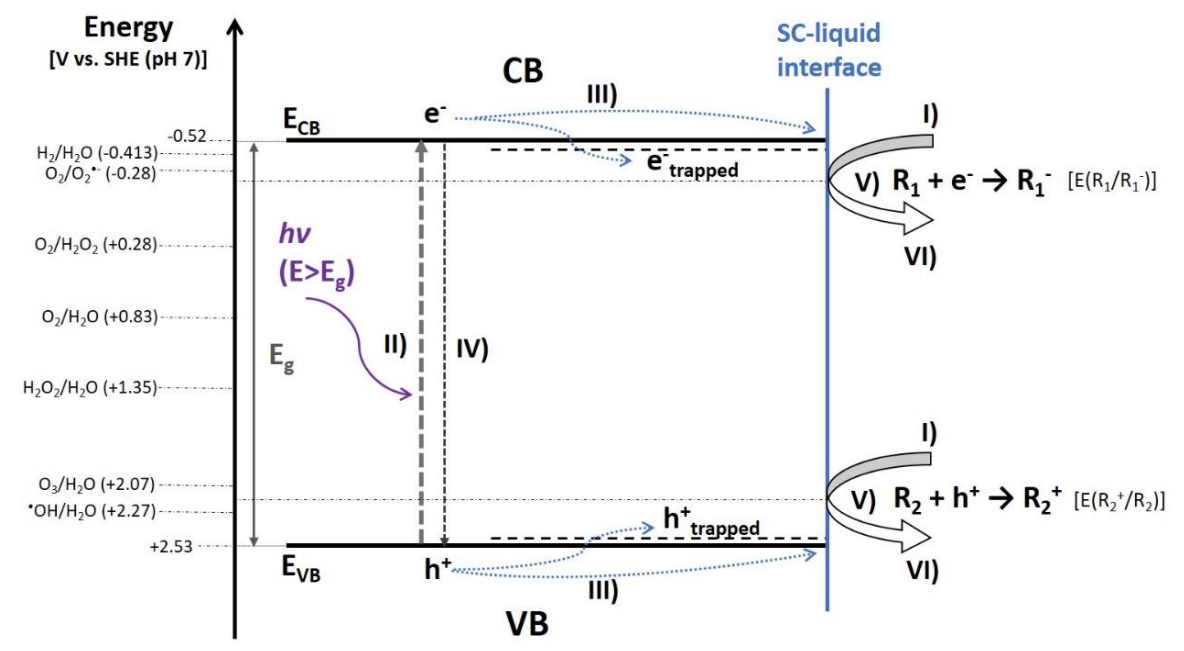

Figure 1.5. Schematic principle of semiconductor (SC) photocatalysis; $E\left(R_{x}{ }^{m} / R_{x}{ }^{n}\right)$ is the electrochemical potential of the redox couple $\left(\mathrm{R}_{\mathrm{x}}{ }^{\mathrm{m}} / \mathrm{R}_{\mathrm{x}}{ }^{\mathrm{n}}\right), \mathrm{E}_{\mathrm{CB}}$ conduction band $(\mathrm{CB})$ minimum, $\mathrm{E}_{\mathrm{VB}}$ valence band (VB) maximum. After photoexcitation II) mobile excited charge carriers can be trapped in bulk defect sites or surface sites, move to the surface III) or can recombine IV). V) shows the redox reaction of adsorbed reactants via charge transfer at the SC-liquid interface; I) and VI) describe ad- and desorption processes along with diffusion of reactants to the catalyst and products away from the surface of the catalyst. Potentials of various redox processes at the $\mathrm{TiO}_{2}$ surface (under neutral conditions) are adapted from Fujishima et al. ${ }^{37}$

Besides the advantages of $\mathrm{TiO}_{2}$ based PCD, several disadvantages are described in the literature. Among others, the necessity of UV light along with challenges of light scattering and distribution in slurry-based reactors, the separation of $\mathrm{TiO}_{2}$ after the treatment, diffusion limitations (especially if the catalyst is used in fixed bed reactors) and low efficiency due to the recombination of photogenerated charge carriers, are frequently discussed. Various strategies have been reported to address these disadvantages. For example, catalyst modification (e.g. surface modification or doping to shift the band gap and position applicable to the solar light spectra or to lower charge carrier recombination), catalyst immobilization, together with optimization of reactor and process design have been introduced. ${ }^{32,42,43,46}$ Especially, over the past three decades a lot of progress has been made and the gathered understanding of $\mathrm{TiO}_{2}$ based $\mathrm{PCD}^{32,35,38,42-44}$ even resulted in scale-up and pilot studies to push PCD to real applications, although the (industrial) applications so far are very limited. ${ }^{32,39,47,48}$ For example, the feasibility of $\mathrm{TiO}_{2}$ based PCD to remove 
hazardous pesticides as well as persistent pharmaceuticals at pilot scale using solar light (by solar concentration using parabolic collectors) has been demonstrated; however, complete mineralization has not been achieved. ${ }^{49,50}$ In a more recent example, the application of a solar based fixed bed $\mathrm{TiO}_{2}$ reactor after treatment in constructed wetlands, allowed for degradation of naphthenic acids with 47-93\% removal efficiencies, to purify waste water from the oil-sand industry. ${ }^{51}$

The generation of mostly unknown intermediates is important to consider, as already described previously. Because of the contribution of various ROS, many intermediates might form, which are difficult to assess and might have a higher toxicity than the parent compounds. In addition, real wastewater is a complex matrix, not only containing many organic compounds, but often also inorganic salts, which influence the photocatalytically induced chemistry. For example, sodium chloride is commonly known to inhibit PCD rates. ${ }^{32,52-56}$ Moreover, the high oxidative potential of $\mathrm{TiO}_{2}$ and ${ }^{\circ} \mathrm{OH}$ induce the risk of chloride oxidation to reactive chlorine species (RCS) and related chlorination reactions of organic compounds..$^{32,33,53,57,58}$ Therefore, it is of high importance to investigate photocatalytic degradation mechanisms, to assess the impact of the technology on the environment and human health.

\subsubsection{Electrochemical degradation}

Electrochemical degradation (ECD) of organic pollutants based on the anodic generation of ROS, in particular ${ }^{\circ} \mathrm{OH}$ is known as the electrochemical advanced oxidation process (EAOP). Advantages (compared to other technologies), include scalability, no production of waste (e.g. sludge), and no necessary addition of chemicals (e.g. $\mathrm{H}_{2} \mathrm{O}_{2}, \mathrm{O}_{3}, \mathrm{Fe}, \mathrm{TiO}_{2}$ ). Moreover, power supply is possible by renewable electricity ( $\mathrm{e}^{-}$are considered as harmless compared to chemicals) and no need for (UV) light render EAOP promising. Thus, a lot of research and development have been conducted and is summarised by several reviews (the list is not exhaustive)..$^{59-68}$

The central element in this process is the anode, which is responsible for the oxidation reactions. Figure 1.6 shows the principle and the commonly described three oxidation mechanisms of EAOP. Application of a sufficient anodic potential to an electrode allows for the generation of hydroxyl radicals from water molecules or adsorbed hydroxide ions (equation 1.10). The hydroxyl radicals can subsequently oxidize organic compounds, as previously described (equation 1.4). This mechanism 
is also described as indirect oxidation (I). In the presence of a suitable mediator, the oxidation of organic molecules can occur via oxidized reactive mediator species (II, the pathway is either called indirect or mediated oxidation). For example, chloride or sulfate ions are known to act as effective mediators, forming reactive chlorine species (RCS; $\left[E_{C l^{*} / C l^{-}}^{0}=2.43 \mathrm{~V} ; \quad E_{\mathrm{Cl}_{2} / \mathrm{Cl}^{-}}^{0}=1.36 \mathrm{~V}\right]$; equation 1.11 and 1.12) or sulfate radicals (equation $1.13 ;\left[\mathrm{E}^{0}=2.44 \mathrm{~V}\right]$ ) respectively. Moreover, organic molecules can also react in a direct oxidation mechanism at the electrode surface (III; equation 1.14). ${ }^{30,59,60,66}$. Due to the high oxidation potentials applied, further side reactions occur at the electrode leading to oxygen evolution (equation 1.15) and generation of other ROS such as hydrogen peroxide (equation 1.16) or ozone (equation 1.17), supporting the oxidative degradation of organic compounds..$^{59,60,66,69}$

$$
\begin{aligned}
& \mathrm{H}_{2} \mathrm{O} \rightarrow{ }^{\circ} \mathrm{OH}+\mathrm{e}^{-}+\mathrm{H}^{+} \quad \text { or } \quad \mathrm{OH}^{-}{ }_{(\text {ads. })} \rightarrow{ }^{\circ} \mathrm{OH}+\mathrm{e}^{-} \\
& \mathrm{Cl}^{-} \rightarrow \mathrm{Cl}^{-}+\mathrm{e}^{-} \\
& 2 \mathrm{Cl}^{-} \rightarrow \mathrm{Cl}_{2}+2 \mathrm{e}^{-}\left[\ldots+\mathrm{H}_{2} \mathrm{O} \leftrightarrow \mathrm{HOCl}+\mathrm{H}^{+}+\mathrm{Cl}^{-}\right] \\
& \mathrm{SO}_{4}^{2-} \rightarrow \mathrm{SO}_{4}^{--}+\mathrm{e}^{-} \\
& \mathrm{R} \rightarrow \mathrm{R}^{+\cdot}+\mathrm{e}^{-} \rightarrow \text { intermediate(s) and final products } \\
& 2 \mathrm{H}_{2} \mathrm{O} \rightarrow \mathrm{O}_{2}+4 \mathrm{e}^{-}+4 \mathrm{H}^{+} \\
& 2 \mathrm{H}_{2} \mathrm{O} \rightarrow \mathrm{H}_{2} \mathrm{O}_{2}+2 \mathrm{e}^{-}+2 \mathrm{H}^{+} \\
& 3 \mathrm{H}_{2} \mathrm{O} \rightarrow \mathrm{O}_{3}+6 \mathrm{e}^{-}+6 \mathrm{H}^{+}
\end{aligned}
$$




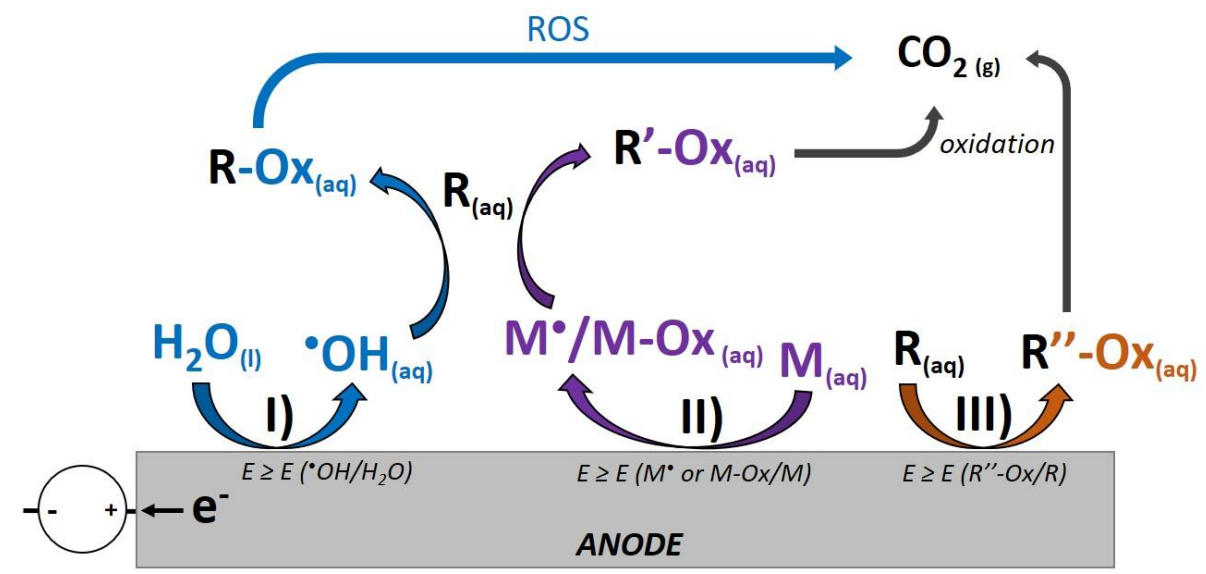

Figure 1.6. Schematic principle of the electrochemical advanced oxidation process (EAOP). Application of a sufficient anodic potential to an electrode (anode) allows for oxidation reactions: I) generation of hydroxyl radicals from water (or adsorbed hydroxide ions) which can subsequently oxidize organic compounds (R), (indirect oxidation); II) oxidation of a mediator (M), which can oxidize $\mathrm{R}$ (mediated oxidation); III) direct electrochemical oxidation of organic compounds. Further oxidation reactions (e.g. via generated reactive oxygen species (ROS)) allow for mineralization of the oxidized organic compounds (R-Ox) to $\mathrm{CO}_{2}$.

Especially the mediated degradation mechanism has been reported as being beneficial to enhance removal rates. ${ }^{60,70-73}$ This is of particular advantage since chloride containing salts are frequently present in wastewaters. However, the formation of undesired (toxic) intermediates and by-products is a critical disadvantage, since they might have negative effects on human health and the environment. ${ }^{74-77}$ Since the degradation mechanism can be manifold, especially in complex wastewater matrices, it is of high importance to investigate degradation pathways and to address the formation of intermediates and by-products for the individual applications.

Given the crucial function of the anodes various materials have been studied. Among others, Pt, dimensionally stable anodes (DSA) based on $\mathrm{IrO}_{2}$ and/or $\mathrm{RuO}_{2}$, doped $\mathrm{SnO}_{2}$ (commonly by $\mathrm{Sb}$ ), $\mathrm{PbO}_{2}$, doped and substoichiometric $\mathrm{TiO}_{2}$, graphite and boron doped diamond (BDD) have been used..$^{65,66,78-80}$ Investigated electrodes are classified into active and inactive anodes related to their oxidation mechanism. ${ }^{66,81}$ Active electrodes such as Pt and DSA commonly have a low OER overpotential. 
During the anodic polarization ${ }^{\circ} \mathrm{OH}$-radicals are generated as intermediates of the OER (equation 1.18), which is strongly bound to the electrode surface $\left(\mathrm{M}^{\mathrm{n}}\left[{ }^{\circ} \mathrm{OH}\right]\right)$ and further oxidized according to equation 1.19. The availability of $\mathrm{OH}$ for oxidation of organics is rather low in the case of active electrode materials and instead primarily selective oxidation reactions of organic compounds occur mostly via oxygen transfer reaction, restoring the initial electrode $\mathrm{M}^{\mathrm{n}}$ surface state (equation 1.20). This mechanism is in strong competition to the OER (equation 1.21) resulting in low mineralization efficiencies. Inactive electrodes show higher yields of $\mathrm{OH}$ generation due to its weakly bonded nature to the electrode surface (equation 1.18). In addition, oxidation to oxygen requires higher potentials $\left(\geq \approx 2.0 \mathrm{~V}\right.$ vs. SHE) at inactive electrodes. Thus the ${ }^{\circ} \mathrm{OH}$ is more easily available for the oxidation of organics (equation 1.22). Examples for inactive electrodes used in EAOP are doped $\mathrm{SnO}_{2}, \mathrm{PbO}_{2}$, doped and substoichiometric $\mathrm{TiO}_{2}$ and BDD. ${ }^{66,81}$

$$
\begin{aligned}
& \mathrm{M}^{\mathrm{n}}[]+\mathrm{H}_{2} \mathrm{O} \rightarrow \mathrm{M}^{\mathrm{n}}\left[{ }^{\bullet} \mathrm{OH}\right]+\mathrm{e}^{-}+\mathrm{H}^{+} \\
& \mathrm{M}^{\mathrm{n}}\left[{ }^{\circ} \mathrm{OH}\right] \rightarrow \mathrm{M}^{\mathrm{n}+2} \mathrm{O}+\mathrm{e}^{-}+\mathrm{H}^{+} \\
& \mathrm{M}^{\mathrm{n}+2} \mathrm{O}+\mathrm{R} \rightarrow \mathrm{M}^{\mathrm{n}}[]+\mathrm{RO} \\
& 2\left[\mathrm{M}^{\mathrm{n}+2} \mathrm{O}\right] \rightarrow 2 \mathrm{M}^{\mathrm{n}}[]+\mathrm{O}_{2} \\
& \mathrm{M}^{\mathrm{n}}\left[{ }^{\bullet} \mathrm{OH}\right]+\mathrm{R} \rightarrow \mathrm{M}^{\mathrm{n}}+\mathrm{R}^{\bullet}+\mathrm{H}_{2} \mathrm{O}
\end{aligned}
$$

Especially BDD is a very promising electrode material for the EAOP and often applied due to its high stability under anodic polarization, high overpotential for OER (> 2 V vs. SHE) and the good mineralization of organic compounds. ${ }^{66,80,82,83}$ However, the high costs of the electrodes (due to the preparation via chemical vapor deposition on mainly expensive substrates to achieve sufficient electrode film stability) is a clear drawback for large scale application..$^{59,64,78}$ In addition, the significant formation of harmful inorganic by-products, such as chlorate and perchlorate (or even bromate if $\mathrm{Br}^{-}$is present in the water) in ppm levels, is a disadvantage reported for BDD electrodes. ${ }^{76,84,85}$. Given that also other available electrodes suffer from crucial disadvantages limiting large scale application, BDD still appears the electrode of choice. For example, high electrode costs and low mineralization efficiency (due to low OER overpotential) are described for Pt, Ir and Ru based electrodes. For lead and antimony based electrodes leaching of toxic 
metal ions is problematic and insufficient electrode stability under anodic polarization are a disadvantage of electrodes based on graphite, $\mathrm{SnO}_{2}$ or substoichiometric $\mathrm{TiO}_{2}{ }^{66,80}$ Material science plays an important role for the further development and exploration of novel, inexpensive, active, stable/recyclable and non-toxic electrode materials. $5,66,68,80$

Among the described electrode materials $\mathrm{TiO}_{2}$ based electrodes are considered as very promising, ${ }^{66,68}$ because of the properties as already discussed for photocatalysis. In particular, the high ability for ${ }^{\circ} \mathrm{OH}$ generation is of special interest. ${ }^{69,86,87}$ However, the poor intrinsic electrical conductivity of $\mathrm{TiO}_{2}$ limits direct application as anode. To overcome this drawback, defect engineering has been applied to change the electrical properties of $\mathrm{TiO}_{2} \cdot{ }^{8-91}$ Defect engineering can be achieved by doping with aliovalent ions. For example, doping with $\mathrm{Nb}$ has been reported in the literature to increase the electrical conductivity of $\mathrm{TiO}_{2} \cdot{ }^{92-94} \mathrm{In}$ addition, defect engineering can be obtained just by formation of intrinsic defects such as the creation of oxygen vacancies leading to substoichiometric $\mathrm{TiO}_{2}$, also often described as the Magnéli phase $\left(\mathrm{Ti}_{\mathrm{n}} \mathrm{O}_{2 \mathrm{n}-1}[\mathrm{n}=4-10]\right)$, or blue/black titanium oxides. ${ }^{89-91}$ Especially the latter has been frequently reported as promising electrode material for EAOP. ${ }^{66,68,95-102}$

An appealing method for the preparation of defect engineered $\mathrm{TiO}_{2}\left(\mathrm{TiO}_{\mathrm{x}}\right)$ by intrinsic defect formation is electrochemical reductive doping (cathodization). Using an electrochemical approach reductive annealing at high temperature in the presence of hydrogen can be avoided, and consequently it has attracted attention for the preparation of $\mathrm{TiO}_{\mathrm{x}}$. Various reasons have been reported for the increase in electrical conductivity of the n-type semiconductor, including defects such as oxygen vacancies, subvalent $\mathrm{Ti}^{(<4+)}$, intercalation of protons, and insertion of hydrogen..$^{98,103-}$ ${ }^{107}$ Nevertheless, a critical drawback of $\mathrm{TiO}_{\mathrm{x}}$ is the instability when oxidation is initiated by anodic polarization (e.g. application in EAOP), resulting in a loss of the electrical conductivity. However, by reversing the potential (to cathodic polarization) or applying polarization switches during the EAOP, recovery of the defects and electrical conductivity has been demonstrated. ${ }^{100,107}$ This underlines the attractiveness and opportunity of the electrochemical preparation approach. For example, the application of polarization cycling has been shown to enhance the lifetime of electrochemically doped $\mathrm{TiO}_{2}$ nanotubes. ${ }^{100}$ Although the special structure of nanotubes are beneficial to realize large electrode surface areas, the cumbersome preparation (especially the need for potentially dangerous fluoride 
salts) prevents any large scale (industrial) application. Therefore, application to structures with lower complexity is desirable.

\subsection{Scope and outline of this thesis}

The research described in this thesis aims at the development, as well as on the understanding of materials and technologies for advanced oxidation processes, in particular photocatalytic treatments and electrochemical degradation processes for saline wastewater streams. The understanding of specific degradation pathways along with the formation of intermediates and their accumulation or removal is crucial to evaluate the impact of these various technologies on the water quality and their overall environmental impact. In addition, the question whether the formation of undesired intermediates and by-products can be limited or reduced, is addressed. Moreover, electrochemical doping of $\mathrm{TiO}_{2}$ is investigated as a method to design efficient electrodes with enhanced lifetimes for electrochemical water treatment.

A general introduction to water scarcity and pollution, wastewater treatment and related challenges, along with the potential of AOP, with focus on photocatalytic and electrochemical technologies for the degradation of organic pollutants, has been provided in this chapter (Chapter 1). In particular, basic principles, advantages, disadvantages and challenges of PCD and ECD are briefly explained.

In Chapter 2, a detailed analysis of the degradation pathways including formation and degradation of undesirable chlorinated aromatic intermediates during PCD, photoelectrochemical degradation (PECD) and ECD in saline water is described. It is highlighted that a quantitative analysis of intermediates, together with the overall removal of organic carbon (mineralization) is required to compare the two different AOPs and to assess their impact on the quality of the treated water and the environment. In addition, the role of chloride ions during PCD, PECD and ECD is discussed, based on literature.

In Chapter 3, the study of Chapter 2 is extended to evaluate the application of PCD and ECD treatment on real wastewater. Here, cooling tower blowdown (CTBD) water from the DOW case study of the Water Nexus project is investigated as wastewater matrix. The reduction in chemical oxygen demand and the removal of total organic carbon is compared. For both technologies, removal of the total organic 
carbon was observed. Moreover, formation of organic and inorganic chlorinated intermediates and by-products has been investigated. The observations are in agreement with the results obtained in Chapter 2. Also for real CTBD wastewater, differences in the degradation mechanism were observed between PCD and ECD, while PCD showed significantly less formation of chlorinated intermediates and byproducts.

Although ECD appears to be inferior compared to PCD in terms of formation of undesirable intermediates and by-products specifically in saline wastewater treatment, PCD also suffers from disadvantages, for example the inhibitory effect of salt. For ECD, among others, especially the easier realization of a continuous treatment process is favorable. Furthermore, contrary to PCD, particle separation after the treatment is not an issue, and UV illumination is not needed, potentially lowering the costs of the treatment. However, a clear need for the development of new electrode materials, e.g. to obtain cost effective, non-toxic, stable (and/or recyclable) electrodes with limited oxygen and chlorine evolution and limited formation of higher oxychlorides is of importance to push the technology towards large scale industrial application.

In Chapter 4 the preparation of $\mathrm{TiO}_{2}$ based electrodes has been investigated. In particular, the process of electrochemical reductive doping has been investigated for preparation of defect engineered $\mathrm{TiO}_{\mathrm{x}}$. The effect of three different counter electrodes, namely Pt, Ir-mixed metal oxide and BDD on the formation of $\mathrm{TiO}_{\mathrm{x}}$ and the resulting charge transfer properties of the material, is presented. The charge transfer properties were of special interest to characterize the doping process to achieve the electrically conductive material. Limitations of the process due to surface contaminations arising from the counter electrode are discussed in detail.

In Chapter 5 the obtained knowledge and optimized conditions for the electrochemical doping of $\mathrm{TiO}_{2}$ described in Chapter 4 are applied to $\mathrm{Nb}$ doped $\mathrm{TiO}_{2}$ substrates. Niobium was chosen based on literature as suitable dopant to increase the electrical conductivity of $\mathrm{TiO}_{2}$ and to allow for an improved oxidative stability. The influence of the $\mathrm{Nb}$ on the resulting charge transfer properties is evaluated along with its effect on electrode stability during anodic polarization. Moreover, the application of reversed polarization and polarization cycling on the recovery of passivated $\mathrm{TiO}_{\mathrm{x}}$ and passivated $\mathrm{TiO}_{\mathrm{x}}: \mathrm{Nb}$ electrodes is discussed. 
In order to apply ECD treatment to saline wastewater, the concentration of oxidised chlorine species and organochlorides needs to be minimized, to reduce the toxicity of the treated water. Therefore, in Chapter 6 a strategy to reduce undesired oxychlorides is described. A material screening revealed titanium as most promising electrode material for reduction of hypochlorite. Based on this observation, a porous Ti hollow fibre electrode has been applied for hypochlorite reduction. The overall enhancement in the removal has been assigned to favourable mass transport conditions close to the electrode-electrolyte interface, initiated by bubbles leaving the porous structure. In addition, the impact of the treatment on the toxicity is discussed.

A summary of the research described in this thesis, along with an outlook and recommendations for further research, are given in Chapter 7.

\subsection{References}

(1) United Nations, Transforming Our Wold: The 2030 Agenda for Sustainable Development; 2015; Vol. A/Res/70/1.

(2) United Nations, The Sustainable Development Goals Report 2019; 2019.

(3) United Nations Sustainable Development Goal 6 - Clean Water and Sanitation https://www.un.org/sustainabledevelopment/water-andsanitation/ (accessed Feb 23, 2020).

(4) World Water Assessment Programme, The United Nations World Water Development Report 2015: Water for a Sustainalbe World. Paris, UNESCO; 2015. https://doi.org/ISBN 978-92-3-100071-3.

(5) Comninellis, C.; Kapalka, A.; Malato, S.; Parsons, S. A.; Poulios, I.; Mantzavinos, D. Advanced Oxidation Processes for Water Treatment: Advances and Trends for R\&D. J. Chem. Technol. Biotechnol. 2008, 83 (6), 769-776. https://doi.org/10.1002/jctb.1873.

(6) World Water Assessment Programme, The United Nations World Water Development Report 2017: Wastewater The Untapped Rescource. Paris, UNESCO; UNESCO: Paris, 2017.

(7) United Nations Sustainable Development Goals https://sustainabledevelopment.un.org/?menu=1300 (accessed Apr 9, 2020).

(8) Shiklomanov, I. A. World Fresh Water Resources. In Water in crisis: a guide to the world's fresh water resources; Gleick, P. H., Ed.; Oxford 
University Press: New York, 1993. https://doi.org/10.2307/2623756.

(9) Mitchell, H. H.; Hamilton, T. S.; Streggerda, F. R.; Bean, H. . The Chemical Composition of the Adult Human Body and Its Bearing on the Biochemistry of Growth. J. Biol. Chem. 1945, 158 (3), 625-637.

(10) Rosegrant, M. W.; Cai, X.; Cline, S. A. Global Water Outlook to 2025; Washington, D.C., 2002; Vol. 14.

(11) Ritchie, H.; Roser, M. Our World in Data - Water Use and Stress https://ourworldindata.org/water-use-stress (accessed Feb 22, 2020).

(12) World Water Assessment Programme, The United Nations World Water Development Report 2019: Leaving No One Behind. Paris, UNESCO; 2019.

(13) Oude Essink, G. H. P. Improving Fresh Groundwater Supply-Problems and Solutions. Ocean Coast. Manag. 2001, 44 (5-6), 429-449. https://doi.org/10.1016/S0964-5691(01)00057-6.

(14) Oude Essink, G. H. P. Salt Water Intrusion in a Three-Dimensional Groundwater System in the Netherlands: A Numerical Study. Transp. Porous Media 2001, 43 (1), 137-158. https://doi.org/10.1023/A:1010625913251.

(15) Barlow, P. M.; Reichard, E. G. Saltwater Intrusion in Coastal Regions of North America. Hydrogeol. J. 2010, 18 (1), 247-260. https://doi.org/10.1007/s10040-009-0514-3.

(16) Nlend, B.; Celle-Jeanton, H.; Huneau, F.; Ketchemen-Tandia, B.; Fantong, W. Y.; Boum-Nkot, S. N.; Etame, J. The Impact of Urban Development on Aquifers in Large Coastal Cities of West Africa: Present Status and Future Challenges. Land use policy 2018, 75 (January), 352-363. https://doi.org/10.1016/j.landusepol.2018.03.007.

(17) World Water Assessment Programme, The United Nations World Water Development Report 2020: Water and Climate Change. Paris, UNESCO; 2020.

(18) Chrislock, M. F.; Doster, E.; Zitomer, R. A.; Wilson, A. E. Eutrophication: Causes, Consequences, and Controls in Aquatic Ecosystems. Nat. Educ. Knowl. 2013, 4 (4), 10.

(19) Smith, V. H. Eutrophication of Freshwater and Coastal Marine Ecosystems a Global Problem. Environ. Sci. Pollut. Res. 2003, 10 (2), 126-139. https://doi.org/10.1065/espr2002.12.142.

(20) Luo, Y.; Guo, W.; Ngo, H. H.; Nghiem, L. D.; Hai, F. I.; Zhang, J.; Liang, S.; Wang, X. C. A Review on the Occurrence of Micropollutants in the 
Aquatic Environment and Their Fate and Removal during Wastewater Treatment. Sci. Total Environ. 2014, 473-474, 619-641.

https://doi.org/http://dx.doi.org/10.1016/j.scitotenv.2013.12.065.

(21) Margot, J.; Rossi, L.; Barry, D. A.; Holliger, C. A Review of the Fate of Micropollutants in Wastewater Treatment Plants. Wiley Interdiscip. Rev. Water 2015, 2 (5), 457-487. https://doi.org/10.1002/wat2.1090.

(22) Gupta, A.; Thakur, I. S. Treatment of Organic Recalcitrant Contaminants in Wastewater. In Biological Wastewater Treatment and Resource Recovery; Farooq, R., Ahmad, Z., Eds.; InTech, 2017. https://doi.org/10.5772/66346.

(23) Smalley, R. E. Future Global Energy Prosperity: The Terawatt Challenge. MRS Bull. 2005, 30 (6), 412-417. https://doi.org/10.1557/mrs2005.124.

(24) Water Nexus programme http://waternexus.nl/programme/ (accessed Apr $22,2020)$.

(25) Samer, M. Biological and Chemical Wastewater Treatment Processes. In Wastewater Treatment Engineering; InTech, 2015; Vol. i, p 13. https://doi.org/10.5772/61250.

(26) Lefebvre, O.; Moletta, R. Treatment of Organic Pollution in Industrial Saline Wastewater: A Literature Review. Water Res. 2006, 40 (20), 36713682. https://doi.org/http://dx.doi.org/10.1016/j.watres.2006.08.027.

(27) Andreozzi, R. Advanced Oxidation Processes (AOP) for Water Purification and Recovery. Catal. Today 1999, 53 (1), 51-59. https://doi.org/10.1016/S0920-5861(99)00102-9.

(28) Oturan, M. A.; Aaron, J.-J. Advanced Oxidation Processes in Water/Wastewater Treatment: Principles and Applications. A Review. Crit. Rev. Environ. Sci. Technol. 2014, 44 (23), 2577-2641. https://doi.org/10.1080/10643389.2013.829765.

(29) Gligorovski, S.; Strekowski, R.; Barbati, S.; Vione, D. Environmental Implications of Hydroxyl Radicals $(\cdot \mathrm{OH})$. Chem. Rev. 2015, 115 (24), 13051-13092. https://doi.org/10.1021/cr500310b.

(30) Armstrong, D. A.; Huie, R. E.; Lymar, S.; Koppenol, W. H.; Merényi, G.; Neta, P.; Stanbury, D. M.; Steenken, S.; Wardman, P. Standard Electrode Potentials Involving Radicals in Aqueous Solution: Inorganic Radicals. Bioinorg. React. Mech. 2013, 9 (1-4), 59-61. https://doi.org/10.1515/irm2013-0005.

(31) Dewil, R.; Mantzavinos, D.; Poulios, I.; Rodrigo, M. A. New Perspectives for Advanced Oxidation Processes. J. Environ. Manage. 2017, 195, 93-99. 
https://doi.org/https://doi.org/10.1016/j.jenvman.2017.04.010.

(32) Chong, M. N.; Jin, B.; Chow, C. W. K.; Saint, C. Recent Developments in Photocatalytic Water Treatment Technology: A Review. Water Res. 2010, 44 (10), 2997-3027.

https://doi.org/https://doi.org/10.1016/j.watres.2010.02.039.

(33) Yang, Y.; Pignatello, J. Participation of the Halogens in Photochemical Reactions in Natural and Treated Waters. Molecules 2017, 22 (10), 1684.

(34) Babu, D. S.; Srivastava, V.; Nidheesh, P. V.; Kumar, M. S. Detoxification of Water and Wastewater by Advanced Oxidation Processes. Sci. Total Environ. 2019, 696, 133961. https://doi.org/10.1016/j.scitotenv.2019.133961.

(35) Linsebigler, A. L.; Lu, G.; Yates, J. T. Photocatalysis on TiO2 Surfaces: Principles, Mechanisms, and Selected Results. Chem. Rev. 1995, 95 (3), 735-758. https://doi.org/10.1021/cr00035a013.

(36) Hoffmann, M. R.; Martin, S. T.; Choi, W.; Bahnemann, D. W. Environmental Applications of Semiconductor Photocatalysis. Chem. Rev. 1995, 95 (1), 69-96. https://doi.org/10.1021/cr00033a004.

(37) Fujishima, A.; Rao, T. N.; Tryk, D. A. Titanium Dioxide Photocatalysis. $J$. Photochem. Photobiol. C Photochem. Rev. 2000, 1 (1), 1-21. https://doi.org/10.1016/S1389-5567(00)00002-2.

(38) Fujishima, A.; Zhang, X.; Tryk, D. A. TiO2 Photocatalysis and Related Surface Phenomena. Surf. Sci. Rep. 2008, 63 (12), 515-582. https://doi.org/https://doi.org/10.1016/j.surfrep.2008.10.001.

(39) Bahnemann, D. Photocatalytic Water Treatment: Solar Energy Applications. Sol. Energy 2004, 77 (5), 445-459.

https://doi.org/http://dx.doi.org/10.1016/j.solener.2004.03.031.

(40) Herrmann, J.-M. Photocatalysis Fundamentals Revisited to Avoid Several Misconceptions. Appl. Catal. B Environ. 2010, 99 (3-4), 461-468. https://doi.org/10.1016/j.apcatb.2010.05.012.

(41) Henderson, M. A. A Surface Science Perspective on TiO2 Photocatalysis. Surf. Sci. Rep. 2011, 66 (6-7), 185-297. https://doi.org/10.1016/j.surfrep.2011.01.001.

(42) Ochiai, T.; Fujishima, A. Photoelectrochemical Properties of TiO2 Photocatalyst and Its Applications for Environmental Purification. $J$. Photochem. Photobiol. C Photochem. Rev. 2012, 13 (4), 247-262. https://doi.org/https://doi.org/10.1016/j.jphotochemrev.2012.07.001. 
(43) Ibhadon, A.; Fitzpatrick, P. Heterogeneous Photocatalysis: Recent Advances and Applications. Catalysts 2013, 3 (1), 189-218. https://doi.org/10.3390/catal3010189.

(44) Schneider, J.; Matsuoka, M.; Takeuchi, M.; Zhang, J.; Horiuchi, Y.; Anpo, M.; Bahnemann, D. W. Understanding TiO 2 Photocatalysis: Mechanisms and Materials. Chem. Rev. 2014, 114 (19), 9919-9986.

https://doi.org/10.1021/cr5001892.

(45) Nosaka, Y.; Nosaka, A. Y. Generation and Detection of Reactive Oxygen Species in Photocatalysis. Chem. Rev. 2017, 117 (17), 11302-11336. https://doi.org/10.1021/acs.chemrev.7b00161.

(46) Park, H.; Park, Y.; Kim, W.; Choi, W. Surface Modification of TiO2 Photocatalyst for Environmental Applications. J. Photochem. Photobiol. C Photochem. Rev. 2013, 15 (1), 1-20. https://doi.org/10.1016/j.jphotochemrev.2012.10.001.

(47) Malato, S.; Blanco, J.; Alarcón, D. C.; Maldonado, M. I.; Fernández-Ibáñez, P.; Gernjak, W. Photocatalytic Decontamination and Disinfection of Water with Solar Collectors. Catal. Today 2007, 122 (1-2), 137-149. https://doi.org/10.1016/j.cattod.2007.01.034.

(48) Loeb, S. K.; Alvarez, P. J. J.; Brame, J. A.; Cates, E. L.; Choi, W.; Crittenden, J.; Dionysiou, D. D.; Li, Q.; Li-Puma, G.; Quan, X.; et al. The Technology Horizon for Photocatalytic Water Treatment: Sunrise or Sunset? Environ. Sci. Technol. 2019, 53 (6), 2937-2947. https://doi.org/10.1021/acs.est.8b05041.

(49) Oller, I.; Gernjak, W.; Maldonado, M. I.; Pérez-Estrada, L. A.; SánchezPérez, J. A.; Malato, S. Solar Photocatalytic Degradation of Some Hazardous Water-Soluble Pesticides at Pilot-Plant Scale. J. Hazard. Mater. 2006, 138 (3), 507-517. https://doi.org/10.1016/j.jhazmat.2006.05.075.

(50) Radjenović, J.; Sirtori, C.; Petrović, M.; Barceló, D.; Malato, S. Solar Photocatalytic Degradation of Persistent Pharmaceuticals at Pilot-Scale: Kinetics and Characterization of Major Intermediate Products. Appl. Catal. B Environ. 2009, 89 (1-2), 255-264. https://doi.org/10.1016/j.apcatb.2009.02.013.

(51) McQueen, A. D.; Hendrikse, M.; Gaspari, D. P.; Kinley, C. M.; Rodgers, J. H.; Castle, J. W. Performance of a Hybrid Pilot-Scale Constructed Wetland System for Treating Oil Sands Process-Affected Water from the Athabasca Oil Sands. Ecol. Eng. 2017, 102, 152-165. https://doi.org/10.1016/j.ecoleng.2017.01.024. 
(52) Abdullah, M.; Low, G. K. C.; Matthews, R. W. Effects of Common Inorganic Anions on Rates of Photocatalytic Oxidation of Organic Carbon over Illuminated Titanium Dioxide. J. Phys. Chem. 1990, 94 (17), 68206825. https://doi.org/10.1021/j100380a051.

(53) Lindner, M.; Bahnemann, D. W.; Hirthe, B.; Griebler, W. D. Solar Water Detoxification: Novel TiO2 Powders as Highly Active Photocatalysts. $J$. Sol. Energy Eng. 1997, 119 (2), 120-125. https://doi.org/10.1115/1.2887890.

(54) Burns, R. A.; Crittenden, J. C.; Hand, D. W.; Selzer, V. H.; Sutter, L. L.; Salman, S. R. Effect of Inorganic Ions in Heterogeneous Photocatalysis of TCE. J. Environ. Eng. 1999, 125 (1), 77-85. https://doi.org/doi:10.1061/(ASCE)0733-9372(1999)125:1(77).

(55) Guillard, C.; Puzenat, E.; Lachheb, H.; Houas, A.; Herrmann, J.-M. Why Inorganic Salts Decrease the TiO2 Photocatalytic Efficiency. Int. J. Photoenergy 2005, 7 (1), 1-9. https://doi.org/10.1155/s1110662x05000012.

(56) Krivec, M.; Dillert, R.; Bahnemann, D. W.; Mehle, A.; Strancar, J.; Drazic, G. The Nature of Chlorine-Inhibition of Photocatalytic Degradation of Dichloroacetic Acid in a TiO2-Based Microreactor. Phys. Chem. Chem. Phys. 2014, 16 (28), 14867-14873. https://doi.org/10.1039/C4CP01043D.

(57) Yuan, R.; Ramjaun, S. N.; Wang, Z.; Liu, J. Photocatalytic Degradation and Chlorination of Azo Dye in Saline Wastewater: Kinetics and AOX Formation. Chem. Eng. J. 2012, 192 (Supplement C), 171-178. https://doi.org/https://doi.org/10.1016/j.cej.2012.03.080.

(58) Calza, P.; Pelizzetti, E. Photocatalytic Transformation of Organic Compounds in the Presence of Inorganic Ions. Pure Appl. Chem. 2001, 73, 1839. https://doi.org/10.1351/pac200173121839.

(59) Martinez-Huitle, C. A.; Ferro, S. Electrochemical Oxidation of Organic Pollutants for the Wastewater Treatment: Direct and Indirect Processes. Chem. Soc. Rev. 2006, 35 (12), 1324-1340. https://doi.org/10.1039/B517632H.

(60) Panizza, M.; Cerisola, G. Direct And Mediated Anodic Oxidation of Organic Pollutants. Chem. Rev. 2009, 109 (12), 6541-6569. https://doi.org/10.1021/cr9001319.

(61) Sirés, I.; Brillas, E.; Oturan, M. A.; Rodrigo, M. A.; Panizza, M. Electrochemical Advanced Oxidation Processes: Today and Tomorrow. A Review. Environ. Sci. Pollut. Res. 2014, 21 (14), 8336-8367. https://doi.org/10.1007/s11356-014-2783-1. 
(62) Chaplin, B. P. Critical Review of Electrochemical Advanced Oxidation Processes for Water Treatment Applications. Environ. Sci. Process. Impacts 2014, 16 (6), 1182-1203. https://doi.org/10.1039/C3EM00679D.

(63) Martínez-Huitle, C. A.; Rodrigo, M. A.; Sirés, I.; Scialdone, O. Single and Coupled Electrochemical Processes and Reactors for the Abatement of Organic Water Pollutants: A Critical Review. Chem. Rev. 2015, 115 (24), 13362-13407. https://doi.org/10.1021/acs.chemrev.5b00361.

(64) Radjenovic, J.; Sedlak, D. L. Challenges and Opportunities for Electrochemical Processes as Next-Generation Technologies for the Treatment of Contaminated Water. Environ. Sci. Technol. 2015, 49 (19), 11292-11302. https://doi.org/10.1021/acs.est.5b02414.

(65) Moreira, F. C.; Boaventura, R. A. R.; Brillas, E.; Vilar, V. J. P. Electrochemical Advanced Oxidation Processes: A Review on Their Application to Synthetic and Real Wastewaters. Appl. Catal. B Environ. 2017, 202, 217-261. https://doi.org/10.1016/j.apcatb.2016.08.037.

(66) Chaplin, B. P. Advantages, Disadvantages, and Future Challenges of the Use of Electrochemical Technologies for Water and Wastewater Treatment; Elsevier Inc., 2018. https://doi.org/10.1016/B978-0-12-813160-2.00017-1.

(67) Garcia-Segura, S.; Ocon, J. D.; Chong, M. N. Electrochemical Oxidation Remediation of Real Wastewater Effluents - A Review. Process Saf. Environ. Prot. 2018, 113, 48-67. https://doi.org/10.1016/j.psep.2017.09.014.

(68) Martínez-Huitle, C. A.; Panizza, M. Electrochemical Oxidation of Organic Pollutants for Wastewater Treatment. Curr. Opin. Electrochem. 2018, 11 (1), 62-71. https://doi.org/10.1016/j.coelec.2018.07.010.

(69) Siahrostami, S.; Li, G. L.; Viswanathan, V.; Nørskov, J. K. One- or TwoElectron Water Oxidation, Hydroxyl Radical, or H2O2Evolution. J. Phys. Chem. Lett. 2017, 8 (6), 1157-1160. https://doi.org/10.1021/acs.jpclett.6b02924.

(70) Comninellis, C.; Nerini, A. Anodic Oxidation of Phenol in the Presence of $\mathrm{NaCl}$ for Wastewater Treatment. J. Appl. Electrochem. 1995, 25 (1), 23-28. https://doi.org/10.1007/bf00251260.

(71) de Moura, D. C.; do Nascimento Brito, C.; Quiroz, M. A.; Pergher, S. B. C.; Martinez-Huitle, C. A. Cl-Mediated Electrochemical Oxidation for Treating an Effluent Using Platinum and Diamond Anodes. J. Water Process Eng. 2015, 8, e31-e36. https://doi.org/10.1016/j.jwpe.2014.11.005. 
(72) Lan, Y.; Coetsier, C.; Causserand, C.; Groenen Serrano, K. On the Role of Salts for the Treatment of Wastewaters Containing Pharmaceuticals by Electrochemical Oxidation Using a Boron Doped Diamond Anode. Electrochim. Acta 2017, 231, 309-318. https://doi.org/10.1016/j.electacta.2017.01.160.

(73) Chen, L.; Lei, C.; Li, Z.; Yang, B.; Zhang, X.; Lei, L. Electrochemical Activation of Sulfate by BDD Anode in Basic Medium for Efficient Removal of Organic Pollutants. Chemosphere 2018, 210 (18), 516-523. https://doi.org/10.1016/j.chemosphere.2018.07.043.

(74) Zöllig, H.; Remmele, A.; Fritzsche, C.; Morgenroth, E.; Udert, K. M. Formation of Chlorination Byproducts and Their Emission Pathways in Chlorine Mediated Electro-Oxidation of Urine on Active and Nonactive Type Anodes. Environ. Sci. Technol. 2015, 49 (18), 11062-11069. https://doi.org/10.1021/acs.est.5b01675.

(75) Jasper, J. T.; Yang, Y.; Hoffmann, M. R. Toxic Byproduct Formation during Electrochemical Treatment of Latrine Wastewater. Environ. Sci. Technol. 2017, 51 (12), 7111-7119. https://doi.org/10.1021/acs.est.7b01002.

(76) Bergmann, M. E. H.; Koparal, A. S.; Iourtchouk, T. Electrochemical Advanced Oxidation Processes, Formation of Halogenate and Perhalogenate Species: A Critical Review. Crit. Rev. Environ. Sci. Technol. 2014, 44 (4), 348-390. https://doi.org/10.1080/10643389.2012.718948.

(77) Schoeny, R. Disinfection By-Products: A Question of Balance. Environ. Health Perspect. 2010, 118 (11), A466-A467. https://doi.org/10.1289/ehp.1003053.

(78) Subba Rao, A. N.; Venkatarangaiah, V. T. Metal Oxide-Coated Anodes in Wastewater Treatment. Environ. Sci. Pollut. Res. 2014, 21 (5), 3197-3217. https://doi.org/10.1007/s11356-013-2313-6.

(79) Särkkä, H.; Bhatnagar, A.; Sillanpää, M. Recent Developments of ElectroOxidation in Water Treatment - A Review. J. Electroanal. Chem. 2015, 754, 46-56. https://doi.org/https://doi.org/10.1016/j.jelechem.2015.06.016.

(80) Shestakova, M.; Sillanpää, M. Electrode Materials Used for Electrochemical Oxidation of Organic Compounds in Wastewater. Rev. Environ. Sci. Biotechnol. 2017, 16 (2), 223-238. https://doi.org/10.1007/s11157-017-9426-1.

(81) Comninellis, C. Electrocatalysis in the Electrochemical Conversion/Combustion of Organic Pollutants for Waste Water Treatment. Electrochim. Acta 1994, 39 (11), 1857-1862. 
https://doi.org/http://dx.doi.org/10.1016/0013-4686(94)85175-1.

(82) Michaud, P. A.; Panizza, M.; Ouattara, L.; Diaco, T.; Foti, G.; Comninellis, C. Electrochemical Oxidation of Water on Synthetic Boron-Doped Diamond Thin Film Anodes. J. Appl. Electrochem. 2003, 33 (2), 151-154. https://doi.org/10.1023/A:1024084924058.

(83) Kraft, A. Doped Diamond: A Compact Review on a New, Versatile Electrode Material. Int. J. Electrochem. Sci. 2007, 2, 355-385.

(84) Bergmann, M. E. H.; Rollin, J.; Iourtchouk, T. The Occurrence of Perchlorate during Drinking Water Electrolysis Using BDD Anodes. Electrochim. Acta 2009, 54 (7), 2102-2107. https://doi.org/10.1016/j.electacta.2008.09.040.

(85) Brito, C. D. N.; De Araújo, D. M.; Martínez-Huitle, C. A.; Rodrigo, M. A. Understanding Active Chlorine Species Production Using Boron Doped Diamond Films with Lower and Higher Sp 3 /Sp 2 Ratio. Electrochem. commun. 2015, 55, 34-38. https://doi.org/10.1016/j.elecom.2015.03.013.

(86) Shi, X.; Siahrostami, S.; Li, G.-L.; Zhang, Y.; Chakthranont, P.; Studt, F.; Jaramillo, T. F.; Zheng, X.; Nørskov, J. K. Understanding Activity Trends in Electrochemical Water Oxidation to Form Hydrogen Peroxide. Nat. Commun. 2017, 8 (1), 701. https://doi.org/10.1038/s41467-017-00585-6.

(87) Nosaka, Y.; Nosaka, A. Understanding Hydroxyl Radical $(\bullet \mathrm{OH})$ Generation Processes in Photocatalysis. ACS Energy Lett. 2016, 1 (2), 356-359. https://doi.org/10.1021/acsenergylett.6b00174.

(88) Nowotny, J.; Alim, M. A.; Bak, T.; Idris, M. A.; Ionescu, M.; Prince, K.; Sahdan, M. Z.; Sopian, K.; Mat Teridi, M. A.; Sigmund, W. Defect Chemistry and Defect Engineering of TiO 2 -Based Semiconductors for Solar Energy Conversion. Chem. Soc. Rev. 2015, 44 (23), 8424-8442. https://doi.org/10.1039/C4CS00469H.

(89) Walsh, F. C.; Wills, R. G. A. The Continuing Development of Magnéli Phase Titanium Sub-Oxides and Ebonex ${ }^{\circledR}$ Electrodes. Electrochim. Acta 2010, 55 (22), 6342-6351. https://doi.org/http://dx.doi.org/10.1016/j.electacta.2010.05.011.

(90) Yan, X.; Tian, L.; Tan, X.; Zhou, M.; Liu, L.; Chen, X. Modifying Oxide Nanomaterials' Properties by Hydrogenation. MRS Commun. 2016, 6 (3), 192-203. https://doi.org/10.1557/mrc.2016.33.

(91) Xu, B.; Sohn, H. Y.; Mohassab, Y.; Lan, Y. Structures, Preparation and Applications of Titanium Suboxides. RSC Adv. 2016, 6 (83), 79706-79722. https://doi.org/10.1039/c6ra14507h. 
(92) Furubayashi, Y.; Hitosugi, T.; Yamamoto, Y.; Inaba, K.; Kinoda, G.; Hirose, Y.; Shimada, T.; Hasegawa, T. A Transparent Metal: Nb-Doped Anatase TiO2. Appl. Phys. Lett. 2005, 86 (25), 252101. https://doi.org/10.1063/1.1949728.

(93) Sheppard, L. R.; Bak, T.; Nowotny, J. Electrical Properties of NiobiumDoped Titanium Dioxide. 1. Defect Disorder †. J. Phys. Chem. B 2006, 110 (45), 22447-22454. https://doi.org/10.1021/jp0637025.

(94) Saha, M.; Ghosh, S.; Paul, S.; Dalal, B.; De, S. K. Nb-Dopant-Induced Tuning of Optical and Electrical Property of Anatase $\mathrm{TiO}_{2}$ Nanocrystals. ChemistrySelect 2018, 3 (23), 6654-6664. https://doi.org/10.1002/slct.201800434.

(95) Chen, G.; Betterton, E. A.; Arnold, R. G. Electrolytic Oxidation of Trichloroethylene Using a Ceramic Anode. J. Appl. Electrochem. 1999, 29 (8), 961-970. https://doi.org/10.1023/a:1003541706456.

(96) Bejan, D.; Malcolm, J. D.; Morrison, L.; Bunce, N. J. Mechanistic Investigation of the Conductive Ceramic Ebonex ${ }^{\circledR}$ as an Anode Material. Electrochim. Acta 2009, 54 (23), 5548-5556. https://doi.org/http://dx.doi.org/10.1016/j.electacta.2009.04.057.

(97) Zaky, A. M.; Chaplin, B. P. Porous Substoichiometric TiO 2 Anodes as Reactive Electrochemical Membranes for Water Treatment. Environ. Sci. Technol. 2013, 47 (12), 6554-6563. https://doi.org/10.1021/es401287e.

(98) Kim, C.; Kim, S.; Choi, J.; Lee, J.; Kang, J. S.; Sung, Y.-E.; Lee, J.; Choi, W.; Yoon, J. Blue TiO2 Nanotube Array as an Oxidant Generating Novel Anode Material Fabricated by Simple Cathodic Polarization. Electrochim. Acta 2014, 141, 113-119.

https://doi.org/http://dx.doi.org/10.1016/j.electacta.2014.07.062.

(99) Kim, C.; Kim, S.; Lee, J.; Kim, J.; Yoon, J. Capacitive and Oxidant Generating Properties of Black-Colored TiO2 Nanotube Array Fabricated by Electrochemical Self-Doping. ACS Appl. Mater. Interfaces 2015, 7 (14), 7486-7491. https://doi.org/10.1021/acsami.5b00123.

(100) Yang, Y.; Hoffmann, M. R. Synthesis and Stabilization of Blue-Black TiO2 Nanotube Arrays for Electrochemical Oxidant Generation and Wastewater Treatment. Environ. Sci. Technol. 2016, 50 (21), 11888-11894. https://doi.org/10.1021/acs.est.6b03540.

(101) Wang, J.; Zhi, D.; Zhou, H.; He, X.; Zhang, D. Evaluating Tetracycline Degradation Pathway and Intermediate Toxicity during the Electrochemical Oxidation over a Ti/Ti4O7 Anode. Water Res. 2018, 137, 324-334. https://doi.org/10.1016/j.watres.2018.03.030. 
(102) Le, T. X. H.; Haflich, H.; Shah, A. D.; Chaplin, B. P. Energy-Efficient Electrochemical Oxidation of Perfluoroalkyl Substances Using a Ti 4 O 7 Reactive Electrochemical Membrane Anode. Environ. Sci. Technol. Lett. 2019, 6 (8), 504-510. https://doi.org/10.1021/acs.estlett.9b00397.

(103) Lindquist, S.-E.; Lindgren, A.; Leygraf, C. Effects of Electrochemical Reduction of Polycrystalline TiO2 Photoelectrodes in Acidic Solutions. Sol. Energy Mater. 1987, 15, 367-382.

(104) Fabregat-Santiago, F.; Barea, E. M.; Bisquert, J.; Mor, G. K.; Shankar, K.; Grimes, C. A. High Carrier Density and Capacitance in $\mathrm{TiO}_{2}$ Nanotube Arrays Induced by Electrochemical Doping. J. Am. Chem. Soc. 2008, 130 (34), 11312-11316. https://doi.org/10.1021/ja710899q.

(105) Kim, C.; Kim, S.; Hong, S. P.; Lee, J.; Yoon, J. Effect of Doping Level of Colored $\mathrm{TiO}_{2}$ Nanotube Arrays Fabricated by Electrochemical Self-Doping on Electrochemical Properties. Phys. Chem. Chem. Phys. 2016, 18 (21), 14370-14375. https://doi.org/10.1039/C6CP01799A.

(106) Swaminathan, J.; Subbiah, R.; Singaram, V. Defect-Rich Metallic Titania (TiO 1.23 ) - An Efficient Hydrogen Evolution Catalyst for Electrochemical Water Splitting. ACS Catal. 2016, 6 (4), 2222-2229. https://doi.org/10.1021/acscatal.5b02614.

(107) Jing, Y.; Almassi, S.; Mehraeen, S.; LeSuer, R. J.; Chaplin, B. P. The Roles of Oxygen Vacancies, Electrolyte Composition, Lattice Structure, and Doping Density on the Electrochemical Reactivity of Magnéli Phase $\mathrm{TiO}_{2}$ Anodes. J. Mater. Chem. A 2018, 6 (46), 23828-23839. https://doi.org/10.1039/C8TA03719A. 


\section{Chapter 2}

\section{Comparative analysis of photocatalytic and electrochemical degradation of 4-ethylphenol in saline conditions}

Electrochemical degradation (ECD) and photocatalytic degradation (PCD) technologies were evaluated for saline water purification, with focus on rate comparison and formation and degradation of chlorinated aromatic intermediates using the same non-chlorinated parent compound, 4-ethylphenol (4EP). At $15 \mathrm{~mA} \mathrm{~cm}^{-2}$, and in the absence of chloride $\left(0.6 \mathrm{~mol} \mathrm{~L}^{-1}\right.$ $\mathrm{NaNO}_{3}$ was used as supporting electrolyte), ECD resulted in an apparent zero-order rate of $30 \mu \mathrm{mol} \mathrm{L}{ }^{-1} \mathrm{~h}^{-1}$, whereas rates of $\approx 300 \mu \mathrm{mol} \mathrm{L}^{-1} \mathrm{~h}^{-1}$ and $\approx 3750 \mu \mathrm{mol} \mathrm{L}^{-1} \mathrm{~h}^{-1}$ were computed for low $\left(0.03 \mathrm{~mol} \mathrm{~L}^{-1}\right)$ and high $\left(0.6 \mathrm{~mol} \mathrm{~L}^{-1}\right) \mathrm{NaCl}$ concentration, respectively. For PCD, initial rates of $\approx 330 \mu \mathrm{mol} \mathrm{L} \mathrm{L}^{-1} \mathrm{~h}^{-1}$ and $\approx 205 \mu \mathrm{mol} \mathrm{L} \mathrm{L}^{-1} \mathrm{~h}^{-1}$ were found for low and high $\mathrm{NaCl}$ concentrations, at a photocatalyst $\left(\mathrm{TiO}_{2}\right)$ concentration of $0.5 \mathrm{~g} \mathrm{~L}^{-1}$, and illumination at $\lambda_{\max } \approx 375 \mathrm{~nm}$, with an intensity $\approx 0.32 \mathrm{~mW} \mathrm{~cm}^{-2}$. In the chlorine mediated ECD approach, significant quantities of free chlorine (hypochlorite, $\mathrm{Cl}_{2}$ ) and chlorinated hydrocarbons were formed in solution, while photocatalytic degradation did not show the formation of free chlorine, nor chlorine-containing intermediates, and resulted in better removal of nonpurgeable hydrocarbons than ECD. The origin of the minimal formation of free chlorine and chlorinated compounds in photocatalytic degradation is discussed based on photoelectrochemical results and existing literature, and explained by a chloride-mediated surface-charge recombination mechanism.

Reproduced with permission from R. Brüninghoff, A.K. van Duijne, L. Braakhuis, P. Saha, A.W. Jeremiasse, B. Mei, G. Mul, Comparative analysis of photocatalytic and electrochemical degradation of 4-ethylphenol in saline conditions Environ. Sci. Technol. 2019, 53, 8725-8735. Copyright 2019 American Chemical Society 


\subsection{Introduction}

Water pollution is one of the greatest challenges of modern society. ${ }^{1,2}$ The treatment of polluted water to enable its re-use is essential, ${ }^{3}$ while efficient removal of (recalcitrant) organic pollutants, present in low concentrations, requires development of innovative technology. ${ }^{4-7}$ Particularly difficult is treatment of industrial effluents containing high amounts of sodium chloride, which impedes biological treatment due to negative effects of the $\mathrm{NaCl}$ on the microbial flora such as plasmolysis. ${ }^{8,9}$

Advanced oxidation processes (AOP) such as photocatalytic degradation (PCD) or electrochemical degradation (ECD) are promising methodologies for the removal of (recalcitrant) organics in saline conditions. Highly reactive oxygen species (ROS), e.g. hydroxyl radicals $\left({ }^{\bullet} \mathrm{OH}\right)$ are generated oxidatively (anodically) in both methodologies. ${ }^{10}$ Sodium chloride, ubiquitous in many industrial wastewaters, ${ }^{8}$ is known to further enhance degradation rates in ECD, due to (anodic) chloride oxidation and the consecutive formation of reactive chlorine species (RCS: e.g. $\mathrm{Cl}^{\bullet}$, $\mathrm{Cl}_{2}$, or $\left.\mathrm{HOCl}\right){ }^{11-15}$ However, the major disadvantage of ECD in saline media is the formation of chlorinated by-products. ${ }^{12,16-20}$ These by-products typically induce high water toxicity, and thus deteriorate the environment. ${ }^{21-23}$

For $\mathrm{TiO}_{2}$-based photocatalytic degradation, chloride is usually considered to be an inhibitor. Several mechanisms have been proposed to explain the inhibition: scavenging of holes or $\mathrm{OH}$ - radicals by chloride ions; ${ }^{24-27}$ blocking of active surfaces sites by chloride ions; ${ }^{25,28-32}$, formation of an inorganic salt layer; $;{ }^{33}$ or chloride acting as external-recombination-center for photogenerated charge carriers. ${ }^{34}$ Often, more than one mechanism is used to explain the inhibiting effect. ${ }^{35-40}$ In addition, aggregation of $\mathrm{TiO}_{2}$ particles has been reported to reduce the number of absorbed photons influencing degradation rates. ${ }^{41}$ While the inhibiting effect of chloride, using $\mathrm{TiO}_{2}$ as photocatalyst, has been discussed frequently in the literature, detailed studies regarding the formation of reactive chlorine species (RCS), such as hypochlorite, and chlorinated intermediates in aqueous solution (starting from a non-chlorinated parent molecule) are rare, and obtained results seem to be inconsistent. For example, negligible amounts of organochloride compounds have been reported during phenol degradation in high saline media $\left[50 \mathrm{gL}^{-1} \mathrm{NaCl}\right], 38,42,43$ which appears in disagreement with detection of several chlorinated intermediates arising from the 
photocatalytic degradation of the azo dye Acid Orange 7 at moderate salinity [5.8$\left.11.8 \mathrm{~g} \mathrm{~L}^{-1}\right] .{ }^{39}$ The role of chloride ions in $\mathrm{TiO}_{2}$-based $\mathrm{PCD}$ of organic pollutants is thus not fully understood ${ }^{44,45}$ and requires further studies. ${ }^{46}$

In particular, the formation of toxic by-products needs attention, to reveal the environmental impact of AOPs. ${ }^{4,20,47-52}$ Although some comparative studies between different AOPs, or a combination of technologies have been reported, ${ }^{53-62}$ to the best of our knowledge a comparative study specifically addressing the concentration dependent formation of chlorinated intermediates during ECD, PCD and photoelectrochemical degradation (PECD), starting from a non-chlorinated parent compound in saline solutions, has not yet been performed.

In this study the influence of $\mathrm{NaCl}$ on the degradation rate and mechanism of the model compound 4-ethylphenol (4EP) is investigated. Two salt concentrations, corresponding to brackish $\left(1.75 \mathrm{~g} \mathrm{~L}^{-1}\right)$ and sea water salt concentrations $\left(35 \mathrm{~g} \mathrm{~L}^{-1}\right)$, covering a relevant concentration range of industrial effluents, ${ }^{8}$ have been studied. $\mathrm{TiO}_{2}$ particle suspensions or $\mathrm{TiO}_{2}$ thin films illuminated by UV light are used for PCD and PECD, respectively. A platinized Ti (Ti/Pt) anode was utilized for ECD, and the performance compared to a Boron-Doped-Diamond (BDD) electrode. The obtained results clearly demonstrate that the rate of degradation of 4EP in ECD and PECD is mainly the result of chemical chlorination, since free chlorine and various chlorinated hydrocarbons were detected. In contrast, the formation of chlorinated compounds was significantly smaller in PCD, and the overall removal effective, despite an inhibiting effect of chloride.

\subsection{Materials and methods}

\subsubsection{Chemicals and reagents}

The following chemicals were used in this study: titanium dioxide (Hombikat UV 100, Sachtleben (Venator)), 4-Ethylphenol (Sigma Aldrich 99\%), sodium chloride (Sigma Aldrich $\geq 99 \%$ ), sodium nitrate (Sigma Aldrich $\geq 99.0 \%$ ), demineralized water (Merck MilliQ system, resistivity >18M $\Omega \cdot \mathrm{cm}$ ), water (LC-MS grade, Biosolve B.V.), acetonitrile (LC-MS grade, Biosolve B.V.), formic acid (98$100 \%$, LC-MS grade, Merck), 1-(4-Hydroxylphenyl)ethanol (for synthesis see appendix Text A2.1), 2-(4-Hydroxylphenyl)ethanol (Sigma Aldrich 98\%), 4Hydroxybenzaldehyde (Sigma Aldrich 98\%), 4-Hydroxyacetophenone (Sigma 
Aldrich 99\%), 4-Ethylresorcinol (Alfa Aesar 98\%), 4-Ethylcatechol (Sigma Aldrich 95\%), and 2-Chloro-4-ethylphenol (AKos GmbH, >95\%), 2,6-Dichloro-4ethylphenol (AKos $\mathrm{GmbH},>90 \%)$.

\subsubsection{Degradation experiments}

If not otherwise stated all experiments were performed in solutions containing $\mathrm{NaCl}$ or $\mathrm{NaNO}_{3}$ at various concentrations $\left(0.03 \mathrm{~mol} \mathrm{~L}^{-1}\right.$ or $\left.0.6 \mathrm{~mol} \mathrm{~L}^{-1}\right)$. Sodium nitrate $\left(\mathrm{NaNO}_{3}\right)$ was used for comparison, since $\mathrm{NaNO}_{3}$ is supposed to be an "inert" water additive in oxidative processes.

\subsubsection{Photocatalytic degradation}

Pre-treatment of $\mathrm{TiO}_{2}$ photocatalyst, via annealing at $600{ }^{\circ} \mathrm{C}$ for $4 \mathrm{~h}$ (named in the following H600), was performed to achieve an improved photocatalytic performance (optimum between adsorbed surface $\mathrm{OH}$ groups and available holes at the surface), as reported in earlier work. ${ }^{63}$ The presence of the anatase phase was confirmed by XRD analysis (see XRD patterns in Figure A2.1).

PCD experiments were performed as described in the following: 4EP stock solution (approx. $50 \mathrm{mg} \mathrm{L}^{-1}$ ) was pre-saturated with air for $20 \mathrm{~min}$. The catalyst $\mathrm{H} 600$ [25(+/- 1) $\mathrm{mg}]$, the required amount of salt and $50 \mathrm{~mL}$ stock solution were mixed in a quartz glass beaker, covered with a quartz glass lid and stirred ( $350 \mathrm{rpm})$ in the dark for $30 \mathrm{~min}$ before the first sample was taken $(0 \mathrm{~h}$ measurement). UV-irradiation of the suspension was achieved using a custom-made closed box reactor ${ }^{64}$ equipped with eight Philips UV lamps (TL-D $18 \mathrm{~W}$ BLB, $\lambda_{\max } \approx 375 \mathrm{~nm}$, intensity $\approx 0.32 \mathrm{~mW} \mathrm{~cm}^{-2}$ ). Any influence of UV light absorption by the salt solutions on the PCD rate was excluded (Figure A2.2). ${ }^{33}$ Liquid samples were taken after $0.5 \mathrm{~h}, 1 \mathrm{~h}$, $2 \mathrm{~h}, 3 \mathrm{~h}, 4 \mathrm{~h}$ and $5 \mathrm{~h}$ of continuous illumination. Each time approx. $1.5 \mathrm{~mL}$ solution was taken. Afterwards, the samples were filtered using a Phenex RC membrane filter (0.2 $\mu \mathrm{m}$; Phenomenex), and analyzed by HPLC-UV and LC-MS.

\subsubsection{Electrochemical degradation}

ECD of 4EP was performed in a custom-made single-compartment cell (see scheme in Figure A2.3). A platinized Ti plate electrode or BDD electrode (Magneto special anodes B.V.; geometric surface area $3.14 \mathrm{~cm}^{2}$ ) was used to study the electrochemical degradation of 4EP. A Pt mesh and a $\mathrm{Ag} / \mathrm{AgCl}$ electrode (3 $\mathrm{M} \mathrm{NaCl}, \mathrm{BASi}$ ) were used as a counter electrode and as a reference electrode, respectively. The reactor was filled with $70 \mathrm{~mL} 4 \mathrm{EP}$ stock solution (pre-saturated with air). Degradation 
experiments were carried out under galvanostatic conditions at $15 \mathrm{~mA} \mathrm{~cm}^{-2}$ (VersaSTAT4 potentiostat, PAR or biologic SP-300/VMP3). The electrolyte was constantly stirred during the experiments. Sampling was performed as described for PCD. For high $\mathrm{NaCl}$ concentration, samples were also taken after $1 \mathrm{~min}, 2.5 \mathrm{~min}$, $5 \mathrm{~min}, 10 \mathrm{~min}, 15 \mathrm{~min}, 20 \mathrm{~min}$ and $30 \mathrm{~min}$. The surface area of the Pt gauze was significantly larger than the applied anode, and therefore the cathodic reaction was not limiting the degradation of hydrocarbons (see Figure A2.3).

To evaluate reactivity of 4EP with reactive chlorine species, $9.5 \mathrm{~mL}$ of $4 \mathrm{EP}$ stock solution [50 mg L-1] was mixed with sodium hypochlorite solution $(0.5 \mathrm{~mL}$, equal to approx. $20 \mathrm{mg} \mathrm{L}^{-1}$ free chlorine) and treated for $15 \mathrm{~min}$. Filtration was followed by LC-MS analysis.

\subsubsection{Photoelectrochemical degradation}

PECD experiments were carried out in a custom-made Teflon based PEC-cell. The reactor was equipped with a thin film of $\mathrm{TiO}_{2}$ on a Ti-electrode (for the preparation see appendix Text A2.2; geometric surface area $\left.3.14 \mathrm{~cm}^{2}\left[\mathrm{TiO}_{2} / \mathrm{Ti}\right]\right)$ or $\mathrm{H} 600$ coated on FTO ([H600/FTO], $\left.2.54 \mathrm{~cm}^{2}\right]$ ) and a Pt-mesh counter electrode. The reactor was filled with the 4EP stock solution containing $0.03 \mathrm{~mol} \mathrm{~L}^{-1} \mathrm{NaCl}$, and pretreated by purging air. Experiments were carried out under potentiostatic conditions at $0.1 \mathrm{~V}$ vs. $\mathrm{Ag} / \mathrm{AgCl}$ reference electrode ( $3 \mathrm{M} \mathrm{NaCl}, \mathrm{BASi}$ ) using a potentiostat (VersaStat3, PAR or biologic SP-300). The electrolyte was constantly stirred and illuminated with a $365 \mathrm{~nm}$ LED [for $\mathrm{TiO}_{2} / \mathrm{Ti}$ experiments] or $375 \mathrm{~nm}$ LED [for H600/FTO experiments] (Roithner Lasertechnik GmbH, APG2C1-365/375-E, $200 \mathrm{~mW}$ output power) placed in front of the glass window of the PEC-cell.

\subsubsection{Analytical methods}

HPLC analysis was performed by a ThermoFisher Scientific Dionex Ultimate 3000 HPLC system equipped with a UV detector and a reversed phase Luna Omega polar C18 column ( $3 \mu \mathrm{m}, 150 \times 2.1 \mathrm{~mm}$, protected by a polar C18 security guard column (both Phenomenex)). The sample injection volume was $5 \mu \mathrm{L}$. The oven temperature was set to $30{ }^{\circ} \mathrm{C}$. A water ([A]; $0.1 \%$ formic acid) - acetonitrile $(0.1 \%$ formic acid) gradient system was used at a flow rate of $0.200 \mathrm{~mL} \mathrm{~min}^{-1}$ and a total run time of $60 \min (0 \min 100 \%$ A, 1 min $100 \%$ A, $30 \min 50 \%$ A, 35 min $50 \%$ A, $45 \mathrm{~min}$ $5 \% \mathrm{~A}, 50 \mathrm{~min} 5 \% \mathrm{~A}, 55 \mathrm{~min} 100 \% \mathrm{~A}, 60 \mathrm{~min} 100 \% \mathrm{~A})$. For detection, UV absorption was measured at $276 \mathrm{~nm}$. For the quantification, an external standard calibration was applied (for more information see Figure A2.4 and Table A2.1-2.3). 
For the identification of intermediates, a Bruker amaZon SL ion trap using electrospray ionization (conditions: capillary $4500 \mathrm{~V}$, end plate offset $500 \mathrm{~V}, 15 \mathrm{psi}$ nebulizer gas pressure $\left(\mathrm{N}_{2}\right), 8 \mathrm{~L} \mathrm{~min}^{-1}$ dry gas flow $\left(\mathrm{N}_{2}\right), 200{ }^{\circ} \mathrm{C}$ dry gas temperature, scan between 50 to $1000 \mathrm{~m} / \mathrm{z}$ ) was coupled to the HPLC system. A divert-valve was used for salt separation. Ionization was performed both in positive and negative mode under alternating conditions using automatic fragmentation for data-dependent acquisition of both MS and LC-MS data.

Free chlorine ((FC); total concentration of $\left.\mathrm{Cl}_{2}+\mathrm{HOCl}+\mathrm{OCl}^{-}\right)$measurements were performed in adaption of the EPA-DPD method 330.5, using a Hanna Instruments free chlorine test kit (HI93701) and photometer (HI83099) for a concentration range of 0.00 to $2.50 \mathrm{mg} \mathrm{L}^{-1}$ [accuracy $+/-0.03 \mathrm{mg} \mathrm{L}^{-1}$ ]. For higher free chlorine concentrations, a Hanna Instruments test kit (HI95771) and photometer (HI96771) were used [accuracy $+/-2 \mathrm{mg} \mathrm{L}^{-1}$ ].

Non-purgeable organic carbon (NPOC) content was determined with a SHIMADZU total organic carbon analyzer, TOC-L CPH/CPN (see appendix Text A2.3 for more information)

\subsection{Results and discussion}

4EP belongs to the group of alkylphenols, which have been found for example in produced water from petrochemical industry, ${ }^{65}$ or as degradation products from alkylphenol ethoxylates (used in chemical industry). ${ }^{66}$ These compounds have become in focus due to their endocrine disruptive effects. ${ }^{67}$ In this study 4EP is used as model compound offering several advantages, for example a moderate toxicity and an adequate water solubility. The structure consists of three functional groups (benzene ring, alcohol group, alkyl chain) representing important functional groups of more complex compounds found in wastewater ${ }^{5,6}$ and is suitable to study the selectivity in reactions with chlorine. ${ }^{68,69}$

\subsubsection{Electrochemical degradation of 4EP}

Degradation curves of 4EP obtained for ECD at various salt conditions are shown in Figure $2.1\left(\mathrm{NaNO}_{3}\right.$ or $\mathrm{NaCl}$ containing electrolytes, constant current experiment at $\mathrm{j}=15 \mathrm{~mA} \mathrm{~cm}{ }^{-2}$ ). A linear degradation behavior was obtained for both $\mathrm{NaNO}_{3}$ concentrations (Figure 2.1a), for which zero-order kinetic constants can be estimated 
to be $\approx 20 \mu \mathrm{mol} \mathrm{L}^{-1} \mathrm{~h}^{-1}$ and $30 \mu \mathrm{mol} \mathrm{L}^{-1} \mathrm{~h}^{-1}$ for the low or high salt concentrations, respectively (voltage-time curves are shown in Figure A2.5 and quantified numbers are presented in Table A2.4).

In contrast to $\mathrm{NaNO}_{3}$, which cannot be oxidized to reactive radicals, the degradation of 4EP in chloride-containing media proceeded much faster (Figure 2.1b). Again assuming linear regression (zero-order), constants of $\approx 300 \mu \mathrm{mol} \mathrm{L}^{-1} \mathrm{~h}^{-1}$ and $\approx 3750 \mu \mathrm{mol} \mathrm{L}^{-1} \mathrm{~h}^{-1}$ can be computed for low and high $\mathrm{NaCl}$ concentration, respectively. The fast 4EP degradation in the $\mathrm{NaCl}$ experiments can be explained by chlorine mediated electrochemical oxidation, where free chlorine (i.e. hypochlorite) and chlorine radicals support the degradation of organic pollutants. ${ }^{11-15}$ In agreement with this hypothesis, the measured concentrations of FC amounted to $0.95 \mathrm{mg} \mathrm{L}^{-1}$ (after $5 \mathrm{~h}$ at $0.03 \mathrm{~mol} \mathrm{~L}^{-1} \mathrm{NaCl}$ ) and $111 \mathrm{mg} \mathrm{L}^{-1}\left(\right.$ after $30 \mathrm{~min}$ at $0.6 \mathrm{~mol} \mathrm{~L}^{-1}$ ).

The presence of RCS was found to induce the formation of undesired chlorinated organic intermediates and by-products $(\mathrm{RCl})$, in agreement with literature. ${ }^{12,16-20} \mathrm{LC}$ MS analysis revealed the formation of 2-chloro-4-ethylphenol (2C4EP) and 2,6dichloro-4-ethylphenol (26DC4EP), see Figure 2.2. The same intermediates were also formed during chemical chlorination of 4EP with sodium hypochlorite solution (20 $\mathrm{mg} \mathrm{L}^{-1} \mathrm{FC}$ ), showing that conversion of 4EP in saline conditions resembles chemical chlorination. The chlorination of the aromatic ring at the ortho position is directed by the adjacent $\mathrm{OH}$-group and is a typical reaction of phenolic compounds with electrophilic oxidants. ${ }^{70,71}$ Furthermore, the identified intermediates are in good agreement with other literature reports on phenol and bisphenol conversion, using degradation at BDD electrodes at low salt concentrations ${ }^{16,18,19}$ and the chemical chlorination of methylphenols. $^{72}$ 
a)

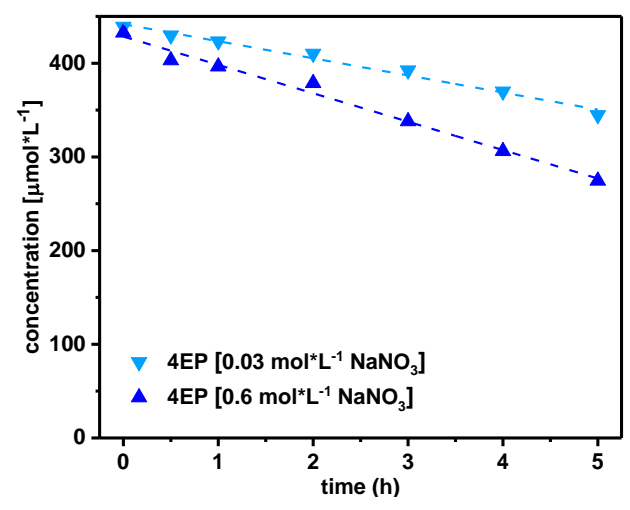

b)

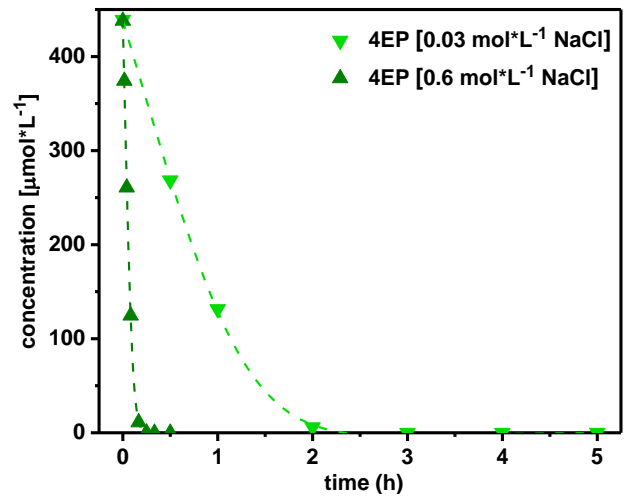

Figure 2.1. Electrochemical degradation of 4EP at various salt conditions: a) $0.03 \mathrm{~mol} \mathrm{~L}^{-1} \mathrm{NaNO}_{3}$ (light blue), $0.6 \mathrm{~mol} \mathrm{~L}^{-1} \mathrm{NaNO}_{3}$ (dark blue); b) $0.03 \mathrm{~mol} \mathrm{~L}^{-1} \mathrm{NaCl}$ (light green), $0.6 \mathrm{~mol} \mathrm{~L}^{-1} \mathrm{NaCl}$ (dark green). ECD was performed at a Ti/Pt working electrode at constant current density of $15 \mathrm{~mA} \mathrm{~cm}^{-2}$.

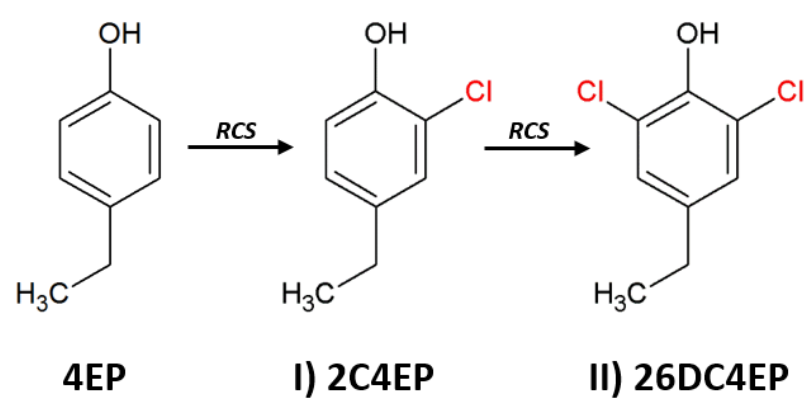

Figure 2.2. Reaction path of 4EP with RCS (mainly hypochlorite) during ECD at $15 \mathrm{~mA} \mathrm{~cm}^{-2}$ at a Ti/Pt electrode or BDD electrode in $\mathrm{NaCl}$ media $\left(0.03 \mathrm{~mol} \mathrm{~L}^{-1} \mathrm{NaCl}\right.$ and $0.6 \mathrm{~mol} \mathrm{~L}^{-1} \mathrm{NaCl}$ ). 2-chloro-4-ethylphenol (2C4EP) and 2,6-dichloro-4-ethylphenol (26DC4EP) were identified as main aromatic intermediates.

In order to further understand the subsequent degradation process of the two intermediates, the concentration vs time profiles were determined (Figure 2.3). Obviously, 4EP is converted into 2C4EP almost instantaneously. For the low $\mathrm{NaCl}$ concentration (Figure 2.3a) a maximum of 2C4EP formation is obtained after $1-1.5 \mathrm{~h}$ of treatment time, with 2C4EP already exceeding the concentration of 4EP. 
The measured concentration of $149 \mu \mathrm{mol} \mathrm{L}^{-1}$ [23.3 mg L $\left.\mathrm{L}^{-1}\right]$ of $2 \mathrm{C} 4 \mathrm{EP}$ corresponds to a molar fraction of $34 \%$ relative to the initial molar concentration of 4EP (for more information see also Figure A2.6).

a)

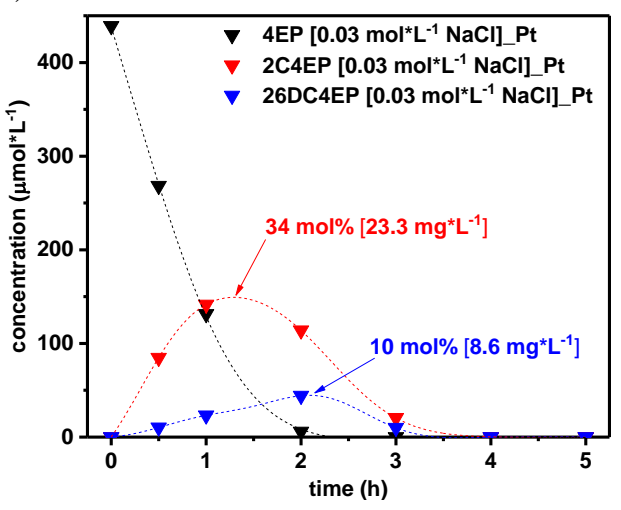

c)

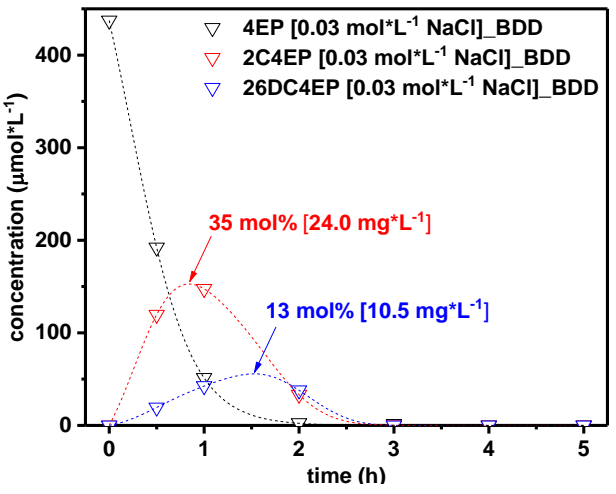

b)

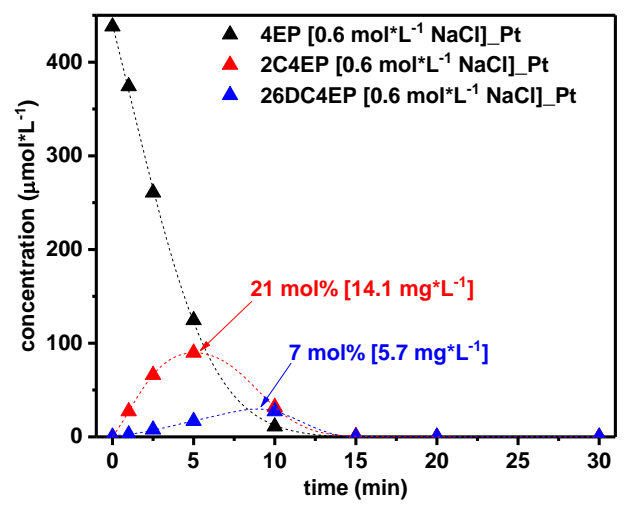

d)

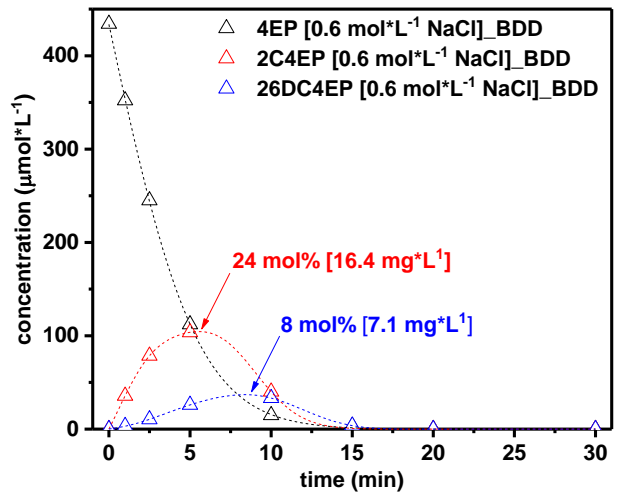

Figure 2.3. Formation and degradation of $2 \mathrm{C} 4 \mathrm{EP}$ (red) and 26DC4EP (blue) formed during ECD of 4EP (black) in $0.03 \mathrm{~mol} \mathrm{~L}^{-1} \mathrm{NaCl}(\mathrm{a} \& \mathrm{c})$ and $0.6 \mathrm{~mol} \mathrm{~L}^{-1} \mathrm{NaCl}$ solution $(\mathrm{b} \& \mathrm{~d})$ using Ti/Pt $(\mathrm{a} \& \mathrm{~b})$ or BDD electrode $(\mathrm{c} \& \mathrm{~d})$.

26DC4EP is already formed during accumulation of 2C4EP indicating a continuous consecutive transformation of 4EP into 2C4EP and 26DC4EP (Figure 2.2). Again these results are in agreement with the chemical chlorination of phenol ${ }^{70}$ and recent studies on phenol degradation at a BDD electrode in low saline solution. ${ }^{16} \mathrm{~A}$ concentration maximum of $45 \mu \mathrm{mol} \mathrm{L}^{-1}$ [8.6 $\mathrm{mg} \mathrm{L}^{-1}$ ] of 26DC4EP corresponding to a molar fraction of $10 \%$ relative to the initial molar concentration of $4 \mathrm{EP}$ was 
obtained after $2 \mathrm{~h}$. It took as long as $4 \mathrm{~h}$ of ECD at low $\mathrm{NaCl}$ concentration, to remove both intermediates completely from solution (below the limit of detection (LOD), see Table A2.3 for more information).

Similar concentration profiles were obtained for the high salt conditions, however within shorter reaction times (Figure 2.3b). Already after $5 \mathrm{~min}$., 2C4EP reached its maximum concentration $\left(90 \mu \mathrm{mol} \mathrm{L}^{-1}\left[14.1 \mathrm{mg} \mathrm{L}^{-1}\right]\right.$, corresponding to $21 \mathrm{~mol} \%$ of the initial 4EP concentration). 26DC4EP reached its maximum concentration after $10 \mathrm{~min}\left(30 \mu \mathrm{mol} \mathrm{L}^{-1}\left[5.7 \mathrm{mg} \mathrm{L}^{-1}\right]\right.$, corresponding to $7 \mathrm{~mol} \%$ of the initial 4EP concentration). After $20 \mathrm{~min}$ of treatment both intermediates were already removed from solution. For comparison, the performance of a BDD electrode is shown in Figure $2.3 \mathrm{c}$ and d) for the low and high $\mathrm{NaCl}$ concentration. While small changes in the kinetic curves of the degradation of 4EP and formation of chlorinated intermediates are present, generally both electrodes perform equally under the studied conditions.

The results suggest that significant amounts of the same mono- and di-chlorinated intermediates were formed and built-up in the solution for both $\mathrm{NaCl}$ concentrations and both electrode types. Although the apparent removal of the starting compound 4EP is fast (compared to $\mathrm{NaNO}_{3}$ ) a large fraction of 4EP is directly converted into chlorinated compounds in a consecutive reaction path (Figure 2.2). Interestingly for the higher salt concentration less 2C4EP and 26DC4EP were measured, however the higher FC concentration led to a faster removal rate which most likely suppresses more accumulation of these intermediates.

In addition to the two identified intermediates various other chlorinated compounds were detected by MS. While identification of their structure exceeds the scope of this work, it is interesting to note that the degradation of these intermediates is significantly delayed (Figure A2.7). The degradation pattern indicates that these compounds are obtained by additional reactions of the two main intermediates, 2C4EP and 26DC4EP. Hydroxylation ${ }^{72,73}$ and subsequent ring opening ${ }^{73,74}$ might cause the formation of several other intermediates. In addition, dimerization has been proposed for chemical chlorination of methylphenols leading to polychlorinated methylphenoxymethylphenols ${ }^{72}$ and the formation of polychlorinated phenol oligomers was observed during ECD of phenol and 2-chlorophenol. ${ }^{74,75}$ Therefore, it is likely that the detected intermediates are congeners of the reported polychlorinated phenol oligomers. 
The formation of small chlorinated end products such as chloromethanes ${ }^{17,76}$ and chlorinated acetic acids ${ }^{17}$ has been reported for ECD in saline water. In order to analyze the residual organic content after oxidation of 4EP, non-purgeable organic carbon (NPOC) measurements were performed. The NPOC values (Figure 2.4) clearly indicate that large amounts, between $64 \%$ to $86 \%$ of the initial organic carbon, were still present. Even after extended treatment times of $5 \mathrm{~h}$ (high salinity) only $23 \%$ of organic carbon was effectively removed. These nonvolatile compounds are most probably low molecular weight organic compounds such as organic acids, which have been detected after aromatic ring cleavage during ECD in $\mathrm{NaCl}$ solution $^{74}$ and might also consist of chlorinated derivates such as chlorinated organic acids. ${ }^{17}$

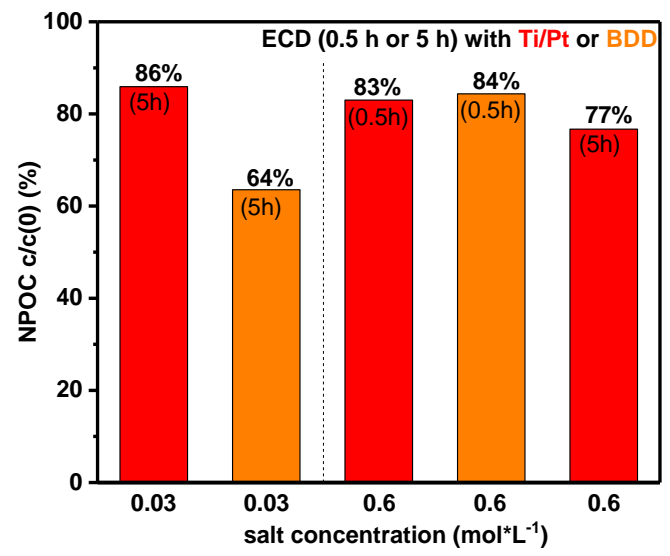

Figure 2.4. Non-purgeable organic carbon (NPOC) measurements of treated waters after $\mathrm{ECD}$ of $4 \mathrm{EP}$ at constant current conditions $\left(15 \mathrm{~mA} \mathrm{~cm}^{-2}\right)$ at a Ti/Pt or BDD electrode in $\mathrm{NaCl}$ media. NPOC values were measured after $5 \mathrm{~h} \mathrm{ECD}$ in $0.03 \mathrm{~mol} \mathrm{~L}^{-1} \mathrm{NaCl}$ media and after $30 \mathrm{~min}$ and $5 \mathrm{~h}$ for $0.6 \mathrm{~mol} \mathrm{~L}^{-1} \mathrm{NaCl}$.

The experimental observations highlight a major bottleneck of electrochemical AOP techniques. Although ECD removal of 4EP in saline conditions appeared to be efficient, especially compared to inert salt conditions, undesirable (poly)chlorinated aromatic intermediates were formed for both electrodes that require longer treatment times. Moreover, the degradation of 4EP and (chlorinated) intermediates on a Ti/Pt electrode led only to a breakdown of the aromatic compounds and the total removal rate of organic carbon was quite poor. Only for BDD at low salt concentration 
slightly higher NPOC removal was achieved, most likely due to an increased contribution of generated $\mathrm{OH}$ radicals. Still, $64 \%$ of the NPOC remained after $5 \mathrm{~h}$ treatment and significant amounts of $\mathrm{RCl}$ were formed (Figure 2.3), leading to the conclusion that for both electrodes chlorination is the main degradation pathway under the studied conditions, which is in agreement with a recent report of high faradaic efficiency for chloride oxidation on BDD electrodes. ${ }^{77}$

\subsubsection{Photocatalytic degradation of 4EP}

The photocatalytic degradation of 4EP at different salt conditions is shown in Figure 2.5. Using a pseudo first order approximation, implying surface mediated conversion is dominating, rate constants were estimated to be $1.13 \mathrm{~h}^{-1}$ in the absence of salt, $0.8 \mathrm{~h}^{-1}$ in the presence of $\mathrm{NaNO}_{3}$ (high and low concentration) and $0.8 \mathrm{~h}^{-1}$ and $0.5 \mathrm{~h}^{-1}$ for low and high concentration of $\mathrm{NaCl}$. To compare the rates to ECD, initial rates can be calculated (using the initial concentration of $410 \mu \mathrm{mol} \mathrm{L}^{-1}\left[50 \mathrm{mg} \mathrm{L}^{-1}\right]$ ) to be $\approx 330 \mu \mathrm{mol} \mathrm{L}^{-1} \mathrm{~h}^{-1}$ or $205 \mu \mathrm{mol} \mathrm{L}^{-1} \mathrm{~h}^{-1}$ for the low or high $\mathrm{NaCl}$ concentration, respectively. At low $\mathrm{NaCl}$ concentration, the rates of ECD and PCD are comparable, but in contrast to $\mathrm{ECD}$, addition of salts, and in particular $\mathrm{NaCl}$ at high concentration, had a negative effect on the degradation rates of the parent compound $4 \mathrm{EP}$, leading to an order of magnitude difference under these conditions $\left(\approx 3750 \mu \mathrm{mol} \mathrm{L}^{-1} \mathrm{~h}^{-1}\right.$ vs $\left.205 \mu \mathrm{mol} \mathrm{L} \mathrm{L}^{-1} \mathrm{~h}^{-1}\right)$. The inhibiting effect of $\mathrm{NaCl}$ is in agreement with observations reported for PCD of phenol. ${ }^{38}$ Since the inhibition at $0.6 \mathrm{~mol} \mathrm{~L}^{-1} \mathrm{NaCl}$ is clearly more significant than at $0.6 \mathrm{~mol} \mathrm{~L}^{-1} \mathrm{NaNO}_{3}$, the inhibition is mainly attributed to the presence of $\mathrm{Cl}^{-}{ }^{24}$

While the exact reason for the negative effect of anions is still under debate, blocking of active surface sites ${ }^{25,28-32}$ appears unlikely as the main explanation. Considering a point of zero charge (PZC) for $\mathrm{TiO}_{2}$ between 5 to $6,{ }^{78}$ the $\mathrm{TiO}_{2}$ particle surface charge in this study is neutral as measurements were performed at circumneutral conditions. Moreover, under illumination the build-up of a negative surface charge has been observed for $\mathrm{TiO}_{2}$ particles $(\mathrm{pH}>\text { isoelectric point })^{79,80}$ hindering a competitive adsorption or blocking of active surface sites by chloride anions. In the case of chloride adsorption on the $\mathrm{TiO}_{2}$ particles $(\mathrm{pH}<\mathrm{PZC}$, for example possible due to a $\mathrm{pH}$ drop during PCD because of dissolved $\mathrm{CO}_{2}$ produced during degradation; see also Figure A2.8) the oxidation of chloride ions, by either photogenerated valence band holes and/or hydroxyl radicals becomes likely and is proposed frequently in literaure. ${ }^{24-27,35-37,39,40,57}$ As a consequence RCS formation would occur supporting 
the 4EP removal as observed in ECD. However, our results indicate that the degradation pathways of 4EP during PCD and ECD are different and RCS likely do not contribute to PCD. Thus, just blocking of active sites by $\mathrm{Cl}^{-}$cannot fully explain the observations. In order to verify this conclusion, we analyzed the intermediates formed during PCD.

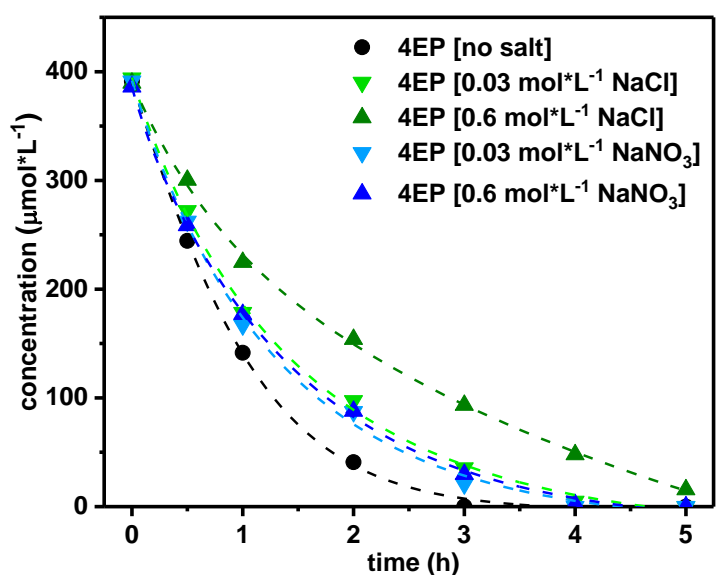

Figure 2.5. Photocatalytic degradation of $4 \mathrm{EP}$ at various salt conditions: no salt (black curve), $0.03 \mathrm{~mol} \mathrm{~L}^{-1} \mathrm{NaNO}_{3}$ (light blue), $0.6 \mathrm{~mol} \mathrm{~L}^{-1} \mathrm{NaNO}_{3}$ (dark blue), $0.03 \mathrm{~mol} \mathrm{~L}^{-1} \mathrm{NaCl}$ (light green), $0.6 \mathrm{~mol} \mathrm{~L}^{-1} \mathrm{NaCl}$ (dark green). $\mathrm{PCD}$ was performed under $375 \mathrm{~nm}$ illumination in a $\mathrm{TiO}_{2}(\mathrm{H} 600)$ slurry $\left[0.5 \mathrm{~g} \mathrm{~L}^{-1}\right]$.

Unlike in the case of ECD, chlorinated intermediates were identified only in extremely low quantities, and LC-MS analysis revealed the following main aromatic intermediates: (1) 1-(4-hydroxyphenyl)ethanol, (2) 4-hydroxybenzaldehyde, (3) 4hydroxyacetophenone, (4) 4-ethylresorcinol and (5) 4-ethylcatechol (Figure 2.6a; more information Table A2.1). Thus, the model compound 4EP is oxidized at least at three carbon atoms during PCD, which is typical for nonselective radical reactions (i.e. by $\left.{ }^{\circ} \mathrm{OH}\right)$. The formation of the isomer 2-(4-hydroxyphenyl)ethanol could not be revealed due to overlapping retention times with (1) (Table A2.1). However, the increased stability of secondary alkyl radicals favors the formation of intermediate (1) and its subsequent oxidation product (3). Therefore, the formation of 2-(4hydroxyphenyl)ethanol is of minor contribution during PCD of 4EP. The same 
intermediates were detected for all PCD conditions. The nonselective radical reaction pathway is also in good agreement with other reports, e.g. for PCD of ethylbenzene, ${ }^{81}$ phenol ${ }^{37,42,82}$ or p-cresol, ${ }^{83}$ confirming that RCS are insignificantly involved in the degradation path of 4EP.

a)<smiles>CC(O)c1ccc(O)cc1</smiles>

(2)<smiles>O=Cc1ccc(O)cc1</smiles><smiles>CC(=O)c1ccc(O)cc1</smiles><smiles>CCc1ccc(O)c(O)c1</smiles>

(4)

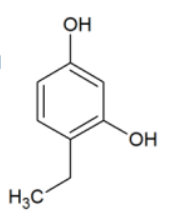

(5)

b)

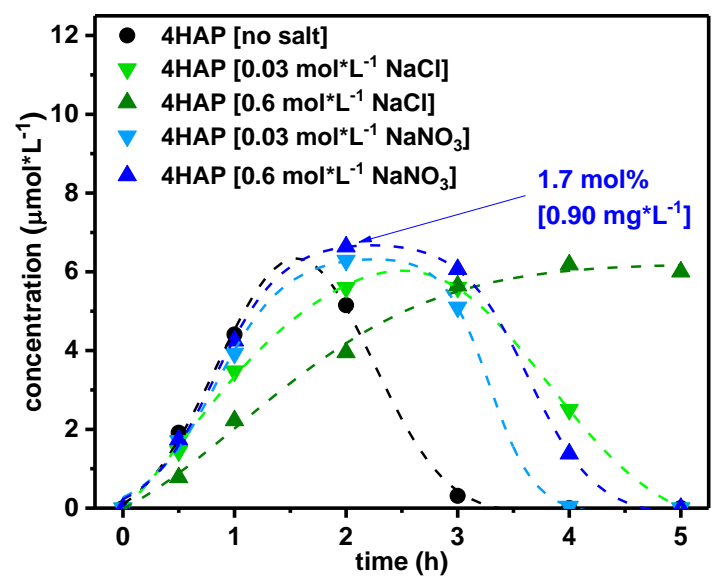

Figure 2.6. a) Chemical structures of the identified aromatic intermediates during PCD of 4EP observed for all studied salt conditions (no salt, $0.03 \mathrm{~mol} \mathrm{~L}^{-1} \mathrm{NaNO}_{3}, 0.6 \mathrm{~mol} \mathrm{~L}^{-1}$ $\mathrm{NaNO}_{3}, \quad 0.03 \mathrm{~mol} \mathrm{~L}^{-1} \mathrm{NaCl}, \quad 0.6 \mathrm{~mol} \mathrm{~L}^{-1} \mathrm{NaCl}$ ): (1) 1-(4-hydroxyphenyl)ethanol, (2) 4-hydroxybenzaldehyde, (3) 4-hydroxyacetophenone, (4) 4-ethylresorcinol, (5) 4-ethylcatechol. b) Formation and degradation of intermediate (3) 4-hydroxyacetophenone during PCD of 4EP at various salt conditions: no salt (black curve), $0.03 \mathrm{~mol} \mathrm{~L}^{-1} \mathrm{NaNO}_{3}$ (light blue), $0.6 \mathrm{~mol} \mathrm{~L}^{-1} \mathrm{NaNO}_{3}$ (dark blue), $0.03 \mathrm{~mol} \mathrm{~L}^{-1}$ $\mathrm{NaCl}$ (light green), $0.6 \mathrm{~mol} \mathrm{~L}^{-1} \mathrm{NaCl}$ (dark green).

For the most abundant intermediate (3), its formation and degradation at different salt conditions is shown in Figure 2.6b. At high $\mathrm{NaCl}$ concentration a pronounced inhibition of formation and subsequent degradation was observed, whereas the influence of $\mathrm{NaNO}_{3}$ or low $\mathrm{NaCl}$ concentration is less. The observations are related with the 4EP removal, where the strongly inhibited 4EP degradation explains the delayed formation of (3) at high $\mathrm{NaCl}$ concentration. This is in agreement with reports for PCD of phenol. ${ }^{38}$ 
As 2C4EP and 26DC4EP were detected as main chlorinated intermediates in ECD the chromatograms obtained from PCD experiments were thoroughly analyzed. Only for high salt concentration small amounts of 2C4EP could be measured and quantified (Figure 2.7). Similarly to ECD measurements, formation of 2C4EP occurs immediately, slowly accumulates in the reactor, and its degradation is strongly retarded in agreement with intermediate (3) monitored during PCD at high saline conditions (see Figure 2.6b). If at all formed, then the concentration of 26DC4EP remained below the LOD.

Again, FC concentrations were determined. For low $\mathrm{NaCl}$ concentrations the measured values are below the LOD; for high $\mathrm{NaCl}$ concentrations only small amounts of FC could be detected $\left[0.15 \mathrm{mg} \mathrm{L}^{-1}\right]$. This shows that PCD is hardly mediated by FC species, in agreement with the low quantities of chlorinated intermediates.

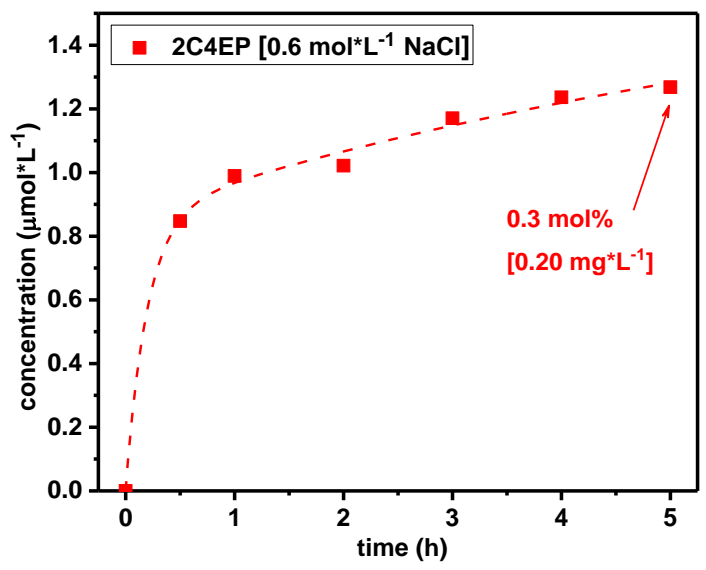

Figure 2.7. Formation of the monochlorinated intermediate 2C4EP during PCD of 4EP in $0.6 \mathrm{~mol} \mathrm{~L}^{-1} \mathrm{NaCl}$ solution.

In general the oxidation of chloride by scavenging $\mathrm{OH}$ radicals is not favored at the conditions of this study. ${ }^{45,52,84}$ Zhang et al. concluded chloride being a poor hydroxyl radical scavenger at circumneutral to alkaline conditions, because the equilibrium of the reaction is favored for the reverse reaction to $\mathrm{Cl}^{-}$and ${ }^{\circ} \mathrm{OH}(>99.98 \%){ }^{52}$ The absence of $\mathrm{FC}$ for smaller $\mathrm{Cl}^{-}$concentrations is also in agreement with findings reported by Krivec et al., ${ }^{32}$ who did not detect $\mathrm{Cl}$ radicals. For higher $\mathrm{NaCl}$ 
concentrations the results match the observations by Azevedo et al. ${ }^{38}$ who reported small amounts of 4-Chlorophenol (not quantified) formed during phenol PCD at high salt concentrations. Anyway, the results indicate that chloride is barely oxidized during PCD, and formation of RCS is negligible.

As for the ECD experiments, the overall removal of organic carbon during the PCD treatment was estimated by determination of the NPOC content. Results obtained after $5 \mathrm{~h}$ of PCD in saline water are shown in Figure 2.8. In the absence of any salt NPOC was below the LOD. This is in agreement with the non-affected 4EP and intermediate removal (compared to salt containing solutions) and indicates a complete removal of the organic carbon within the duration of the PCD experiments. For the low and high $\mathrm{NaCl}$ concentration, residual NPOC remained in the solution in agreement with the delay in 4EP degradation. For example, although 4EP and the main intermediate (3) were removed after $5 \mathrm{~h}$ treatment in $0.03 \mathrm{~mol} \mathrm{~L}^{-1} \mathrm{NaCl}$ solutions, a residual NPOC content of $13 \%$ was measured. Since the UV chromatogram did not show any significant peaks after $5 \mathrm{~h}$ of PCD, the residual organic carbon most likely exists in compounds arising from ring-opening reactions, such as short chain aliphatic compounds and carboxylic acids. ${ }^{82,85,86}$ At high $\mathrm{NaCl}$ concentration a residual NPOC of $46 \%$ remained. Calculated photonic efficiencies of PCD experiments for the various salt conditions are shown in Table A2.5 and an estimation of the energy consumption compared to ECD experiments is shown in Table A2.6. For the applied conditions in this study the energy consumption of the PCD treatment was approx. between one and two orders of magnitude higher compared to the ECD; however, it is important to note that the applied reactors were not optimized for energy consumption, and the applied light sources have low efficiency for illumination of the photocatalytic slurry (less than 1\%). Although ECD thus seems to appear beneficial in terms of consumed energy per kg removed NPOC, degradation of 4EP by PCD leads to significantly smaller NPOC than ECD at comparable rate of 4EP conversion (low $\mathrm{NaCl}$ concentration). Moreover, the concentration of chlorinated intermediates formed during PCD is significantly lower (for low and high $\mathrm{NaCl}$ concentration) compared to $\mathrm{ECD}$, thus photocatalysis appears the preferred method for application, in particular if illumination efficiency and reactor design are optimized. 


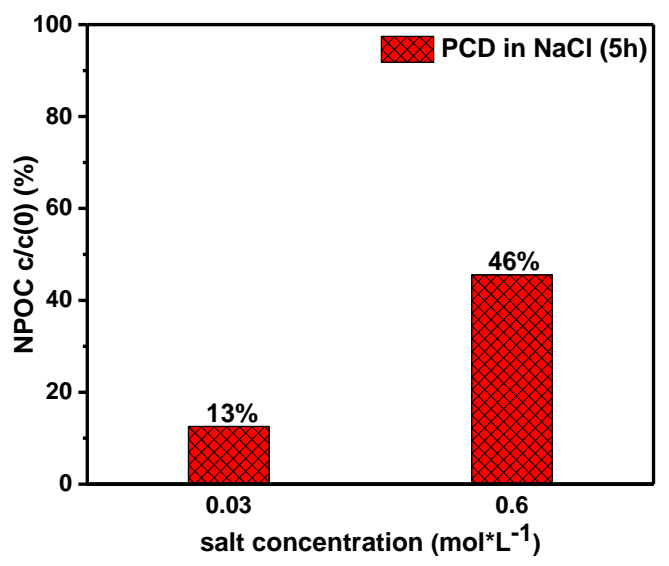

Figure 2.8. Non-purgeable organic carbon (NPOC) measurements of treated waters after $5 \mathrm{~h}$ PCD of 4EP in $0.03 \mathrm{~mol} \mathrm{~L}^{-1} \mathrm{NaCl}$ and $0.6 \mathrm{~mol} \mathrm{~L}^{-1} \mathrm{NaCl}$.

Finally, photoelectrochemical degradation (PECD), a hybrid technology, was studied. The experiments were performed with a $\mathrm{TiO}_{2} / \mathrm{Ti}$ electrode at an applied anodic bias of $0.1 \mathrm{~V}$ vs $\mathrm{Ag} / \mathrm{AgCl}$ irradiated with UVA light (see Figure A2.9 for more information). In recent reports Zanoni et al. ${ }^{87}$ showed already that oxidation of chloride to $\mathrm{FC}$ at $\mathrm{TiO}_{2}$ photoelectrodes occurs and the generation of RCS has been proposed to assist the PECD of organic compounds. ${ }^{46,57,61,88}$ Still, reports discussing the formation of intermediates are scarce. ${ }^{50,89}$ After 15 min of irradiation at low $\mathrm{NaCl}$ concentration, $92 \%$ of 4EP was removed and an intensive formation of RCS was observed (as detected by FC $\left[27 \mathrm{mg} \mathrm{L}^{-1}\right]$ ). The HPLC analysis (Figure 2.9) revealed significant amounts of the same intermediates, as observed during ECD $\left(57 \mu \mathrm{mol} \mathrm{L}^{-1} \quad\left[9 \mathrm{mg} \mathrm{L}^{-1}\right] \quad 2 \mathrm{C} 4 \mathrm{EP} \quad\right.$ and $\left.\quad 89 \mu \mathrm{mol} \mathrm{L}^{-1} \quad\left[17 \mathrm{mg} \mathrm{L}^{-1}\right] \quad 26 \mathrm{DC} 4 \mathrm{EP}\right)$. Interestingly, without additional bias (resembling PCD conditions) intermediate (3) was observed as main intermediate and the formation chlorinated compounds was excluded (Figure A2.10). Thus, the 4EP reaction pathway can be easily modified by the applied bias. The blank experiment (PECD in dark at $0.1 \mathrm{~V} v \mathrm{vs} . \mathrm{Ag} / \mathrm{AgCl}$ ) did not lead to any photocurrent, RCS formation or 4EP degradation (Figure A2.11), because the applied potential was below any relevant standard redox potential (e.g. $1.36 \mathrm{~V}$ vs. SHE for chlorine evolution or $2.7 \mathrm{~V}$ vs. SHE for ${ }^{\bullet} \mathrm{OH}$ generation). To verify the observations and exclude a particular effect of the applied $\mathrm{TiO}_{2}, \mathrm{PECD}$ experiments were conducted with the H600 photocatalyst coated on FTO glass, showing similar trends (see Table A2.7). 


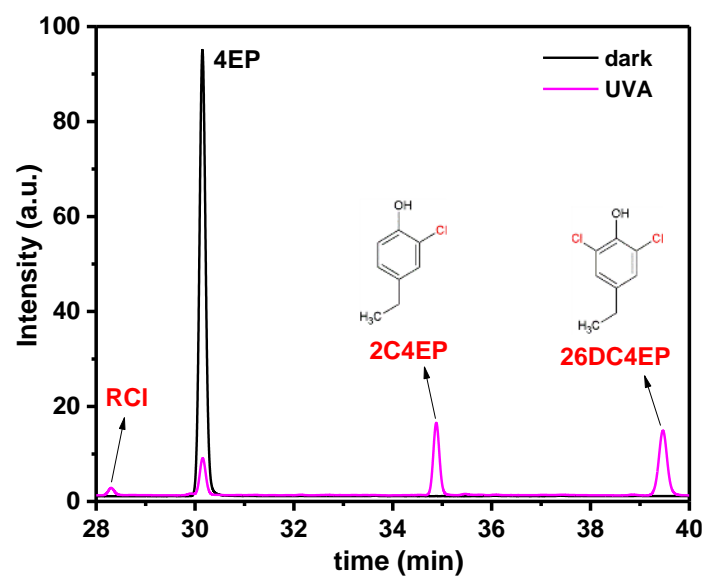

Figure 2.9. HPLC chromatogram obtained after $15 \mathrm{~min}$ PECD of $4 \mathrm{EP}$ in $0.03 \mathrm{~mol} \mathrm{~L}^{-1} \mathrm{NaCl}$ solution using a $\mathrm{TiO}_{2} / \mathrm{Ti}$ electrode with $0.1 \mathrm{~V}$ vs $\mathrm{Ag} / \mathrm{AgCl}$ bias and $365 \mathrm{~nm} \mathrm{UV}$ light. The majority of 4EP was removed and transformed into significant amounts of the monochlorinated 2C4EP and dichlorinated 26DC4EP, similar as observed during ECD experiments.

The effect of an applied anodic bias can be explained by the following: In a photocatalytic approach charge carrier (electrons and holes) are usually generated close to the particle surface and physical separation of reduction and oxidation sites is hardly achieved on the nanoscale. Thus, oxidation and reduction occur in close proximity and the recombination of oxidized chloride with photogenerated CB electrons is likely. This surface-charge recombination mechanism (quenching of photogenerated charge carriers by chloride ions) ${ }^{34}$ is effectively suppressed when an anodic bias is applied, e.g. in PECD experiments. Upon biasing the electrode photogenerated conduction band (CB) electrons from the $\mathrm{TiO}_{2}$ surface are pulled towards the back contact and in contrast to $\mathrm{PCD}$, reduction of $\mathrm{Cl}$-radicals by available CB electrons is unfeasible. Therefore, pronounced RCS generation could be observed during PECD, leading to a distinctive formation of RCl. In addition, the Coulombic repulsion between the $\mathrm{TiO}_{2}$ surface and chloride ions ${ }^{90}$ is lowered upon polarization of the $\mathrm{TiO}_{2}$ surface. ${ }^{50}$ This facilitates the adsorption of $\mathrm{Cl}^{-}$on the positively charged $\mathrm{TiO}_{2}$ surface allowing for chloride oxidation (RCS formation) and subsequent formation of $\mathrm{RCl}$. 


\subsection{Conclusions}

Combining all information, it is evident that although not all of the organic carbon could be removed during PCD, the removal of organic carbon was more effective in the purely light-driven approach compared to ECD (under the conditions applied in this study). Especially, the significantly smaller formation of RCS and RCl intermediates during PCD is of importance. During ECD in saline media 4EP was mainly removed by conversion into (polychlorinated) compounds and only small amounts of 4EP could be mineralized. In contrast, during PCD only for high $\mathrm{NaCl}$ concentrations minor formation of monochlorinated 2C4EP could be detected. The measured 2C4EP concentration during ECD at $0.6 \mathrm{~mol} \mathrm{~L}^{-1}$ was nearly two orders of magnitude higher than that detected after $5 \mathrm{~h}$ of PCD. The difference in the AOP techniques is likely governed by an external recombination mechanism helping to suppress $\mathrm{FC}$ and $\mathrm{RCl}$ formation. Overall, the formation of chlorinated intermediates during both AOP technologies is important for consideration of practical wastewater treatment applications.

\subsection{Acknowledgements}

Magneto special anodes B.V. is acknowledged for electrode support. Dyllian Huijgens is acknowledged for preliminary PCD experiments. Erna Fränzel-Luiten and Robert Meijer are acknowledged for technical support.

\subsection{References}

(1) World Water Assessment Programme, The United Nations World Water Development Report 2015: Water for a Sustainalbe World. Paris, UNESCO; 2015. https://doi.org/ISBN 978-92-3-100071-3.

(2) Smalley, R. E. Future Global Energy Prosperity: The Terawatt Challenge. MRS Bull. 2005, 30 (6), 412-417. https://doi.org/10.1557/mrs2005.124.

(3) World Water Assessment Programme, The United Nations World Water Development Report 2017: Wastewater The Untapped Rescource. Paris, UNESCO; UNESCO: Paris, 2017.

(4) Garcia-Segura, S.; Ocon, J. D.; Chong, M. N. Electrochemical Oxidation Remediation of Real Wastewater Effluents - A Review. Process Saf. Environ. Prot. 2018, 113, 48-67. 
https://doi.org/10.1016/j.psep.2017.09.014.

(5) Margot, J.; Rossi, L.; Barry, D. A.; Holliger, C. A Review of the Fate of Micropollutants in Wastewater Treatment Plants. Wiley Interdiscip. Rev. Water 2015, 2 (5), 457-487. https://doi.org/10.1002/wat2.1090.

(6) Luo, Y.; Guo, W.; Ngo, H. H.; Nghiem, L. D.; Hai, F. I.; Zhang, J.; Liang, S.; Wang, X. C. A Review on the Occurrence of Micropollutants in the Aquatic Environment and Their Fate and Removal during Wastewater Treatment. Sci. Total Environ. 2014, 473-474, 619-641. https://doi.org/http://dx.doi.org/10.1016/j.scitotenv.2013.12.065.

(7) Gupta, A.; Thakur, I. S. Treatment of Organic Recalcitrant Contaminants in Wastewater. In Biological Wastewater Treatment and Resource Recovery; Farooq, R., Ahmad, Z., Eds.; InTech, 2017. https://doi.org/10.5772/66346.

(8) Lefebvre, O.; Moletta, R. Treatment of Organic Pollution in Industrial Saline Wastewater: A Literature Review. Water Res. 2006, 40 (20), 36713682. https://doi.org/http://dx.doi.org/10.1016/j.watres.2006.08.027.

(9) Kargi, F.; Dincer, A. R. Effect of Salt Concentration on Biological Treatment of Saline Wastewater by Fed-Batch Operation. Enzyme Microb. Technol. 1996, 19 (7), 529-537. https://doi.org/10.1016/S01410229(96)00070-1.

(10) Dewil, R.; Mantzavinos, D.; Poulios, I.; Rodrigo, M. A. New Perspectives for Advanced Oxidation Processes. J. Environ. Manage. 2017, 195, 93-99. https://doi.org/https://doi.org/10.1016/j.jenvman.2017.04.010.

(11) Comninellis, C.; Nerini, A. Anodic Oxidation of Phenol in the Presence of $\mathrm{NaCl}$ for Wastewater Treatment. J. Appl. Electrochem. 1995, 25 (1), 23-28. https://doi.org/10.1007/bf00251260.

(12) Panizza, M.; Cerisola, G. Electrochemical Oxidation of 2-Naphthol with in Situ Electrogenerated Active Chlorine. Electrochim. Acta 2003, 48 (11), 1515-1519. https://doi.org/https://doi.org/10.1016/S0013-4686(03)00028-8.

(13) Panizza, M.; Cerisola, G. Direct And Mediated Anodic Oxidation of Organic Pollutants. Chem. Rev. 2009, 109 (12), 6541-6569. https://doi.org/10.1021/cr9001319.

(14) Martinez-Huitle, C. A.; Ferro, S. Electrochemical Oxidation of Organic Pollutants for the Wastewater Treatment: Direct and Indirect Processes. Chem. Soc. Rev. 2006, 35 (12), 1324-1340. https://doi.org/10.1039/B517632H. 
(15) Sirés, I.; Brillas, E.; Oturan, M. A.; Rodrigo, M. A.; Panizza, M. Electrochemical Advanced Oxidation Processes: Today and Tomorrow. A Review. Environ. Sci. Pollut. Res. 2014, 21 (14), 8336-8367. https://doi.org/10.1007/s11356-014-2783-1.

(16) Saylor, G. L.; Chen, L.; Kupferle, M. J. Using Toxicity Testing to Evaluate Electrochemical Reactor Operations. Environ. Toxicol. Chem. 2012, 31 (3), 494-500. https://doi.org/10.1002/etc.1719.

(17) Jasper, J. T.; Yang, Y.; Hoffmann, M. R. Toxic Byproduct Formation during Electrochemical Treatment of Latrine Wastewater. Environ. Sci. Technol. 2017, 51 (12), 7111-7119. https://doi.org/10.1021/acs.est.7b01002.

(18) Li, H.; Long, Y.; Zhu, X.; Tian, Y.; Ye, J. Influencing Factors and Chlorinated Byproducts in Electrochemical Oxidation of Bisphenol A with Boron-Doped Diamond Anodes. Electrochim. Acta 2017, 246, 1121-1130. https://doi.org/10.1016/j.electacta.2017.06.163.

(19) Burgos-Castillo, R. C.; Sirés, I.; Sillanpää, M.; Brillas, E. Application of Electrochemical Advanced Oxidation to Bisphenol A Degradation in Water. Effect of Sulfate and Chloride Ions. Chemosphere 2018, 194, 812-820. https://doi.org/10.1016/j.chemosphere.2017.12.014.

(20) Chaplin, B. P. Critical Review of Electrochemical Advanced Oxidation Processes for Water Treatment Applications. Environ. Sci. Process. Impacts 2014, 16 (6), 1182-1203. https://doi.org/10.1039/C3EM00679D.

(21) Hanberg, A. Toxicology of Environmentally Persistent Chlorinated Organic Compounds. Pure Appl. Chem. 1996, 68 (9), 1791-1799. https://doi.org/10.1351/pac199668091791.

(22) Schoeny, R. Disinfection By-Products: A Question of Balance. Environ. Health Perspect. 2010, 118 (11), A466-A467.

https://doi.org/10.1289/ehp.1003053.

(23) Villanueva, C. M.; Cordier, S.; Font-Ribera, L.; Salas, L. A.; Levallois, P. Overview of Disinfection By-Products and Associated Health Effects. Curr. Environ. Heal. reports 2015, 2 (1), 107-115. https://doi.org/10.1007/s40572-014-0032-x.

(24) Lindner, M.; Bahnemann, D. W.; Hirthe, B.; Griebler, W. D. Solar Water Detoxification: Novel $\mathrm{TiO}_{2}$ Powders as Highly Active Photocatalysts. $J$. Sol. Energy Eng. 1997, 119 (2), 120-125. https://doi.org/10.1115/1.2887890. 
(25) Burns, R. A.; Crittenden, J. C.; Hand, D. W.; Selzer, V. H.; Sutter, L. L.; Salman, S. R. Effect of Inorganic Ions in Heterogeneous Photocatalysis of TCE. J. Environ. Eng. 1999, 125 (1), 77-85. https://doi.org/doi:10.1061/(ASCE)0733-9372(1999)125:1(77).

(26) Calza, P.; Pelizzetti, E. Photocatalytic Transformation of Organic Compounds in the Presence of Inorganic Ions. Pure Appl. Chem. 2001, 73, 1839. https://doi.org/10.1351/pac200173121839.

(27) Yang, S.; Chen, Y.; Lou, L.; Wu, X. Involvement of Chloride Anion in Photocatalytic Process. J. Environ. Sci. 2005, 17 (5), 761-765.

(28) Chen, H. Y.; Zahraa, O.; Bouchy, M. Inhibition of the Adsorption and Photocatalytic Degradation of an Organic Contaminant in an Aqueous Suspension of $\mathrm{TiO}_{2}$ by Inorganic Ions. J. Photochem. Photobiol. A Chem. 1997, 108 (1), 37-44. https://doi.org/10.1016/S1010-6030(96)04411-5.

(29) Zhang, W.; An, T.; Cui, M.; Sheng, G.; Fu, J. Effects of Anions on the Photocatalytic and Photoelectrocatalytic Degradation of Reactive Dye in a Packed-Bed Reactor. J. Chem. Technol. Biotechnol. 2005, 80 (2), 223-229. https://doi.org/10.1002/jctb.1185.

(30) Chong, M. N.; Jin, B.; Chow, C. W. K.; Saint, C. Recent Developments in Photocatalytic Water Treatment Technology: A Review. Water Res. 2010, 44 (10), 2997-3027. https://doi.org/https://doi.org/10.1016/j.watres.2010.02.039.

(31) Umar, M.; Abdul Aziz, H. Photocatalytic Degradation of Organic Pollutants in Water. In Organic Pollutants - Monitoring, Risk and Treatment; Nageeb Rashed, M., Ed.; InTech, 2013. https://doi.org/10.5772/53699.

(32) Krivec, M.; Dillert, R.; Bahnemann, D. W.; Mehle, A.; Strancar, J.; Drazic, G. The Nature of Chlorine-Inhibition of Photocatalytic Degradation of Dichloroacetic Acid in a $\mathrm{TiO}_{2}$-Based Microreactor. Phys. Chem. Chem. Phys. 2014, 16 (28), 14867-14873. https://doi.org/10.1039/C4CP01043D.

(33) Guillard, C.; Puzenat, E.; Lachheb, H.; Houas, A.; Herrmann, J.-M. Why Inorganic Salts Decrease the $\mathrm{TiO}_{2}$ Photocatalytic Efficiency. Int. J. Photoenergy 2005, 7 (1), 1-9. https://doi.org/10.1155/s1110662x05000012.

(34) Sunada, F.; Heller, A. Effects of Water, Salt Water, and Silicone Overcoating of the $\mathrm{TiO}_{2}$ Photocatalyst on the Rates and Products of Photocatalytic Oxidation of Liquid 3-Octanol and 3-Octanone. Environ. Sci. Technol. 1998, 32 (2), 282-286. https://doi.org/10.1021/es970523f.

(35) Abdullah, M.; Low, G. K. C.; Matthews, R. W. Effects of Common Inorganic Anions on Rates of Photocatalytic Oxidation of Organic Carbon 
over Illuminated Titanium Dioxide. J. Phys. Chem. 1990, 94 (17), 68206825. https://doi.org/10.1021/j100380a051.

(36) Piscopo, A.; Robert, D.; Weber, J. V. Influence of PH and Chloride Anion on the Photocatalytic Degradation of Organic Compounds. Appl. Catal. B Environ. 2001, 35 (2), 117-124. https://doi.org/http://dx.doi.org/10.1016/S0926-3373(01)00244-2.

(37) Sökmen, M.; Özkan, A. Decolourising Textile Wastewater with Modified Titania: The Effects of Inorganic Anions on the Photocatalysis. $J$. Photochem. Photobiol. A Chem. 2002, 147 (1), 77-81. https://doi.org/10.1016/S1010-6030(01)00627-X.

(38) Azevedo, E. B.; Neto, F. R. de A.; Dezotti, M. TiO 2 -Photocatalyzed Degradation of Phenol in Saline Media: Lumped Kinetics, Intermediates, and Acute Toxicity. Appl. Catal. B Environ. 2004, 54 (3), 165-173. https://doi.org/http://dx.doi.org/10.1016/j.apcatb.2004.06.014.

(39) Yuan, R.; Ramjaun, S. N.; Wang, Z.; Liu, J. Photocatalytic Degradation and Chlorination of Azo Dye in Saline Wastewater: Kinetics and AOX Formation. Chem. Eng. J. 2012, 192 (Supplement C), 171-178. https://doi.org/https://doi.org/10.1016/j.cej.2012.03.080.

(40) Adishkumar, S.; Kanmani, S.; Rajesh Banu, J. Solar Photocatalytic Treatment of Phenolic Wastewaters: Influence of Chlorides, Sulphates, Aeration, Liquid Volume and Solar Light Intensity. Desalin. Water Treat. 2014, 52 (40-42), 7957-7963. https://doi.org/10.1080/19443994.2013.834522.

(41) Pellegrino, F.; Pellutiè, L.; Sordello, F.; Minero, C.; Ortel, E.; Hodoroaba, V. D.; Maurino, V. Influence of Agglomeration and Aggregation on the Photocatalytic Activity of $\mathrm{TiO}_{2}$ Nanoparticles. Appl. Catal. B Environ. 2017, 216, 80-87. https://doi.org/10.1016/j.apcatb.2017.05.046.

(42) L'Amour, R. J. A.; Azevedo, E. B.; Leite, S. G. F.; Dezotti, M. Removal of Phenol in High Salinity Media by a Hybrid Process (Activated Sludge+photocatalysis). Sep. Purif. Technol. 2008, 60 (2), 142-146. https://doi.org/https://doi.org/10.1016/j.seppur.2007.08.008.

(43) Azevedo, E. B.; Tôrres, A. R.; Aquino Neto, F. R.; Dezotti, M. TiO $2^{-}$ Photocatalyzed Degradation of Phenol in Saline Media in an Annular Reactor: Hydrodynamics, Lumped Kinetics, Intermediates, and Acute Toxicity. Brazilian J. Chem. Eng. 2009, 26, 75-87.

(44) Henderson, M. A. A Surface Science Perspective on $\mathrm{TiO}_{2}$ Photocatalysis. Surf. Sci. Rep. 2011, 66 (6-7), 185-297. https://doi.org/10.1016/j.surfrep.2011.01.001. 
(45) Yang, Y.; Pignatello, J. Participation of the Halogens in Photochemical Reactions in Natural and Treated Waters. Molecules 2017, 22 (10), 1684.

(46) Su, Y.; Wang, G.-B.; Kuo, D. T. F.; Chang, M.; Shih, Y.

Photoelectrocatalytic Degradation of the Antibiotic Sulfamethoxazole Using $\mathrm{TiO}_{2} /$ Ti Photoanode. Appl. Catal. B Environ. 2016, 186 (Supplement C), 184-192. https://doi.org/https://doi.org/10.1016/j.apcatb.2016.01.003.

(47) Ghernaout, D.; Naceur, M. W.; Aouabed, A. On the Dependence of Chlorine By-Products Generated Species Formation of the Electrode Material and Applied Charge during Electrochemical Water Treatment. Desalination 2011, 270 (1-3), 9-22. https://doi.org/10.1016/j.desal.2011.01.010.

(48) Radjenovic, J.; Sedlak, D. L. Challenges and Opportunities for Electrochemical Processes as Next-Generation Technologies for the Treatment of Contaminated Water. Environ. Sci. Technol. 2015, 49 (19), 11292-11302. https://doi.org/10.1021/acs.est.5b02414.

(49) Bessegato, G. G.; Guaraldo, T. T.; de Brito, J. F.; Brugnera, M. F.; Zanoni, M. V. B. Achievements and Trends in Photoelectrocatalysis: From Environmental to Energy Applications. Electrocatalysis 2015, 6 (5), 415441. https://doi.org/10.1007/s12678-015-0259-9.

(50) Garcia-Segura, S.; Brillas, E. Applied Photoelectrocatalysis on the Degradation of Organic Pollutants in Wastewaters. J. Photochem. Photobiol. C Photochem. Rev. 2017, 31, 1-35. https://doi.org/10.1016/J.JPHOTOCHEMREV.2017.01.005.

(51) Hao, Z.; Yin, Y.; Wang, J.; Cao, D.; Liu, J. Formation of Organobromine and Organoiodine Compounds by Engineered TiO2nanoparticle-Induced Photohalogenation of Dissolved Organic Matter in Environmental Waters. Sci. Total Environ. 2018, 631-632, 158-168. https://doi.org/10.1016/j.scitotenv.2018.03.027.

(52) Zhang, K.; Parker, K. M. Halogen Radical Oxidants in Natural and Engineered Aquatic Systems. Environ. Sci. Technol. 2018, https://doi.org/10.1021/acs.est.8b02219.

(53) Selcuk, H.; Bekbolet, M. Photocatalytic and Photoelectrocatalytic Humic Acid Removal and Selectivity of $\mathrm{TiO}_{2}$ coated Photoanode. Chemosphere 2008, 73 (5), 854-858. https://doi.org/10.1016/j.chemosphere.2008.05.069.

(54) Zhang, F.; Li, M.; Li, W.; Feng, C.; Jin, Y.; Guo, X.; Cui, J. Degradation of Phenol by a Combined Independent Photocatalytic and Electrochemical Process. Chem. Eng. J. 2011, 175 (1), 349-355. https://doi.org/10.1016/j.cej.2011.09.122. 
(55) Osiewała, L.; Socha, A.; Perek, A.; Socha, M.; Rynkowski, J.

Electrochemical, Photochemical, and Photoelectrochemical Treatment of

Sodium p-Cumenesulfonate. Water. Air. Soil Pollut. 2013, 224 (9).

https://doi.org/10.1007/s11270-013-1657-3.

(56) Hurwitz, G.; Pornwongthong, P.; Mahendra, S.; Hoek, E. M. V.

Degradation of Phenol by Synergistic Chlorine-Enhanced Photo-Assisted

Electrochemical Oxidation. Chem. Eng. J. 2014, 240 (Supplement C), 235243. https://doi.org/https://doi.org/10.1016/j.cej.2013.11.087.

(57) Tantis, I.; Bousiakou, L.; Karikas, G.-A.; Lianos, P. Photocatalytic and Photoelectrocatalytic Degradation of the Antibacterial Agent Ciprofloxacin. Photochem. Photobiol. Sci. 2015, 14 (3), 603-607. https://doi.org/10.1039/C4PP00377B.

(58) Suhadolnik, L.; Pohar, A.; Likozar, B.; Čeh, M. Mechanism and Kinetics of Phenol Photocatalytic, Electrocatalytic and Photoelectrocatalytic Degradation in $\mathrm{T}^{\mathrm{TiO}_{2}}$-Nanotube Fixed-Bed Microreactor. Chem. Eng. J. 2016, 303, 292-301. https://doi.org/10.1016/j.cej.2016.06.027.

(59) Serna-Galvis, E. A.; Silva-Agredo, J.; Giraldo, A. L.; Flórez-Acosta, O. A.; Torres-Palma, R. A. Comparative Study of the Effect of Pharmaceutical Additives on the Elimination of Antibiotic Activity during the Treatment of Oxacillin in Water by the Photo-Fenton, $\mathrm{TiO}_{2}$-Photocatalysis and Electrochemical Processes. Sci. Total Environ. 2016, 541, 1431-1438. https://doi.org/10.1016/j.scitotenv.2015.10.029.

(60) Granda-Ramírez, C. F.; Hincapié-Mejía, G. M.; Serna-Galvis, E. A.; Torres-Palma, R. A. Degradation of Recalcitrant Safranin T Through an Electrochemical Process and Three Photochemical Advanced Oxidation Technologies. Water. Air. Soil Pollut. 2017, 228 (11). https://doi.org/10.1007/s11270-017-3611-2.

(61) Cao, D.; Wang, Y.; Zhao, X. Combination of Photocatalytic and Electrochemical Degradation of Organic Pollutants from Water. Curr. Opin. Green Sustain. Chem. 2017, 6, 78-84. https://doi.org/10.1016/j.cogsc.2017.05.007.

(62) Escudero, C. J.; Iglesias, O.; Dominguez, S.; Rivero, M. J.; Ortiz, I. Performance of Electrochemical Oxidation and Photocatalysis in Terms of Kinetics and Energy Consumption. New Insights into the p-Cresol Degradation. J. Environ. Manage. 2017, 195, 117-124. https://doi.org/https://doi.org/10.1016/j.jenvman.2016.04.049.

(63) Carneiro, J. T.; Savenije, T. J.; Moulijn, J. A.; Mul, G. Toward a Physically Sound Structure-Activity Relationship of TiO2-Based Photocatalysts. $J$. 
Phys. Chem. C 2010, 114 (1), 327-332. https://doi.org/10.1021/jp906395w.

(64) Romão, J. S.; Hamdy, M. S.; Mul, G.; Baltrusaitis, J. Photocatalytic Decomposition of Cortisone Acetate in Aqueous Solution. J. Hazard. Mater. 2015, 282 (Supplement C), 208-215. https://doi.org/https://doi.org/10.1016/j.jhazmat.2014.05.087.

(65) Boitsov, S.; Mjøs, S. A.; Meier, S. Identification of Estrogen-like Alkylphenols in Produced Water from Offshore Oil Installations. Mar. Environ. Res. 2007, 64 (5), 651-665. https://doi.org/http://dx.doi.org/10.1016/j.marenvres.2007.07.001.

(66) Priac, A.; Morin-Crini, N.; Druart, C.; Gavoille, S.; Bradu, C.; Lagarrigue, C.; Torri, G.; Winterton, P.; Crini, G. Alkylphenol and Alkylphenol Polyethoxylates in Water and Wastewater: A Review of Options for Their Elimination. Arab. J. Chem. 2017, 10, S3749-S3773. https://doi.org/10.1016/j.arabjc.2014.05.011.

(67) Kochukov, M. Y.; Jeng, Y. J.; Watson, C. S. Alkylphenol Xenoestrogens with Varying Carbon Chain Lengths Differentially and Potently Activate Signaling and Functional Responses in GH3/B6/F10 Somatomammotropes. Environ. Health Perspect. 2009, 117 (5), 723-730. https://doi.org/10.1289/ehp.0800182.

(68) Reckhow, D. A.; Singer, P. C.; Malcolm, R. L. Chlorination of Humic Materials: Byproduct Formation and Chemical Interpretations. Environ. Sci. Technol. 1990, 24 (11), 1655-1664. https://doi.org/10.1021/es00081a005.

(69) Bond, T.; Henriet, O.; Goslan, E. H.; Parsons, S. A.; Jefferson, B. Disinfection Byproduct Formation and Fractionation Behavior of Natural Organic Matter Surrogates. Environ. Sci. Technol. 2009, 43 (15), 59825989. https://doi.org/10.1021/es900686p.

(70) Lee, G. F.; Morris, J. C. Kinetics of Chlorination of Phenol-Chlorophenolic Tastes and Odors. Int.J.Air Wat.Poll. 1962, 6 (567), 419-431.

(71) Rule, K. L.; Ebbett, V. R.; Vikesland, P. J. Formation of Chloroform and Chlorinated Organics by Free-Chlorine-Mediated Oxidation of Triclosan. Environ. Sci. Technol. 2005, 39 (9), 3176-3185.

https://doi.org/10.1021/es048943+.

(72) Onodera, S.; Yamada, K.; Yamaji, Y.; Ishikura, S.; Suzuki, S. Chemical Changes of Organic Compounds in Chlorinated Water: X. Formation of Polychlorinated Methylphenoxymethylphenols (Predioxins) during Chlorination of Methylphenols in Dilute Aqueous Solution. J. Chromatogr. 1986, 354, 293-303. 
(73) Onodera, S.; Tabata, M.; Suzuki, S.; Ishikura, S. Gas Chromatographic Identification and Determination of Chlorinated Quinones Formed during Chlorination of Dihydric Phenols with Hypochlorite in Dilute Aqueous Solution. J. Chromatogr. 1980, 200, 137-144.

(74) Vallejo, M.; San Román, M. F.; Ortiz, I. Quantitative Assessment of the Formation of Polychlorinated Derivatives, PCDD/Fs, in the Electrochemical Oxidation of 2-Chlorophenol As Function of the Electrolyte Type. Environ. Sci. Technol. 2013, 47 (21), 12400-12408. https://doi.org/10.1021/es403246g.

(75) Chen, L.; Campo, P.; Kupferle, M. J. Identification of Chlorinated Oligomers Formed during Anodic Oxidation of Phenol in the Presence of Chloride. J. Hazard. Mater. 2015, 283, 574-581. https://doi.org/10.1016/j.jhazmat.2014.10.001.

(76) Zöllig, H.; Remmele, A.; Fritzsche, C.; Morgenroth, E.; Udert, K. M. Formation of Chlorination Byproducts and Their Emission Pathways in Chlorine Mediated Electro-Oxidation of Urine on Active and Nonactive Type Anodes. Environ. Sci. Technol. 2015, 49 (18), 11062-11069. https://doi.org/10.1021/acs.est.5b01675.

(77) Mostafa, E.; Reinsberg, P.; Garcia-Segura, S.; Baltruschat, H. Chlorine Species Evolution during Electrochlorination on Boron-Doped Diamond Anodes: In-Situ Electrogeneration of $\mathrm{Cl}_{2}, \mathrm{Cl}_{2} \mathrm{O}$ and $\mathrm{ClO}_{2}$. Electrochim. Acta 2018, 281, 831-840. https://doi.org/10.1016/j.electacta.2018.05.099.

(78) Kosmulski, M. PH-Dependent Surface Charging and Points of Zero Charge. IV. Update and New Approach. J. Colloid Interface Sci. 2009, 337 (2), 439-448. https://doi.org/10.1016/j.jcis.2009.04.072.

(79) Dunn, W. W.; Aikawa, Y.; Bard, A. J. Characterization of Particulate Titanium Dioxide Photocatalysts by Photoelectrophoretic and Electrochemical Measurements. J. Am. Chem. Soc. 1981, 103 (12), 34563459. https://doi.org/10.1021/ja00402a033.

(80) Boxall, C.; Kelsall, G. H. Photoelectrophoresis of Colloidal Semiconductors, Part 1.- The Technique and Its Applications. J.Chem.Soc.Faraday Trans. 1991, 87 (21), 3537-3545.

(81) Vidal, A.; Herrero, J.; Romero, M.; Sanchez, B.; Sanchez, M. Heterogeneous Photocatalysis: Degradation of Ethylbenzene in $\mathrm{TiO}_{2}$ Aqueous Suspensions. J. Photochem. Photobiol. A Chem. 1994, 79 (3), 213-219. https://doi.org/http://dx.doi.org/10.1016/1010-6030(93)03763-7.

(82) Dang, T. T. T.; Le, S. T. T.; Channei, D.; Khanitchaidecha, W.; Nakaruk, A. Photodegradation Mechanisms of Phenol in the Photocatalytic Process. 
Res. Chem. Intermed. 2016, 42 (6), 5961-5974.

https://doi.org/10.1007/s11164-015-2417-3.

(83) Khunphonoi, R.; Grisdanurak, N. Mechanism Pathway and Kinetics of PCresol Photocatalytic Degradation over Titania Nanorods under UV-Visible Irradiation. Chem. Eng. J. 2016, 296, 420-427. https://doi.org/10.1016/j.cej.2016.03.117.

(84) Gligorovski, S.; Strekowski, R.; Barbati, S.; Vione, D. Environmental Implications of Hydroxyl Radicals $(\cdot \mathrm{OH})$. Chem. Rev. 2015, 115 (24), 13051-13092. https://doi.org/10.1021/cr500310b.

(85) Devi, L. G.; Krishnamurthy, G. $\mathrm{TiO}_{2}$ - and $\mathrm{BaTiO}_{3}$-Assisted Photocatalytic Degradation of Selected Chloroorganic Compounds in Aqueous Medium: Correlation of Reactivity/Orientation Effects of Substituent Groups of the Pollutant Molecule on the Degradation Rate. J. Phys. Chem. A 2011, 115 (4), 460-469. https://doi.org/10.1021/jp103301z.

(86) Pang, X.; Chen, C.; Ji, H.; Che, Y.; Ma, W.; Zhao, J. Unraveling the Photocatalytic Mechanisms on $\mathrm{TiO}_{2}$ surfaces Using the Oxygen-18 Isotopic Label Technique. Molecules 2014, 19 (10), 16291-16311. https://doi.org/10.3390/molecules191016291.

(87) Zanoni, M. V. B.; Sene, J. J.; Selcuk, H.; Anderson, M. A. Photoelectrocatalytic Production of Active Chlorine on Nanocrystalline Titanium Dioxide Thin-Film Electrodes. Environ. Sci. Technol. 2004, 38 (11), 3203-3208. https://doi.org/10.1021/es0347080.

(88) An, T.; Zhang, W.; Xiao, X.; Sheng, G.; Fu, J.; Zhu, X. Photoelectrocatalytic Degradation of Quinoline with a Novel ThreeDimensional Electrode-Packed Bed Photocatalytic Reactor. 2004, 161, 233-242. https://doi.org/10.1016/j.nainr.2003.08.004.

(89) Selcuk, H. Disinfection and Formation of Disinfection By-Products in a Photoelectrocatalytic System. Water Res. 2010, 44 (13), 3966-3972. https://doi.org/10.1016/J.WATRES.2010.04.034.

(90) Boxall, C. The Electrophoresis of Semiconductor Particles. Chem. Soc. Rev. 1994, 23, 137-145. 


\subsection{Appendix}

\section{Text A2.1. Synthesis of 1-(4-hydroxylphenyl)ethanol}

The following chemicals were used for the synthesis: 4-hydroxyacetophenone (Sigma Aldrich 99\%), sodium borohydride (Sigma Aldrich $\geq 96 \%$ ), ammonium chloride (Alfa Aesar, 99.999\%), methyl tert-butyl ether (Sigma Aldrich, $\geq 99.8 \%$ ). The synthesis of 1-(4-hydroxylphenyl)ethanol was performed by selective reduction of 4-hydroxyacetophenone with $\mathrm{NaBH}_{4}$ [Shao 2014]. The obtained 1-(4-hydroxylphenyl)ethanol was extracted using MTBE. The compound was used without further purification steps.

\section{Text A2.2. Synthesis of $\mathrm{TiO}_{2}$ photoelectrodes}

$\underline{\mathrm{TiO}}_{2} / \mathrm{Ti}$ photoelectrodes:

Ti substrate $(2.5 \times 2.5 \mathrm{~cm}, 1 \mathrm{~mm}$ thickness [Magneto special anodes B.V.]) were cleaned with soap, ethanol and water. The substrates were etched in boiling concentrated $\mathrm{HCl}\left(37 \mathrm{w} \%\right.$ ) for $60 \mathrm{~min}$, rinsed with $\mathrm{H}_{2} \mathrm{O}$ and washed in an ultrasonic bath (10 min). Titanium hydroxide was electrodeposited on the Ti substrate (20 mm diameter surface) from a $\mathrm{TiCl}_{3}$ precursor solution based on [Wu 2014] (30 $\mathrm{mM} \mathrm{TiCl}_{3}$, $\mathrm{H}_{2} \mathrm{O}_{2} 15 \mathrm{mM}$, 75mM NaNO 3 ; all from Sigma) for two times $5 \mathrm{~min}$ at $-2.0 \mathrm{~V}$ vs. $\mathrm{Ag} / \mathrm{AgCl}$ electrode in a custom-made electrochemical reactor. The deposited layer was converted to crystalline $\mathrm{TiO}_{2}$ at $500{ }^{\circ} \mathrm{C}$ in an oven (air atmosphere) for $5 \mathrm{~h}$.

H600/FTO photoelectrodes:

H600 photocatalyst and titanium(IV) isopropoxide ((TTIP, Sigma Aldrich, 97\%), used as grafting additive to allow a sufficient electrical contact, stability and adhesion between the H600 and the FTO glass substrate [molar ratio H600/TTIP approx. 20:1]) were suspended in isopropanol using ultra sonication (> $60 \mathrm{~min}$ ). Afterwards the $\mathrm{H600}$ photocatalyst suspension was drop-casted on cleaned FTO glass substrates and the isopropanol was evaporated using a heating plate. The dried electrodes were annealed at $450{ }^{\circ} \mathrm{C}$ in an oven (air atmosphere) for $1 \mathrm{~h}$ (heating rate $\left.2{ }^{\circ} \mathrm{C} / \mathrm{min}\right)$ 


\section{Text A2.3. NPOC measurements}

NPOC measurements were performed using a SHIMADZU total organic carbon analyzer TOC-L CPH/CPN. Samples were acidified with sulfuric acid to obtain a $\mathrm{pH}<3$ and purged with carrier gas to remove inorganic carbon $\left(\mathrm{CO}_{2}\right.$ and carbonates). Afterwards, the remaining organic carbon was converted to $\mathrm{CO}_{2}$ at $720{ }^{\circ} \mathrm{C}$ and measured with a nondispersive infrared sensor (NDIR). NPOC content of $\mathrm{NaNO}_{3}$ containing samples were measured, however the values were not reliable due to a missing scrubber eliminating $\mathrm{NO}_{\mathrm{x}}$ gases evolved during the measurement leading to interferences with the $\mathrm{CO}_{2}$ detection (NDIR).

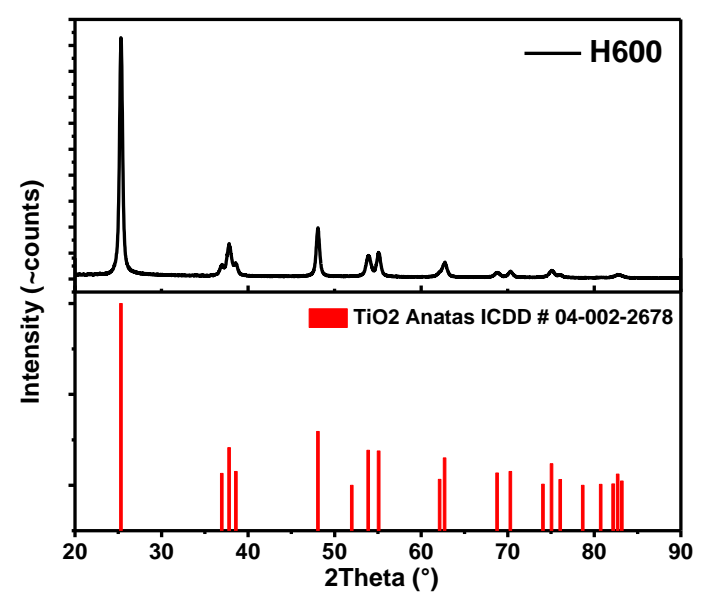

Figure A2.1. XRD of H600 confirming the presence of pure anatase phase after the annealing step 


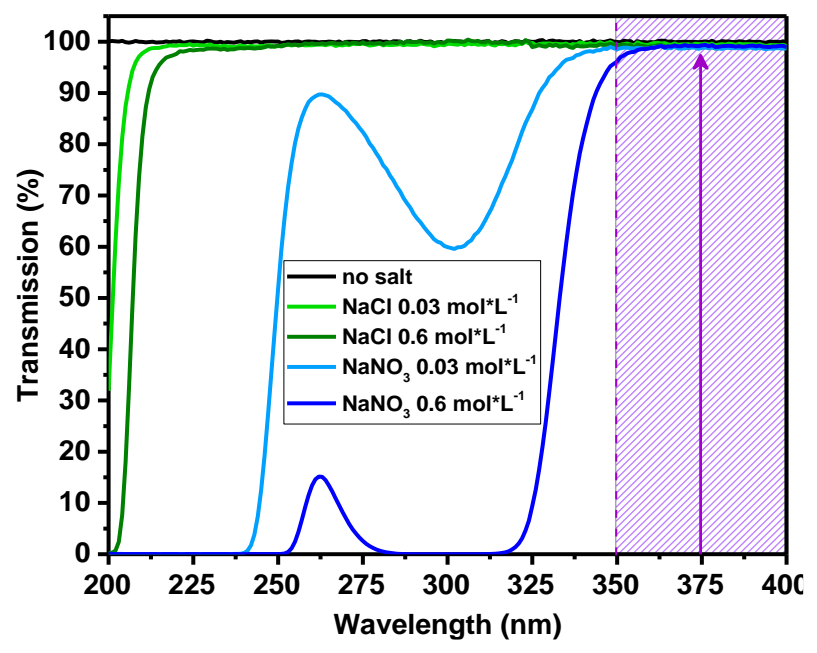

Figure A2.2. UV transmission spectra of various salt solutions used in this study. The UVA illumination of the applied light source used in PCD experiments was between 350 to $400 \mathrm{~nm}$ with an emission maximum at $375 \mathrm{~nm}$. The graph shows that above $350 \mathrm{~nm}$ no significant absorption of UV light occurs, excluding any light absorption effect of the salt solutions on the PCD rate.

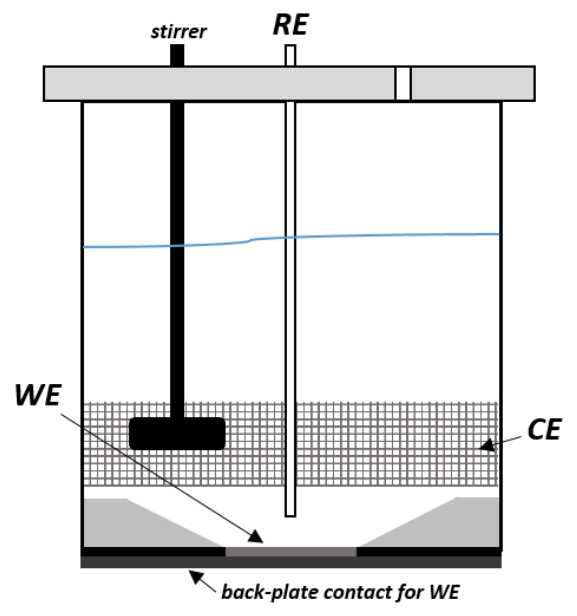

Figure A2.3. Cell design used in ECD. The cell consists of a platinized Ti (Ti/Pt) or BDD working electrode (WE: geometric surface area $=3.14 \mathrm{~cm}^{2}$ ), a platinized Ti mesh counter electrode (CE: surface area $>15 \mathrm{~cm}^{2}$ ), a reference electrode (RE; $\mathrm{Ag} / \mathrm{AgCl}, 3 \mathrm{M} \mathrm{NaCl}$ ), and a glass stirrer (area $\approx 4 \mathrm{~cm}^{2}, 100 \mathrm{rpm}$ ) 
Table A2.1. 4EP and identified intermediates detected by HPLC-UV/MS

\begin{tabular}{|c|c|c|c|c|}
\hline $\begin{array}{l}\text { compound } \\
\text { abbreviation }\end{array}$ & Compound name & $\begin{array}{l}\text { retention } \\
\text { time }(\mathrm{min}) \\
\text { @ } 276 \mathrm{~nm}\end{array}$ & $\begin{array}{l}\text { MS base peak } \\
(\mathrm{m} / \mathrm{z})\end{array}$ & $\begin{array}{l}\text { molar } \\
\text { mass } \\
{[\mathrm{g} / \mathrm{mol}]}\end{array}$ \\
\hline $4 \mathrm{EP}$ & 4-ethylphenol & 30.1 & $\begin{array}{l}123.08[\mathrm{M}+\mathrm{H}]^{+} \\
\left(121.04[\mathrm{M}-\mathrm{H}]^{-}\right) \\
\left(241.1[(2 \mathrm{M}-2 \mathrm{H})-\mathrm{H}]^{-}\right)\end{array}$ & 122.17 \\
\hline I) $2 \mathrm{C} 4 \mathrm{EP}$ & $\begin{array}{l}\text { 2-chloro-4- } \\
\text { ethylphenol }\end{array}$ & 34.7 & $\begin{array}{l}309.08[(2 \mathrm{M}-2 \mathrm{H})-\mathrm{H}]^{-(*)} \\
\left(154.99[\mathrm{M}-\mathrm{H}]^{-}\right)^{(*)}\end{array}$ & 156.61 \\
\hline II) $26 \mathrm{DC} 4 \mathrm{EP}$ & $\begin{array}{l}\text { 2,6-dichloro-4- } \\
\text { ethylphenol }\end{array}$ & 39.2 & $188.98[\mathrm{M}-\mathrm{H}]^{-(*)}$ & 191.05 \\
\hline 1) $\mathrm{HPE}$ & $\begin{array}{l}\text { 1-(4-hydroxy- } \\
\text { phenyl)ethanol }\end{array}$ & 15.8 & $\begin{array}{l}121.0\left[\mathrm{M}-\mathrm{H}_{2} \mathrm{O}+\mathrm{H}\right]^{+} \\
\left(137.05[\mathrm{M}-\mathrm{H}]^{-}\right)\end{array}$ & 138.16 \\
\hline 1) $\mathrm{HPE}$ & $\begin{array}{l}\text { 2-(4-hydroxy- } \\
\text { phenyl)ethanol }\end{array}$ & 15.8 & $\begin{array}{l}121.0\left[\mathrm{M}-\mathrm{H}_{2} \mathrm{O}+\mathrm{H}\right]^{+} \\
\left(137.05[\mathrm{M}-\mathrm{H}]^{-}\right)\end{array}$ & 138.16 \\
\hline 2) $4 \mathrm{HBA}$ & $\begin{array}{l}\text { 4-hydroxy- } \\
\text { benzaldehyde }\end{array}$ & 18.6 & $\begin{array}{l}121.03[\mathrm{M}-\mathrm{H}]^{-} \\
\left(123.03[\mathrm{M}+\mathrm{H}]^{+}\right)\end{array}$ & 122.12 \\
\hline 3) $4 \mathrm{HAP}$ & $\begin{array}{l}\text { 4-hydroxy- } \\
\text { acetophenone }\end{array}$ & 20.2 & $\begin{array}{l}137.04[\mathrm{M}+\mathrm{H}]^{+} \\
\left(135.04[\mathrm{M}-\mathrm{H}]^{-}\right)\end{array}$ & 136.15 \\
\hline 4) $4 \mathrm{ER}$ & 4-ethylresorcinol & 23.9 & $\begin{array}{l}139.05[\mathrm{M}+\mathrm{H}]^{+} \\
\left(137.05[\mathrm{M}-\mathrm{H}]^{-}\right)\end{array}$ & 138.17 \\
\hline 5) $4 \mathrm{EC}$ & 4-ethylcatechol & 24.7 & $\begin{array}{l}139.05[\mathrm{M}+\mathrm{H}]^{+} \\
\left(137.05[\mathrm{M}-\mathrm{H}]^{-}\right)\end{array}$ & 138.17 \\
\hline
\end{tabular}

$\mathrm{m} / \mathrm{z}=$ major signal, $(\mathrm{m} / \mathrm{z})=$ minor signal; ${ }^{(*)}$ no formic acid buffer used; all compounds were confirmed with commercial standards (except 1-(4-hydroxyphenyl)ethanol [see Text A2.1.]) 

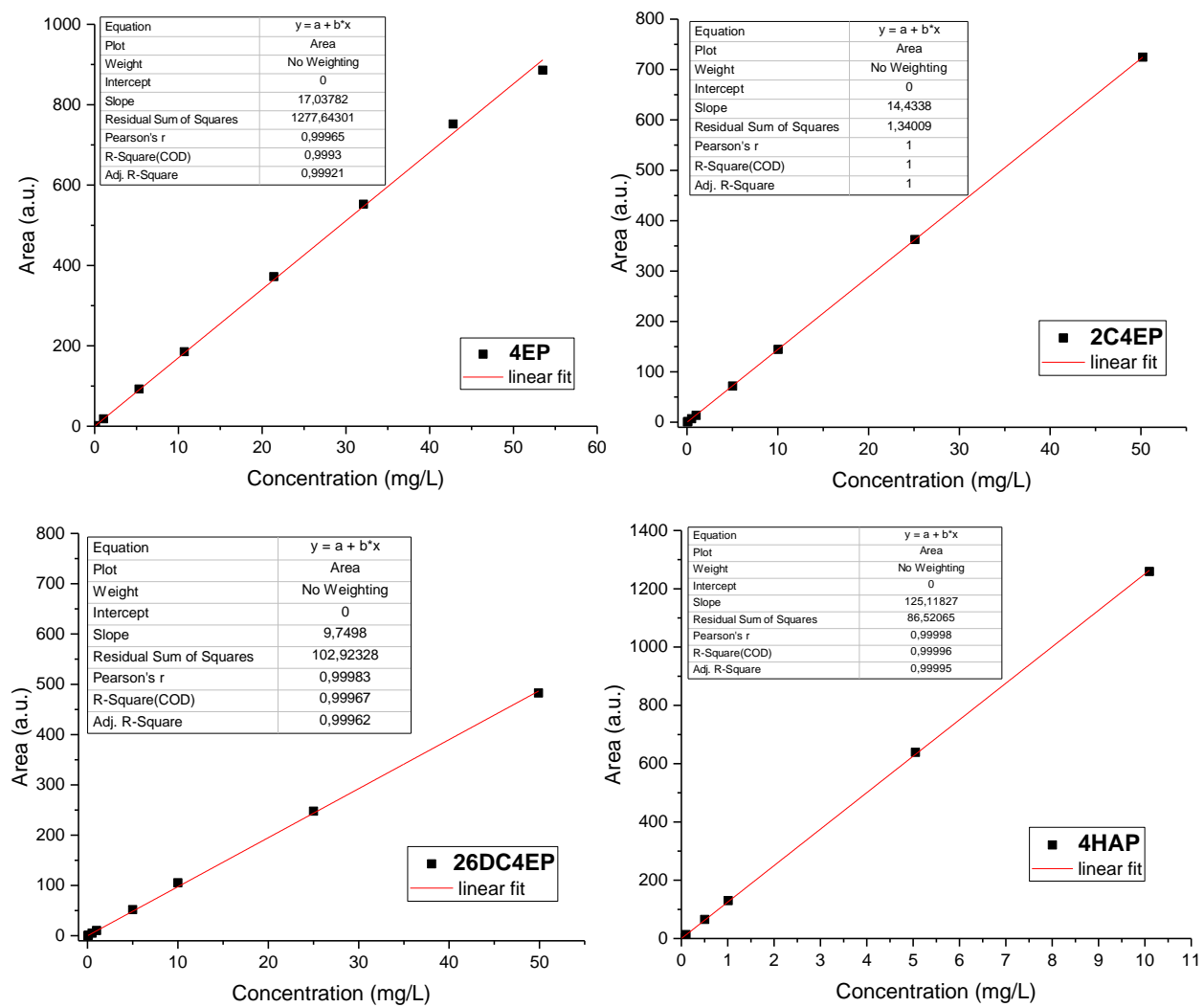

Figure A2.4. Calibration curves of a) 4EP, b) 2C4EP, c) 26DC4EP and d) 4HAP for quantification by HPLC-UV

Table A2.2. Coefficient of determination $\left(\mathrm{R}^{2}\right)$ from the linear regression analysis of the calibration curves

\begin{tabular}{|l|c|}
\hline \multicolumn{1}{|c|}{ Compound } & $\mathbf{R}^{2}$ of linear fit \\
\hline 4EP & 0.9993 \\
\hline I) 2C4EP & 0.99999 \\
\hline II) 26DC4EP & 0.99967 \\
\hline III) 4HAP & 0.99996 \\
\hline
\end{tabular}


Table A2.3. Limit of detection of various identified intermediates

\begin{tabular}{|l|c|}
\hline \multicolumn{1}{|c|}{ Compound } & LOD in $\mathbf{~ m ~ L ~}^{-\mathbf{1}}$ \\
\hline 4EP & 0.05 \\
\hline I) 2C4EP & 0.05 \\
\hline II) 26DC4EP & 0.05 \\
\hline III) 4HAP & 0.01 \\
\hline
\end{tabular}

$\frac{S}{N}=\frac{2 H}{h} ; H:$ signal amplitude, $h:$ background amplitude

(according European Pharmacopoeia 6.2, Council of Europe, Strasbourg, France (2008), adapted from [Heyden 2009])

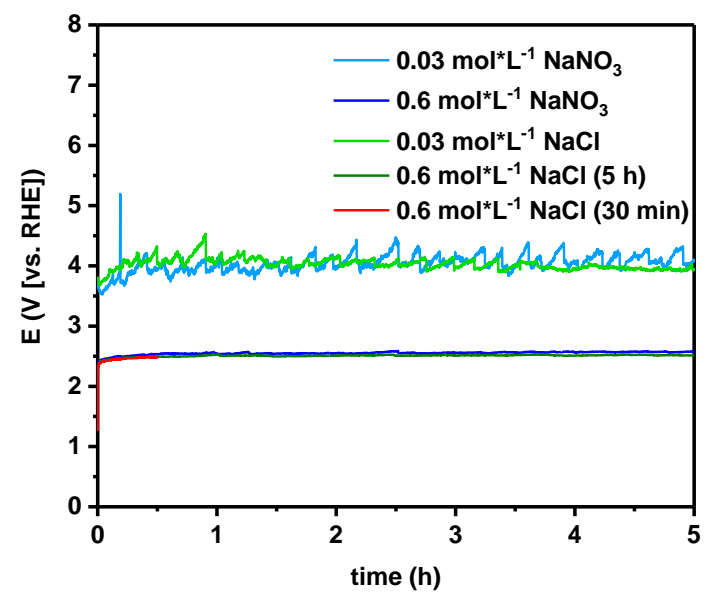

Figure A2.5. Potential vs. time (E-t) curves obtained during ECD experiments are shown for all studied salt conditions. Higher potentials were measured for the low salt conditions, however due to a higher solution resistance similar iR drop corrected potentials were obtained (see Table A2.4). A stronger gas bubble evolution was observed for the low salt concentration experiments. This can be also seen in the E-t curves ("bubble effect": growth of bubbles on the electrode surface until spontaneous release to the bulk solution lead to a constantly changing electrode surface area resulting in small potential changes). The enhanced gas evolution along with a slower 4EP removal for the low salt concentrations can be explained by a higher FE for the higher salt concentrations. 
Table A2.4. iR drop corrected potentials obtained during ECD for various salt conditions of this study

\begin{tabular}{|c|c|c|c|c|c|}
\hline $\begin{array}{c}\text { salt / } \\
\text { electrode }\end{array}$ & $\begin{array}{c}\text { concentration } \\
{\left[\mathrm{mol} \mathrm{L}^{-1}\right]} \\
\text { (degradation } \\
\text { time) }\end{array}$ & 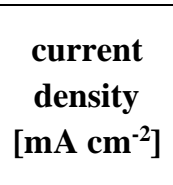 & $\begin{array}{c}\text { potential } \\
\text { (average) } \\
\text { [V vs RHE] }\end{array}$ & $\begin{array}{c}\text { iR } \\
\text { drop } \\
{[\text { Ohm] }}\end{array}$ & $\begin{array}{c}\text { potential } \\
\text { (average) iR } \\
\text { drop corrected } \\
\text { [V vs. } \text { RHE] }\end{array}$ \\
\hline $\begin{array}{c}\mathrm{NaNO}_{3} / \\
\mathrm{Ti} / \mathrm{Pt}\end{array}$ & $0.03(5 \mathrm{~h})$ & 15 & 4.0 & 33.8 & 2.4 \\
\hline $\begin{array}{c}\mathrm{NaNO}_{3} / \\
\mathrm{Ti} / \mathrm{Pt}\end{array}$ & $0.60(5 \mathrm{~h})$ & 15 & 2.6 & 2.3 & 2.5 \\
\hline $\begin{array}{c}\mathrm{NaCl} / \\
\mathrm{Ti} / \mathrm{Pt}\end{array}$ & $0.03(5 \mathrm{~h})$ & 15 & 4.0 & 34.4 & 2.4 \\
\hline $\begin{array}{c}\mathrm{NaCl} / \\
\mathrm{Ti} / \mathrm{Pt}\end{array}$ & $0.60(5 \mathrm{~h})$ & 15 & 2.5 & 2.1 & 2.4 \\
\hline $\begin{array}{c}\mathrm{NaCl} / \\
\mathrm{Ti} / \mathrm{Pt}\end{array}$ & $0.60(30 \mathrm{~min})$ & 15 & 2.4 & $\mathrm{ND} *$ & $2.3 * *$ \\
\hline $\begin{array}{c}\mathrm{NaCl} / \\
\mathrm{BDD}\end{array}$ & $0.03(5 \mathrm{~h})$ & 15 & 4.75 & 36.7 & 3.0 \\
\hline $\begin{array}{c}\mathrm{NaCl} / \\
\mathrm{BDD}\end{array}$ & $0.60(30 \mathrm{~min})$ & 15 & 2.85 & 2.2 & 2.7 \\
\hline
\end{tabular}

*) not determined; **) calculated with $2.1 \mathrm{Ohm}$ iR drop (see $0.6 \mathrm{~mol} \mathrm{~L}^{-1} \mathrm{NaCl}(5 \mathrm{~h})$ )
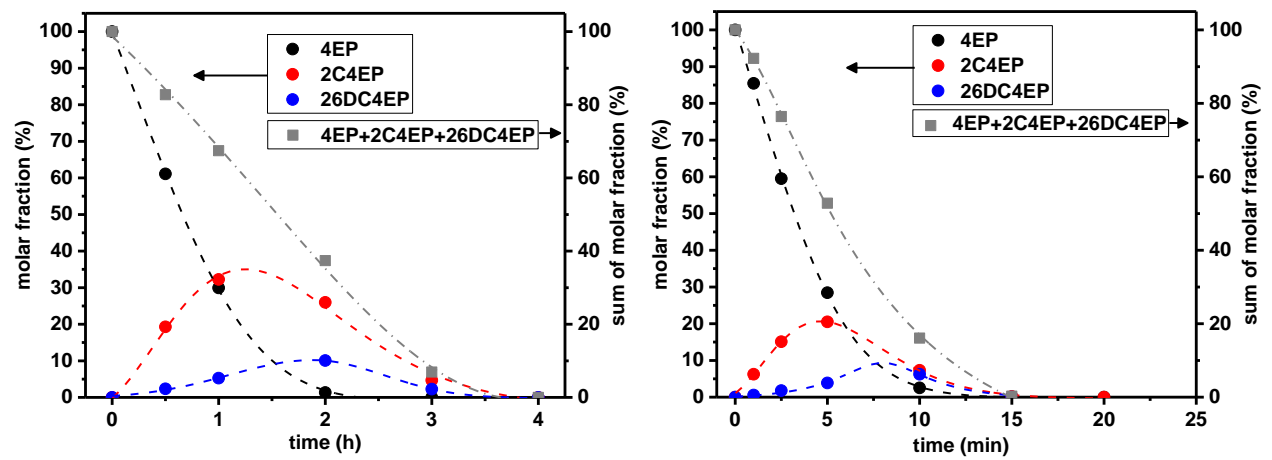

Figure A2.6. Molar fraction of the identified intermediates (relative to initial 4EP concentration) and the sum of molar fraction obtained during ECD in a) $0.03 \mathrm{~mol} \mathrm{~L}^{-1} \mathrm{NaCl}$ and b) $0.6 \mathrm{~mol} \mathrm{~L}^{-1} \mathrm{NaCl}$ solution using Ti/Pt. 

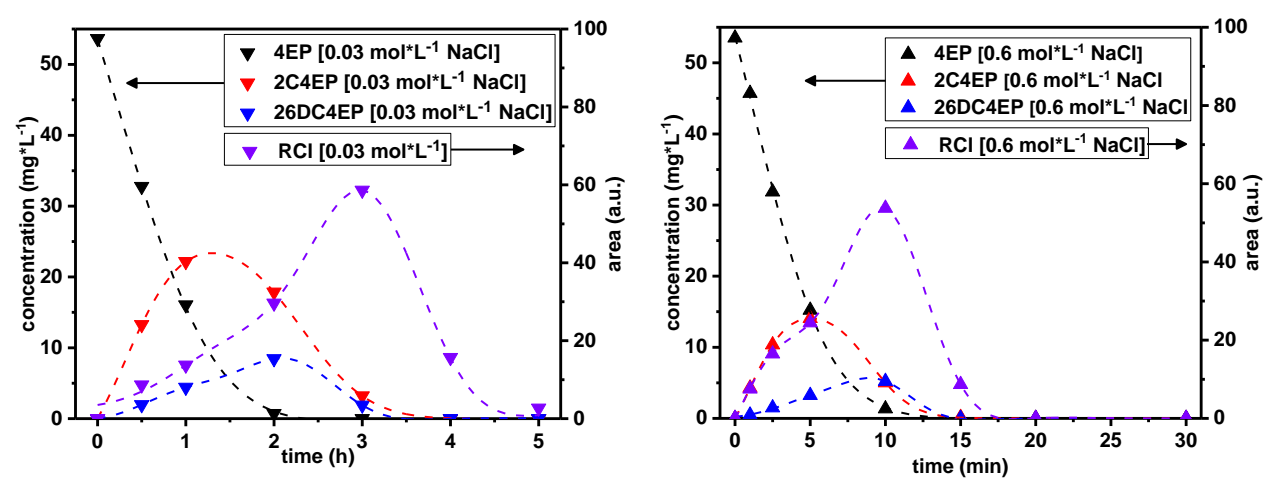

Figure A2.7. Formation curve of an additional chlorinated intermediates $(\mathrm{RCl})$ produced during ECD in a) $0.03 \mathrm{~mol} \mathrm{~L}^{-1} \mathrm{NaCl}$ and b) $0.6 \mathrm{~mol} \mathrm{~L}^{-1} \mathrm{NaCl}$ solution using $\mathrm{Ti} / \mathrm{Pt}$. The structure could not be fully revealed but MS data indicate that it is likely a polychlorinated compound. From the graphs it can be seen that the compound accumulates during the treatment for both $\mathrm{NaCl}$ concentrations and reaches its maximum concentration after the starting compound 4EP was already fully removed. The figure shows that the compound can be degraded, however the removal takes longer as compared to 4EP, 2C4EP or 26DC4EP.

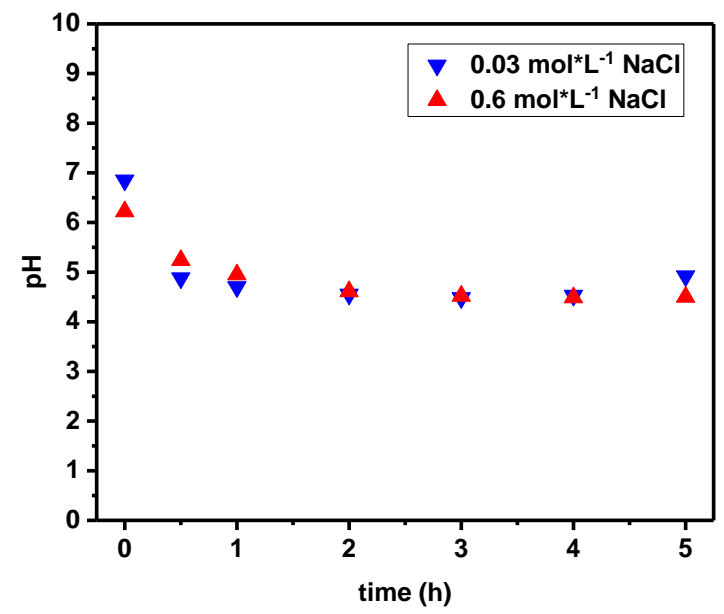

Figure A2.8. $\mathrm{pH}$ vs. time curves obtained during $\mathrm{PCD}$ experiments in $\mathrm{NaCl}$ solution. The initial $\mathrm{pH}$ drops due to $\mathrm{CO}_{2}$ evolution and dissolution in the water to a value around $\mathrm{pH}$ of 4.5 and remains constant. 
Table A2.5. Calculated photonic efficiencies [Serpone 1997] of PCD experiments using the number of transformed molecules (estimated from initial rate constants for 4EP removal) and a photon flux of $1.93 * 10^{-8} \mathrm{~mol} \mathrm{~s}^{-1}$ (for $375 \mathrm{~nm}$ illumination) entering the reactor.

\begin{tabular}{|c|c|}
\hline salt condition & photonic efficiency \\
\hline No salt & 0.33 \\
\hline $0.03 \mathrm{~mol} \mathrm{~L}^{-1} \mathrm{NaNO}_{3}$ & 0.24 \\
\hline $0.6 \mathrm{~mol} \mathrm{~L}^{-1} \mathrm{NaNO}_{3}$ & 0.24 \\
\hline $0.03 \mathrm{~mol} \mathrm{~L}^{-1} \mathrm{NaCl}$ & 0.24 \\
\hline $0.06 \mathrm{~mol} \mathrm{~L}^{-1} \mathrm{NaCl}$ & 0.15 \\
\hline
\end{tabular}

Table A2.6. Estimated energy consumption for ECD (BDD) and PCD treatments under conditions investigated in this study for $0.03 \mathrm{~mol} \mathrm{~L}^{-1}$ and $0.6 \mathrm{~mol} \mathrm{~L}^{-1} \mathrm{NaCl}$. It is important to note that the used reactors are not optimized for energy consumption. In addition, the energy consumption for the BDD treatment at high salt concentration is based only on $30 \mathrm{~min}$ of treatment.

\begin{tabular}{|c|c|c|c|c|c|c|}
\hline $\begin{array}{c}\text { treatment } \\
\text { and } \\
\text { condition }\end{array}$ & $\begin{array}{c}\text { treatment } \\
\text { time }\end{array}$ & $\begin{array}{c}\text { energy } \\
\text { consumption }\end{array}$ & $\begin{array}{c}\text { removed } \\
\text { NPOC }\end{array}$ & $\begin{array}{c}\text { removed } \\
\text { NPOC/h }\end{array}$ & $\begin{array}{c}\text { total } \\
\text { removed } \\
\text { NPOC }\end{array}$ & $\begin{array}{c}\text { Energy/removed } \\
\text { kg NPOC }\end{array}$ \\
\hline$\left[\mathbf{m o l ~ L}^{-1}\right]$ & {$[\mathbf{h}]$} & {$[\mathrm{Wh}]$} & {$[\%]$} & {$[\%]$} & {$[\mathrm{kg}]$} & {$[\mathrm{kWh} / \mathbf{k g}]$} \\
\hline ECD: & & & & & & \\
\hline 0.03 & 5 & 2.36 & 36 & 7 & 0.00100 & $\mathbf{2 . 3}$ \\
\hline 0.6 & 0.5 & 0.08 & 16 & 32 & 0.00042 & $\mathbf{0 . 2}$ \\
\hline PCD: & & & & & & \\
\hline 0.03 & 5 & 48 & 87 & 17 & 0.00141 & $\mathbf{3 3 . 9}$ \\
\hline 0.6 & 5 & 48 & 54 & 11 & 0.00097 & $\mathbf{4 9 . 7}$ \\
\hline
\end{tabular}




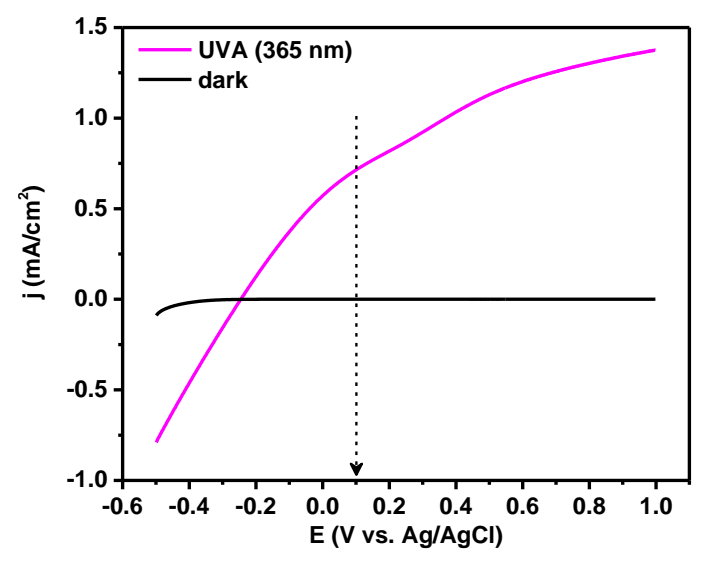

Figure A2.9. Linear sweep voltammograms obtained in $0.03 \mathrm{~mol} \mathrm{~L}^{-1} \mathrm{NaCl}$ solution under UVA illumination and in dark using a $\mathrm{TiO}_{2} / \mathrm{Ti}$ photoelectrode (scan speed $100 \mathrm{mV} / \mathrm{s}$ ). The dashed line indicates the potential applied in the PECD experiments $(0.1 \mathrm{~V}$ vs. $\mathrm{Ag} / \mathrm{AgCl})$.

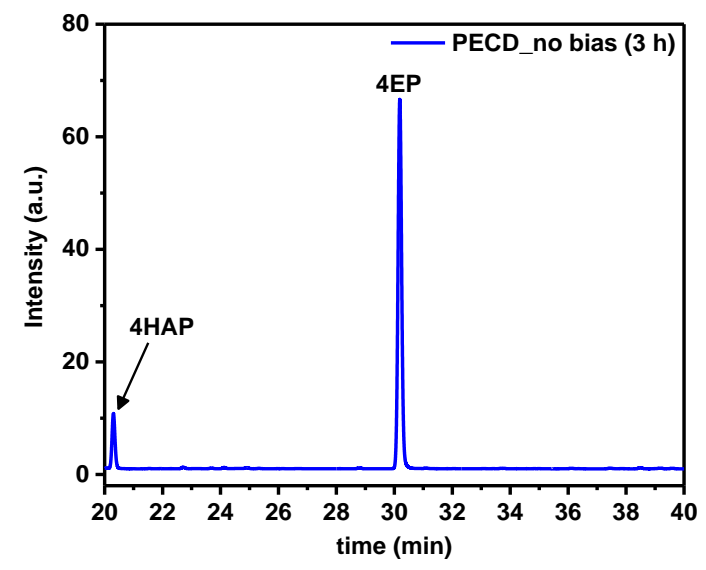

Figure A2.10. Chromatogram obtained after $3 \mathrm{~h}$ photo(electro)chemical degradation of 4EP in $0.03 \mathrm{~mol} \mathrm{~L}^{-1} \mathrm{NaCl}$ without the application of a bias to the $\mathrm{TiO}_{2} / \mathrm{Ti}$ photoelectrode. The chromatogram reveals that intermediate (3) 4HAP is formed as main intermediate as observed in the slurry based PCD experiments. In addition, the absence of the chlorinated intermediates 2C4EP and 26DC4EP is confirmed, which is in agreement with the absence of free chlorine 


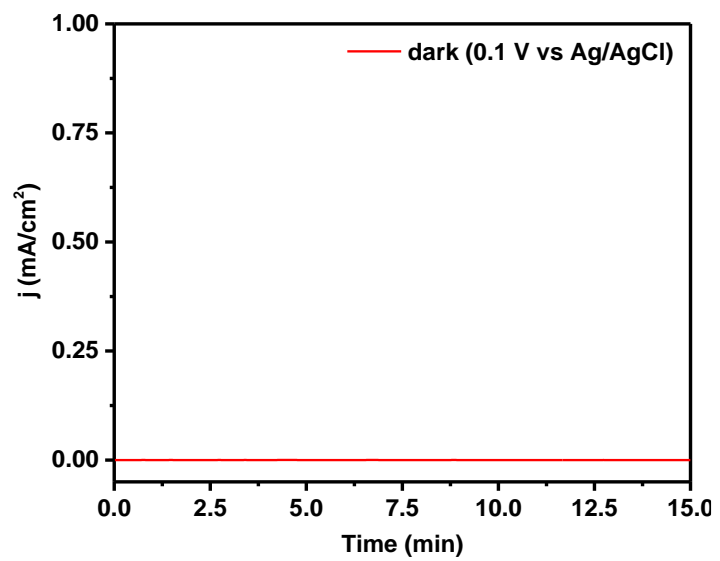

Figure A2.11. Photocurrent measured during $15 \mathrm{~min}$ of PECD of 4EP in the dark at $0.1 \mathrm{~V}$ vs. $\mathrm{Ag} / \mathrm{AgCl}$ in $0.03 \mathrm{~mol} \mathrm{~L}^{-1} \mathrm{NaCl}$ solution. The graph shows that no photocurrent is generated during the dark measurement, which is in accordance with the non-existent 4EP degradation or formation of RCS 
Table A2.7. Photoelectrochemical degradation of $4 \mathrm{EP}$ in $0.03 \mathrm{~mol} \mathrm{~L}^{-1} \mathrm{NaCl}$ solution using $\mathrm{H} 600 \mathrm{TiO}_{2}$ photocatalyst coated on FTO glass. Experiments have been conducted for $30 \mathrm{~min}$ or $240 \mathrm{~min}$ with $375 \mathrm{~nm}$ LED illumination or under dark conditions. The applied bias was $0.1 \mathrm{~V}$ vs. $\mathrm{Ag} / \mathrm{AgCl}$.

\begin{tabular}{|c|c|c|c|c|}
\hline Experiment & Compound & $\begin{array}{c}\text { Concentration } \\
{\left[\mathrm{mg} \mathrm{L}^{-1}\right]}\end{array}$ & $\begin{array}{c}\text { Concentration } \\
{\left[\mu \mathrm{mol} \mathrm{L} \mathrm{L}^{-1}\right]}\end{array}$ & $\begin{array}{c}\text { 4EP } \\
\text { removal } \\
{[\%]}\end{array}$ \\
\hline \multirow[t]{4}{*}{$\begin{array}{c}\text { UV and } 0.1 \mathrm{~V} \\
{[30 \mathrm{~min}]}\end{array}$} & $4 \mathrm{EP}$ & 30.6 & 250 & 39 \\
\hline & 2C4EP & 9.1 & 58 & - \\
\hline & 26DC4EP & 1.2 & 6 & - \\
\hline & 4HAP & $<\mathrm{LOD}$ & $<$ LOD & - \\
\hline \multirow[t]{4}{*}{$\begin{array}{c}\text { Dark and } 0.1 \mathrm{~V} \\
{[30 \mathrm{~min}]}\end{array}$} & $4 \mathrm{EP}$ & 49.5 & 406 & $<1$ \\
\hline & 2C4EP & $<\mathrm{LOD}$ & $<\mathrm{LOD}$ & - \\
\hline & 26DC4EP & $<\mathrm{LOD}$ & $<\mathrm{LOD}$ & - \\
\hline & 4HAP & $<\mathrm{LOD}$ & $<\mathrm{LOD}$ & - \\
\hline \multirow[t]{4}{*}{$\begin{array}{c}\text { Only UV } \\
\text { (no bias) } \\
{[240 \mathrm{~min}]}\end{array}$} & $4 \mathrm{EP}$ & 38.7 & 317 & 23 \\
\hline & 2C4EP & $<\mathrm{LOD}$ & $<\mathrm{LOD}$ & - \\
\hline & 26DC4EP & $<$ LOD & $<\mathrm{LOD}$ & - \\
\hline & 4HAP & 0.4 & 3 & - \\
\hline
\end{tabular}

\section{References Appendix:}

Shao 2014: $\quad$ Shao, L., Wu, Y., Xu, J., He, J., Zhao, Y., Peng, L., Li, Y., Yang, Y., Xia, C., Zhao, Q., Natural Products and Bioprospecting, 2014, 4, 181-188, Synthesis of 1-Ascorbic Acid Lactone Derivatives

Wu 2014: $\quad$ Wu, T., Lin, W., Hsiao, Y., Su, C., Hu, C., Huang, C., Muniyandi, R., Journal of The Electrochemical Society, 2014, 161, H762-H769, Electrochemical Photocatalytic Degradation of Orange G Using TiO2 Films Prepared by Cathodic Deposition

Heyden 2009: Heyden, Y. and Boqué, R., LCGC Europe, 2009, 22, 82-85, The Limit of Detection

Serpone 1997: Serpone, N., Journal of Photochemistry and Photobiology A: Chemsitry, 104,1997, 1-12, Relative photonic efficiencies and quantum yields in heterogeneous photocatalysis 


\section{Chapter 3}

\section{Photocatalytic and electrochemical degradation treatment of cooling tower blowdown water - a case study}

Re-use of cooling tower blowdown (CTBD) water has a huge potential to reduce the required fresh water intake in the chemical industry. Conditioning chemicals present in the CTBD water need to be removed in order to enable re-use. Advanced oxidation processes (AOP), such as photocatalytic or electrochemical degradation, have the potential to remove these chemicals from the CTBD water. However, the formation of undesirable (toxic) intermediates and by-products needs to be prevented. In this chapter a case study involving the DOW chemical company and the Water Nexus project is described. It will be shown that by $5 \mathrm{~h}$ of PCD or ECD treatment, about $55 \%$ of the total organic carbon (TOC) can be removed from the CTBD water. However, during ECD a significantly faster reduction in the chemical oxygen demand (COD) indicates a different degradation mechanism. Analysis of adsorbable organic halide (AOX) and oxychloride concentrations confirmed significant formation of chlorinated intermediates and by-products during ECD. Thus, in agreement with Chapter 2, also for the real wastewater chlorination is a major degradation mechanism during ECD, whereas for PCD the formation of chlorinated intermediates and by-products is limited.

This chapter is based on a collaboration with Pradip Saha (Wageningen University and Research). The study described here is part of a manuscript for publication: P. Saha, R. Brüninghoff et al., Comparison of advanced oxidation processes for cooling tower blowdown organic compounds removal: organic carbon and chlorinated species evaluations; in preparation. 


\subsection{Introduction}

Cooling towers are one of the largest water consumers in industry, generating huge amounts of wastewater, typically referred to as the cooling tower blowdown (CTBD) water. ${ }^{1,2}$ For example, at the site of DOW Benelux B.V. about $10^{6} \mathrm{~m}^{3}$ of CTBD water is generated per year. To increase sustainability of industrial processes, re-use of this CTBD water offers a tremendous potential to decrease environmental impact. In fact, re-use is a viable option to particularly achieve one of the sustainability goals, namely reduction of fresh water intake in water stressed areas. In general, re-use of water can be considered for industrial applications, such as cooling towers or agricultural purposes. ${ }^{2,3}$ A specific example of the Water Nexus project is the re-use of CTBD water at the DOW location in Terneuzen, Zeeland (The Netherlands), a region suffering from fresh water scarcity. ${ }^{2}$

Cooling towers in the industry are used for the purpose of temperature control of processes. The working principle thereby is commonly based on heat exchange between the heat generating process and the environment using cooling water. Importantly, the water in the cooling tower evaporates enhancing the cooling function but this additionally causes an up-concentration of compounds contained in the water. In general, CTBD water is considered as brackish water and is characterized by a complex composition that varies with process conditions (e.g. degree of evaporation). For example, the CTBD water of $D O W$ contains salts such as nitrates, phosphates, and carbonates in lower amounts $\left[<100 \mathrm{mg} \mathrm{L}^{-1}\right]$, but also significant amounts of chloride [400-600 mg L $\mathrm{L}^{-1}$ and sulfate $\left[500-1500 \mathrm{mg} \mathrm{L}^{-1}\right]$. The overall conductivity is $3500-4500 \mu \mathrm{S} / \mathrm{cm}$ and the total organic carbon (TOC) content is between $40-60 \mathrm{mg} \mathrm{L}^{-1}{ }^{2}$ The TOC content mostly arises from conditioning chemicals, which are required for efficient operation of the cooling tower. Commonly used chemicals are i) biocides such as chloramine, N-bromosuccinimide, glutaraldehyde, 1,2-benisothiazolone, ii) corrosion inhibitors such as benzotriazoles and iii) antiscalants (dispersants and surfactants) based on phosphonates, amines, carboxylates, co- and terpolymers. ${ }^{3}$

In order to re-use the CTBD water certain quality requirements need to be fulfilled. For example, the TOC concentration should be $<15 \mathrm{mg} \mathrm{L}^{-1} .{ }^{2}$ Moreover, the conductivity should be $<1 \mathrm{mS} \mathrm{cm}^{-1}$. In general, desalination (or dilution with fresh 
water) is performed to lower the conductivity. ${ }^{2}$ However, physicochemical desalination is often hampered by membrane fouling, electrode or reactor degradation caused by the used conditioning chemicals. Thus, a pretreatment, i.e. TOC removal, is required before conventional desalination can be effectively performed. ${ }^{1,3,4}$

Among the typical conditioning chemicals benzotriazole is of great concern as benzotriazole is non-biodegradable and toxic to aquatic life with long lasting effects. Moreover, it is believed to be an endocrine disrupting compound. ${ }^{5,6}$ Thus, mineralization is desirable before re-use or discharge of the CTBD water. As its removal by conventional water treatment is incomplete, ${ }^{7,8}$ Advanced Oxidation Processes (AOP) are considered for degradation. Among others, photocatalytic degradation (PCD) and electrochemical degradation (ECD) of benzotriazole have been reported as promising. ${ }^{9-11}$

A major obstacle of AOPs, however, is the formation of (undesirable and likely harmful) intermediates and by-products. ${ }^{12-17}$ Especially, for chloride containing waste waters, formation of chlorinated organic intermediates and inorganic oxychlorides, which induce toxicity, have been reported (see also Chapter 2 for more details), causing a high risk for human health and the environment. ${ }^{18-21}$ As shown in Chapter 2, formation of chlorinated intermediates is suppressed in PCD, whereas during ECD significant amounts of chlorinated organic compounds have been observed in oxidative treatment of 4-ethylphenol. ${ }^{17}$ Still, study of the reactivity of components in real wastewater is important to evaluate the treatment under more realistic and complex conditions. In this case study, specifically CTBD water from $D O W$ is used. The removal of TOC and reduction of the chemical oxygen demand (COD) (to allow for subsequent desalination technology and to meet TOC requirements for re-use) is studied using PCD and ECD technology. For both technologies a similar TOC removal was achieved; however, differences in the degradation mechanism are observed based on the development of COD and formation of chlorinated intermediates and by-products. In agreement with the observations from Chapter 2, chlorination is identified as a major degradation mechanism during ECD treatment of CTBD water, whereas PCD does not results in significant amounts of chlorinated compounds. 


\subsection{Materials and methods}

\subsubsection{Chemicals and materials}

The following chemicals and materials were used: titanium dioxide (Hombikat UV 100, Sachtleben (Venator), pre-treated as described in Chapter 2); $\mathrm{H}_{2} \mathrm{SO}_{4}$ ( $\geq 97.5 \%$, Sigma Aldrich), $\mathrm{NaOH}$ (Sigma Aldrich). Cooling tower blowdown (CTBD) water was provided by $D O W$. A BDD working electrode, a platinum coated titanium plate counter electrode (both Magneto special anodes B.V.), and a $\mathrm{Ag} / \mathrm{AgCl}$ reference electrode (QM711X/Gel (Prosense)) were used for ECD.

\subsubsection{Photocatalytic degradation}

Photocatalytic degradation was performed as described in Chapter 2, with the following variations: CTBD water (room temperature) was used as wastewater matrix and pre-saturated with air for $20 \mathrm{~min}$ before degradation experiments were performed. $40 \mathrm{mg}$ [+/-1]/80 $\mathrm{mL} \mathrm{TiO}_{2}$ photocatalyst (H600) was used. For $\mathrm{pH}$ adjustment of the CTBD water (before the experiments where necessary), diluted $\mathrm{H}_{2} \mathrm{SO}_{4}$ (for $\mathrm{pH} 3$ ) or diluted $\mathrm{NaOH}$ (for $\mathrm{pH} 10$ ) were used. No sampling during experiments was carried out, instead for every data point, a separate experiment was performed. Centrifugation (10 min at $8000 \mathrm{rpm}$ ) was used after the degradation time $(1,2,3.5$ or $5 \mathrm{~h})$ to separate the $\mathrm{TiO}_{2}$. After the experiments, samples were immediately frozen and shipped (under frozen conditions) to Wageningen University and Research (WUR) for further analysis.

\subsubsection{Electrochemical degradation}

A current density of $8.5 \mathrm{~mA} \mathrm{~cm}^{-2}$ was applied for all ECD experiments (based on the highest rate of removal obtained from previous experiments). ${ }^{22}$ The current density was applied using an IviumStat.h potentiostat controlled by Iviumstat software (Ivium Technologies B.V. The Netherlands). The degradation experiments were carried out in a single chambered flow cell with a reactor volume of $33.6 \mathrm{~mL}$ and a flow of $775 \mathrm{~mL} \mathrm{~min}^{-1}$. The total volume of treated CTBD water per experiment was $360 \mathrm{~mL}$. The BDD working electrode area was $22.4 \mathrm{~cm}^{2}$. For $\mathrm{pH}$ adjustment of the CTBD water (before the experiments where necessary) diluted $\mathrm{H}_{2} \mathrm{SO}_{4}$ (for $\mathrm{pH} 3$ ) or diluted $\mathrm{NaOH}$ (for $\mathrm{pH} 10$ ) were used. A detailed description of the ECD experiment setup can be found in Saha et al. ${ }^{22}$ 


\subsubsection{Analytical methods}

The FC concentration was determined using a Hanna Instruments Free Chlorine Photometer (HI 96711) and reagents (HI-93701). Samples were measured directly after the PCD experiments (after separation of the $\mathrm{TiO}_{2}$ ). Hanna Instruments $\mathrm{CAL}$ Check $^{\mathrm{TM}}$ standards (HI-96771-11) were used for photometer validation.

Hypochlorite concentrations (generated during ECD experiments) were determined by an USEPA-DPD 330.5 adapted method using a DPD free chlorine test kit (P/N 2105569) and a spectrophotometer (DR/3900; both Hach Lange GmbH, Germany). Chlorate and perchlorate concentrations were determined using a Dionex ICS-2100 ion chromatograph (Thermo, USA) equipped with a Dionex IonPac AS19 column (4x250 mm) using a hydroxide gradient (Dionex KOH cartridge P/N 058900).

The chemical oxygen demand (COD) was determined using a COD test kit (LCK314 or LCK414) and a spectrophotometer (DR/3900; both Hach Lange GmbH, Germany). The total organic carbon (TOC) was determined using a SHIMADZU total organic carbon analyzer TOC-L CPH/CPN. The organic carbon was thereby converted to $\mathrm{CO}_{2}$ (after the removal of inorganic carbon under $\mathrm{H}_{2} \mathrm{SO}_{4}$ acidified conditions) at $720{ }^{\circ} \mathrm{C}$ and measured with a nondispersive infrared sensor.

The adsorbable organic halide (AOX, based on $\mathrm{mg} \mathrm{L}^{-1} \mathrm{Cl}$ ) concentration was measured with a LCK 390 AOX Cuvette Test (Hach, The Netherlands) and a spectrophotometer (DR/3900, Hach Lange GmbH, Germany).

\subsection{Results and discussion}

Due to the complexity of the wastewater, the degradation was monitored by two parameters, i.e. the chemical oxygen demand (COD) and total organic carbon (TOC) content to evaluate the treatment. The COD is an indirect parameter giving an indication of the oxidizability (reactivity) of the organic compounds present in the wastewater by chemical reaction with $\mathrm{Kr}_{2} \mathrm{Cr}_{2} \mathrm{O}_{7}$. The TOC gives direct information about the organic carbon concentration, measured as $\mathrm{CO}_{2}$ produced during catalytic combustion at high temperatures, and is representative of the degree of mineralization. $^{23,24}$ 
In Figure 3.1 the removal of COD and TOC are shown for the continuous treatment of CTBD water using PCD or ECD over $5 \mathrm{~h}$. During PCD a nearly linear decrease was observed for both, for the COD and the TOC content, resulting in a reduction to $46 \%$ and $50 \%$ respectively. The reduction of COD (corresponding oxidizability of organic compounds) was only slightly faster $\left(0.15 \mathrm{~h}^{-1}\right)$ than TOC removal $\left(0.14 \mathrm{~h}^{-1}\right.$; rate constants obtained by pseudo-first order). The observation implies that for the PCD treatment of CTBD water the observed oxidation of organic compounds mainly leads to their mineralization. Overall, the error bars indicate a good reproducibility. In addition, water collected in summer was treated. The slightly lower COD and TOC values observed can probably be explained by some variations of the CTBD water composition (e.g. variations by season in concentration and composition), influencing the PCD.

a)

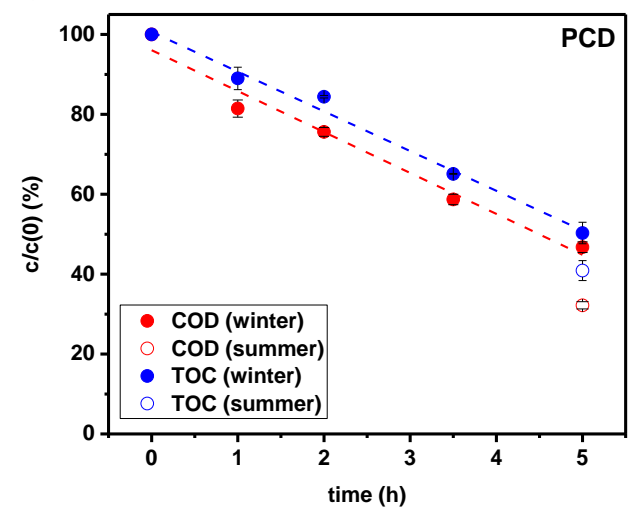

b)

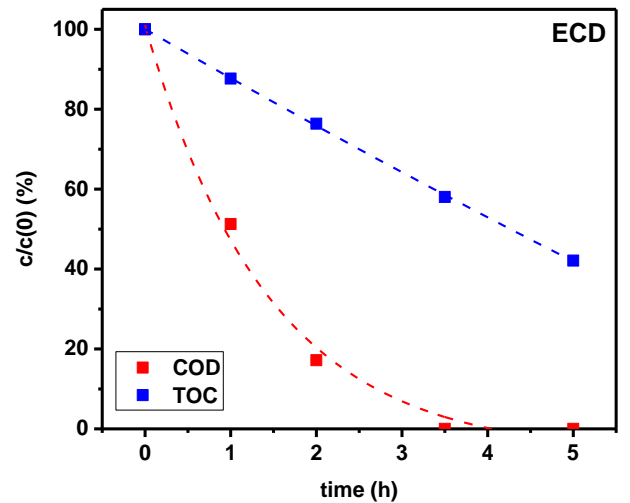

Figure 3.1. Development of COD (red) and TOC (blue) during a) PCD and b) ECD of CTBD water (collected in winter). Additionally, for PCD (a) the COD and TOC after $5 \mathrm{~h}$ treatment is shown for CTBD water collected in summer. Error bars are deviation of the mean from duplicate experiments.

In general, it can be assumed, that the PCD is somewhat inhibited due to the presence of inorganic salts, ${ }^{25-28}$ such as nitrates, sulphates, carbonates, phosphates and chlorides which are present in the CTBD water matrix. ${ }^{2}$ For example, carbonates (present in the CTBD water) are known to scavenge hydroxyl radicals, limiting degradation rates. ${ }^{21,29-31}$ Moreover, in particular the presence of chlorides and their inhibiting effect on PCD has been discussed in detail in Chapter 2. Nevertheless, the results show that the organic load of the CTBD water can be effectively reduced by 
PCD, independent of potential variations in the composition as shown by the water collected in summer and winter.

In contrast, for ECD a much faster reduction of the COD is observed, likely due to a contribution of mediators such as sulfate radicals formed on the BDD electrode supporting oxidation reactions, ${ }^{21,32-35}$ but also due to oxidation of chloride forming reactive chlorine species (RCS) reacting with the organic matter. ${ }^{13,17,21,36,37}$ Already after $3.5 \mathrm{~h}$ degradation, the COD was reduced by $100 \%$, indicating a fast removal of oxidizable compounds $\left(0.88 \mathrm{~h}^{-1}\right)$. However, the removal of TOC was much slower following a linear trend (similar as observed during PCD; $0.17 \mathrm{~h}^{-1}$ ). After $3.5 \mathrm{~h} \mathrm{ECD}$ still 59\% residual TOC was present in the water and after $5 \mathrm{~h}$ the TOC was reduced to $43 \%$. Although the TOC removal of ECD is only slightly faster compared to PCD, the differences in the COD indicate, that during ECD a faster oxidation of organic compounds occurs. The faster oxidation can be likely attributed to generated mediator species; however, the oxidation did not lead to complete mineralization of the organic compounds as shown by the residual TOC. A negative effect of chloride ions in sulphate radical mediated electrochemical oxidation on the mineralization of resorcinol has been demonstrated in a study by Farhat et al. ${ }^{33}$ and was explained by scavenging of sulfate radicals by the chloride ions resulting in less reactive halogen radicals.

The differences observed between PCD and ECD for COD is an indication for a different degradation mechanism. Based on the literature and observations discussed in Chapter 2, it can be assumed that during ECD a part of the organic compounds in the CTBD water react easily with generated RCS, leading to their fast oxidation but incomplete mineralization. Moreover, the results show that the determination of the TOC is crucial to characterize the mineralization, because a significant amount of oxidized organic compounds in the CTBD water are not measured by the COD method. 
a)

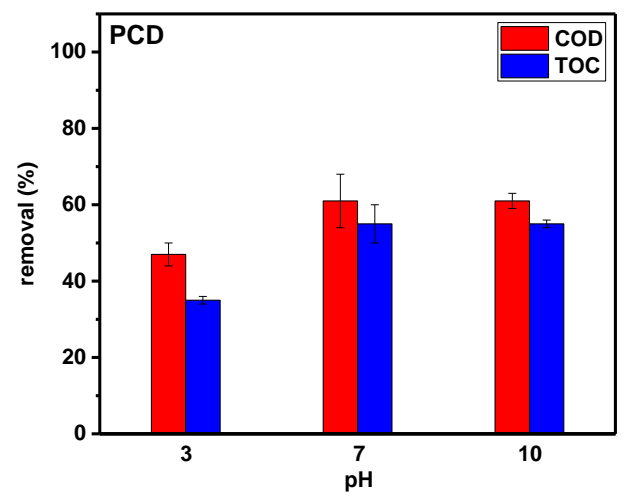

b)

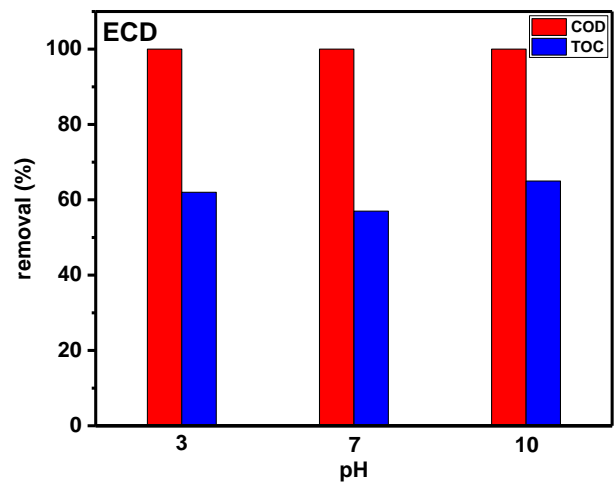

Figure 3.2. Reduction of COD (red) and removal TOC (blue) after $5 \mathrm{~h}$ of a) PCD and b) ECD of CTBD water at various initial $\mathrm{pH}(\mathrm{pH} 3, \mathrm{pH} 7$ (original $\mathrm{pH}$ of CTBD) and $\mathrm{pH} 10$ ). The PCD removal for $\mathrm{pH} 7$ is based on averaged duplicate experiments of CTBD water collected in summer and winter. Error bars are deviations of the mean from duplicate experiments.

In Figure 3.2 the reduction or removal of COD and TOC is shown after $5 \mathrm{~h}$ of PCD or ECD treatment of CTBD water at various initial $\mathrm{pH}$ (for data see Table A3.1), to study whether the initial $\mathrm{pH}$ has an effect on the removal and formation of byproducts. In general, for PCD the removal due to UV photolysis (no catalyst) was negligible $(<1.5 \%, \mathrm{pH} 7)$. The TOC removal due to absorption on the catalyst was $\approx 10 \%$ (pH 7). For all conditions, reduction of COD and TOC after $5 \mathrm{~h}$ of PCD was similar; however, a slightly higher reduction of COD was observed as already discussed. Though only minor variations in TOC removal and COD between the initial $\mathrm{pH}$ conditions are observed, neutral conditions are somewhat preferred for CTBD treatment, allowing to remove $55 \%$ of the TOC content and $61 \%$ of the COD. Similarities between neutral and slightly basic starting conditions are explained by an observed drop in $\mathrm{pH}$ during the $\mathrm{PCD}$ treatment to $\approx 7$, due to formation of $\mathrm{CO}_{2}$ and probably also carboxylic acids acidifying the solution (see also Chapter 2), resulting in similar $\mathrm{pH}$ conditions. The less effective treatment in acidic environment (46\% COD; $35 \%$ TOC removal), is likely related to generally stronger anion interactions with the surface of the $\mathrm{TiO}_{2}$ catalyst, due to the positive surface charge (protonated) at the respective $\mathrm{pH},{ }^{38}$ inhibiting the degradation. ${ }^{27,39,40}$

For ECD, independent of the initial $\mathrm{pH}$ conditions, the COD was reduced by $100 \%$ after the $5 \mathrm{~h}$ treatment. Only minor differences in the TOC removal were observed. At pH 7 about 57\% TOC was removed, comparable to the TOC removal achieved 
during the PCD treatment (55\%, $\mathrm{pH} 7$ ). For $\mathrm{pH} 3$ the TOC removal was $62 \%$ and for $\mathrm{pH} 10$ 65\% TOC were removed. Overall, for both processes treatment is most effective using as received water $(\mathrm{pH} 7)$.

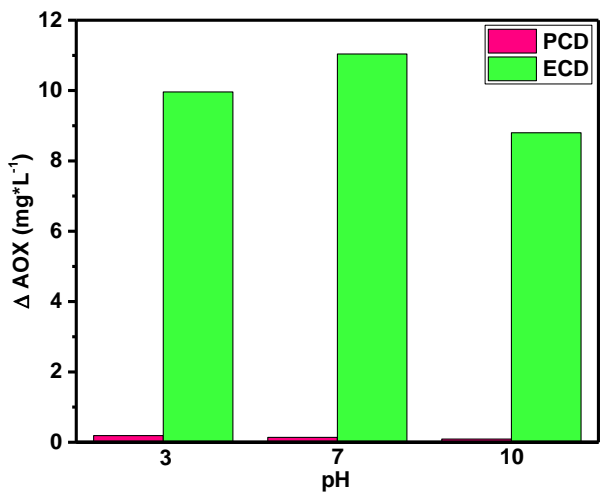

Figure 3.3. Increase in AOX concentration after $5 \mathrm{~h}$ of PCD (pink) and ECD (light green) of CTBD water at various initial $\mathrm{pH}$ conditions.

As discussed, differences in the development of the COD during PCD and ECD treatment of the CTBD water indicate different degradation mechanisms. In Chapter 2 the formation of significant amounts of chlorinated intermediates during ECD in chloride containing water has been described. Therefore, by-products have been investigated after the treatment of CTBD water. Due to the complexity of the matrix, the characterization of the by-products was limited to the concentration of adsorbable organic halides (AOX; based on chlorine) and inorganic oxychlorides. Table 3.1 shows the absolute AOX concentrations, along with the measured oxychloride concentration. Changes in AOX concentrations between PCD and ECD treatment are visualized in Figure 3.3. For PCD, independent of the $\mathrm{pH}$, formation of free chlorine (FC) was negligible. Moreover, the increase in AOX concentration was only marginal $\left(\Delta<0.2 \mathrm{mg} \mathrm{L}^{-1}\right)$. Overall, the limited formation of chlorinated intermediates and by-products during PCD is in good agreement with Chapter 2. ${ }^{17}$ In strong contrast, for ECD pronounced formation of oxychlorides was observed, which is comparable to observations by Farhat et al. ${ }^{33}$ The significant formation of chlorate (up to $497 \mathrm{mg} \mathrm{L}^{-1}$ ) and even perchlorate (up to $118 \mathrm{mg} \mathrm{L}^{-1}$ ) can be attributed to further oxidation of generated RCS (mainly hypochlorite) on the BDD electrode, which is in agreement with the high overpotential of BDD electrodes for the oxidation of water. ${ }^{37,41,42} \mathrm{In}$ addition to the formation of oxychlorides, a significant increase in the AOX concentration (up to $11.8 \mathrm{mg} \mathrm{L}^{-1}$ ) was determined and similar 
observations have been reported for other chloride containing wastewaters. ${ }^{33,43}$ The initial $\mathrm{pH}$ had negligible effect on the formation of AOX and oxychlorides. Compared to the PCD treatment of the CTBD water, the AOX increase is more than one order of magnitude larger. Moreover, it is important to note that the generated chlorinated organic compounds (during ECD) were not detected by the COD measurements, indicating them as hardly oxidizable intermediates or by-products. In agreement with observations of Chapter 2, during ECD of CTBD water chlorination can be considered as a major degradation path, whereas for PCD hydroxylation is likely the dominant mechanism.

Table 3.1. AOX, hypochlorite, chlorate and perchlorate concentration before and after PCD and ECD treatment of CTBD water at various initial $\mathrm{pH}$ conditions $(3,7,10)$. For PCD, no oxychlorides were detected.

\begin{tabular}{|c|c|c|c|c|c|}
\hline \multirow{2}{*}{ solution } & PCD & \multicolumn{4}{|c|}{ ECD } \\
\cline { 2 - 6 } & $\begin{array}{c}\mathrm{AOX} \\
{\left[\mathrm{mg} \mathrm{L}^{-1}\right]}\end{array}$ & $\begin{array}{c}\mathrm{AOX} \\
{\left[\mathrm{mg} \mathrm{L}^{-1}\right]}\end{array}$ & $\begin{array}{c}\mathrm{OCl}^{-} \\
{\left[\mathrm{mg} \mathrm{L}^{-1}\right]}\end{array}$ & $\begin{array}{c}\mathrm{ClO}_{3}^{-} \\
{\left[\mathrm{mg} \mathrm{L}^{-1}\right]}\end{array}$ & $\begin{array}{c}\mathrm{ClO}_{4}^{-} \\
{\left[\mathrm{mg} \mathrm{L}^{-1}\right]}\end{array}$ \\
\hline $\begin{array}{c}\text { Original CTBD } \\
(\mathrm{pH} \mathrm{7})\end{array}$ & 0.7 & 0.7 & 0 & 0.1 & 0 \\
\hline $\mathrm{pH} \mathrm{3}$ & $0.9[+/-0.1]$ & 11.8 & 160 & 448 & 118 \\
\hline $\mathrm{pH} \mathrm{7}$ & $0.9[+/-0.05]$ & 10.7 & 210 & 219 & 112 \\
\hline $\mathrm{pH} \mathrm{10}$ & $0.8[+/-0.02]$ & 9.5 & 160 & 497 & 113 \\
\hline
\end{tabular}

\subsection{Conclusions}

In this case study, photocatalytic degradation and electrochemical degradation have been compared for their effectiveness in removal of organic components from cooling tower blowdown water from $D O W$-Terneuzen. Based on TOC, both technologies show removal of organic compounds from the CTBD water of $\approx 55 \%$ after $5 \mathrm{~h}$ of treatment. Significant variations between PCD and ECD were observed in the reduction of COD, which is much more effective in ECD. The results can be explained by differences in the degradation mechanism of the organic compounds in the CTBD water. During ECD, formation of RCS leads to fast reactions to chlorine containing organic compounds, which are insensitive to COD measurements. This is important information which needs to be taken into account for application of these technologies in practice. The results confirm, that PCD is an alternative to ECD for the treatment of chloride containing wastewaters, to avoid the formation of significant amounts of chlorinated intermediates and by-products. Optimization of 
the process, e.g. by reactor design and advanced illumination strategies might further improve the efficiency of the process.

\subsection{Acknowledgements}

Magneto special anodes B.V. is acknowledged for the support of the BDD electrode

\subsection{References}

(1) Löwenberg, J.; Baum, J. A.; Zimmermann, Y. S.; Groot, C.; van den Broek, W.; Wintgens, T. Comparison of Pre-Treatment Technologies towards Improving Reverse Osmosis Desalination of Cooling Tower Blow Down.

Desalination 2015, 357, 140-149.

https://doi.org/10.1016/j.desal.2014.11.018.

(2) Groot, C. K.; Van Den Broek, W. B. P.; Loewenberg, J.; Koeman-Stein, N.; Heidekamp, M.; De Schepper, W. Mild Desalination of Various Raw Water Streams. Water Sci. Technol. 2015, 72 (3), 371-376.

https://doi.org/10.2166/wst.2015.228.

(3) Wagner, T. V.; Parsons, J. R.; Rijnaarts, H. H. M.; de Voogt, P.;

Langenhoff, A. A. M. A Review on the Removal of Conditioning

Chemicals from Cooling Tower Water in Constructed Wetlands. Crit. Rev.

Environ. Sci. Technol. 2018, 48 (19-21), 1094-1125.

https://doi.org/10.1080/10643389.2018.1512289.

(4) Gonzalez-Olmos, R.; Penadés, A.; Garcia, G. Electro-Oxidation as Efficient Pretreatment to Minimize the Membrane Fouling in Water Reuse Processes.

J. Memb. Sci. 2018, 552 (January), 124-131.

https://doi.org/10.1016/j.memsci.2018.01.041.

(5) ECHA (European Chemicals Agency). Benzotriazole https://echa.europa.eu/de/substance-information//substanceinfo/100.002.177 (accessed March 4, 2020).

(6) Hem, L. J.; Hartnik, T.; Roseth, R.; Breedveld, G. D. Photochemical Degradation of Benzotriazole. J. Environ. Sci. Heal. Part A 2003, 38 (3), 471-481. https://doi.org/10.1081/ESE-120016907.

(7) Asimakopoulos, A. G.; Ajibola, A.; Kannan, K.; Thomaidis, N. S. Occurrence and Removal Efficiencies of Benzotriazoles and Benzothiazoles in a Wastewater Treatment Plant in Greece. Sci. Total Environ. 2013, 452453, 163-171. https://doi.org/10.1016/j.scitotenv.2013.02.041. 
(8) Weiss, S.; Jakobs, J.; Reemtsma, T. Discharge of Three Benzotriazole Corrosion Inhibitors with Municipal Wastewater and Improvements by Membrane Bioreactor Treatment and Ozonation. Environ. Sci. Technol. 2006, 40 (23), 7193-7199. https://doi.org/10.1021/es061434i.

(9) Xu, J.; Li, L.; Guo, C.; Zhang, Y.; Wang, S. Removal of Benzotriazole from Solution by BiOBr Photocatalysis under Simulated Solar Irradiation. Chem. Eng. J. 2013, 221, 230-237. https://doi.org/10.1016/j.cej.2013.01.081.

(10) Chen, Y.; Ye, J.; Li, C.; Zhou, P.; Liu, J.; Ou, H. Degradation of 1 H Benzotriazole by $\mathrm{UV} / \mathrm{H}_{2} \mathrm{O}_{2}$ and $\mathrm{UV} / \mathrm{TiO}_{2}$ : Kinetics, Mechanisms, Products and Toxicology. Environ. Sci. Water Res. Technol. 2018, 4 (9), 1282-1294. https://doi.org/10.1039/C8EW00116B.

(11) Saha, P.; Wagner, T. V.; Ni, J.; Langenhoff, A. A. M.; Bruning, H.; Rijnaarts, H. H. M. Cooling Tower Water Treatment using a Combination of Electrochemical Oxidation and Constructed Wetlands; Process Saf. Eviron. 2020, 144, 42-51. https://doi.org/10.1016/j.psep.2020.07.019

(12) Garcia-Segura, S.; Ocon, J. D.; Chong, M. N. Electrochemical Oxidation Remediation of Real Wastewater Effluents - A Review. Process Saf. Environ. Prot. 2018, 113, 48-67.

https://doi.org/10.1016/j.psep.2017.09.014.

(13) Chaplin, B. P. Critical Review of Electrochemical Advanced Oxidation Processes for Water Treatment Applications. Environ. Sci. Process. Impacts 2014, 16 (6), 1182-1203. https://doi.org/10.1039/C3EM00679D.

(14) Ghernaout, D.; Naceur, M. W.; Aouabed, A. On the Dependence of Chlorine By-Products Generated Species Formation of the Electrode Material and Applied Charge during Electrochemical Water Treatment. Desalination 2011, 270 (1-3), 9-22. https://doi.org/10.1016/j.desal.2011.01.010.

(15) Bessegato, G. G.; Guaraldo, T. T.; de Brito, J. F.; Brugnera, M. F.; Zanoni, M. V. B. Achievements and Trends in Photoelectrocatalysis: From Environmental to Energy Applications. Electrocatalysis 2015, 6 (5), 415441. https://doi.org/10.1007/s12678-015-0259-9.

(16) Grebel, J. E.; Pignatello, J. J.; Mitch, W. A. Effect of Halide Ions and Carbonates on Organic Contaminant Degradation by Hydroxyl RadicalBased Advanced Oxidation Processes in Saline Waters. Environ. Sci. Technol. 2010, 44 (17), 6822-6828. https://doi.org/10.1021/es1010225.

(17) Brüninghoff, R.; van Duijne, A. K.; Braakhuis, L.; Saha, P.; Jeremiasse, A. W.; Mei, B.; Mul, G. Comparative Analysis of Photocatalytic and Electrochemical Degradation of 4-Ethylphenol in Saline Conditions. 
Environ. Sci. Technol. 2019, 53 (15), 8725-8735.

https://doi.org/10.1021/acs.est.9b01244.

(18) Jasper, J. T.; Yang, Y.; Hoffmann, M. R. Toxic Byproduct Formation during Electrochemical Treatment of Latrine Wastewater. Environ. Sci. Technol. 2017, 51 (12), 7111-7119. https://doi.org/10.1021/acs.est.7b01002.

(19) Villanueva, C. M.; Cordier, S.; Font-Ribera, L.; Salas, L. A.; Levallois, P. Overview of Disinfection By-Products and Associated Health Effects. Curr. Environ. Heal. reports 2015, 2 (1), 107-115. https://doi.org/10.1007/s40572-014-0032-X.

(20) Schoeny, R. Disinfection By-Products: A Question of Balance. Environ. Health Perspect. 2010, 118 (11), A466-A467. https://doi.org/10.1289/ehp.1003053.

(21) Chaplin, B. P. Advantages, Disadvantages, and Future Challenges of the Use of Electrochemical Technologies for Water and Wastewater Treatment; Elsevier Inc., 2018. https://doi.org/10.1016/B978-0-12-813160-2.00017-1.

(22) Saha, P.; Bruning, H.; Wagner, T. V.; Rijnaarts, H. H. M. Removal of Organic Compounds from Cooling Tower Blowdown Water by Electrochemical Oxidation: Role of Electrodes and Operational Parameters. Chemosphere. 2020, 259, 127491. https://doi.org/10.1016/j.chemosphere.2020.127491

(23) Mantech. COD vs. TOC in Water and Wastewater Treatment https://mantech-inc.com/blog/cod-vs-toc-in-water-and-wastewatertreatment/ (accessed March 4, 2020).

(24) Shimadzu. TOC Analyzers https://www.shimadzu.com/an/toc/lab/toc14.html (accessed March 4, 2020).

(25) Abdullah, M.; Low, G. K. C.; Matthews, R. W. Effects of Common Inorganic Anions on Rates of Photocatalytic Oxidation of Organic Carbon over Illuminated Titanium Dioxide. J. Phys. Chem. 1990, 94 (17), 68206825. https://doi.org/10.1021/j100380a051.

(26) Lindner, M.; Bahnemann, D. W.; Hirthe, B.; Griebler, W. D. Solar Water Detoxification: Novel TiO2 Powders as Highly Active Photocatalysts. $J$. Sol. Energy Eng. 1997, 119 (2), 120-125. https://doi.org/10.1115/1.2887890.

(27) Burns, R. A.; Crittenden, J. C.; Hand, D. W.; Selzer, V. H.; Sutter, L. L.; Salman, S. R. Effect of Inorganic Ions in Heterogeneous Photocatalysis of TCE. J. Environ. Eng. 1999, 125 (1), 77-85. 
https://doi.org/doi:10.1061/(ASCE)0733-9372(1999)125:1(77).

(28) Guillard, C.; Puzenat, E.; Lachheb, H.; Houas, A.; Herrmann, J.-M. Why Inorganic Salts Decrease the $\mathrm{TiO}_{2}$ Photocatalytic Efficiency. Int. J.

Photoenergy 2005, 7 (1), 1-9. https://doi.org/10.1155/s1110662x05000012.

(29) Zhang, W.; An, T.; Cui, M.; Sheng, G.; Fu, J. Effects of Anions on the Photocatalytic and Photoelectrocatalytic Degradation of Reactive Dye in a Packed-Bed Reactor. J. Chem. Technol. Biotechnol. 2005, 80 (2), 223-229. https://doi.org/10.1002/jctb.1185.

(30) Gligorovski, S.; Strekowski, R.; Barbati, S.; Vione, D. Environmental Implications of Hydroxyl Radicals $(\cdot \mathrm{OH})$. Chem. Rev. 2015, 115 (24), 13051-13092. https://doi.org/10.1021/cr500310b.

(31) Bhatkhande, D. S.; Pangarkar, V. G.; Beenackers, A. A. C. M.

Photocatalytic Degradation for Environmental Applications - a Review. J. Chem. Technol. Biotechnol. 2002, 77 (1), 102-116. https://doi.org/10.1002/jctb.532.

(32) Chen, L.; Lei, C.; Li, Z.; Yang, B.; Zhang, X.; Lei, L. Electrochemical Activation of Sulfate by BDD Anode in Basic Medium for Efficient Removal of Organic Pollutants. Chemosphere 2018, 210 (18), 516-523. https://doi.org/10.1016/j.chemosphere.2018.07.043.

(33) Farhat, A.; Keller, J.; Tait, S.; Radjenovic, J. Assessment of the Impact of Chloride on the Formation of Chlorinated By-Products in the Presence and Absence of Electrochemically Activated Sulfate. Chem. Eng. J. 2017, 330 (August), 1265-1271. https://doi.org/10.1016/j.cej.2017.08.033.

(34) Martínez-Huitle, C. A.; Rodrigo, M. A.; Sirés, I.; Scialdone, O. Single and Coupled Electrochemical Processes and Reactors for the Abatement of Organic Water Pollutants: A Critical Review. Chem. Rev. 2015, 115 (24), 13362-13407. https://doi.org/10.1021/acs.chemrev.5b00361.

(35) Farhat, A.; Keller, J.; Tait, S.; Radjenovic, J. Removal of Persistent Organic Contaminants by Electrochemically Activated Sulfate. Environ. Sci.

Technol. 2015, 49 (24), 14326-14333. https://doi.org/10.1021/acs.est.5b02705.

(36) Martinez-Huitle, C. A.; Ferro, S. Electrochemical Oxidation of Organic Pollutants for the Wastewater Treatment: Direct and Indirect Processes. Chem. Soc. Rev. 2006, 35 (12), 1324-1340. https://doi.org/10.1039/B517632H.

(37) Radjenovic, J.; Sedlak, D. L. Challenges and Opportunities for Electrochemical Processes as Next-Generation Technologies for the 
Treatment of Contaminated Water. Environ. Sci. Technol. 2015, 49 (19), 11292-11302. https://doi.org/10.1021/acs.est.5b02414.

(38) Boxall, C. The Electrophoresis of Semiconductor Particles. Chem. Soc. Rev. 1994, 23, 137-145.

(39) Wang, K. H.; Hsieh, Y. H.; Wu, C. H.; Chang, C. Y. The PH and Anion Effects on the Heterogeneous Photocatalytic Degradation of OMethylbenzoic Acid in $\mathrm{TiO}_{2}$ Aqueous Suspension. Chemosphere 2000, 40 (4), 389-394. https://doi.org/10.1016/S0045-6535(99)00252-0.

(40) Piscopo, A.; Robert, D.; Weber, J. V. Influence of PH and Chloride Anion on the Photocatalytic Degradation of Organic Compounds. Appl. Catal. B Environ. 2001, 35 (2), 117-124. https://doi.org/http://dx.doi.org/10.1016/S0926-3373(01)00244-2.

(41) Bergmann, M. E. H.; Rollin, J.; Iourtchouk, T. The Occurrence of Perchlorate during Drinking Water Electrolysis Using BDD Anodes. Electrochim. Acta 2009, 54 (7), 2102-2107. https://doi.org/10.1016/j.electacta.2008.09.040.

(42) Bergmann, M. E. H.; Koparal, A. S.; Iourtchouk, T. Electrochemical Advanced Oxidation Processes, Formation of Halogenate and Perhalogenate Species: A Critical Review. Crit. Rev. Environ. Sci. Technol. 2014, 44 (4), 348-390. https://doi.org/10.1080/10643389.2012.718948.

(43) Bagastyo, A. Y.; Batstone, D. J.; Kristiana, I.; Escher, B. I.; Joll, C.; Radjenovic, J. Electrochemical Treatment of Reverse Osmosis Concentrate on Boron-Doped Electrodes in Undivided and Divided Cell Configurations. J. Hazard. Mater. 2014, 279, 111-116. https://doi.org/10.1016/j.jhazmat.2014.06.060. 


\subsection{Appendix}

Table A3.1. Removal of COD and TOC after $5 \mathrm{~h}$ of PCD or ECD of CTBD water at various $\mathrm{pH}$. The season summer or winter indicates the time when the CTBD water was collected.

\begin{tabular}{|c|c|c|c|c|c|c|}
\hline & \multicolumn{4}{|c|}{ PCD } & \multicolumn{2}{c|}{ ECD } \\
\hline solution & $\begin{array}{c}\text { COD } \\
\text { removal } \\
{[\%]}\end{array}$ & $\begin{array}{c}\text { TOC } \\
\text { removal } \\
{[\%]}\end{array}$ & $\begin{array}{c}\text { COD } \\
\text { removal } \\
{[\%]}\end{array}$ & $\begin{array}{c}\text { TOC } \\
\text { removal } \\
{[\%]}\end{array}$ & $\begin{array}{c}\text { COD } \\
\text { removal } \\
{[\%]}\end{array}$ & $\begin{array}{c}\text { TOC } \\
\text { removal } \\
{[\%]}\end{array}$ \\
\hline $\mathrm{CTBD}:$ & summer & summer & winter & winter & winter & winter \\
\hline $\mathrm{pH} \mathrm{3:}$ & 47 & 35 & - & - & 100 & 62 \\
\hline $\mathrm{pH} \mathrm{7:}$ & 67 & 59 & 54 & 50 & 100 & 57 \\
\hline $\mathrm{pH} \mathrm{10:}$ & 61 & 55 & - & - & 100 & 65 \\
\hline
\end{tabular}




\section{Chapter 4}

\section{Electrochemical defect engineering of titania}

Substoichiometric or defect engineered titania $\left(\mathrm{TiO}_{\mathrm{x}}\right)$ is of interest due to significant electrical conductivity and potential applications in photo- and electrocatalytic processes. Electrochemical doping of $\mathrm{TiO}_{2}$ via cathodic polarization is an appealing preparation method. Here, we explored the preparation of $\mathrm{TiO}_{\mathrm{x}}$ by cathodic polarization in an undivided cell using iridium-mixed-metal-oxide (IrMMO) and boron doped diamond (BDD) counter electrodes as alternatives to commonly utilized platinum counter electrodes, in order to avoid noble metal contaminations which might influence the doping procedure. Superior charge transfer properties of crystalline $\mathrm{TiO}_{x}$ electrodes as shown by $\mathrm{Fe}^{2+/ 3+}$ redox couple voltammetry and electrochemical impedance measurements, were obtained for $\mathrm{TiO}_{\mathrm{x}}$ samples prepared with BDD. Spectroscopic characterization and time of flight secondary ion mass spectrometry indicate superior bulk doping. Although state of the art analytical characterization techniques (LEIS and XPS) did not reveal surface contamination, electrochemical measurements suggest cathodic deposition of Ir during $\mathrm{TiO}_{\mathrm{x}}$ preparation. Due to Ir contamination hydrogen evolution preferentially occurred over $\mathrm{TiO}_{\mathrm{x}}$ bulk doping reducing the efficiency of the doping process. Our results highlight the necessity of inherently stable counter electrodes such as $\mathrm{BDD}$ for electrochemical preparation of $\mathrm{TiO}_{\mathrm{x}}$ and reveal the pronounced influence of trace contamination on the doping mechanism and the electrochemical properties of $\mathrm{TiO}_{\mathrm{x}}$ electrodes.

This chapter is based on R. Brüninghoff, A. Paradelo Rodríguez, R.P.H. Jong, J.M. Sturm, U. Breuer, C. Lievens, A.W. Jeremiasse, G. Mul, B. Mei, Electrochemical preparation of defect-engineered titania: bulk doping versus surface contamination; in preparation 


\subsection{Introduction}

Titanium dioxide has attracted significant interest in optoelectronics and photocatalysis among others for photocatalytic remediation, ${ }^{1,2}$ solar water splitting, ${ }^{2,3}$ and found utilization as protective layer in photoelectrochemistry. ${ }^{4-6} \mathrm{~A}$ poor intrinsic electrical conductivity, however, is limiting its application in electrochemistry. Substoichiometric or in general defect engineered $\mathrm{TiO}_{2}$ materials (in the following $\mathrm{TiO}_{\mathrm{x}}$ ) have been proposed to overcome this drawback, ${ }^{7-9}$ and have already been successfully applied i.e. in electrochemical water treatment ${ }^{10-21}$ or as anode material in batteries. ${ }^{7,8}$

It is known that the electrical conductivity can be optimized by tuning the Ti/O ratio of $\mathrm{TiO}_{\mathrm{x}}$ electrodes. ${ }^{7,22,23}$ Nevertheless, a strong dependence on the precise preparation procedure exists, thus preparation of $\mathrm{TiO}_{\mathrm{x}}$ materials is topic of ongoing research. ${ }^{7-9,23,24}$ Hydrogenation is the most commonly used technique including high pressure (either for green body formation or during annealing) and temperature in a reductive atmosphere (e.g. $\left.\mathrm{H}_{2}\right){ }^{7-9}$ To enable milder preparation conditions, other preparative techniques have been developed and specifically electrochemical preparation via cathodic polarization (reductive self-doping) appears to be suitable. ${ }^{16-19,25-30}$ Still a comprehensive description of the electrochemically induced surface and bulk defects has not yet been reported $^{8,9}$ and the exact doping mechanism, e.g. formation of oxygen vacancies, reduction of Ti centers, proton intercalation and/or hydrogen doping, alongside with $\mathrm{TiO}_{\mathrm{x}}$ stability are frequently discussed. ${ }^{8,9,13,24,31}$

The electrochemical preparation (hereafter named "cathodization") additionally induces the risk of surface contamination. As such it is noticed that $\mathrm{Pt}$ is frequently used as counter electrode in preparative electrochemistry. Since the dissolution of $\mathrm{Pt}$ under anodic potentials has been reported the suitability of Pt as a counter electrode (CE) for preparative means is clearly questionable. ${ }^{32} \mathrm{Pt}$ contamination $^{33-35}$ or deliberate $\mathrm{Pt}$ deposition ${ }^{36}$ occurs during electrochemical treatments that might significantly influence the properties of the material under investigation. ${ }^{33-37}$ Indeed, Pt contamination of the $\mathrm{TiO}_{\mathrm{x}}$ surface, due to oxidative dissolution of $\mathrm{Pt}_{-} \mathrm{CE}^{32,34}$ and subsequent deposition on negatively polarized substrates (i.e. $\mathrm{TiO}_{2}$ or $\mathrm{TiO}_{\mathrm{x}}$ as used 
in this study) has been confirmed here (see Figure A4.1 and A4.2), resulting in a superior hydrogen evolution performance (Figure A4.3 and A4.4).

The preparation in a membrane-separated two compartment cell induce additional complexity and costs. Moreover, membrane crossover of dissolved ions still occurs. ${ }^{38-40}$ Therefore, in this study the use of "more" inert counter electrodes and their influence on the $\mathrm{TiO}_{x}$ properties has been studied in detail. Specifically, we investigated the electrochemical preparation of $\mathrm{TiO}_{\mathrm{x}}$ via cathodic polarization using two CEs, namely: Ir-mixed-metal-oxide (IrMMO, i.e. a dimensionally stable anode widely used in industrial electrolysis $)^{41,42}$ and Boron doped diamond (BDD).

Whereas Pt (here used as a reference case) is known for its corrosion under certain electrochemical conditions, ${ }^{32,34,35}$ DSA and BDD are known for their excellent corrosion stability. ${ }^{41-45}$ In contrast to Pt-CE clean $\mathrm{TiO}_{\mathrm{x}}$ surfaces are obtained for treatments with IrMMO and BDD-CEs as revealed by XPS and low energy ion scattering spectroscopy. Interestingly, charge transfer (CT) properties and electrical resistances of crystalline $\mathrm{TiO}_{\mathrm{x}}$ electrodes prepared with IrMMO and BDD-CEs are distinctively different and especially for extended cathodization times $\left(t_{c} \geq 180 \mathrm{~min}\right.$ ) the use of a BDD-CE is beneficial. The CT properties are directly related to increased $\mathrm{H}$-doping as revealed by bulk characterization using secondary-ion mass spectrometry. By electroanalytical measurements we show that trace contaminations of Ir, below the detection limit of sensitive surface characterization techniques, are likely present, favoring hydrogen evolution over bulk modification. The results presented in this study provide important insights into the electrochemical doping of $\mathrm{TiO}_{\mathrm{x}}$ and are relevant for the development and understanding of self-doped semiconductors.

\subsection{Materials and methods}

\subsubsection{Chemicals and materials}

The following chemicals, materials and equipment were used in this study. Chemicals were purchased from Sigma Aldrich (unless otherwise noted): $\mathrm{H}_{2} \mathrm{SO}_{4}$ $(\geq 97.5 \%), \quad \mathrm{HCl} \quad(37 \%), \quad \mathrm{NaOH}(\geq 98 \%), \quad \mathrm{NiCl}_{2} * 6 \mathrm{H}_{2} \mathrm{O} \quad(99.9 \%), \quad \mathrm{K} 3 \mathrm{Fe}(\mathrm{CN})_{6}$ $(\geq 99.0 \%), \quad \mathrm{K} 4 \mathrm{Fe}(\mathrm{CN})_{6} * 3 \mathrm{H}_{2} \mathrm{O}(\geq 99.5 \%), \quad \mathrm{Na}_{2} \mathrm{SO}_{4} \quad(>99.0 \%), \quad \mathrm{NaCl}(\geq 99 \%)$; demineralized water (MQ water; Merck MilliQ system, resistivity >18 M $\Omega \mathrm{cm}$ ), Ti plates $(2.5 \times 2.5 \mathrm{~cm}, 1 \mathrm{~mm}$ thickness, Ti grade 1 [ $>99.7 \%$ ], Magneto special anodes 
B.V., P/N "C1148”), BDD-CE (Magneto special anodes B.V., P/N "DAU”), IrMMO-CE (Magneto special anodes B.V., P/N "CHH”), Pt-gauze-CE (Heraeus, P/N 81015295), ICP/OES standards of Merck (Multi IV, Ti, Cr, Pt, Ir of 1000 mg/L), FTO glass ( 13 $\Omega /$ sq, Sigma Aldrich).

All electrochemical experiments were carried out using polytetrafluoroethylene based custom-made reactors (cell volume approximately $10 \mathrm{~mL}$ ) with adapters to adjust the exposed working electrode (WE) area (diameter $20.5 \mathrm{~mm}, 18.0 \mathrm{~mm}$, $13 \mathrm{~mm}, 7 \mathrm{~mm}$ ) and a Biologic SP-300 or VSP-9 potentiostat, controlled by EC-lab software. Experiments were performed in a three-electrode set-up using $\mathrm{Ag} / \mathrm{AgCl}$ electrode ( $3 \mathrm{M} \mathrm{NaCl}, \mathrm{BASi}$ ) as reference electrode (RE). The stability of the RE was monitored using a master-RE (Ag/AgCl; $3 \mathrm{M} \mathrm{NaCl}, \mathrm{BASi})$. Distance between WE and $\mathrm{CE}$ during cathodization using either BDD or IrMMO-CE was $30 \mathrm{~mm}$.

\subsubsection{Cleaning and etching}

Before sample preparation, Ti substrates were chemically etched (resulting in a rough surface morphology, see Figure A4.5) to ensure a clean and comparable surface. Shortly, Ti plates were degreased with soap, ethanol and rinsed with MQwater. The plates were etched for $20 \mathrm{~min}$ in boiling concentrated $\mathrm{HCl}\left(>50^{\circ} \mathrm{C}\right)$; rinsed thoroughly with MQ-water and treated in an ultrasonic bath (MQ-water) for 15 min. Afterwards plates were rinsed again with MQ-water and dried under $\mathrm{N}_{2}$ flow.

\subsubsection{Anodization and annealing}

For the formation of a $\mathrm{TiO}_{2}$ layer on the $\mathrm{Ti}$ substrates a potential of $5.5 \mathrm{~V}$ vs. $\mathrm{Ag} / \mathrm{AgCl}\left(3.30 \mathrm{~cm}^{2}\right.$ exposed $\mathrm{WE}$ area $)$ was applied for $30 \mathrm{~min}$ according to a method described in literature. ${ }^{30}$ The anodization reactor was equipped with a Ptgauze counter electrode, $\mathrm{H}_{2} \mathrm{SO}_{4}$ was used as electrolyte $\left[1 \mathrm{~mol} \mathrm{~L}^{-1}\right.$. Annealing was performed by treating $\mathrm{TiO}_{2}$ substrates (after anodization) at $450{ }^{\circ} \mathrm{C}$ or $550{ }^{\circ} \mathrm{C}$ for $1 \mathrm{~h}$ $\left(10^{\circ} \mathrm{C} / \mathrm{min}\right.$ heating rate, Carbolite oven CWF 1100) in air.

\subsubsection{Cathodization}

Annealed $\mathrm{TiO}_{2}$ substrates were cathodized using either a constant potential (CP) method $(-1.03 \mathrm{~V} \text { vs. } \mathrm{Ag} / \mathrm{AgCl})^{30}$ or constant current (CC) conditions ( -5 or $-10 \mathrm{~mA} \mathrm{~cm}^{-2}$ ). The samples were cathodized between $15-240 \mathrm{~min}$ in $\mathrm{H}_{2} \mathrm{SO}_{4}$ electrolyte $\left[1 \mathrm{~mol} \mathrm{~L}^{-1}\right]$. The exposed area of the WE was $2.54 \mathrm{~cm}^{2}$. As CE either a 
Pt-gauze, IrMMO or BDD plate electrodes were used. No artificial agitation of the electrolyte was performed, however mixing of the electrolyte due to bubble formation (HER and OER) occurs. The prepared samples are labelled $\mathrm{TiO}_{\mathrm{x}}-\mathrm{CE}-\mathrm{x}$, where $\mathrm{CE}$ reflects the used counter electrode and $\mathrm{x}$ indicates the cathodization time $\left(\mathrm{t}_{\mathrm{c}}\right)$.

\subsubsection{Cyclic voltammetry \& electrochemical impedance spectroscopy}

$\mathrm{CV}$ were recorded in either $\mathrm{H}_{2} \mathrm{SO}_{4}\left[1 \mathrm{~mol} \mathrm{~L}^{-1}\right]$ for hydrogen evolution reaction, $\mathrm{NaOH}\left[0.05 \mathrm{~mol} \mathrm{~L}^{-1}\right]$ for oxygen evolution reaction or in an aqueous iron couple $\left(\mathrm{Fe}^{2+/ 3+}\right)$ solution $\left[0.2 \mathrm{~mol} \mathrm{~L}^{-1} \mathrm{~K}_{3} \mathrm{Fe}(\mathrm{CN})_{6}, \quad 0.2 \mathrm{~mol} \mathrm{~L}^{-1} \mathrm{~K}_{4} \mathrm{Fe}(\mathrm{CN})_{6}, \quad 0.2 \mathrm{~mol} \mathrm{~L}^{-1}\right.$ $\left.\mathrm{Na}_{2} \mathrm{SO}_{4}\right]^{46}$ in the potential range of interest. The exposed sample area was $1.33 \mathrm{~cm}^{2}$ for HER and OER-CV and $0.38 \mathrm{~cm}^{2}$ for $\mathrm{Fe}^{2+/ 3+}-\mathrm{CV}$. All CVs were recorded using a scan rate of $20 \mathrm{mV} \mathrm{s}^{-1}$ and were corrected for the solution resistance (iR drop compensation $85 \%$, determined by EIS $\left[10^{5} \mathrm{~Hz}\right]$ at open circuit potential). Potentials reported against reversible hydrogen electrode (RHE) are converted using the following equation: $\quad \mathrm{E}_{\mathrm{RHE}}=\mathrm{E}_{\text {measured }}+\mathrm{E}_{\mathrm{Ag} / \mathrm{AgCl}}^{0}+0.059 \mathrm{~V} * \mathrm{pH}$; with $\mathrm{E}_{\mathrm{Ag} / \mathrm{AgCl}}^{0}=0.206 \mathrm{~V}$. EIS measurements were performed in the $\mathrm{Fe}^{2+/ 3+}$ solution at open circuit potential in a frequency range from $10^{6} \mathrm{~Hz}$ to $10^{-1} \mathrm{~Hz} .{ }^{46}$ The sinus amplitude was set to $10.0 \mathrm{mV}$. Spectra were recorded with 10 points per decade and an average of 3 measurements per frequency. The exposed sample area was $0.38 \mathrm{~cm}^{2}$.

\subsubsection{Ni-electrodeposition}

$\mathrm{Ni}$ was deposited from a $\mathrm{NiCl}_{2}$ precursor solution $(5 \mathrm{mmol} \mathrm{L}-1$; containing $0.1 \mathrm{~mol} \mathrm{~L}^{-1} \mathrm{NaCl}$, adjusted to $\mathrm{pH} 3$ with $0.1 \mathrm{~mol} \mathrm{~L}^{-1} \mathrm{HCl}$ ) at $-1.47 \mathrm{~V}$ vs. $\mathrm{Ag} / \mathrm{AgCl}{ }^{47}$

Further information regarding analytical methods and sample characterization can be found in the appendix (Text A4.1).

\subsection{Results and discussion}

$\mathrm{TiO}_{\mathrm{x}}$ was prepared by cathodization in acidic electrolyte from crystalline, rutile phase $\mathrm{TiO}_{2}$ (XRD, see Figure A4.6). Substrate annealing was performed at $450^{\circ} \mathrm{C}$ (for $60 \mathrm{~min}$ ) prior to cathodization. The intrinsic $\mathrm{CT}$ properties of $\mathrm{TiO}_{\mathrm{x}}$ surfaces were analyzed using $\mathrm{Fe}^{2+/ 3+}$ redox couple voltammetry and electrochemical impedance measurements. While for the bare $\mathrm{TiO}_{2}$ substrates $\left(\mathrm{t}_{\mathrm{c}}=0 \mathrm{~min}\right)$ the $\mathrm{CT}$ was negligible, for $\mathrm{TiO}_{\mathrm{x}}$-BDD-180 and $\mathrm{TiO}_{\mathrm{x}}$-IrMMO-180 oxidative as well as reductive currents 
were recorded (Figure 4.1a) suggesting $\mathrm{CT}$ from the $\mathrm{TiO}_{\mathrm{x}}$ surface to the $\mathrm{Fe}^{2+/ 3+}$ (Figure A4.7a for CV in only background electrolyte). Interestingly, $\mathrm{TiO}_{\mathrm{x}}-\mathrm{BDD}-180$ showed superior quasi-reversible $\mathrm{CT}$ properties $\left(\Delta \mathrm{E}_{\mathrm{p}}\right.$ of $\left.0.60 \mathrm{~V}\right)$. For $\mathrm{TiO}_{\mathrm{x}}-\mathrm{IrMMO}-$ 180 a peak-to-peak separation of $\Delta \mathrm{E}_{\mathrm{p}} \approx 1.2 \mathrm{~V}$ was determined, pointing towards a high electrode resistance. For comparison, $\Delta \mathrm{E}_{\mathrm{p}}=0.16 \mathrm{~V}$ is determined for the fast $\mathrm{CT}$ at IrMMO-WE (Figure A4.7b) and a peak-to-peak separation of $\Delta \mathrm{E}_{\mathrm{p}}=0.42$ $0.45 \mathrm{~V}$ has been reported recently for Mn-doped $\mathrm{TiO}_{2}$ layers prepared by sophisticated atomic layer deposition. ${ }^{46}$ The results of the $\mathrm{Fe}^{2+/ 3+}$ redox couple measurements are in good agreement with the charge transfer resistances obtained by impedance spectroscopy (Figure 4.1b). For $\mathrm{TiO}_{\mathrm{x}}$-IrMMO-180 a CT resistance of approximately $500 \Omega$ (equivalent to the semicircle diameter; fitted EIS data analysis shown in Table A4.1, description in Text A4.2) was measured. For $\mathrm{TiO}_{\mathrm{x}}-\mathrm{BDD}-180$ the layer resistance decreased to only $\approx 40 \Omega$ (reproducibility shown in Figure A4.9), which is also a factor of ten lower than resistances determined for commercial $\mathrm{TiO}_{\mathrm{x}}$ electrode materials $(\approx 430 \Omega$ ). In general, cathodization times of $180 \mathrm{~min}$ resulted in optimized CT properties for both $\mathrm{TiO}_{\mathrm{x}}-\mathrm{IrMMO}$ and $\mathrm{TiO}_{\mathrm{x}}$-BDD electrodes (Figure 4.1c and Figure A4.10a-d) While the resistances initially decreased linearly with cathodization time, significant differences in CT properties are observed for electrodes prepared at longer cathodization times. In addition, we also revealed that a higher calcination temperature during substrate annealing is detrimental (Figure A4.11) and amorphous substrates show inferior CT properties compared to annealed substrates (Figure A4.10e and f). Nevertheless, the oxidative current measured in the first cycle with the $\mathrm{Fe}^{2+/ 3+}$ redox couple is superimposed by fast passivation (re-oxidation), as indicated by the lower oxidative current and the shift in peak position in subsequent CVs and EIS measurements (Figure A4.8).

Clearly, the prepared $\mathrm{TiO}_{\mathrm{x}}$ substrates are not capable of withstanding oxidative environments. As surface functionalization by electrocatalysts is often required to promote the reaction kinetics, amongst others in photoelectrochemical water splitting, ${ }^{48,49}$ electrodeposition of Ni nanoparticles was performed. The resulting Ni$\mathrm{TiO}_{\mathrm{x}}$ electrodes were used for the electrochemical oxygen evolution reaction (OER) in alkaline electrolyte. As shown in Figure 4.1d for $\mathrm{TiO}_{2}$ substrates with $\mathrm{Ni}$ functionalization high overpotentials, governed by low intrinsic conductivity of the $\mathrm{TiO}_{2}$ layer, are required and bare $\mathrm{TiO}_{x}$ substrates only passivates. For both Nimodified $\mathrm{TiO}_{\mathrm{x}}$ electrodes significant anodic currents due to oxygen evolution are observed with Ni-modified $\mathrm{TiO}_{\mathrm{x}}$-IrMMO-180 possessing inferior behavior. 
Compared to Ni electrodeposited on conductive FTO substrates $(\approx 1.6 \mathrm{~V}$ vs. RHE for Ni-FTO $)^{50,51}$ the OER onset potential is anodically shifted by $\approx 0.2 \mathrm{~V}$.

a)

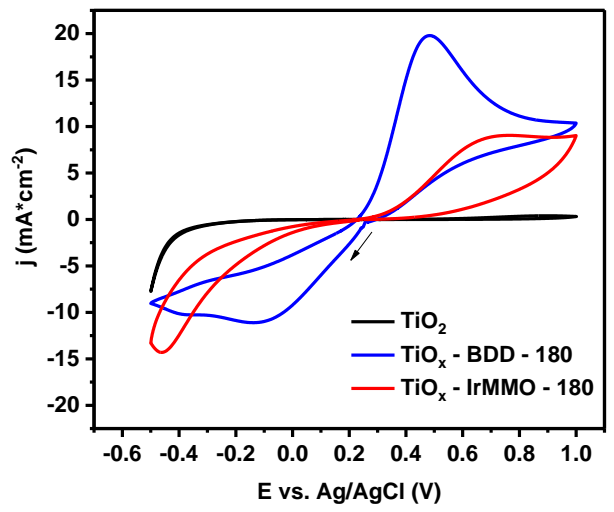

c)

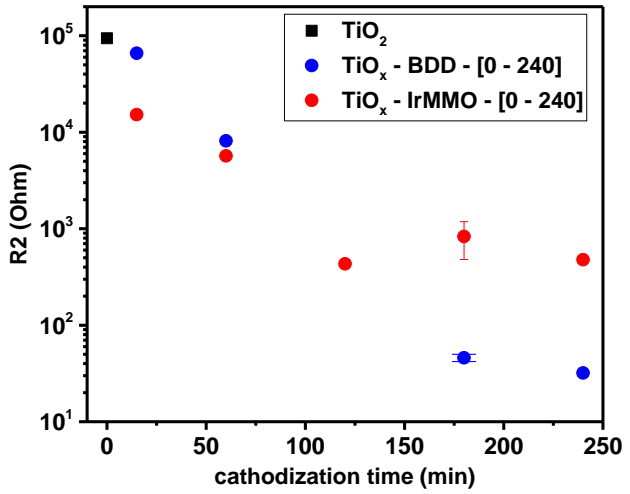

b)

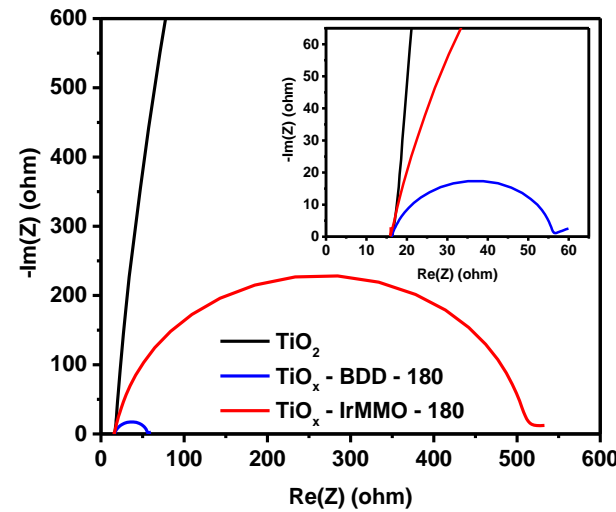

d)

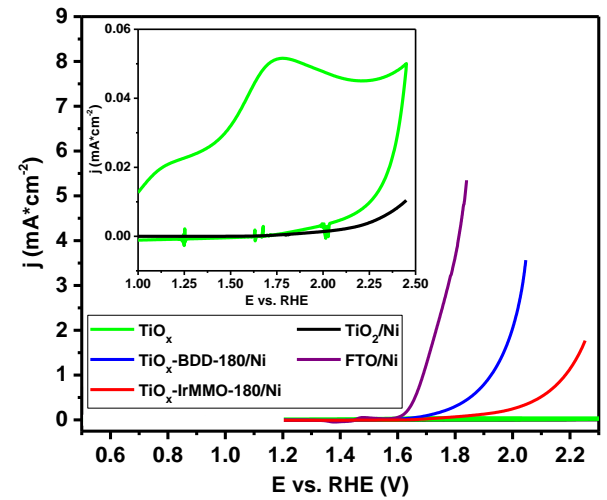

Figure 4.1. Analysis of $\mathrm{TiO}_{\mathrm{x}}$ samples (cathodization time $\mathrm{t}_{\mathrm{c}}=180 \mathrm{~min}$ ) prepared using either a BDD-CE (blue graphs) or a IrMMO-CE (red graphs) in comparison to noncathodized $\mathrm{TiO}_{2}$ substrates $\left(\mathrm{t}_{\mathrm{c}}=0 \mathrm{~min}\right.$ ). a) $\mathrm{CV}$ of $\mathrm{Fe}^{2+/ 3+}$ oxidation/reduction (cycle 1), b) EIS measurements (inset: enlarged section; full scale graphs are shown in Figure A4.8). c) Calculated CT resistance of the $\mathrm{TiO}_{\mathrm{x}}$ layer as function of the cathodization time. d) $\mathrm{CV}$ in $\mathrm{NaOH}\left(0.05 \mathrm{~mol} \mathrm{~L}^{-1}\right)$ showing OER activity of $\mathrm{TiO}_{x}$ samples $\left(\mathrm{t}_{\mathrm{c}}=180 \mathrm{~min}\right)$ modified with $\mathrm{Ni}$ catalyst. For comparison a bare $\mathrm{TiO}_{\mathrm{x}}$ sample without $\mathrm{Ni}(\mathrm{green}), \mathrm{TiO}_{2}\left(\mathrm{t}_{\mathrm{c}}=0 \mathrm{~min}\right)$ with $\mathrm{Ni}$ (black) and a Ni modified FTO substrate (purple) are shown. The insulating $\mathrm{TiO}_{2}$ layer prevents any significant OER activity, whereas the bare $\mathrm{TiO}_{x}$ sample without $\mathrm{Ni}$ catalyst suffers from fast oxidation and passivation of the $\mathrm{TiO}_{\mathrm{x}}$ substrate (inset). The $\mathrm{TiO}_{\mathrm{x}}$-BDD-180 sample with $\mathrm{Ni}$ catalyst shows a clear OER activity at lower overpotential compared to the $\mathrm{TiO}_{\mathrm{x}}$-IrMMO-180 sample due to the better CT properties of the substrate. 
Chronopotentiometry measurements $\left(5 \mathrm{~mA} \mathrm{~cm}{ }^{-2}, \mathrm{NaOH}\right.$ solution $\left.\mathrm{pH} 12.7\right)$ support the observations of $\mathrm{CT}$ properties and OER (Figure A4.12). Moreover, it is interesting to note that for $\mathrm{TiO}_{\mathrm{x}}-\mathrm{BDD}-180 / \mathrm{Ni}$ a constant potential during $30 \mathrm{~min}$ of operation is observed suggesting superior stability compared to bare $\mathrm{TiO}_{\mathrm{x}}$ substrates. This is in good agreement with previous reports, showing that Cobalt doping of $\mathrm{TiO}_{x}$ nanotubes increase the lifetime of $\mathrm{TiO}_{\mathrm{x}}$ under oxidative conditions ${ }^{52}$ and $\mathrm{Ni}$ or $\mathrm{Pt}$ islands are essential for water oxidation at $\mathrm{TiO}_{2}$-protected $\mathrm{Si}$ photoanodes. ${ }^{5,53}$ Again, for $\mathrm{TiO}_{\mathrm{x}}$-IrMMO-180 significantly higher OER overpotential are required to

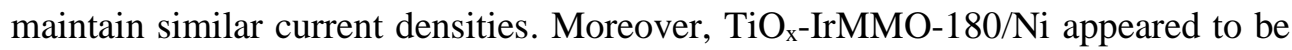
less stable, as evidenced by the constant potential increase. It is important to note that the Ni deposition was not optimized and further improvements in performance are feasible.

Given the beneficial properties of $\mathrm{TiO}_{\mathrm{x}}$-BDD it appeared to be counterintuitive that higher cathodization currents have been obtained during $\mathrm{TiO}_{\mathrm{x}}$ preparation with IrMMO-CEs (Figure 4.2a). To circumvent current induced changes constant current (CC) experiments have been performed using conditions corresponding to the average and final current density obtained during constant potential (CP) cathodization with BDD, i.e. current densities of $-5 \mathrm{~mA} \mathrm{~cm} \mathrm{~cm}^{-2}$ and $-10 \mathrm{~mA} \mathrm{~cm}{ }^{-2}$.

The CT measurements of $\mathrm{TiO}_{\mathrm{x}}$ samples cathodized under $\mathrm{CC}$ conditions $\left(\mathrm{t}_{\mathrm{c}}=180 \mathrm{~min}\right)$ are summarized in Figure 4.2c $\left(\mathrm{Fe}^{2+/ 3+} \mathrm{CV}\right.$; EIS is shown in Figure A4.13). Even though, equal cathodization current densities $\left(-5 \mathrm{~mA} \mathrm{~cm} \mathrm{~cm}^{-2}\right)$ should result in a similar reduction rate, $\mathrm{TiO}_{\mathrm{x}}-\mathrm{BDD}$ electrodes possessed superior CT behavior. Cathodization at $-10 \mathrm{~mA} \mathrm{~cm}^{-2}$ (IrMMO) led only to minor improvement in the $\mathrm{CT}$ resistance (1444 $\Omega$ ) compared to $-5 \mathrm{~mA} \mathrm{~cm}^{-2}(1596 \Omega)$ and the $\mathrm{TiO}_{\mathrm{x}}-\mathrm{IrMMO}_{\mathrm{O}}$ electrodes are clearly inferior to $\mathrm{TiO}_{\mathrm{x}}-\mathrm{BDD}\left(315 \Omega,-5 \mathrm{~mA} \mathrm{~cm}^{-2}\right)$. A strong effect of the reduction rate is therefore excluded as explanation for the differences in the obtained CT properties. However, in agreement with higher cathodization currents obtained during CP cathodization a lower potential (approx. $100 \mathrm{mV}$ ) is required in case of IrMMO-CE during CC cathodization to maintain the set current (Figure 4.2b). Measurements of double layer capacitances (for more information see Text A4.3 and Figure A4.14) indicated that electrochemical surface areas are similar $\left(0.11 \mathrm{mF} \mathrm{cm}^{-2}\right)$, independent of the $\mathrm{CE}$ used during preparation, thus surface area induced potential or current differences are excluded. 
a)

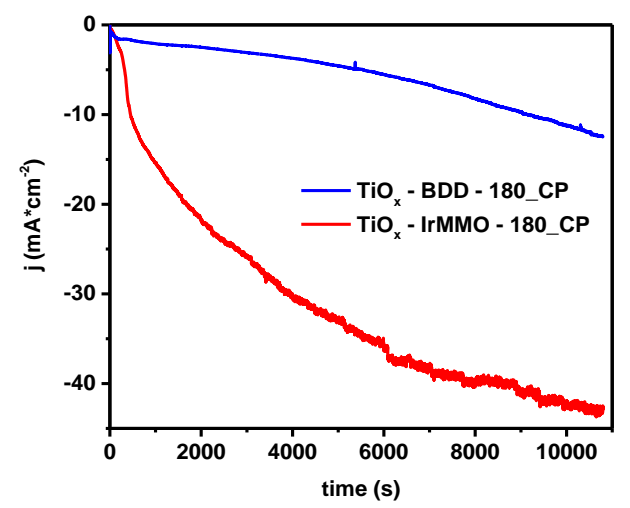

c)

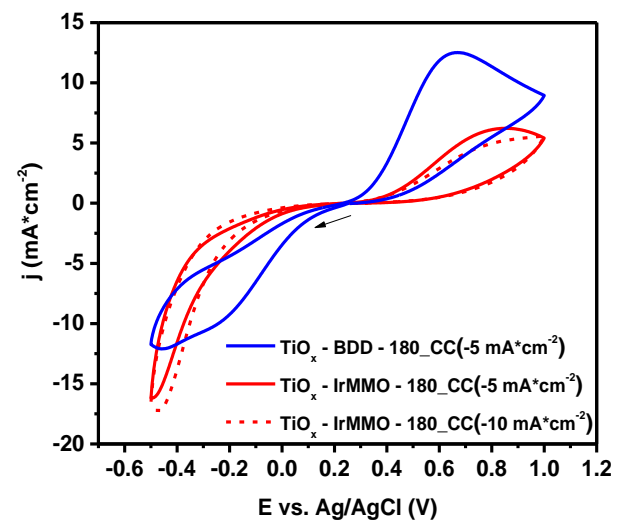

b)

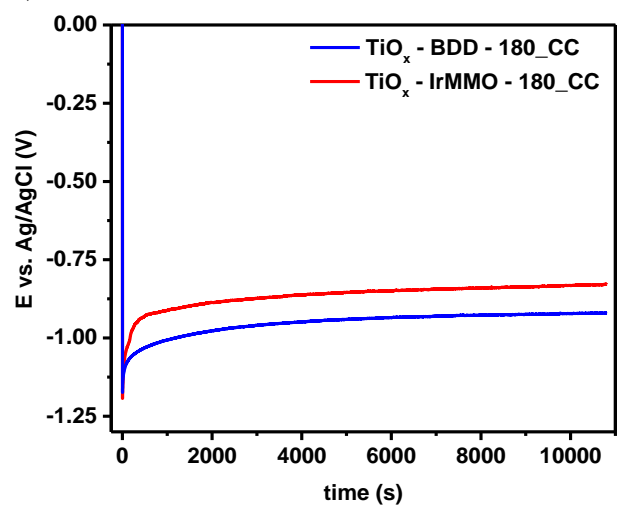

Figure 4.2. Current densities or potentials obtained during cathodization of $\mathrm{TiO}_{2}$ substrates $\left(\mathrm{t}_{\mathrm{c}}=180 \mathrm{~min}\right.$ ) using BDD (blue) or IrMMO-CE (red) under a) constant potential conditions (CP @ -1.03 V vs. $\mathrm{Ag} / \mathrm{AgCl}$ ) and b) constant current conditions (CC @ $-5 \mathrm{~mA} \mathrm{~cm}^{-2}$ ). c) $\mathrm{Fe}^{2+/ 3+}$ redox couple $\mathrm{CV}$ of $\mathrm{TiO}_{\mathrm{x}}$ samples prepared under constant current conditions (CC; $-5 \mathrm{~mA} \mathrm{~cm}{ }^{-2}$ or $-10 \mathrm{~mA} \mathrm{~cm}^{-2}, \mathrm{t}_{\mathrm{c}}=180 \mathrm{~min}$ ) using BDD-CE or IrMMO-CE. The $\mathrm{TiO}_{\mathrm{x}}-\mathrm{BDD}$ sample shows superior electrochemical CT properties compared to the $\mathrm{TiO}_{\mathrm{x}}$-IrMMO samples.

Extended material characterization has been carried out in order to understand the influence of the $\mathrm{CE}$ on the levels of doping. Ir contamination was not observed by XPS analysis, evident in the survey spectra (Figure A4.15 and Text A4.4) and the surface composition of $\mathrm{TiO}_{\mathrm{x}}-\mathrm{IrMMO}$ and $\mathrm{TiO}_{\mathrm{x}}-\mathrm{BDD}$ electrodes is similar. Given the detection limit of XPS ${ }^{49} \mathrm{TiO}_{\mathrm{x}}$ surfaces were additionally characterized by highly surface sensitive low energy ion scattering spectroscopy (LEIS). ${ }^{54}$ Even for samples subjected to 180 min cathodization treatment Ir deposition could not be detected 
(Figure 4.3a; see also Figure A4.16 for $\mathrm{TiO}_{\mathrm{x}}$-IrMMO-240). XPS also confirmed a similar Ti/O surface ratio $(0.42-0.45)$ indicating that excessive substoichiometric (surface) doping can be excluded. This was additionally confirmed by the Ti2p and O1s score spectra (Figure A4.17). All Ti2p core spectra resemble the peak shape and binding energies of annealed $\mathrm{TiO}_{2}$ substrates (non-cathodized) with $\mathrm{Ti}^{4+}$ at a binding energy (B.E.) of $458.8 \mathrm{eV}$ being the predominant $\mathrm{Ti}$ oxidation state. For oxygen a binding energy of $530.0 \mathrm{eV}(\mathrm{O} 1 \mathrm{~s})$ is indicative of $\mathrm{TiO}_{2}$ lattice oxygen. ${ }^{55}$ The observations are in agreement with XPS investigations of Ebonex electrodes by Pouilleau et al. ${ }^{56}$ or a recent study on self-doped $\mathrm{TiO}_{2}$ nanotubes by Gan et al ${ }^{57}$ who identified substoichiometric doping of $\mathrm{TiO}_{x}$ electrodes to be present only in the bulk. It is interesting to note that for amorphous cathodized electrodes, XPS spectra (Figure A4.18) revealed the formation of $\mathrm{Ti}^{3+}$ (B.E. $457.0 \mathrm{eV}$ ), $\mathrm{Ti}^{2+}$ (B.E. $454.9 \mathrm{eV}$ ) and even metallic titanium $\left(\mathrm{Ti}^{0}\right.$ at B.E. $\left.453.7 \mathrm{eV}\right) .{ }^{55}$ The observed difference in surface composition is in good agreement with theoretical calculations showing that the energy required for the formation of oxygen vacancies in amorphous $\mathrm{TiO}_{2}$ is lower than for crystalline $\mathrm{TiO}_{2}$ substrates. ${ }^{58,59}$ Since the XPS suggests a similar chemical composition of the surface of the $\mathrm{TiO}_{\mathrm{x}}$ samples prepared from annealed substrates, extensive formation of $\mathrm{Ti}^{\mathrm{m}+}(\mathrm{m}<4$, [represented by e'] $)$ surface defects according to equation 4.1 can be excluded as main doping mechanism.

$$
2 \mathrm{TiO}_{2} \rightarrow 2 \mathrm{Ti}_{\mathrm{Ti}^{\mathrm{x}}}^{\mathrm{x}}+3 \mathrm{O}_{\mathrm{O}}+\mathrm{V}_{\mathrm{O}} \cdot{ }^{*}+1 / 2 \mathrm{O}_{2}+2 \mathrm{e}^{\circ}
$$

Bulk characterization of the $\mathrm{TiO}_{\mathrm{x}}$ substrates was performed by VIS-NIR absorption spectroscopy (Figure 4.3b) and TOF-SIMS (Figure 4.3c and d). For $\mathrm{TiO}_{\mathrm{x}}-\mathrm{BDD}$ a higher absorption, especially in the NIR region, is observed, which can be attributed to a higher bulk doping. ${ }^{60,61}$ Likely due to the intercalation of protons, ${ }^{25,27,31}$ and/or the insertion of hydrogen ${ }^{62-67}$ as shown in equation 4.2 , that occurs during negative polarization of $\mathrm{TiO}_{2}$ leading to a strong n-type doping resulting in enhanced electrical conductivity of the material. ${ }^{25,31,65,66}$ Indeed, using TOF-SIMS, higher Hsignals are observed for cathodized $\mathrm{TiO}_{\mathrm{x}}$ compared to bare $\mathrm{TiO}_{2}$ substrates. Differences in $\mathrm{H}$-intensities especially for longer sputtering times, i.e. deeper in the bulk of the material, between $\mathrm{TiO}_{\mathrm{x}}-\mathrm{BDD}$ and $\mathrm{TiO}_{\mathrm{x}}-\mathrm{IrMMO}$ are in good agreement with the increased VIS-NIR absorbance and electrochemical CT measurements.

$$
\mathrm{H}^{+}{ }_{\mathrm{aq}}+\mathrm{e}^{-}+\mathrm{Ti}^{\mathrm{x}} \mathrm{Ti}+\mathrm{O}_{\mathrm{O}}^{\mathrm{x}} \rightarrow \mathrm{Ti}^{\prime}{ }_{\mathrm{Ti}}+(\mathrm{OH})^{\circ} \mathrm{O}
$$


a)

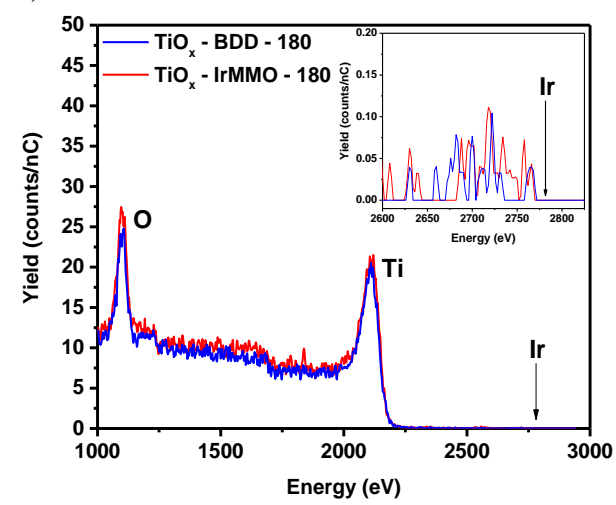

c)

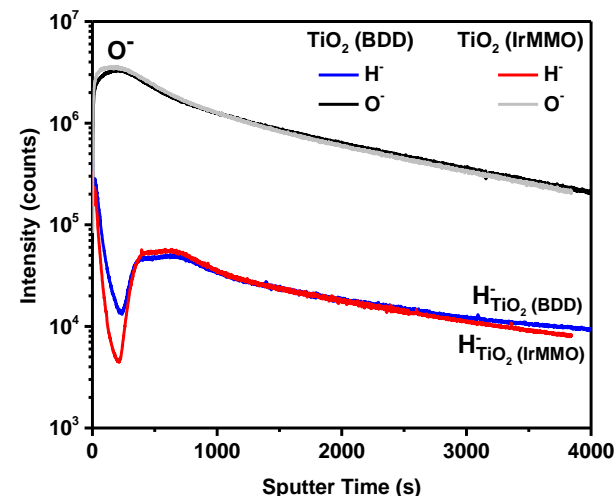

b)

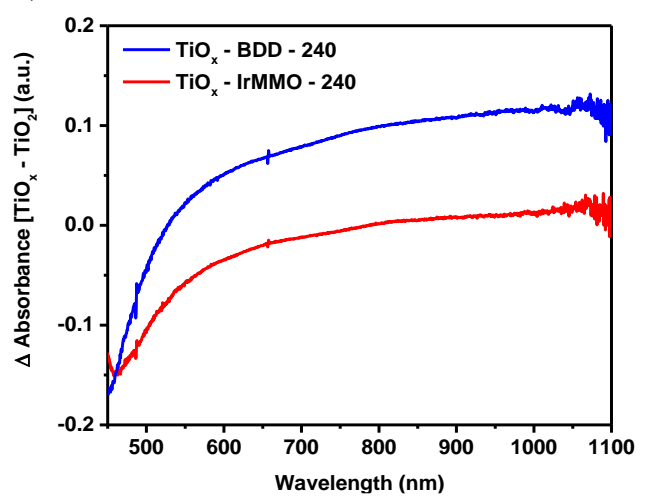

d)

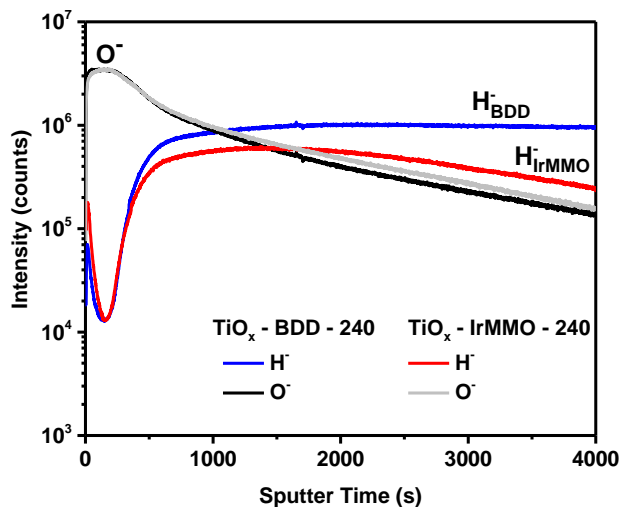

Figure 4.3. a) LEIS spectra of $\mathrm{TiO}_{\mathrm{x}}-\mathrm{BDD}-180$ and $\mathrm{TiO}_{\mathrm{x}}$-IrMMO-180 sample showing clear signals for oxygen and titanium, whereas for Ir no clear signal can be observed (indicated by the arrow; inset shows enlarged section). b) UV-NIR absorption of $\mathrm{TiO}_{\mathrm{x}}$ samples $\left(\mathrm{t}_{\mathrm{c}}=240 \mathrm{~min}\right.$ ) cathodized with BDD (blue) or IrMMO-CE (red) shown as delta absorbance spectra (absorbance of $\mathrm{TiO}_{2}$ background is subtracted). The spectra show a clear higher absorbance for BDD cathodized samples. c) TOF-SIMS depth profile measurements of $\mathrm{TiO}_{2}$ substrates $\left(\mathrm{t}_{\mathrm{c}}=0 \mathrm{~min}\right.$, measured on the non-cathodized sample area) and d) cathodized $\mathrm{TiO}_{\mathrm{x}}$ areas $\left(\mathrm{t}_{\mathrm{c}}=240 \mathrm{~min}\right.$; BDD or IrMMO-CE). Whereas the $\mathrm{TiO}_{2}$ substrates gives similar intensities for oxygen and hydrogen, a clearly increased hydrogen signal is measured for the cathodized areas. In addition, the $\mathrm{TiO}_{\mathrm{x}}-\mathrm{BDD}$ sample gives a higher $\mathrm{H}$-signal compared to $\mathrm{TiO}_{\mathrm{x}}$-IrMMO indicating a higher $\mathrm{H}$-doping.

The hydrogen evolution reaction (HER) in acidic environment is very sensitive to trace amounts of noble metals as observed for Pt (see also Figure A4.3) ${ }^{49}$ and $\operatorname{Ir}^{40}$ Therefore, $\mathrm{TiO}_{\mathrm{x}}$ electrodes prepared using BDD and IrMMO CEs have been characterized by cyclic voltammetry in acidic environment. As shown in Figure 4.4a 
for $\mathrm{TiO}_{\mathrm{x}}$-IrMMO-180 lower potentials are required to induce significant cathodic currents. The difference between $\mathrm{TiO}_{\mathrm{x}}$ substrates becomes even more significant after 25 or 50 consecutive CVs when either BDD or IrMMO are used as CE (Figure 4.4b). Only for $\mathrm{TiO}_{\mathrm{x}}$-IrMMO-180 the cathodic current onset potential decreased during cycling. Although DSA are corrosion resistant, they have a limited lifetime, ${ }^{41,42,68}$ and the oxidative dissolution of $\mathrm{Ir}^{\mathrm{metal}}{ }^{32}$, and to a lesser extend $\mathrm{IrO}_{2}{ }^{69}$, have recently been reported. We therefore propose that $\mathrm{Ir}$ dissolution, especially immediately after application of an anodic current (polarization) ${ }^{70}$ occurs during cathodization and trace amounts of $\mathrm{Ir}$ deposited on the $\mathrm{TiO}_{\mathrm{x}}$ surface exist.

a)

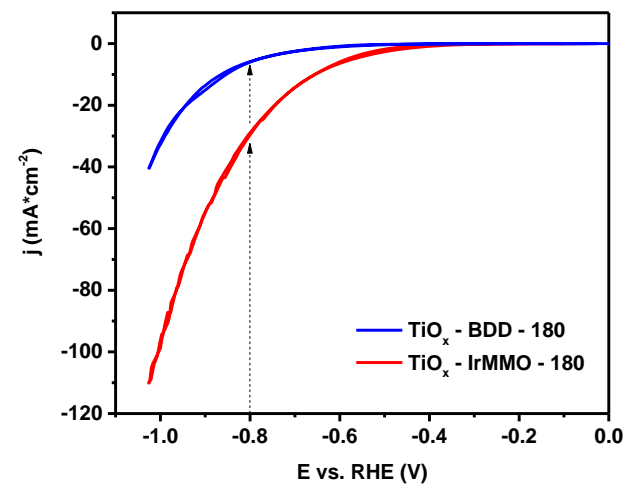

b)

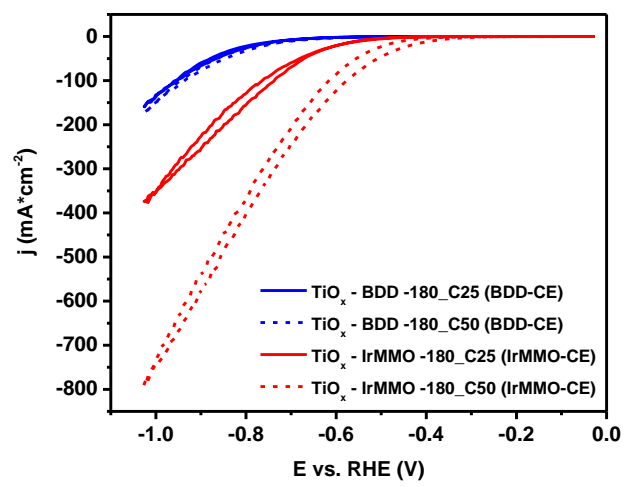

Figure 4.4. HER-CV of $\mathrm{TiO}_{\mathrm{x}}$ samples $\left(\mathrm{t}_{\mathrm{c}}=180 \mathrm{~min}\right.$ ) cathodized with BDD (blue) or IrMMO-CE (red). a) The initial CV ( $3^{\text {rd }}$ cycle, measured with BDD-CE) shows similar current densities as obtained at the end of the cathodization process (indicated with the arrows) with $\mathrm{TiO}_{\mathrm{x}}$-IrMMO showing higher current than $\mathrm{TiO}_{\mathrm{x}}-\mathrm{BDD}$. In addition, a lower onset potential is observed for $\mathrm{TiO}_{\mathrm{x}}-\mathrm{IrMMO}$. b) $25^{\text {th }}$ and $50^{\text {th }} \mathrm{CV}$ cycle: after the $25^{\text {th }}$ cycle $\mathrm{TiO}_{\mathrm{x}}-\mathrm{BDD}$ shows an increased current density compared to a) but no further improvement is observed after 50 cycles (CV recorded with BDD-CE). In strong contrast, the $\mathrm{TiO}_{\mathrm{x}^{-}}$ IrMMO CV, measured with a IrMMO-CE, shows an continuous increase of current density and decrease of onset potential with increasing cycle number. All CVs were recorded in $1 \mathrm{M} \mathrm{H}_{2} \mathrm{SO}_{4}$.

As suggested by the used state of the art advanced analytical techniques (XPS or LEIS respectively) and the absence of Ir traces in the electrolyte (ICP-OES compare Table A4.2), Ir can only be present in sub-ppm concentrations at the $\mathrm{TiO}_{\mathrm{x}}$ surface. However, impurities and defects have been proposed to affect the hydrogen diffusion and insertion into $\mathrm{TiO}_{2}{ }^{71,72}$ and thus $\mathrm{Ir}$ likely influenced the doping process. Finally it should be mentioned that other influence of the $\mathrm{CE}$ were excluded, e.g. by 
colorimetric redox tests to reveal the presence of peroxides ${ }^{73}$ as $\mathrm{H}_{2} \mathrm{O}_{2}$ might be generated at BDD electrodes ${ }^{74}$ and by bubbling oxygen to allow for a constant oxygen saturation of the electrolyte during cathodization.

\subsection{Conclusions}

In this study substoichiometric $\mathrm{TiO}_{\mathrm{x}}$ electrodes were prepared by electrochemical self-doping via cathodization of rutile $\mathrm{TiO}_{2}$ substrates with different counter electrodes. We clearly reveal that the use of inert counter electrodes, such as BDD, is favorable for $\mathrm{TiO}_{\mathrm{x}}$ preparation. Though no surface contamination of Ir could be detected by either XPS or LEIS, electrochemical analysis suggests that Ir traces influence bulk H-doping by favoring hydrogen evolution when IrMMO is used as counter electrode. For substrates treated with BDD counter electrodes increasing cathodization time led to a decrease in layer resistance and superior CT properties. The lowest layer resistance was obtained for annealed $\mathrm{TiO}_{2}$ substrates cathodized for 180 min (using BDD-CE). By the use of BDD, surface contamination is circumvented.

\subsection{Acknowledgements}

We would like to thank Magneto special anodes B.V. for providing Ti substrates, BDD and IrMMO electrodes. Devin O'Neill is acknowledged for VIS-NIR reflection measurements.

\subsection{References}

(1) Ochiai, T.; Fujishima, A. Photoelectrochemical Properties of $\mathrm{TiO}_{2}$ Photocatalyst and Its Applications for Environmental Purification.

J. Photochem. Photobiol. C Photochem. Rev. 2012, 13 (4), 247-262. https://doi.org/https://doi.org/10.1016/j.jphotochemrev.2012.07.001.

(2) Schneider, J.; Matsuoka, M.; Takeuchi, M.; Zhang, J.; Horiuchi, Y.; Anpo, M.; Bahnemann, D. W. Understanding $\mathrm{TiO}_{2}$ Photocatalysis: Mechanisms and Materials. Chem. Rev. 2014, 114 (19), 9919-9986.

https://doi.org/10.1021/cr5001892.

(3) Henderson, M. A. A Surface Science Perspective on $\mathrm{TiO}_{2}$ Photocatalysis. Surf. Sci. Rep. 2011, 66 (6-7), 185-297. https://doi.org/10.1016/j.surfrep.2011.01.001. 
(4) Seger, B.; Pedersen, T.; Laursen, A. B.; Vesborg, P. C. K.; Hansen, O.; Chorkendorff, I. Using $\mathrm{TiO}_{2}$ as a Conductive Protective Layer for Photocathodic $\mathrm{H}_{2}$ Evolution. J. Am. Chem. Soc. 2013, 135 (3), 1057-1064. https://doi.org/10.1021/ja309523t.

(5) Mei, B.; Pedersen, T.; Malacrida, P.; Bae, D.; Frydendal, R.; Hansen, O.; Vesborg, P. C. K.; Seger, B.; Chorkendorff, I. Crystalline $\mathrm{TiO}_{2}$ : A Generic and Effective Electron-Conducting Protection Layer for Photoanodes and Cathodes. J. Phys. Chem. C 2015, 119 (27), 15019-15027.

https://doi.org/10.1021/acs.jpcc.5b04407.

(6) Reed, P. J.; Mehrabi, H.; Schichtl, Z. G.; Coridan, R. H. Enhanced Electrochemical Stability of $\mathrm{TiO}_{2}$-Protected, Al-Doped ZnO Transparent Conducting Oxide Synthesized by Atomic Layer Deposition. ACS Appl. Mater. Interfaces 2018, acsami.8b16531. https://doi.org/10.1021/acsami.8b16531.

(7) Walsh, F. C.; Wills, R. G. A. The Continuing Development of Magnéli Phase Titanium Sub-Oxides and Ebonex ${ }^{\circledR}$ Electrodes. Electrochim. Acta 2010, 55 (22), 6342-6351. https://doi.org/http://dx.doi.org/10.1016/j.electacta.2010.05.011.

(8) Xu, B.; Sohn, H. Y.; Mohassab, Y.; Lan, Y. Structures, Preparation and Applications of Titanium Suboxides. RSC Adv. 2016, 6 (83), 79706-79722. https://doi.org/10.1039/c6ra14507h.

(9) Yan, X.; Tian, L.; Tan, X.; Zhou, M.; Liu, L.; Chen, X. Modifying Oxide Nanomaterials' Properties by Hydrogenation. MRS Commun. 2016, 6 (3), 192-203. https://doi.org/10.1557/mrc.2016.33.

(10) Chen, G.; Betterton, E. A.; Arnold, R. G. Electrolytic Oxidation of Trichloroethylene Using a Ceramic Anode. J. Appl. Electrochem. 1999, 29 (8), 961-970. https://doi.org/10.1023/a:1003541706456.

(11) Bejan, D.; Malcolm, J. D.; Morrison, L.; Bunce, N. J. Mechanistic Investigation of the Conductive Ceramic Ebonex ${ }^{\circledR}$ as an Anode Material. Electrochim. Acta 2009, 54 (23), 5548-5556. https://doi.org/http://dx.doi.org/10.1016/j.electacta.2009.04.057.

(12) Gayen, P.; Spataro, J.; Avasarala, S.; Ali, A. M.; Cerrato, J. M.; Chaplin, B. P. Electrocatalytic Reduction of Nitrate Using Magnéli Phase $\mathrm{TiO}_{2}$ Reactive Electrochemical Membranes Doped with Pd-Based Catalysts. Environ. Sci. Technol. 2018, 52 (16), 9370-9379. https://doi.org/10.1021/acs.est.8b03038.

(13) Chaplin, B. P. Advantages, Disadvantages, and Future Challenges of the Use of Electrochemical Technologies for Water and Wastewater Treatment; 
Elsevier Inc., 2018. https://doi.org/10.1016/B978-0-12-813160-2.00017-1.

(14) Bejan, D.; Guinea, E.; Bunce, N. J. On the Nature of the Hydroxyl Radicals Produced at Boron-Doped Diamond and Ebonex ${ }^{\circledR}$ Anodes. Electrochim. Acta 2012, 69, 275-281. https://doi.org/http://dx.doi.org/10.1016/j.electacta.2012.02.097.

(15) Zaky, A. M.; Chaplin, B. P. Porous Substoichiometric $\mathrm{TiO}_{2}$ Anodes as Reactive Electrochemical Membranes for Water Treatment. Environ. Sci. Technol. 2013, 47 (12), 6554-6563. https://doi.org/10.1021/es401287e.

(16) Kim, C.; Kim, S.; Choi, J.; Lee, J.; Kang, J. S.; Sung, Y.-E.; Lee, J.; Choi, W.; Yoon, J. Blue $\mathrm{TiO}_{2}$ Nanotube Array as an Oxidant Generating Novel Anode Material Fabricated by Simple Cathodic Polarization. Electrochim. Acta 2014, 141, 113-119. https://doi.org/http://dx.doi.org/10.1016/j.electacta.2014.07.062.

(17) Kim, C.; Kim, S.; Lee, J.; Kim, J.; Yoon, J. Capacitive and Oxidant Generating Properties of Black-Colored $\mathrm{TiO}_{2}$ Nanotube Array Fabricated by Electrochemical Self-Doping. ACS Appl. Mater. Interfaces 2015, 7 (14), 7486-7491. https://doi.org/10.1021/acsami.5b00123.

(18) Kim, C.; Kim, S.; Hong, S. P.; Lee, J.; Yoon, J. Effect of Doping Level of Colored $\mathrm{TiO}_{2}$ Nanotube Arrays Fabricated by Electrochemical Self-Doping on Electrochemical Properties. Phys. Chem. Chem. Phys. 2016, 18 (21), 14370-14375. https://doi.org/10.1039/C6CP01799A.

(19) Yang, Y.; Hoffmann, M. R. Synthesis and Stabilization of Blue-Black $\mathrm{TiO}_{2}$ Nanotube Arrays for Electrochemical Oxidant Generation and Wastewater Treatment. Environ. Sci. Technol. 2016, 50 (21), 11888-11894. https://doi.org/10.1021/acs.est.6b03540.

(20) Nayak, S.; Chaplin, B. P. Fabrication and Characterization of Porous, Conductive, Monolithic Ti4O7electrodes. Electrochim. Acta 2018, 263, 299-310. https://doi.org/10.1016/j.electacta.2018.01.034.

(21) Wang, J.; Zhi, D.; Zhou, H.; He, X.; Zhang, D. Evaluating Tetracycline Degradation Pathway and Intermediate Toxicity during the Electrochemical Oxidation over a $\mathrm{Ti}^{2} \mathrm{Ti}_{4} \mathrm{O}_{7}$ Anode. Water Res. 2018, 137, 324-334. https://doi.org/10.1016/j.watres.2018.03.030.

(22) Hayfield, P. C. S. Development of a New Material: Monolithic $\mathrm{Ti}_{4} \mathrm{O}_{7}$ Ebonex Ceramic; Royal Society of Chemistry, 2002. https://doi.org/10.1039/9781847550699-FP001.

(23) Leichtweiss, T.; Henning, R. A.; Koettgen, J.; Schmidt, R. M.; Holländer, B.; Martin, M.; Wuttig, M.; Janek, J. Amorphous and Highly 
Nonstoichiometric Titania $\left(\mathrm{TiO}_{\mathrm{x}}\right)$ Thin Films Close to Metal-like Conductivity. J. Mater. Chem. A 2014, 2 (18), 6631-6640. https://doi.org/10.1039/c3ta14816e.

(24) Hannula, M.; Ali-Löytty, H.; Lahtonen, K.; Sarlin, E.; Saari, J.; Valden, M. Improved Stability of Atomic Layer Deposited Amorphous $\mathrm{TiO}_{2}$ Photoelectrode Coatings by Thermally Induced Oxygen Defects. Chem. Mater. 2018, 30 (4), 1199-1208. https://doi.org/10.1021/acs.chemmater.7b02938.

(25) Fabregat-Santiago, F.; Barea, E. M.; Bisquert, J.; Mor, G. K.; Shankar, K.; Grimes, C. A. High Carrier Density and Capacitance in $\mathrm{TiO}_{2}$ Nanotube Arrays Induced by Electrochemical Doping. J. Am. Chem. Soc. 2008, 130 (34), 11312-11316. https://doi.org/10.1021/ja710899q.

(26) Wang, G.; Yang, Y.; Ling, Y.; Wang, H.; Lu, X.; Pu, Y. C.; Zhang, J. Z.; Tong, Y.; Li, Y. An Electrochemical Method to Enhance the Performance of Metal Oxides for Photoelectrochemical Water Oxidation. J. Mater. Chem. A 2016, 4 (8), 2849-2855. https://doi.org/10.1039/c5ta10477g.

(27) Berger, T.; Lana-Villarreal, T.; Monllor-Satoca, D.; Gómez, R. Charge Transfer Reductive Doping of Nanostructured $\mathrm{TiO}_{2}$ thin Films as a Way to Improve Their Photoelectrocatalytic Performance. Electrochem. commun. 2006, 8 (11), 1713-1718. https://doi.org/10.1016/j.elecom.2006.08.006.

(28) Frites, M.; Khan, S. U. M. Effect of Cathodic Polarization of ${\mathrm{N}-\mathrm{TiO}_{2}}_{2}$ Thin Films on Their Photoresponse towards Water Splitting Reactions. ECS Electrochem. Lett. 2014, 3 (12), H44-H46. https://doi.org/10.1149/2.0071412eel.

(29) Zhang, Z.; Hedhili, M. N.; Zhu, H.; Wang, P. Electrochemical Reduction Induced Self-Doping of $\mathrm{Ti}^{3+}$ for Efficient Water Splitting Performance on $\mathrm{TiO}_{2}$ Based Photoelectrodes. Phys. Chem. Chem. Phys. 2013, 15 (37), 15637. https://doi.org/10.1039/c3cp52759j.

(30) Swaminathan, J.; Subbiah, R.; Singaram, V. Defect-Rich Metallic Titania $\left(\mathrm{TiO}_{1.23}\right)$ - An Efficient Hydrogen Evolution Catalyst for Electrochemical Water Splitting. ACS Catal. 2016, 6 (4), 2222-2229. https://doi.org/10.1021/acscatal.5b02614.

(31) Jing, Y.; Almassi, S.; Mehraeen, S.; LeSuer, R. J.; Chaplin, B. P. The Roles of Oxygen Vacancies, Electrolyte Composition, Lattice Structure, and Doping Density on the Electrochemical Reactivity of Magnéli Phase $\mathrm{TiO}_{2}$ Anodes. J. Mater. Chem. A 2018, 6 (46), 23828-23839. https://doi.org/10.1039/C8TA03719A. 
(32) Cherevko, S.; Zeradjanin, A. R.; Topalov, A. A.; Kulyk, N.; Katsounaros, I.; Mayrhofer, K. J. J. Dissolution of Noble Metals during Oxygen Evolution in Acidic Media. ChemCatChem 2014, 6 (8), 2219-2223. https://doi.org/10.1002/cctc.201402194.

(33) Gottlieb, E.; Kopeć, M.; Banerjee, M.; Mohin, J.; Yaron, D.;

Matyjaszewski, K.; Kowalewski, T. In-Situ Platinum Deposition on Nitrogen-Doped Carbon Films as a Source of Catalytic Activity in a Hydrogen Evolution Reaction. ACS Appl. Mater. Interfaces 2016, 8 (33), 21531-21538. https://doi.org/10.1021/acsami.6b03924.

(34) Wei, R.; Fang, M.; Dong, G.; Ho, J. C. Is Platinum a Suitable Counter Electrode Material for Electrochemical Hydrogen Evolution Reaction? Sci. Bull. 2017, 62 (14), 971-973. https://doi.org/10.1016/j.scib.2017.06.006.

(35) Chen, J. G.; Jones, C. W.; Linic, S.; Stamenkovic, V. R. Best Practices in Pursuit of Topics in Heterogeneous Electrocatalysis. ACS Catal. 2017, 7 (9), 6392-6393. https://doi.org/10.1021/acscatal.7b02839.

(36) Ji, L.; Wang, J.; Zuo, S.; Chen, Z. In Situ Preparation of Pt Nanoparticles Supported on N-Doped Carbon as Highly Efficient Electrocatalysts for Hydrogen Production. J. Phys. Chem. C 2017, 121 (16), 8923-8930. https://doi.org/10.1021/acs.jpcc.7b01447.

(37) Cherevko, S.; Kulyk, N.; Chung, C. H. Utilization of Surface Active Sites on Gold in Preparation of Highly Reactive Interfaces for Alcohols Electrooxidation in Alkaline Media. Electrochim. Acta 2012, 69, 190-196. https://doi.org/10.1016/j.electacta.2012.02.094.

(38) Gubler, L. Membranes and Separators for Redox Flow Batteries. Curr. Opin. Electrochem. 2019, 18, 31-36. https://doi.org/10.1016/j.coelec.2019.08.007.

(39) Maurya, S.; Shin, S.-H.; Kim, Y.; Moon, S.-H. A Review on Recent Developments of Anion Exchange Membranes for Fuel Cells and Redox Flow Batteries. RSC Adv. 2015, 5 (47), 37206-37230. https://doi.org/10.1039/C5RA04741B.

(40) Haraldsted, J. P. B.; Révay, Z.; Frydendal, R.; Verdaguer-Casadevall, A.; Rossmeisl, J.; Kibsgaard, J.; Chorkendorff, I. Trace Anodic Migration of Iridium and Titanium Ions and Subsequent Cathodic Selectivity Degradation in Acid Electrolysis Systems. Mater. Today Energy 2019, 14. https://doi.org/10.1016/j.mtener.2019.100352.

(41) Beer, H. B. The Invention and Industrial Development of Metal Anodes. J. Electrochem. Soc. 1980, 127 (8), 303C. https://doi.org/10.1149/1.2130021. 
(42) Duby, P. The History of Progress in Dimensionally Stable Anodes. JOM 1993, 45 (3), 41-43. https://doi.org/10.1007/BF03222350.

(43) Chen, Q.; Granger, M. C.; Lister, T. E.; Swain, G. M. Morphological and Microstructural Stability of Boron-Doped Diamond Thin Film Electrodes in an Acidic Chloride Medium at High Anodic Current Densities. $J$.

Electrochem. Soc. 1997, 144 (11), 3806-3812.

https://doi.org/10.1149/1.1838096.

(44) Ashcheulov, P.; Taylor, A.; Mortet, V.; Poruba, A.; Le Formal, F.; Krýsová, H.; Klementová, M.; Hubík, P.; Kopeček, J.; Lorinčík, J.; et al.

Nanocrystalline Boron-Doped Diamond as a Corrosion-Resistant Anode for Water Oxidation via Si Photoelectrodes. ACS Appl. Mater. Interfaces 2018, 10 (35), 29552-29564. https://doi.org/10.1021/acsami.8b08714.

(45) Kraft, A. Doped Diamond: A Compact Review on a New, Versatile Electrode Material. Int. J. Electrochem. Sci. 2007, 2, 355-385.

(46) Siddiqi, G.; Luo, Z.; Xie, Y.; Pan, Z.; Zhu, Q.; Röhr, J. A.; Cha, J. J.; Hu, S. Stable Water Oxidation in Acid Using Manganese-Modified $\mathrm{TiO}_{2}$ Protective Coatings. ACS Appl. Mater. Interfaces 2018, 10 (22), 1880518815. https://doi.org/10.1021/acsami.8b05323.

(47) Wang, R.; Bertocci, U.; Tan, H.; Bendersky, L. A.; Moffat, T. P. SelfTerminated Electrodeposition of Ni, Co, and Fe Ultrathin Films. J. Phys. Chem. C 2016, 120 (29), 16228-16237.

https://doi.org/10.1021/acs.jpcc.6b01901.

(48) Sun, K.; McDowell, M. T.; Nielander, A. C.; Hu, S.; Shaner, M. R.; Yang, F.; Brunschwig, B. S.; Lewis, N. S. Stable Solar-Driven Water Oxidation to $\mathrm{O}_{2(\mathrm{G})}$ by Ni-Oxide-Coated Silicon Photoanodes. J. Phys. Chem. Lett. 2015, 6 (4), 592-598. https://doi.org/10.1021/jz5026195.

(49) Kemppainen, E.; Bodin, A.; Sebok, B.; Pedersen, T.; Seger, B.; Mei, B.; Bae, D.; Vesborg, P. C. K.; Halme, J.; Hansen, O.; et al. Scalability and Feasibility of Photoelectrochemical $\mathrm{H}_{2}$ Evolution: The Ultimate Limit of $\mathrm{Pt}$ Nanoparticle as an HER Catalyst. Energy Environ. Sci. 2015, 8 (10), 29912999. https://doi.org/10.1039/c5ee02188j.

(50) Li, X.; Walsh, F. C.; Pletcher, D. Nickel Based Electrocatalysts for Oxygen Evolution in High Current Density, Alkaline Water Electrolysers. Phys.

Chem. Chem. Phys. 2011, 13 (3), 1162-1167. https://doi.org/10.1039/c0cp00993h.

(51) Mei, B.; Permyakova, A. A.; Frydendal, R.; Bae, D.; Pedersen, T.; Malacrida, P.; Hansen, O.; Stephens, I. E. L.; Vesborg, P. C. K.; Seger, B.; et al. Iron-Treated $\mathrm{NiO}$ as a Highly Transparent p-Type Protection Layer for 
Efficient Si-Based Photoanodes. J. Phys. Chem. Lett. 2014, 5 (20), 34563461. https://doi.org/10.1021/jz501872k.

(52) Yang, Y.; Kao, L. C.; Liu, Y.; Sun, K.; Yu, H.; Guo, J.; Liou, S. Y. H.; Hoffmann, M. R. Cobalt-Doped Black $\mathrm{TiO}_{2}$ Nanotube Array as a Stable Anode for Oxygen Evolution and Electrochemical Wastewater Treatment. ACS Catal. 2018, 8 (5), 4278-4287.

https://doi.org/10.1021/acscatal.7b04340.

(53) McDowell, M. T.; Lichterman, M. F.; Carim, A. I.; Liu, R.; Hu, S.; Brunschwig, B. S.; Lewis, N. S. The Influence of Structure and Processing on the Behavior of $\mathrm{TiO}_{2}$ Protective Layers for Stabilization of $\mathrm{N}-\mathrm{Si} / \mathrm{TiO}_{2} / \mathrm{Ni}$ Photoanodes for Water Oxidation. ACS Appl. Mater. Interfaces 2015, 7 (28), 15189-15199. https://doi.org/10.1021/acsami.5b00379.

(54) Brongersma, H. H. Low-Energy Ion Scattering. In Characterization of Materials; Kaufmann, E. N., Ed.; Wiley, 2012; pp 2024-2044.

(55) Biesinger, M. C.; Lau, L. W. M.; Gerson, A. R.; Smart, R. S. C. Resolving Surface Chemical States in XPS Analysis of First Row Transition Metals, Oxides and Hydroxides: Sc, Ti, V, Cu and Zn. Appl. Surf. Sci. 2010, 257 (3), 887-898. https://doi.org/10.1016/j.apsusc.2010.07.086.

(56) Pouilleau, J.; Devilliers, D.; Groult, H.; Marcus, P. Surface Study of a Titanium-Based Ceramic Electrode Material by X-Ray Photoelectron Spectroscopy. J. Mater. Sci. 1997, 32 (21), 5645-5651. https://doi.org/10.1023/A:1018645112465.

(57) Gan, L.; Wu, Y.; Song, H.; Lu, C.; Zhang, S.; Li, A. Self-Doped $\mathrm{TiO}_{2}$ Nanotube Arrays for Electrochemical Mineralization of Phenols.

Chemosphere 2019, 226, 329-339.

https://doi.org/10.1016/j.chemosphere.2019.03.135.

(58) Pham, H. H.; Wang, L.-W. Oxygen Vacancy and Hole Conduction in Amorphous $\mathrm{TiO}_{2}$. Phys. Chem. Chem. Phys. 2015, 17 (1), 541-550. https://doi.org/10.1039/C4CP04209C.

(59) Deskins, N. A.; Du, J.; Rao, P. The Structural and Electronic Properties of Reduced Amorphous Titania. Phys. Chem. Chem. Phys. 2017, 19 (28), 18671-18684. https://doi.org/10.1039/C7CP02940C.

(60) Idígoras, J.; Anta, J. A.; Berger, T. Charge-Transfer Reductive in Situ Doping of Mesoporous $\mathrm{TiO}_{2}$ Photoelectrodes: Impact of Electrolyte Composition and Film Morphology. J. Phys. Chem. C 2016, 120 (49), 27882-27894. https://doi.org/10.1021/acs.jpcc.6b09926. 
(61) Berger, T.; Anta, J. A.; Morales-Flórez, V. Electrons in the Band Gap: Spectroscopic Characterization of Anatase $\mathrm{TiO}_{2}$ Nanocrystal Electrodes under Fermi Level Control. J. Phys. Chem. C 2012, 116 (21), 11444-11455. https://doi.org/10.1021/jp212436b.

(62) Lindquist, S.-E.; Lindgren, A.; Leygraf, C. Effects of Electrochemical Reduction of Polycrystalline $\mathrm{TiO}_{2}$ Photoelectrodes in Acidic Solutions. Sol. Energy Mater. 1987, 15, 367-382.

(63) Mo, L. Bin; Wang, Y.; Bai, Y.; Xiang, Q. Y.; Li, Q.; Yao, W. Q.; Wang, J. O.; Ibrahim, K.; Wang, H. H.; Wan, C. H.; et al. Hydrogen Impurity Defects in Rutile $\mathrm{TiO}_{2}$. Sci. Rep. 2015, 5, 1-7. https://doi.org/10.1038/srep17634.

(64) Marinopoulos, A. G.; Vilão, R. C.; Alberto, H. V; Gil, J. M. Electronic Structure and Migration of Interstitial Hydrogen in the Rutile Phase of $\mathrm{TiO}_{2}$. J. Phys. Condens. Matter 2018, 30 (42), 425503. https://doi.org/10.1088/1361-648X/aae0a2.

(65) Chester, P. F.; Bradhurst, D. H. Electrolytically Induced Conductivity in Rutile. Nature 1963, 199, 1056-1057.

(66) Chen, W. P.; Wang, Y.; Chan, H. L. W. Hydrogen: A Metastable Donor in Crystals Single. Appl. Phys. Lett. 2008, 112907. https://doi.org/10.1063/1.2900957.

(67) Dickens, P.; Crouch-Baker, S.; Weller, M. Hydrogen Insertion in Oxides. Solid State Ionics 1986, 18-19 (PART 1), 89-97. https://doi.org/10.1016/0167-2738(86)90092-5.

(68) Kariman, A.; Marshall, A. T. Improving the Stability of DSA Electrodes by the Addition of $\mathrm{TiO}_{2}$ Nanoparticles . J. Electrochem. Soc. 2019, 166 (8), E248-E251. https://doi.org/10.1149/2.0761908jes.

(69) Cherevko, S.; Geiger, S.; Kasian, O.; Kulyk, N.; Grote, J.-P.; Savan, A.; Shrestha, B. R.; Merzlikin, S.; Breitbach, B.; Ludwig, A.; et al. Oxygen and Hydrogen Evolution Reactions on $\mathrm{Ru}, \mathrm{RuO}_{2}$, Ir, and $\mathrm{IrO}_{2}$ Thin Film Electrodes in Acidic and Alkaline Electrolytes: A Comparative Study on Activity and Stability. Catal. Today 2016, 262, 170-180. https://doi.org/10.1016/j.cattod.2015.08.014.

(70) Cherevko, S.; Reier, T.; Zeradjanin, A. R.; Pawolek, Z.; Strasser, P.; Mayrhofer, K. J. J. Stability of Nanostructured Iridium Oxide Electrocatalysts during Oxygen Evolution Reaction in Acidic Environment. Electrochem. commun. 2014, 48, 81-85. https://doi.org/10.1016/j.elecom.2014.08.027. 
(71) Johnson, O. W.; Paek, S. H.; Deford, J. W. Diffusion of $\mathrm{H}$ and $\mathrm{D}$ in $\mathrm{TiO}_{2}$ : Suppression of Internal Fields by Isotope Exchange. J. Appl. Phys. 1975, 46 (3), 1026-1033. https://doi.org/10.1063/1.322206.

(72) Koudriachova, M. V.; de Leeuw, S. W.; Harrison, N. M. First-Principles Study of $\mathrm{H}$ Intercalation in Rutile $\mathrm{TiO}_{2}$. Phys. Rev. B 2004, 70 (16), 165421. https://doi.org/10.1103/PhysRevB.70.165421.

(73) Deadman, B. J.; Hellgardt, K.; Hii, K. K. A Colorimetric Method for Rapid and Selective Quantification of Peroxodisulfate, Peroxomonosulfate and Hydrogen Peroxide. React. Chem. Eng. 2017, 2 (4), 462-466. https://doi.org/10.1039/c7re00050b.

(74) Michaud, P. A.; Panizza, M.; Ouattara, L.; Diaco, T.; Foti, G.; Comninellis, C. Electrochemical Oxidation of Water on Synthetic Boron-Doped Diamond Thin Film Anodes. J. Appl. Electrochem. 2003, 33 (2), 151-154. https://doi.org/10.1023/A:1024084924058.

\subsection{Appendix}

\section{Text A4.1. Additional experimental information}

ICP-OES measurements: The total elemental concentrations of $\mathrm{Ir}, \mathrm{Ti}, \mathrm{Pt}, \mathrm{Ni}, \mathrm{Cu}, \mathrm{Fe}$, $\mathrm{Zn}, \mathrm{Mg}, \mathrm{Cr}, \mathrm{Sr}, \mathrm{Co}, \mathrm{Cd}, \mathrm{Mn}$ in solution were determined with ICP/OES (Perkin Elmer 8300DV). Calibration was performed by diluting a $1000 \mathrm{mg} / \mathrm{L}$ Merck ICP/OES standard solution. All the results were corrected with blank experiments. Each obtained concentration is the average of 3 measurements.

Low Energy Ion Scattering Spectroscopy (LEIS) was performed with an ION-TOF GmbH Qtac100 LEIS spectrometer with a base pressure of $2 \times 10^{-10}$ mbar. Detailed information about the setup can be found in [1]. The primary ions were normal incident on the sample surface, the scattering angle was $145^{\circ}$ and the analyzer integrated over $360^{\circ}$ azimuth.

Standard LEIS measurements were performed using a $\mathrm{He}^{+}$ion beam with an energy of $3 \mathrm{keV}$ and a beam current of typically 2-3 nA, measured with a Faraday cup. The typical ion dose density was $2 \times 10^{14}$ ions $\mathrm{cm}^{-2}$. The default measurement area was $1 \times 1 \mathrm{~mm}^{2}$. In order to achieve enhanced mass resolution for heavy elements, additional measurements were performed with $8 \mathrm{keV} \mathrm{Ar}^{+}$, using a typical ion current of $0.8 \mathrm{nA}$ and ion dose density of $1 \times 10^{14}$ ions $\cdot \mathrm{cm}^{-2}$. 
For sputter profiles a separate Ar ion gun was used. The angle of incidence was $59^{\circ}$ with respect to the surface normal. The beam settings were: $500 \mathrm{eV}$ ion energy, $2 \times 2 \mathrm{~mm}^{2}$ sputter area, typical ion current $100 \mathrm{nA}$. Spectra were recorded after cumulative dose densities of $2.5 \times 10^{15}$ ions $\mathrm{cm}^{-2}$ and $8 \times 10^{15}$ ions $\mathrm{cm}^{-2}$

Samples were cleaned from contamination (hydrocarbons due to air exposure) by sputtering with $3 \mathrm{keV} \mathrm{He}^{+}$ions from the primary beam at a dose density of $5 \times 10^{15}$ ions $\mathrm{cm}^{-2}$.

SEM images were recorded at the MESA+ NanoLab facility using a Zeiss Merlin HR-SEM with either an InLens secondary electron (InLens SE) detector or an Energy Selective Backscatter (ESB) detector.

XPS was performed at the MESA+ NanoLab facility with a Quantera SXM from Physical Electronics using monochromatic $\mathrm{Al} \mathrm{K \alpha}$ radiation $(1486.6 \mathrm{eV})$. The data was analyzed using CasaXPS software. All spectra were energy calibrated to the carbon $\mathrm{C} 1 \mathrm{~s}$ peak at $284.8 \mathrm{eV}$.

Time of Flight Secondary Ion Mass Spectrometry (ToF-SIMS) was performed with an IONTOF GmbH, (Münster, Germany) TOF.SIMS ${ }^{5}$.NCS

Depth profiling in ToF-SIMS uses a dual beam configuration with one beam for the analysis and a separate one initiating sputtering enabling access to a depth of some $\mu \mathrm{m}$. The spectrometer is in the direction of the sample normal and the two beams are coming under $45^{\circ}$ to the normal and both guns are $180^{\circ}$ against each other.

A pulsed $30 \mathrm{keV} \mathrm{Bi}^{+}$beam for acquiring the mass spectral data. $\mathrm{A} 1 \mathrm{keV} \mathrm{Cs}^{+}$beam was used for sputtering during the time the ions are drifting through the reflectron type flight tube. The sputter-raster is $300 \mu \mathrm{m} * 300 \mu \mathrm{m}$ and the analysis-raster is $50 \mu \mathrm{m} * 50 \mu \mathrm{m}$ in the center of the sputter raster. The analysis current was $2.6 \mathrm{pA}$ and the sputter current was $45 \mathrm{nA}$. The measurements were carried out in the spectroscopy mode with high mass resolution and detecting the negative secondary ions. 
a)

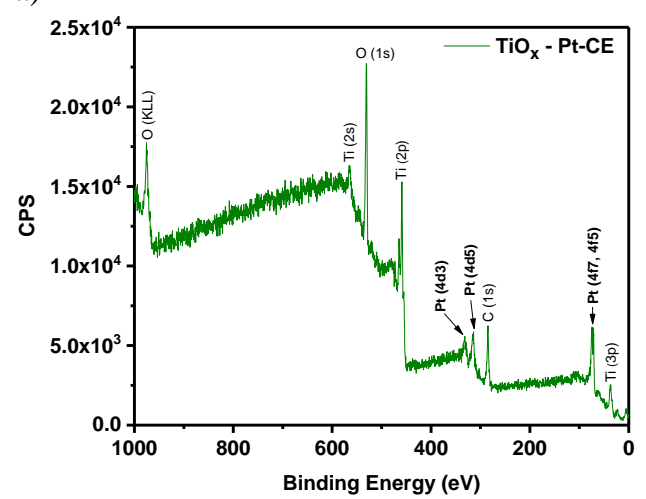

b)

c)
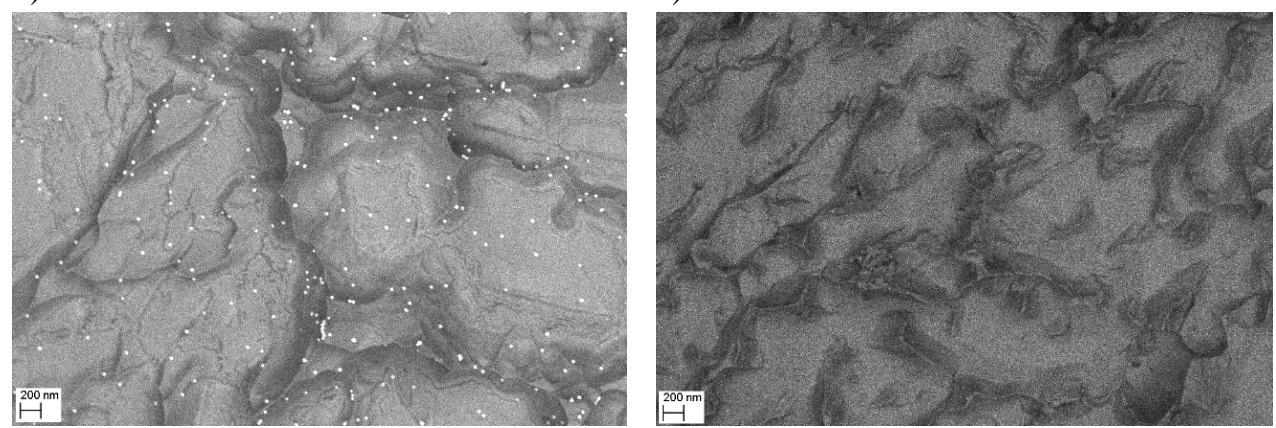

Figure A4.1. a). XPS of a $\mathrm{TiO}_{x}$ sample cathodized using a Pt-CE ( $\left.t_{c}=180 \mathrm{~min}\right)$ showing clear Pt signals. b) SEM image of a $\mathrm{TiO}_{x}$ surface prepared using Pt-CE $\left(t_{c}=120 \mathrm{~min}\right)$ showing bright Pt particles (using an energy selective backscattered (ESB) detector) c) No obvious metal particles are visible for an anodized $\mathrm{TiO}_{2}$ substrate. 
a)

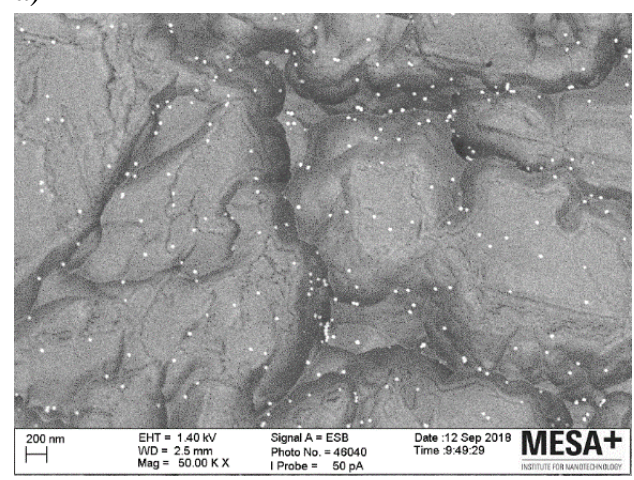

c)

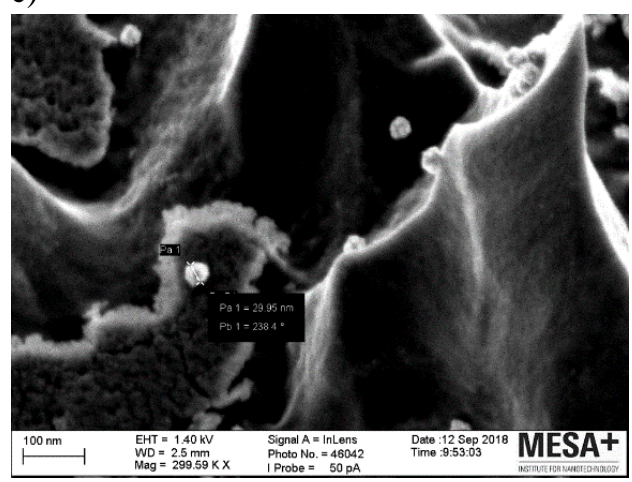

e)

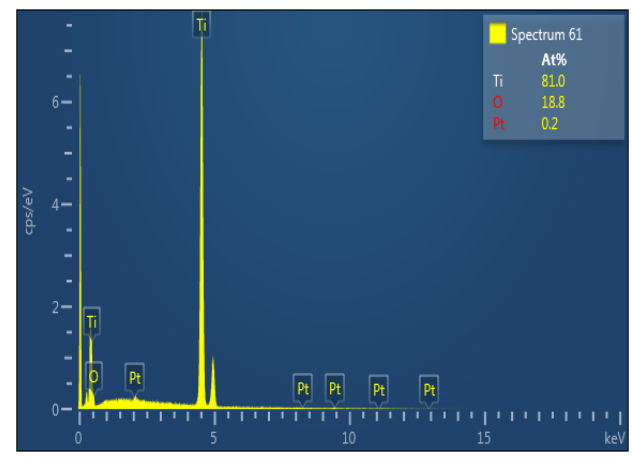

b)

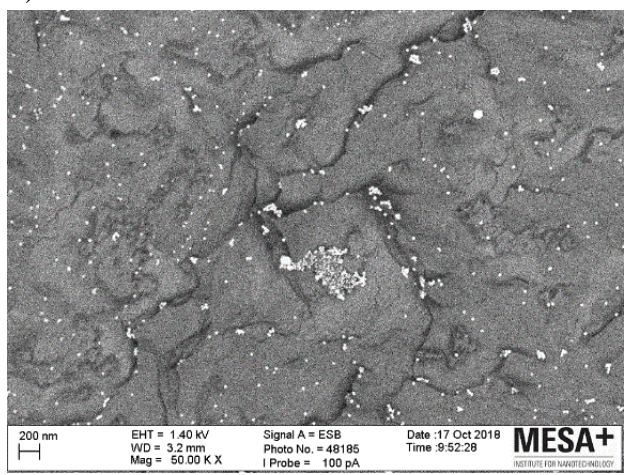

d)

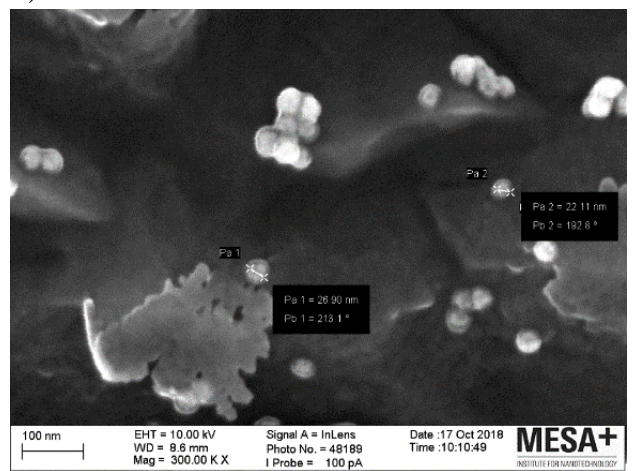

f)

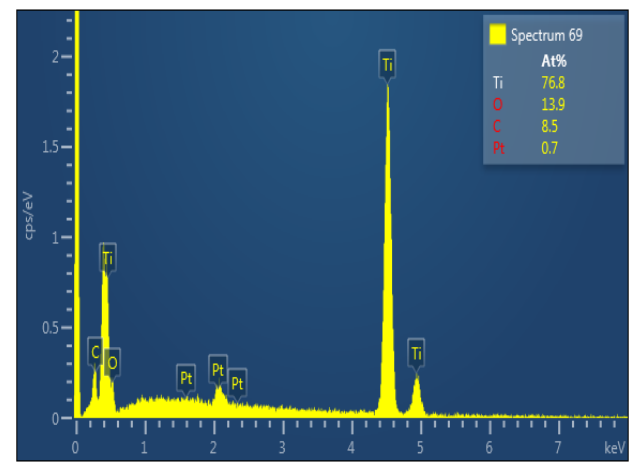

Figure A4.2. SEM images of cathodized $\mathrm{TiO}_{x}$ prepared using a Pt-CE; a \& c) $120 \mathrm{~min}$ cathodization; b \& d) 180 min cathodization. With longer cathodization time more $\mathrm{Pt}$ particles and more Pt particle clusters are visible. The size of the Pt particles is similar (between $\approx 15-30 \mathrm{~nm}$ for both cathodization times). e \&f) SEM-EDX of accumulated Pt clusters, confirming the bright spots in SEM images as Pt. 
a)

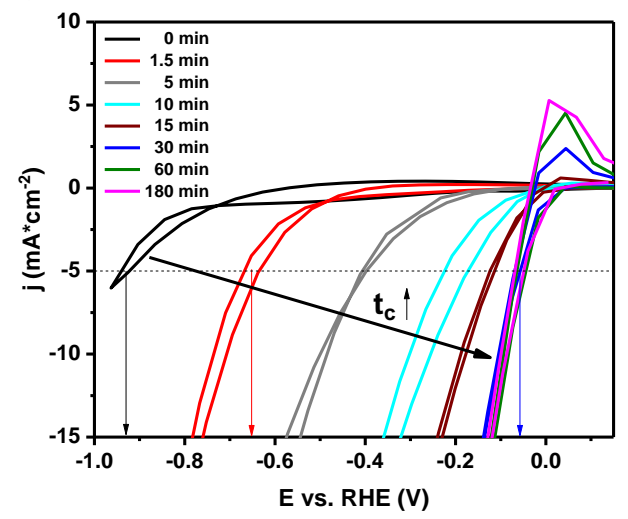

b)

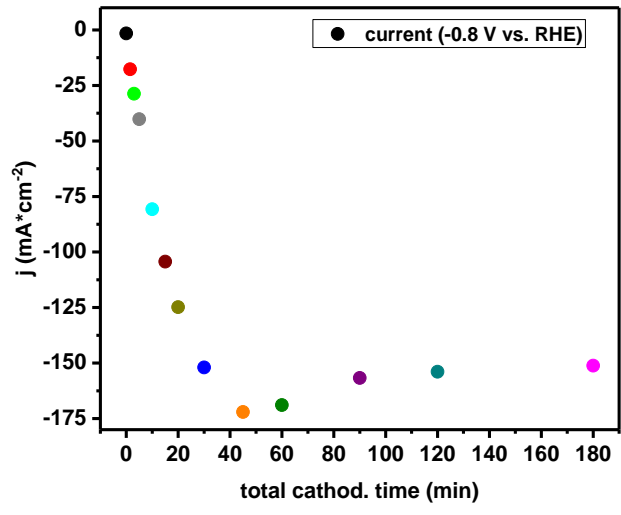

Figure A4.3. a) HER-CV of cathodized $\mathrm{TiO}_{x}$ between consecutive cathodization steps. The total cathodization time $\left(\mathrm{t}_{\mathrm{c}}\right)$ of the sample, before individual CVs were recorded, is shown in the legend ( $0 \mathrm{~min}, 1.5 \mathrm{~min}, 5 \mathrm{~min}, 10 \mathrm{~min}, 15 \mathrm{~min}, 30 \mathrm{~min}, 60 \mathrm{~min}, 180 \mathrm{~min}$ ). A Pt-CE was applied during the experiment. Geometric sample surface area was $2.54 \mathrm{~cm}^{2}$. The CVs showing the decreasing HER overpotential (@ $-5 \mathrm{~mA} \mathrm{~cm}^{-2}$, indicated with an arrow) for increasing $\mathrm{t}_{\mathrm{c}}: \mathrm{t}_{\mathrm{c}}=0 \mathrm{~min},-0.93 \mathrm{~V} ; \mathrm{t}_{\mathrm{c}}=1.5 \mathrm{~min},-0.65 \mathrm{~V} ; \mathrm{t}_{\mathrm{c}}=30 \mathrm{~min},-0.06 \mathrm{~V}$. b) Increasing $\mathrm{TiO}_{\mathrm{x}}$ HER-CV current density (@ -0.8 V vs. RHE) with increasing total cathodization time obtained during sequential cathodization using a Pt-CE. Highest current density was obtained after $45 \mathrm{~min}$ total cathodization time. No further increase of current density for longer cathodization but slight decrease, reaching a plateau after $2 \mathrm{~h}$ of total cathodization time. Cathodization and $\mathrm{CVs}$ were performed in $1 \mathrm{~mol} \mathrm{~L}^{-1} \mathrm{H}_{2} \mathrm{SO}_{4}$ electrolyte

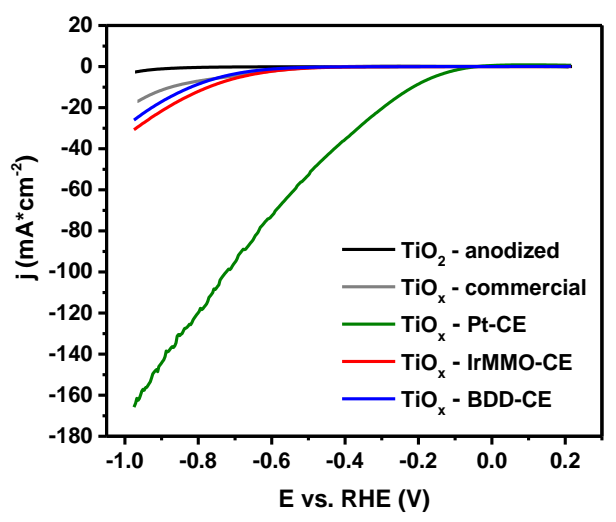

Figure A4.4. $\mathrm{CV}$ of electrochemically prepared $\mathrm{TiO}_{\mathrm{x}}$ samples after 120 min cathodization using various $\mathrm{CE}(\mathrm{Pt}, \mathrm{IrMMO}, \mathrm{BDD})$, a commercial $\mathrm{TiO}_{\mathrm{x}}$ electrode and a non-cathodized $\mathrm{TiO}_{2}$ sample (only anodized, $\mathrm{t}_{\mathrm{c}}=0 \mathrm{~min}$ ) [electrolyte $1 \mathrm{~mol} \mathrm{~L}^{-1} \mathrm{H}_{2} \mathrm{SO}_{4}$ ] showing HER activity. For a better clarity forward and backward scans were averaged 
a)

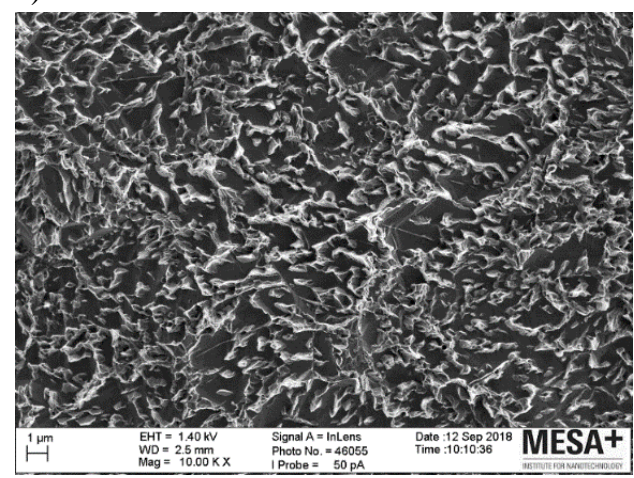

Figure A4.5. SEM images of an etched Ti substrate surface a \& b) before and c) after anodization. A rough surface is obtained after the etching pre-treatment leading to rims of less etched Ti substrate. The higher oxygen content of the anodized layer led to lower contrast in the SEM image (c) compared to the just etched sample (b). b)

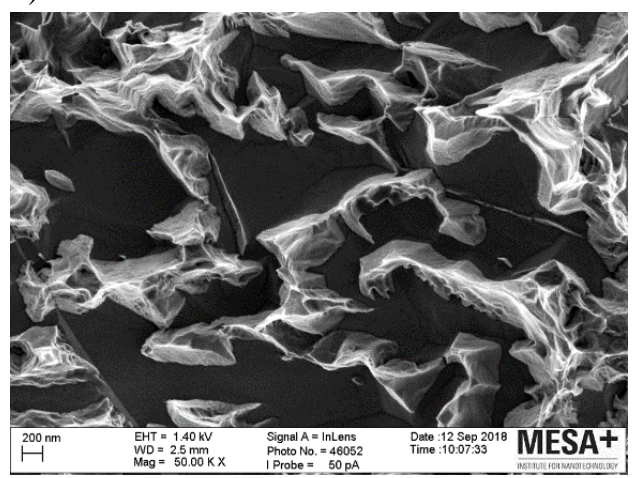

c)

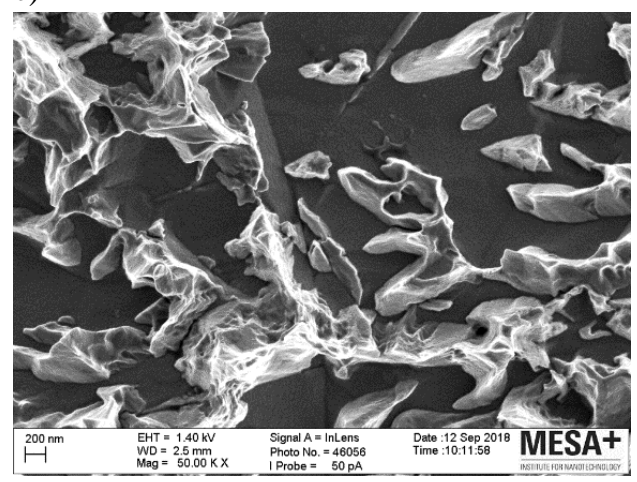

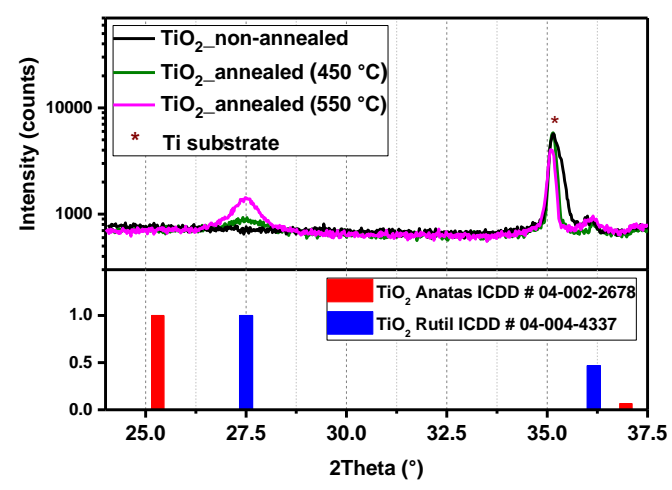

Figure A4.6. XRD of anodized $\mathrm{TiO}_{2}$ on Ti substrates. The black diffractogram shows a nonannealed sample, the green diffractogram shows an annealed sample $\left(450^{\circ} \mathrm{C}\right)$. After annealing the peak at $27.5^{\circ}{ }^{2}$ Theta indicates the presence of rutile phase (main peak corresponding to the [110] plane); the presence of anatase phase is not detected. Peaks related to the Ti substrate are indicated by an asterisk. $\mathrm{TiO}_{2}$ substrates annealed at higher temperature 
$\left(550^{\circ} \mathrm{C}\right.$, pink graph) reveals a more distinctive peak at $27.5^{0} 2$ Theta indicating the development of a higher crystallinity or thicker $\mathrm{TiO}_{2}$ layer (due to thermal growth). Peaks of substoichiometric crystalline $\mathrm{TiO}_{\mathrm{x}}$ could not be detected. XRD were measured using a Bruker D2 Phaser.

a)

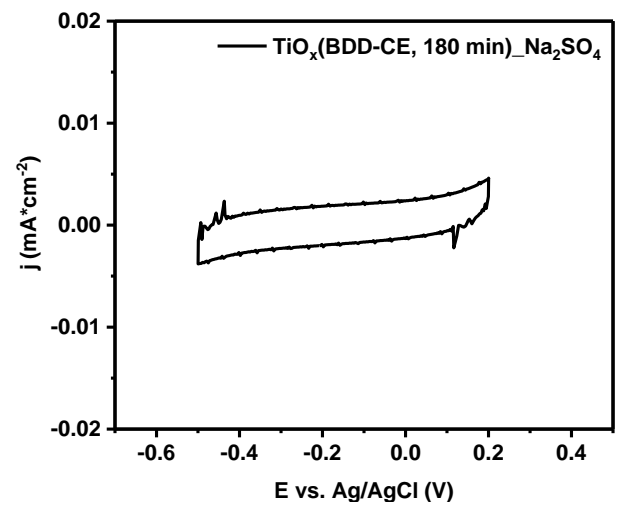

b)

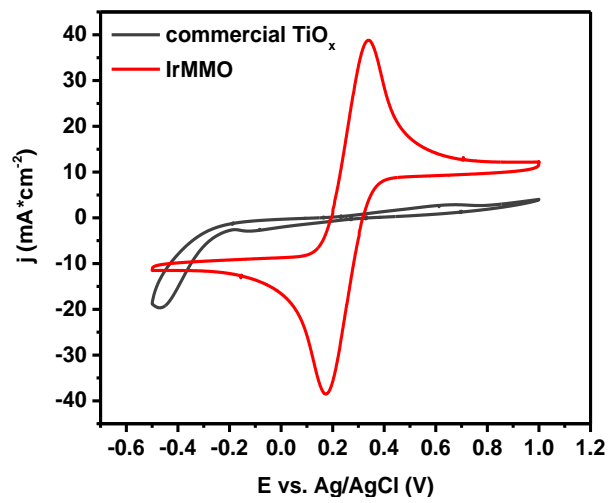

Figure A4.7. a) $\mathrm{CV}$ of a cathodized $\mathrm{TiO}_{\mathrm{x}}$ electrode (180 min, BDD-CE) in background electrolyte $\left(0.2 \mathrm{~mol} \mathrm{~L}^{-1} \mathrm{Na}_{2} \mathrm{SO}_{4}\right)$ confirming the absence of the reductive peak due to the missing $\mathrm{Fe}^{2+/ 3+}$-couple. b) $\mathrm{CV}\left(\mathrm{Fe}^{2+/ 3+}\right)$ of a commercial $\mathrm{TiO}_{\mathrm{x}}$ electrode (black) and commercial IrMMO electrode (red); for the IrMMO electrode the oxidation peak potential is $\mathrm{E}_{\mathrm{p}(\mathrm{ox})}=0.34 \mathrm{~V}$ (vs. $\mathrm{Ag} / \mathrm{AgCl}$ ) and the reduction peak potential $\mathrm{E}_{\mathrm{p}(\mathrm{red})}=0.18 \mathrm{~V}$ (vs. $\mathrm{Ag} / \mathrm{AgCl}$ ) resulting in a peak-to-peak separation of $\Delta \mathrm{E}_{\mathrm{p}}=0.16 \mathrm{~V}$.

The theoretical $\Delta \mathrm{E}_{\mathrm{p}}$ of an ideal electrochemical reversible system is $0.057 \mathrm{~V}$. The deviation of the measured $\mathrm{Fe}^{2+/ 3+}-\Delta \mathrm{E}_{\mathrm{p}}$ for the conductive IrMMO electrode compared to the theoretical value is influenced for example by reaction with residual oxygen (quasireversible electrochemical system), the iR drop (no 100\% iR drop compensation) and a non-ideal cell geometry (e.g. electrode distance). Larger peak-to-peak separation indicate electrochemical irreversible processes, which is a result of slow electron transfer kinetics at the electrode surface. [2] 
a)

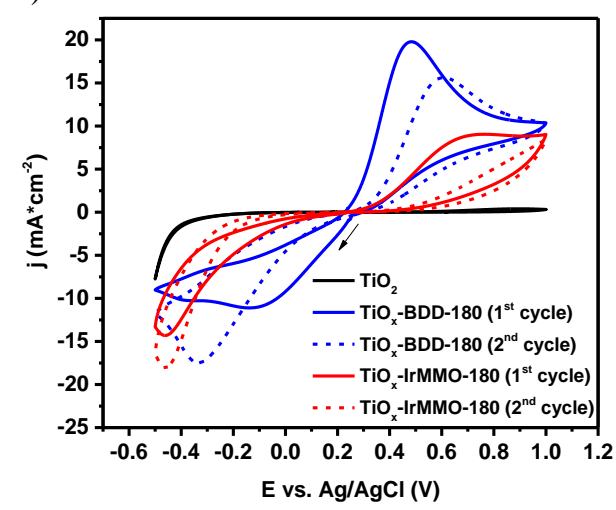

Figure A4.8. $\mathrm{TiO}_{\mathrm{x}}$ samples $\left(\mathrm{t}_{\mathrm{c}}=180 \mathrm{~min}\right)$ prepared using either a BDD-CE (blue graphs) or a IrMMO-CE (red graphs) in comparison to non-cathodized $\mathrm{TiO}_{2}$ substrates $\left(\mathrm{t}_{\mathrm{c}}=0 \mathrm{~min}\right)$. a) $\mathrm{CV}$ of $\mathrm{Fe}^{2+/ 3+}$ couple (cycle $1 \& 2$ ), b) EIS measurements (before and after CV), c) full scale EIS graphs. A clear passivation after the $1^{\text {st }} \mathrm{CV}$ cycle can be seen in the $2^{\text {nd }} \mathrm{CV}$ cycle and EIS measurement after CV. b)

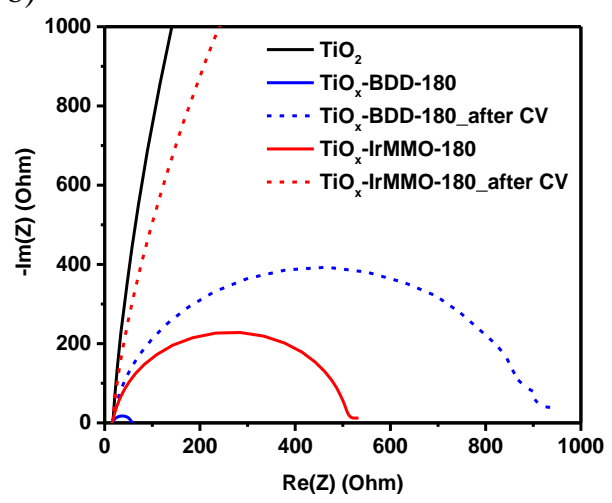

c)

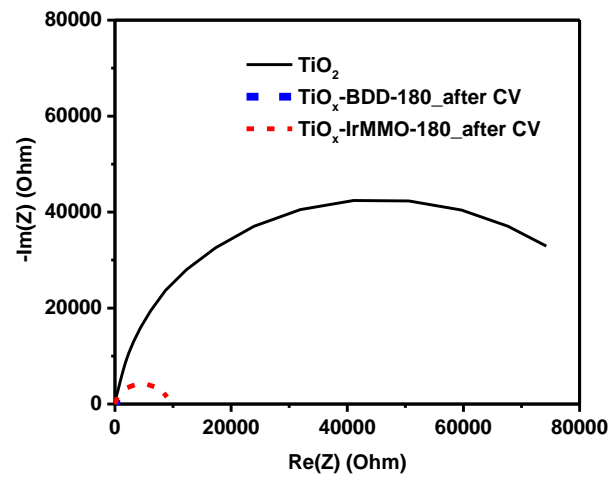


Text A4.2. Electrochemical impedance spectroscopy - model and fitted data:

Results from EIS measurements were fitted with a simplified Randles cell as equivalent circuit using ZView software. Resistor R1 models the solution resistance, Resistor R2 models the layer resistance and CPE1 models the double-layer capacitance as constant phase element. [3]

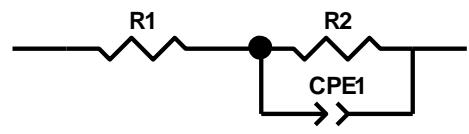

Table A4.1. Charge transfer resistance $\mathrm{R} 2$ of $\mathrm{TiO}_{\mathrm{x}}$ samples prepared under various conditions: CE used during cathodization (BDD or IrMMO), cathodization method (CP or $\mathrm{CC}$ ) and cathodization time $\left(\mathrm{t}_{\mathrm{c}}\right)$. In addition to $\mathrm{R} 2$, fitted values for the solution resistance (R1), double layer capacitance (CPE1-T), constant phase element factor (CPE1-P) and the chi-squared value of the fit are given. All potentials are reported against $\mathrm{Ag} / \mathrm{AgCl}-\mathrm{RE}$.

\begin{tabular}{|l|l|l|l|l|l|l|l|}
\hline $\mathbf{C E}$ & $\begin{array}{l}\text { cathodization } \\
\text { method }\end{array}$ & $\begin{array}{l}\mathbf{t}_{\mathbf{c}} \\
{[\mathbf{m i n}]}\end{array}$ & $\begin{array}{l}\mathbf{R} 1 \\
{[\mathbf{O h m}]}\end{array}$ & $\begin{array}{l}\mathbf{R 2} \\
{[\mathbf{O h m}]}\end{array}$ & $\begin{array}{l}\text { CPE1-T } \\
{[\mathbf{F}]}\end{array}$ & CPE1-P & $\chi^{2}$ \\
\hline- & - & 0 & 16.27 & $\mathbf{9 4 1 7 8}$ & $7.96 \mathrm{E}-06$ & 0.93484 & 0.00197 \\
\hline BDD & $\mathrm{CP}(-1 \mathrm{~V})$ & 15 & 16.92 & $\mathbf{6 5 8 9 6}$ & $1.77 \mathrm{E}-05$ & 0.95588 & 0.00063 \\
\hline BDD & $\mathrm{CP}(-1 \mathrm{~V})$ & 60 & 16.69 & $\mathbf{8 1 3 5}$ & $2.23 \mathrm{E}-05$ & 0.94712 & 0.00039 \\
\hline BDD & $\mathrm{CP}(-1 \mathrm{~V})$ & $180(\# 1)$ & 16.34 & $\mathbf{4 0 . 4 6}$ & $6.23 \mathrm{E}-05$ & 0.89372 & 0.00023 \\
\hline BDD & $\mathrm{CP}(-1 \mathrm{~V})$ & $180(\# 2)$ & 15.36 & $\mathbf{5 1 . 7 8}$ & $5.23 \mathrm{E}-05$ & 0.91064 & 0.00021 \\
\hline BDD & $\mathrm{CP}(-1 \mathrm{~V})$ & $180(\# 3)$ & 14.99 & $\mathbf{4 5 . 5 1}$ & $4.51 \mathrm{E}-05$ & 0.91852 & 0.0006 \\
\hline BDD & $\mathrm{CP}(-1 \mathrm{~V})$ & 240 & 15.19 & $\mathbf{3 2 . 0 8}$ & $6.63 \mathrm{E}-05$ & 0.91189 & 0.00015 \\
\hline BDD & $\begin{array}{l}\mathrm{CC} \\
(-5 \mathrm{~mA} \mathrm{~cm}\end{array}$ & 180 & 15.49 & $\mathbf{3 1 5}$ & $3.15 \mathrm{E}-05$ & 0.92232 & 0.00031 \\
\hline BDD & $\mathrm{CP}(-1 \mathrm{~V})$ & 180 & 15.1 & $\mathbf{4 3 9 5}$ & $2.20 \mathrm{E}-05$ & 0.95062 & 0.00039 \\
\hline IrMMO & $\mathrm{CP}(-1 \mathrm{~V})$ & 15 & 15.57 & $\mathbf{1 5 2 2 7}$ & $1.97 \mathrm{E}-05$ & 0.94866 & 0.00054 \\
\hline IrMMO & $\mathrm{CP}(-1 \mathrm{~V})$ & 60 & 16.21 & $\mathbf{5 6 8 0}$ & $2.13 \mathrm{E}-05$ & 0.94146 & 0.00024 \\
\hline IrMMO & $\mathrm{CP}(-1 \mathrm{~V})$ & 120 & 15.4 & $\mathbf{4 3 3}$ & $3.98 \mathrm{E}-05$ & 0.92093 & 0.00084 \\
\hline IrMMO & $\mathrm{CP}(-1 \mathrm{~V})$ & $180(\# 1)$ & 16.12 & $\mathbf{5 0 4}$ & $3.13 \mathrm{E}-05$ & 0.92352 & 0.00085 \\
\hline IrMMO & $\mathrm{CP}(-1 \mathrm{~V})$ & $180(\# 2)$ & 15.66 & $\mathbf{6 3 3}$ & $2.30 \mathrm{E}-05$ & 0.94135 & 0.00014 \\
\hline IrMMO & $\mathrm{CP}(-1 \mathrm{~V})$ & $180(\# 3)$ & 14.90 & $\mathbf{1 3 6 0}$ & $2.05 \mathrm{E}-05$ & 0.95268 & 0.00019 \\
\hline IrMMO & $\mathrm{CP}(-1 \mathrm{~V})$ & 240 & 14.84 & $\mathbf{4 7 7}$ & $3.04 \mathrm{E}-05$ & 0.92377 & 0.00014 \\
\hline IrMMO & $\begin{array}{l}\mathrm{CC} \\
\left(-5 \mathrm{~mA} \mathrm{~cm}{ }^{-2}\right)\end{array}$ & 180 & 15.41 & $\mathbf{1 5 9 6}$ & $1.84 \mathrm{E}-05$ & 0.94993 & 0.0001 \\
\hline IrMMO & $\begin{array}{l}\mathrm{CC} \\
(-10 \mathrm{~mA} \mathrm{~cm}\end{array}$ & 180 & 16.23 & $\mathbf{1 4 4 4}$ & $2.76 \mathrm{E}-05$ & 0.93501 & 0.00013 \\
\hline
\end{tabular}


a)

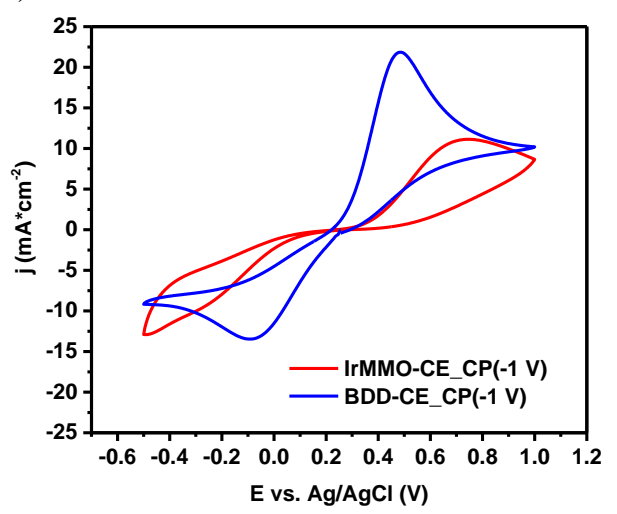

b)

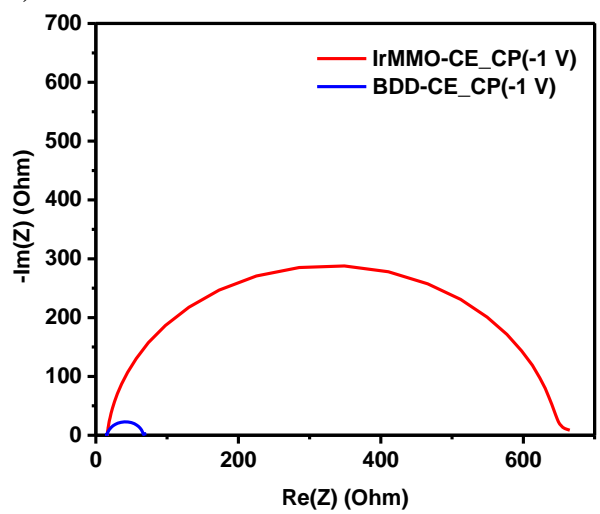

Figure A4.9. Replicates of $\mathrm{CP}$ cathodization using either IrMMO-CE or BDD-CE $\left(-1.03 \mathrm{~V}\right.$ vs $\left.\mathrm{Ag} / \mathrm{AgCl} ; \mathrm{t}_{\mathrm{c}}=180 \mathrm{~min}\right)$ confirming the superior CT properties of $\mathrm{TiO}_{\mathrm{x}}$ prepared with BDD-CE compared to IrMMO-CE; a) $\mathrm{CVs}$ of $\mathrm{Fe}^{2+/ 3+}$ couple, b) EIS measurements. Samples were characterized after XPS measurements, confirming a certain stability (even under vacuum). 
a)

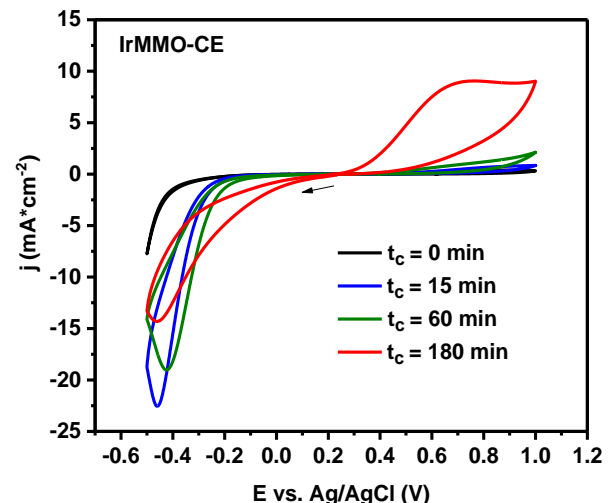

c)

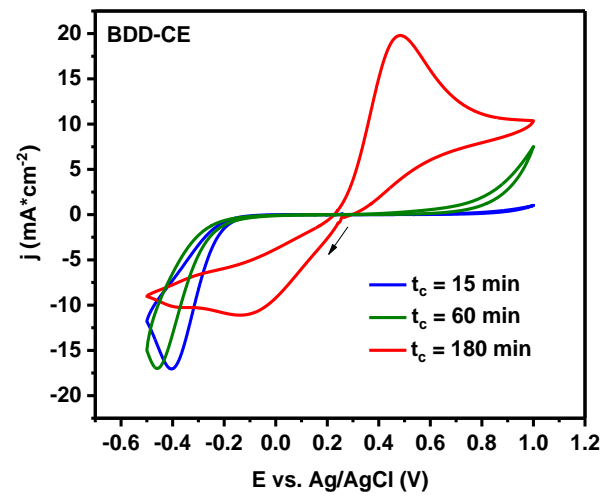

e)

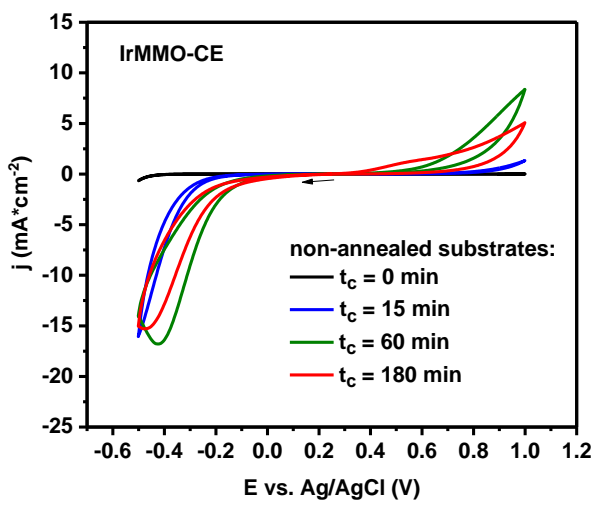

b)

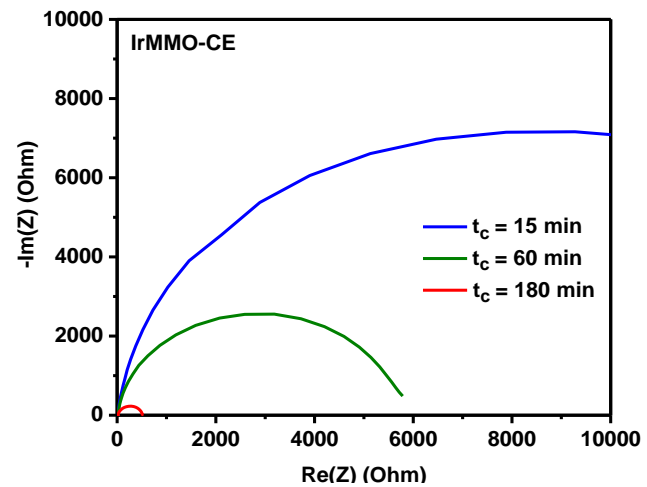

d)

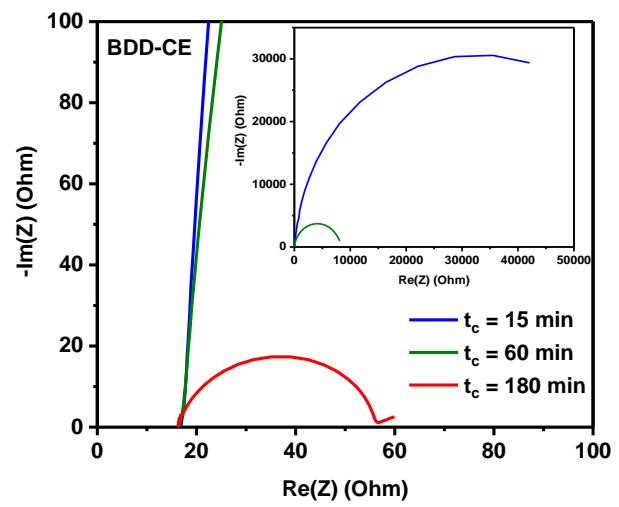

f)

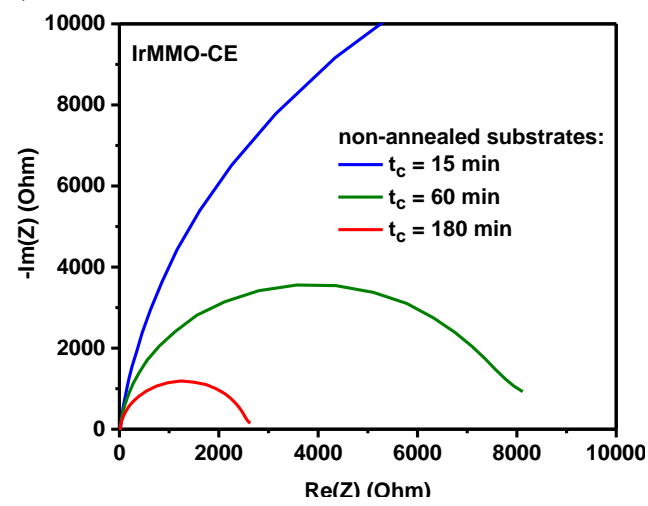

Figure A4.10. $\mathrm{TiO}_{\mathrm{x}}$ samples cathodized at various times $(0 \mathrm{~min}, 15 \mathrm{~min}, 60 \mathrm{~min}$, $180 \mathrm{~min}$ ). Left: $\mathrm{CV}$ s of $\mathrm{Fe}^{2+/ 3+}$ couple; right: EIS measurements. a \& b) IrMMO-CE; $\mathrm{c} \& \mathrm{~d}$ ) BDD-CE (inset in d: full scale spectra of $\mathrm{t}_{\mathrm{c}}=15 \mathrm{~min}$ and $60 \mathrm{~min}$ ). $\mathrm{TiO}_{\mathrm{x}}-\mathrm{IrMMO}$ 180 and $\mathrm{TiO}_{\mathrm{x}}-\mathrm{BDD}-180$ show the best $\mathrm{CT}$ properties compared to shorter $\mathrm{t}_{\mathrm{c}}$. 
e \& f) $\mathrm{TiO}_{\mathrm{x}}$-IrMMO samples prepared from non-annealed substrates showing inferior CT properties compared to samples prepared from annealed substrates ( $\mathrm{a} \& \mathrm{~b})$.

a)

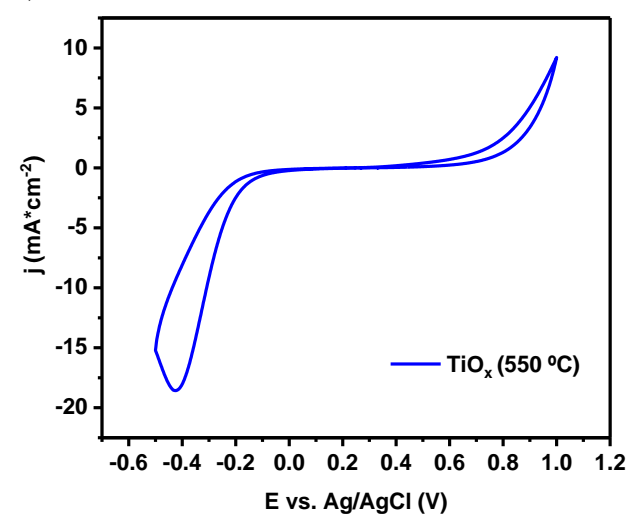

b)

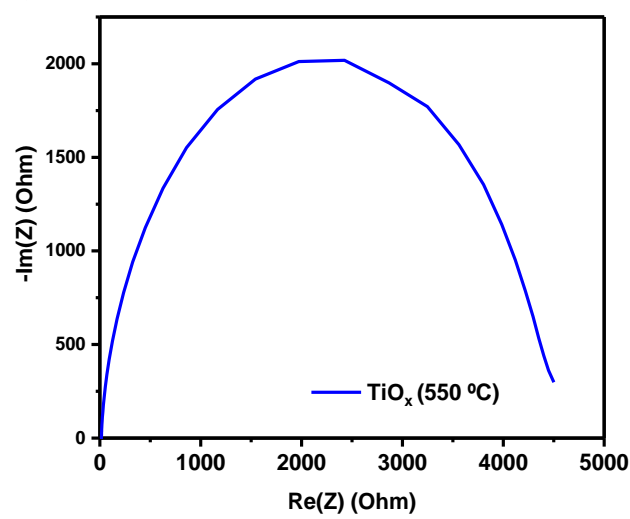

Figure A4.11. $\mathrm{TiO}_{\mathrm{x}}$ sample cathodized for $180 \mathrm{~min}$ with a BDD-CE after annealing of the $\mathrm{TiO}_{2}$ substrate at $550^{\circ} \mathrm{C}$. a) $\mathrm{CV}$ of $\mathrm{Fe}^{2+/ 3+}$ couple; b) EIS measurements. Both measurements show that the electrochemical response of the sample is far below that of samples with substrates annealed at $450^{\circ} \mathrm{C}$ (Figure A4.9).

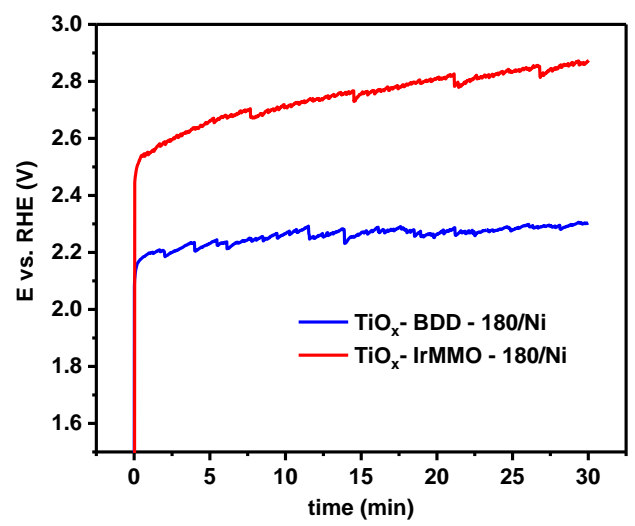

Figure A4.12. Chronopotentiometry of $\mathrm{Ni}$ functionalized $\mathrm{TiO}_{\mathrm{x}}-\mathrm{BDD}-180$ (blue graph) and $\mathrm{TiO}_{\mathrm{x}}$-IrMMO-180 (red) sample recorded in $\mathrm{NaOH}\left(0.05 \mathrm{~mol} \mathrm{~L}^{-1}\right)$ at $5 \mathrm{~mA} \mathrm{~cm}^{-2}$. The noise is induced by bubble growth and detachment. The $\mathrm{TiO}_{\mathrm{x}}-\mathrm{IrMMO}-180 / \mathrm{Ni}$ shows a clearly higher OER overpotential compared to $\mathrm{TiO}_{\mathrm{x}}-\mathrm{BDD}-180 / \mathrm{Ni}$, in agreement with $\mathrm{CV}$ studies of Figure 4.1. After $30 \mathrm{~min}$ deactivation of samples were observed (data not shown). 


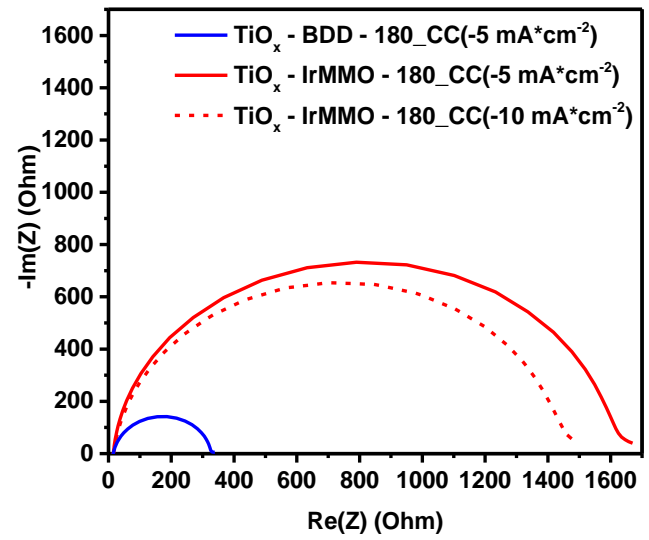

Figure A4.13. EIS of $\mathrm{TiO}_{x}$ samples prepared under constant current conditions (CC: $-5 \mathrm{~mA} \mathrm{~cm}{ }^{-2}$ or $-10 \mathrm{~mA} \mathrm{~cm}^{-2}, \mathrm{t}_{\mathrm{c}}=180 \mathrm{~min}$ ) using BDD-CE or IrMMO-CE. The $\mathrm{TiO}_{\mathrm{x}}-\mathrm{BDD}$ sample shows superior electrochemical CT properties compared to the $\mathrm{TiO}_{\mathrm{x}}$-IrMMO samples

\section{Text A4.3. Electrochemical active surface area (ECSA) determination}

According to Nayak et al. [4]

$$
\frac{I_{a}-I_{c}}{2}=C_{d l} * v
$$

$\mathrm{I}_{\mathrm{a}}$ : anodic plateau current at a given potential $[\mathrm{A}]$

$\mathrm{I}_{\mathrm{c}}$ : cathodic plateau current at a given potential $[\mathrm{A}]$

$\mathrm{v}$ : scan rate $\left[\mathrm{V} \mathrm{s}^{-1}\right]$

$\mathrm{C}_{\mathrm{dl}}$ : double layer capacitance $[\mathrm{F}]$

a)

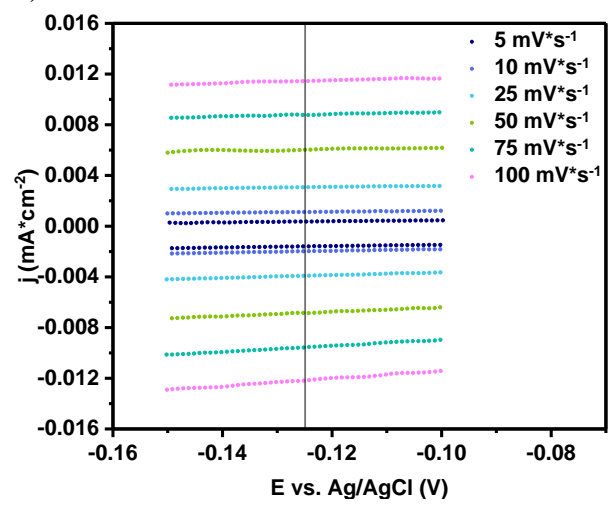

b)

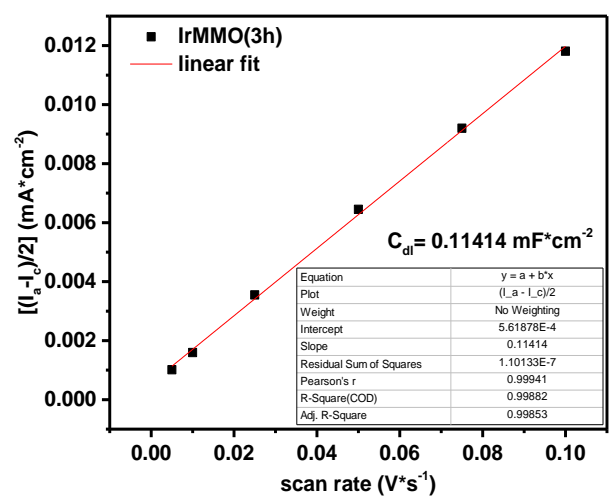


c)

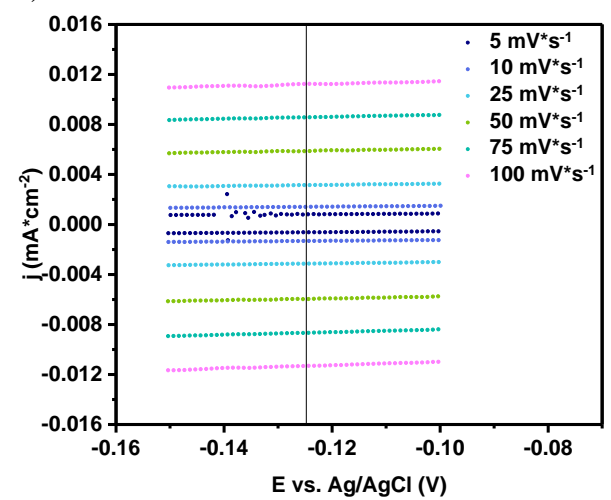

e)

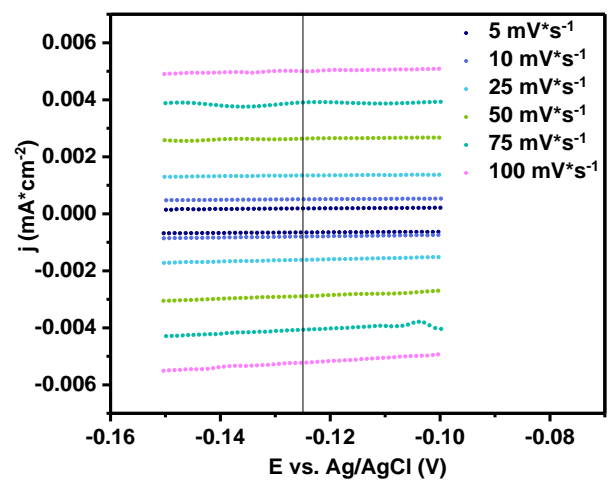

d)

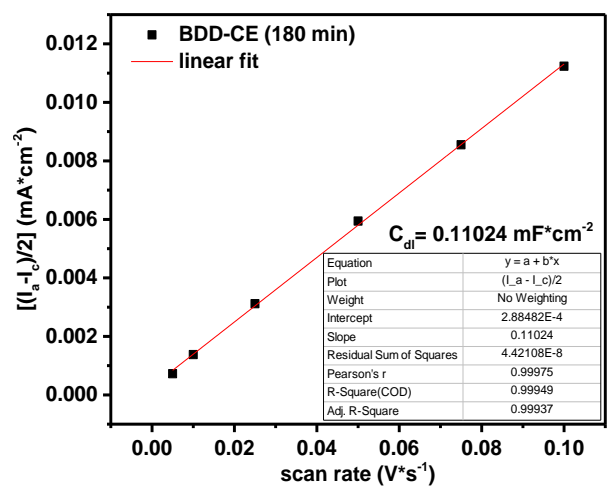

f)

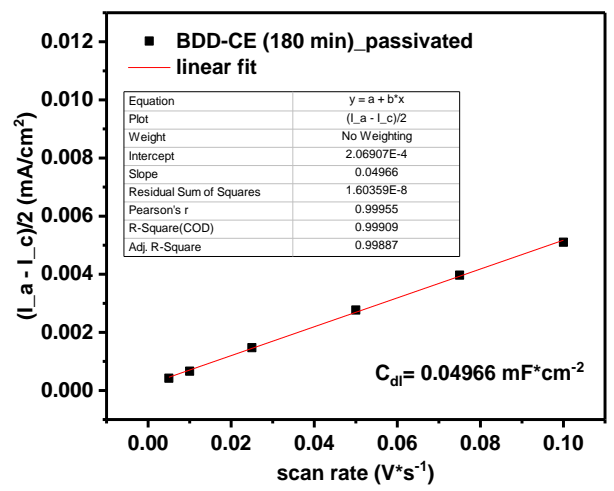

Figure A4.14. Determination of the electrochemical active surface area (ECSA) via double layer capacitance $\left(\mathrm{C}_{\mathrm{dl}}\right)$. The potential range of a non-faradaic $\mathrm{CV}$ region was recorded in background electrolyte $\left[0.2 \mathrm{~mol} \mathrm{~L}^{-1} \mathrm{Na}_{2} \mathrm{SO}_{4}\right]$ at various scan rates $(5,10,25$, $50,75,100 \mathrm{mV} \mathrm{s}^{-1}$ ) showing $\mathrm{TiO}_{\mathrm{x}}$ samples cathodized for $180 \mathrm{~min}$ with a) IrMMO-CE, c) BDD-CE, e) BDD-CE (measurement after sample passivation). ( $\left.\mathrm{I}_{\mathrm{a}}-\mathrm{I}_{\mathrm{c}}\right) / 2$ vs. scan rate plots of $\mathrm{TiO}_{\mathrm{x}}$ samples cathodized for $180 \mathrm{~min}$ with b) IrMMO-CE, d) BDD-CE, f) BDDCE (after sample passivation). The slope of the linear fits corresponds to the $C_{d l}$ per geometric surface area as a measure for the ECSA (per geometric surface area). $I_{a}$ and $I_{c}$ were collected at $-0.125 \mathrm{~V}$ vs. $\mathrm{Ag} / \mathrm{AgCl}$ along the vertical line (figure a, c \& e). All samples were etched before anodization and annealed before cathodization. The similar capacitance of samples cathodized with IrMMO-CE (b) and BDD-CE (d) indicates similar ECSA of the prepared $\mathrm{TiO}_{x}$. The passivated sample (e \& f) was measured after $\mathrm{Fe}^{2+/ 3+_{-}}$ CVs. The reduced $\mathrm{C}_{\mathrm{dl}}$ can be explained by a lower ECSA due to passivation observed during the CVs. 


\section{Text A4.4. XPS analysis}

The carbon content of cathodized $\mathrm{TiO}_{\mathrm{x}}$ samples (Figure A4.15) was between 7-12\%, with higher contents found on samples cathodized with IrMMO-CE. This fact shows that the detected carbon is arising from adventitious carbon and samples prepared with BDD-CE are not extraordinarily contaminated with carbon from the BDD-CE, which is also in agreement with observations from LEIS measurements; excluding carbon as reason for differences in electrochemical behavior.

Detected sulfate (1-3\%) comes from the $\mathrm{H}_{2} \mathrm{SO}_{4}$ electrolyte. The highest value (3\%) was found on $\mathrm{TiO}_{x}$ cathodized with IrMMO-CE (CP cathodization), which can be explained by the highest current densities obtained during cathodization leading to slightly more sulfate deposition. Since the sulfate concentration of samples prepared by BDD (CP and CC) and IrMMO (CC) samples were similar, sulfur can be excluded as reason for the observed differences in the CT properties. On all samples a small $\mathrm{N}$ content was detected $(<1 \%)$.

XPS data analysis was performed in accordance to Biesinger et al. [5]. 
a)

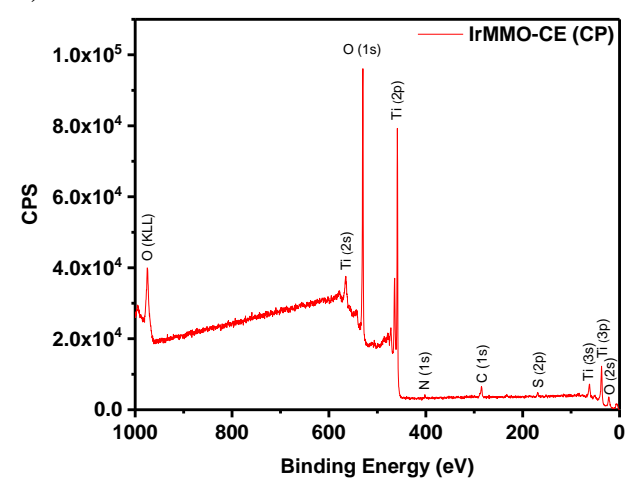

c)

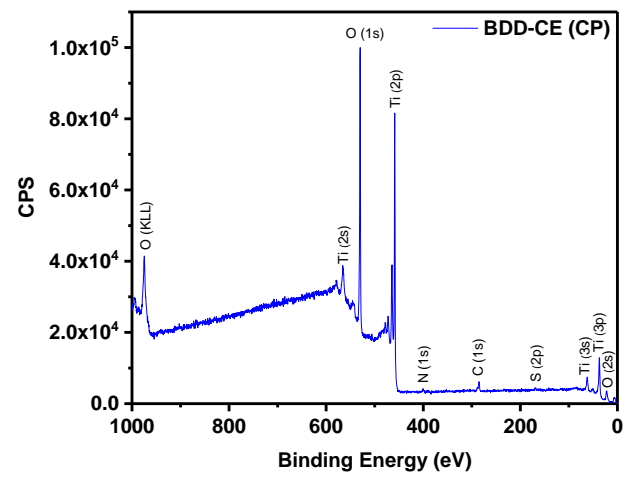

b)

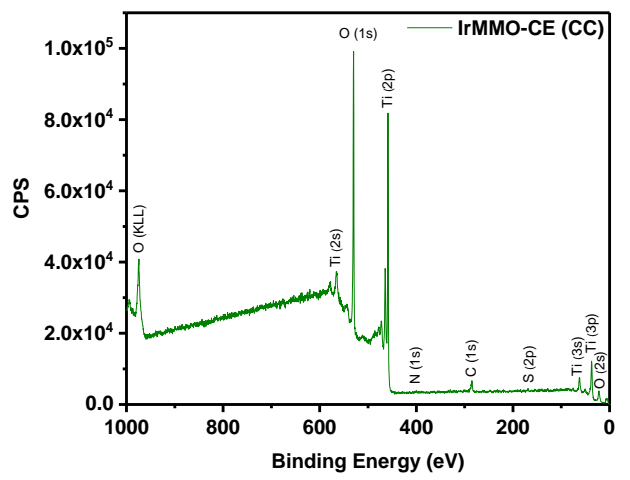

d)

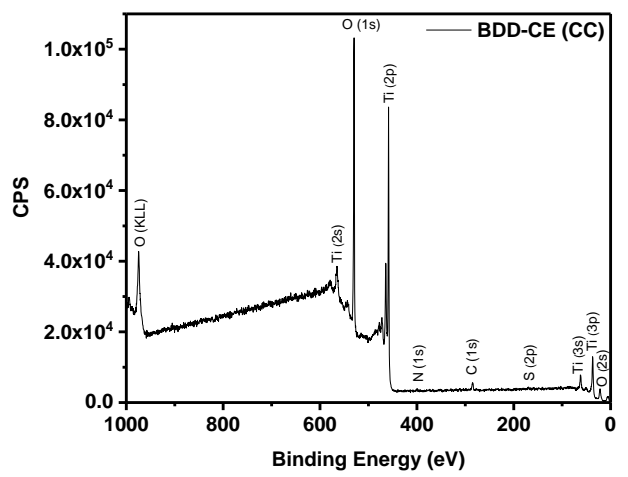

Figure A4.15. XPS survey spectra of $\mathrm{TiO}_{x}$ samples prepared from annealed $\mathrm{TiO}_{2}$ substrates cathodized for 180 min either under constant potential conditions (CP: $-1.03 \mathrm{~V}$ vs. $\mathrm{Ag} / \mathrm{AgCl}$; $\&$ c) or constant current conditions ( $\mathrm{CC}:-5 \mathrm{~mA} \mathrm{~cm}{ }^{-2}$; b \& d) with IrMMO$\mathrm{CE}(\mathrm{a} \& \mathrm{~b})$ or BDD-CE (c \& d). The survey spectra reveal no obvious differences between the samples. 
a)

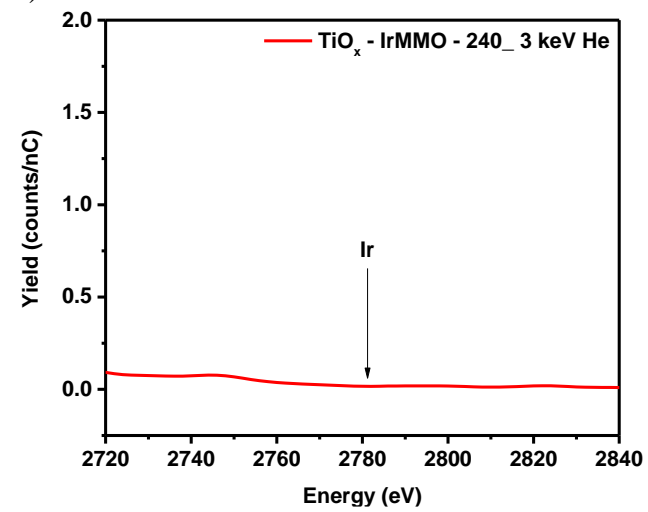

b)

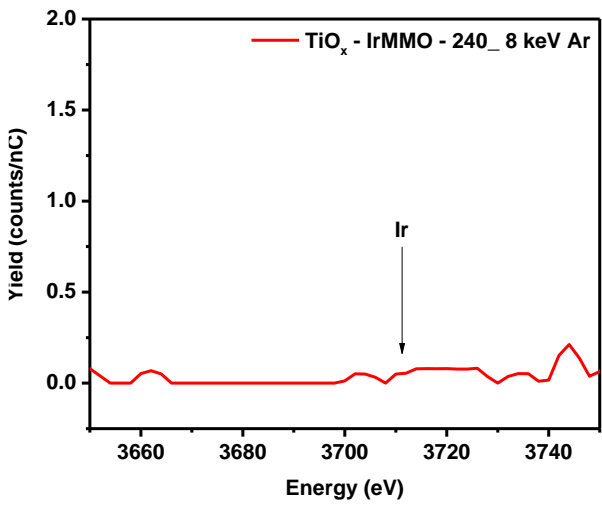

Figure A4.16. LEIS spectra of $\mathrm{TiO}_{\mathrm{x}}$-IrMMO-240 sample recorded using a) $3 \mathrm{keV} \mathrm{He}$ and b) $8 \mathrm{keV}$ Ar. No clear signals for Ir can be observed (indicated by the arrow; graphs only show enlarged section of Ir scattering energies). 
a)

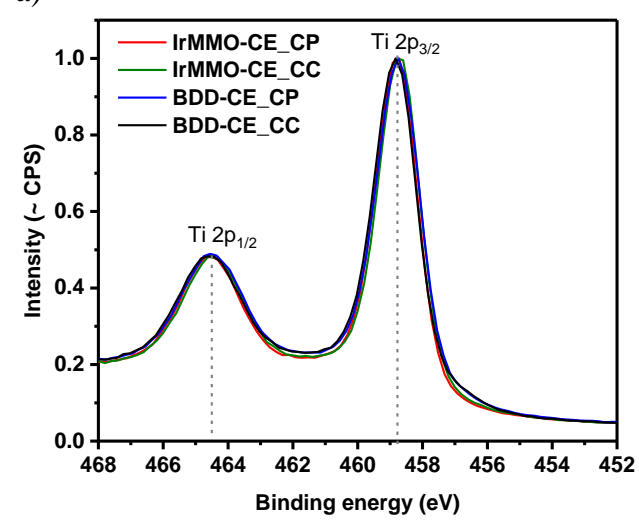

c)

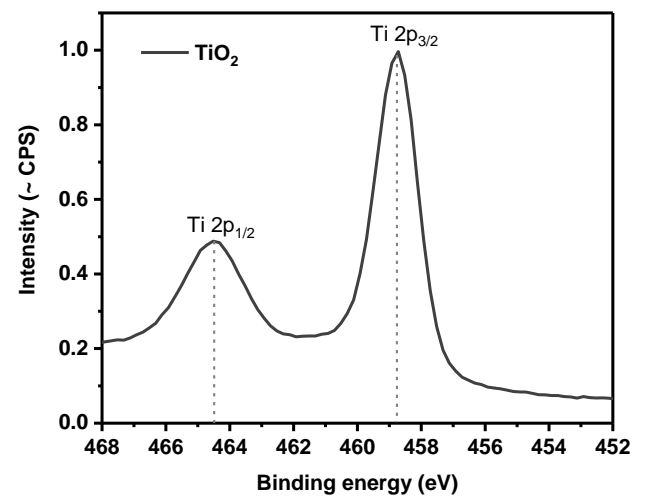

b)

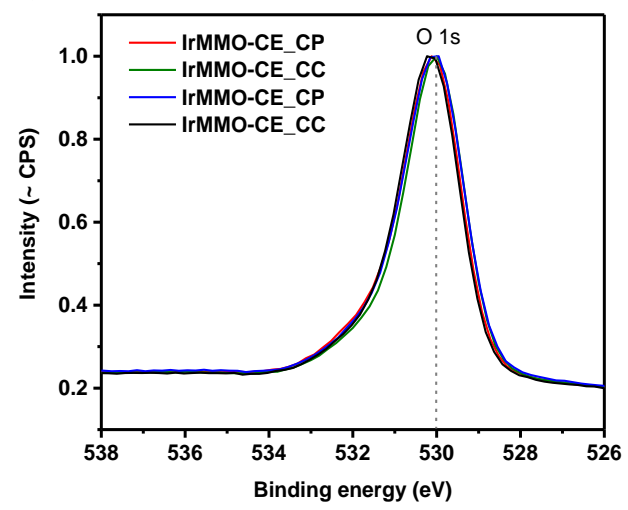

d)

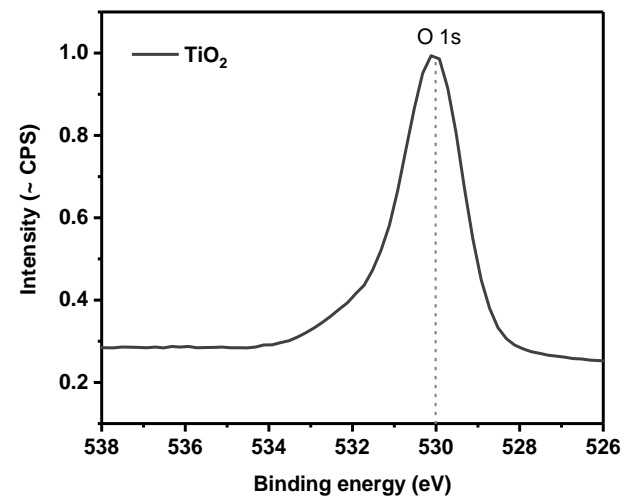

Figure A4.17. XPS core spectra of the Ti 2p peak (left: a \& c) and O 1s peak (right: b \& d). a \& b) $\mathrm{TiO}_{\mathrm{x}}$ samples prepared from annealed substrates under various cathodization conditions $\left(\mathrm{t}_{\mathrm{c}}=180 \mathrm{~min}\right.$; IrMMO-CE or BDD-CE; CP[-1.03 V vs. $\left.\mathrm{Ag} / \mathrm{AgCl}\right]$ or $\mathrm{CC}$ [-5 $\left.\mathrm{mA} \mathrm{cm}^{-2}\right]$ cathodization). $\left.\mathrm{c} \& \mathrm{~d}\right) \mathrm{TiO}_{2}$ substrates $\left(\mathrm{t}_{\mathrm{c}}=0 \mathrm{~min}\right)$. No clear differences between various cathodized $\mathrm{TiO}_{x}$ samples and non-cathodized $\mathrm{TiO}_{2}$ substrate can be observed, revealing similar chemical composition of the surfaces. The predominant $\mathrm{Ti}$ oxidation state is $+\mathrm{IV}$, as shown by identical binding energies $(\mathrm{B} . \mathrm{E} .=458.8 \mathrm{eV}$ ) of the $\mathrm{Ti}$ $2 \mathrm{p}_{3 / 2}$ peaks and the oxygen signals are dominated by lattice oxide (peak at $530.0 \mathrm{eV}$ B.E.) in good agreement with Biesinger et al. [5] 
a)

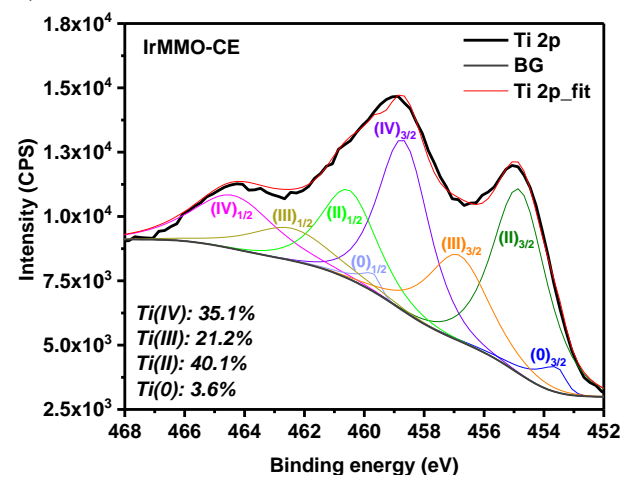

c)

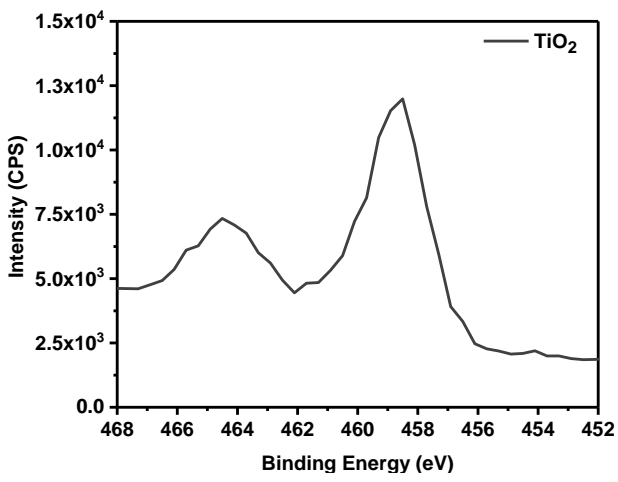

b)

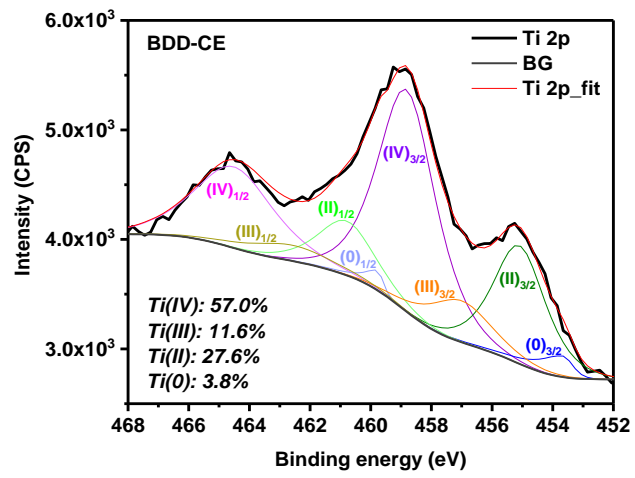

Figure A4.18. XPS core spectra and fit of the $\mathrm{Ti} 2 \mathrm{p}$ peak of amorphous $\mathrm{TiO}_{\mathrm{x}}$ samples (non-annealed) prepared under $\mathrm{CP}$ conditions [-1.03 V vs. $\left.\mathrm{Ag} / \mathrm{AgCl}, \mathrm{t}_{\mathrm{c}}=180 \mathrm{~min}\right]$. The spectra show a clear presence of $\mathrm{Ti}^{3+}$ (B.E. $457.0 \mathrm{eV}$ ), $\mathrm{Ti}^{2+}$ (B.E. $454.9 \mathrm{eV}$ ) and $\mathrm{Ti}^{0}$ (B.E. $453.7 \mathrm{eV}$ ) defects formed for cathodized samples using a) IrMMO-CE or b) BDD-CE compared to c) non-cathodized, amorphous $\mathrm{TiO}_{2}$ substrate. $\mathrm{TiO}_{\mathrm{x}}$ cathodized with $\mathrm{IrMMO}-$ CE reveal higher content of substoichiometric doping, which can be explained by higher current densities obtained during cathodization with IrMMO-CE leading to a higher degree of reduction. 
Table A4.2. ICP-OES analysis of the electrolyte before (blank) and after cathodization using either IrMMO or BDD-CE. The blank measurement is an average of two individual blank samples. The detection limit (D.L.) was $0.01 \mathrm{mg} \mathrm{L}^{-1}$. Wavelengths of detection: $\operatorname{Ir}(205.222 \mathrm{~nm}), \operatorname{Ag}(338.289 \mathrm{~nm})$, Ti $(368.510 \mathrm{~nm}), \mathrm{Cu}(213.597 ; 324.752 ; 327.393 \mathrm{~nm})$, $\mathrm{Fe}(259.939 \mathrm{~nm}), \mathrm{Zn}(206.200 \mathrm{~nm})$. All values are an average of triplicate measurements. Ag, $\mathrm{Ni}, \mathrm{Mg}, \mathrm{Cr}, \mathrm{Sr}, \mathrm{Co}, \mathrm{Cd}, \mathrm{Mn}$ were below the D.L.

\begin{tabular}{|c|c|c|c|c|c|}
\hline Sample & $\begin{array}{c}\mathrm{Ir} \\
{\left[\mathrm{mg} \mathrm{L}^{-1}\right]}\end{array}$ & $\begin{array}{c}\mathrm{Ti} \\
{\left[\mathrm{mg} \mathrm{L}^{-1}\right]}\end{array}$ & $\begin{array}{c}\mathrm{Cu} \\
{\left[\mathrm{mg} \mathrm{L}^{-1}\right]}\end{array}$ & $\begin{array}{c}\mathrm{Fe} \\
{\left[\mathrm{mg} \mathrm{L}^{-1}\right]}\end{array}$ & $\begin{array}{c}\mathrm{Zn} \\
{\left[\mathrm{mg} \mathrm{L}^{-1}\right]}\end{array}$ \\
\hline Blank $\left(\mathrm{H}_{2} \mathrm{SO}_{4}\right)$ & < D.L. & 0.03 & 0.04 & 0.02 & 0.02 \\
\hline $\begin{array}{c}\text { IrMMO- } \\
\text { CE180 min }\end{array}$ & < D.L. & 0.33 & 0.06 & 0.03 & 0.03 \\
\hline $\begin{array}{c}\text { IrMMO-CE } \\
240 \mathrm{~min}\end{array}$ & < D.L. & 0.39 & 0.08 & 0.02 & 0.04 \\
\hline $\begin{array}{c}\text { BDD-CE } \\
180 \mathrm{~min}\end{array}$ & < D.L. & 0.27 & 0.02 & 0.02 & 0.02 \\
\hline $\begin{array}{c}\text { BDD-CE } \\
240 \mathrm{~min}\end{array}$ & < D.L. & 0.32 & 0.03 & 0.02 & 0.02 \\
\hline
\end{tabular}

\section{References Appendix}

[1] H. H. Brongersma, Characterization of Materials (John Wiley \& Sons, Inc., 2012)

[2] Elgrishi,N., Rountree, K.J., McCarthy, B.D., Rountree, E.S., Eisenhart, T.T. and Dempsey, J.L., J.Chem.Educ.,95,2018,197, A practical beginner's guide to cyclic voltammetry

[3] Siddiqi, G.; Luo, Z.; Xie, Y.; Pan, Z.; Zhu, Q.; Röhr, J. A.; Cha, J. J.; Hu, S. Stable Water Oxidation in Acid Using Manganese-Modified TiO 2 Protective Coatings. ACS Appl. Mater. Interfaces 2018, 10 (22), 18805-18815

[4] Nayak,S and Chaplin, B, Electrochim.Acta, 263, 2018, 299, Fabrication and characterization of porous, conductive, monolithic $\mathrm{Ti}_{4} \mathrm{O}_{7}$ electrodes

[5] Biesinger, M.C., Lau, L.W.M, Gerson, A.R. and Smart, R.St.C., Appl. Surface Science, 257,2010,887, Resolving surface chemical states in XPS analysis of first row transition metals, oxides and hydroxides: $\mathrm{Sc}, \mathrm{Ti}, \mathrm{V}, \mathrm{Cu}$ and $\mathrm{Zn}$. 


\section{Chapter 5}

\section{Influence of Niobium on the charge transfer properties, lifetime and recovery of electrochemically reduced $\mathrm{TiO}_{\mathrm{x}}$}

Doping of $\mathrm{TiO}_{2}$ with $\mathrm{Nb}$ is a promising way to increase the electrical conductivity of $\mathrm{TiO}_{2}$, as requirement to be used in electrochemical applications, e.g. as electrode (substrate) material for electrochemical wastewater treatment. Moreover, reductive treatment of $\mathrm{TiO}_{2}: \mathrm{Nb}$ has been suggested to increase the conductivity. In this chapter the electrochemical reductive treatment of $\mathrm{TiO}_{2}: \mathrm{Nb}$ is evaluated. The influence of $\mathrm{Nb}$ on the cathodization procedure and the resulting charge transfer properties of electrochemically reduced $\mathrm{TiO}_{\mathrm{x}}: \mathrm{Nb}$ is discussed. For comparison, $\mathrm{Nb}$ free $\mathrm{TiO}_{x}$ was prepared under identical conditions. Charge transfer properties were characterized by ferrocyanide/ferricyanide cyclic voltammetry and electrochemical impedance spectroscopy. For both materials enhanced charge transfer properties were obtained after cathodization; however, inferior charge transfer was observed for $\mathrm{TiO}_{\mathrm{x}}: \mathrm{Nb}$. XPS measurements revealed the absence of $\mathrm{Nb}^{<5+}$ and/or $\mathrm{Ti}^{<4+}$ after cathodization, indicating $\mathrm{H}$-doping and proton intercalation as main doping mechanism responsible for the enhanced charge transfer properties after cathodization. It is shown that the $\mathrm{Nb}$ doped $\mathrm{TiO}_{2}$ substrate favors hydrogen evolution during the cathodization, likely resulting in inferior proton doping explaining the differences in observed charge transfer properties compared to $\mathrm{Nb}$ free $\mathrm{TiO}_{\mathrm{x}}$. In addition, the effect of $\mathrm{Nb}$ on the stability under anodic conditions was studied. Chronopotentiometry in $\mathrm{Na}_{2} \mathrm{SO}_{4}$ electrolyte showed a beneficial effect of $\mathrm{Nb}$ on the stability leading to a longer electrode lifetime. Using polarization switch after passivation, the recovery of charge transfer properties was characterized. $\mathrm{Nb}$ free $\mathrm{TiO}_{\mathrm{x}}$ showed superior recovery due to the absence of $\mathrm{Nb}$. 


\subsection{Introduction}

Requirements for electrodes used in water treatment are diverse. Besides high mineralization rates, a low price, non-toxicity and electrode stability are of high importance. Moreover, in the case of electrode passivation regeneration of the electrodes is desirable to enhance the lifetime. ${ }^{1,2}$ In the previous chapter (Chapter 4) the electrochemical doping of $\mathrm{TiO}_{2}$ electrodes has been discussed; however, the obtained stability is insufficient for application under oxidative conditions. Another approach to enhance the electrical conductivity of $\mathrm{TiO}_{2}$ is doping with aliovalent ions. ${ }^{3}$ Especially, doping with Niobium has been described as promising, ${ }^{4-6}$ for example in the context of optoelectronics such as transparent conductive oxides, ${ }^{4,6,7}$ for $\mathrm{DSSC}^{8,9}$ or as electrode support material. ${ }^{10-12}$

Besides the enhanced conductivity, operation of $\mathrm{TiO}_{2}: \mathrm{Nb}$ electrodes under anodic conditions have been reported. For example, during PEC water splitting ${ }^{13-15}$ or as electrode (support) material for fuel cell applications, ${ }^{10,16,17}$ water electrolysis ${ }^{12}$ or for water treatment. ${ }^{18-20}$. In addition, the passivation of $\mathrm{TiO}_{2}: \mathrm{Nb}$ electrodes has been proposed to be reversible. ${ }^{16}$ However, information about the reversibility of $\mathrm{TiO}_{2}: \mathrm{Nb}$ electrodes and application for electrochemical water treatment is limited. ${ }^{16,19-22}$

In general, the electronic structure of $\mathrm{TiO}_{2}$ is influenced by $\mathrm{Nb}$ doping. In $\mathrm{TiO}_{2}: \mathrm{Nb}$ the Fermi-level is shifted towards the unoccupied conduction band (corresponding mainly to Ti3d-orbitals), thereby inducing electrical conductivity in the semiconductor. ${ }^{23,24}$ The pentavalent $\mathrm{Nb}$ ion is substituting tetravalent $\mathrm{Ti}$ cations. Possible mechanisms for charge compensation are the formation of $\mathrm{Ti}^{3+}$ defects (per $\mathrm{Nb}^{5+}$ ), formation of Ti vacancies (per four $\mathrm{Nb}^{5+}$ ) or the formation of $\mathrm{Nb}^{4+}$ according to the following Kröger-Vink notations (Eq. 5.1-5.3): ${ }^{23}$

$$
\begin{gathered}
\frac{1}{2} N b_{2} O_{5}+T i_{T i}^{x} \rightarrow N b_{T i}^{\cdot}+T i_{T i}^{\prime}+\frac{5}{4} O_{2} \\
\frac{1}{2} N b_{2} O_{5}+T i_{T i}^{x} \rightarrow N b_{T i}^{\cdot}+\frac{1}{4} V_{T i}^{\prime \prime \prime \prime}+T i O_{2}+\frac{1}{4} O_{2} \\
N b O_{2}+T i_{T i}^{x} \rightarrow N b_{T i}^{x}+T i O_{2}
\end{gathered}
$$

The mechanism depends strongly on the preparation method and conditions, such as dopant concentration, annealing temperature, chemical environment and oxygen 
partial pressure..$^{23,25,26}$ For example, $\mathrm{Nb}^{5+}$ and $\mathrm{Ti}^{4+}$ have been identified as main valence states in air annealed $\mathrm{TiO}_{2}: \mathrm{Nb}$ and charge compensation was attributed to the formation of $\mathrm{Ti}$ vacancies; ${ }^{23,26}$ however, for $\mathrm{Nb} \geq 10$ at $\%$ also $\mathrm{Ti}^{3+}$ formation has been observed. ${ }^{27}$ In contrast, $\mathrm{TiO}_{2}: \mathrm{Nb}$ ceramics annealed under vacuum, starting from $\mathrm{NbO}_{2}$ precursors, led to $\mathrm{Nb}^{5+}$ formation and charge compensation by $\mathrm{Ti}^{3+}{ }^{25}$ and reductive annealing in hydrogen atmosphere resulted in the formation of $\mathrm{Ti}^{3+}$ and $\mathrm{Nb}^{4+} .{ }^{11}$ Particularly, an increase in the electrical conductivity of $\mathrm{TiO}_{2}: \mathrm{Nb}$ has been attributed to the formation of tetravalent $\mathrm{Nb}$ during reductive annealing, because the remaining single $\mathrm{d}$-valence electrons enable strong n-type doping. Thus $\mathrm{Nb}^{4+}$ is believed to be the favored oxidation state to achieve high electrical conductivity. ${ }^{19,21}$

For $\mathrm{TiO}_{2}: \mathrm{Nb}$ electrode substrates (prepared via vacuum annealing) a higher stability under OER conditions was observed compared to substoichiometric $\mathrm{TiO}_{2}$ substrates (prepared via $\mathrm{H}_{2}$ annealing). ${ }^{10}$ The higher resistance against electrochemical and also thermal oxidation was explained by the absence of oxygen defects, and was reversible (under ORR conditions), because $\mathrm{Nb}$ doping compensated for the $\mathrm{Ti}^{3+}$ defects. In contrast, substoichiometric $\mathrm{TiO}_{2}$ showed a higher increase in electrical resistance during anodic polarization due to oxidation of the $\mathrm{Ti}^{3+}$, forming the thermodynamically more favorable $\mathrm{TiO}_{2}$ in an irreversible process. ${ }^{10,16}$ In contradiction, Jing et al. reported reversibility of substoichiometric $\mathrm{TiO}_{2}$ (prepared via $\mathrm{H}_{2}$ annealing) under cathodic polarization (in acidic medium) after passivation ${ }^{1}$ and Yang et al. observed enhanced stability of blue-black $\mathrm{TiO}_{2}$ nanotube arrays (prepared via cathodization) in polarization cycling during wastewater treatment. ${ }^{2}$ Moreover, $\mathrm{Wu}$ et al. observed reversible proton intercalation of altered, electrochemically doped $\mathrm{TiO}_{2}$ nanotube capacitors by polarization cycling. ${ }^{28}$ Overall, the application of a reversed potential indicate a promising method to recover electrical conductivity of passivated $\mathrm{TiO}_{\mathrm{x}}$ and $\mathrm{TiO}_{\mathrm{x}}: \mathrm{Nb}$ to enhance their lifetime. However, for a comparison between these materials, material preparation under similar conditions is necessary to derive conclusions.

The variety in $\mathrm{Nb}$ doping approaches and charge compensation mechanisms suggests that material preparation is of high importance to achieve high electrically conductive electrodes along with a good stability. In the previous chapter the cathodization method has been demonstrated to clearly increase the electrical conductivity and charge transfer $(\mathrm{CT})$ in $\mathrm{TiO}_{2}$. Therefore, in this chapter the method 
is applied to $\mathrm{Nb}$ doped $\mathrm{TiO}_{2}$ to evaluate the influence of $\mathrm{Nb}$ on the obtained $\mathrm{CT}$ properties and electrode stability under anodic conditions. CT properties were determined by ferrocyanide/ferricyanide cyclic voltammetry and electrochemical impedance spectroscopy (EIS). The stability under oxidative conditions was characterized and compared to $\mathrm{Nb}$ free $\mathrm{TiO}_{\mathrm{x}}$, which were prepared under identical conditions. In addition, polarization switches were applied in neutral media $\left(\mathrm{Na}_{2} \mathrm{SO}_{4}\right.$ electrolyte) to study the recovery of CT properties of passivated $\mathrm{TiO}_{\mathrm{x}}: \mathrm{Nb}$ and $\mathrm{TiO}_{\mathrm{x}}$ for a potential application of the electrode material in electrochemical water treatment.

\subsection{Materials and methods}

\subsubsection{Chemicals and materials}

The same chemicals, materials and reactors as described in Chapter 4 were used. TiNb alloy plates ( $5 \mathrm{w} \% \mathrm{Nb} ; 12.5 \times 12.5,0.5 \mathrm{~mm}$ thickness) were purchased from Hauner metallische Werkstoffe. $5 \mathrm{w} \% \mathrm{Nb}$ was chosen according to common concentration ranges studied in the literature. ${ }^{4,10,19,21,23,27}$ The adapters used for electrochemical experiments were $11 \mathrm{~mm}$ (for sample preparation and characterization) or $7 \mathrm{~mm}$ diameter (for $\mathrm{Fe}^{2+/ 3+} \mathrm{CV}$ and EIS measurements).

\subsubsection{Sample preparation}

$\mathrm{TiO}_{x}$ and $\mathrm{TiO}_{x}: \mathrm{Nb}$ samples were prepared as described in Chapter 4. For $\mathrm{TiO}_{\mathrm{x}}: \mathrm{Nb}$ electrodes $\mathrm{TiNb}$ alloys were used as substrate for anodization to obtain $\mathrm{Nb}$ doping. ${ }^{18,29,30}$ Annealing after anodization was only performed at $450^{\circ} \mathrm{C}$. For cathodization a BDD counter electrode was used exclusively. Optimized cathodization parameters according to Chapter 4 (-1.03 V vs. $\mathrm{Ag} / \mathrm{AgCl}$ for $180 \mathrm{~min}$ ) were applied.

\subsubsection{Characterization}

Electrode stability was studied by chronoamperometry carried out in $0.5 \mathrm{~mol} \mathrm{~L}^{-1}$ $\mathrm{Na}_{2} \mathrm{SO}_{4}$ solution at $5 \mathrm{~mA} \mathrm{~cm} \mathrm{~cm}^{-2}$ (until potentiostat overload). Electrode recovery was performed at $-5 \mathrm{~mA} \mathrm{~cm}^{-2}$ for $15 \mathrm{~min}$. In addition, fast polarization switches were used following a sequence of $15 \mathrm{~s}$ of anodic polarization and $15 \mathrm{~s}$ of cathodic polarization for a total time of $30 \mathrm{~min}$. In all cases, BDD was used as counter electrode. For description of $\mathrm{Fe}^{2+/ 3+} \mathrm{CV}$ and EIS measurements see Chapter 4. 


\subsection{Results and discussion}

\subsubsection{CT properties of cathodized $\mathrm{Nb}$-doped and undoped $\mathrm{TiO}_{\mathrm{x}}$}

$\mathrm{Nb}$ doped and undoped $\mathrm{TiO}_{\mathrm{x}}$ were prepared under identical conditions to understand the influence of $\mathrm{Nb}$ on the $\mathrm{CT}$ properties obtained after cathodization. Here, only optimized conditions as determined in Chapter 4 were applied, i.e. BDD was used as counter electrode to avoid contaminations and a cathodization time $\left(t_{c}\right)$ of $180 \mathrm{~min}$ was used. Likewise, for both substrates, the presence of the Rutile phase was confirmed by XRD (Figure A5.1).

Figure 5.1 shows the $\mathrm{CT}$ properties of cathodized $\mathrm{TiO}_{\mathrm{x}}$ and $\mathrm{Nb}$ doped $\mathrm{TiO}_{\mathrm{x}}$. The $\mathrm{CV}$ of $\mathrm{Fe}^{2+}$ oxidation and $\mathrm{Fe}^{3+}$ reduction (Figure 5.1a) shows an approximately two times larger peak-to-peak separation for $\mathrm{TiO}_{\mathrm{x}}: \mathrm{Nb}\left(\Delta \mathrm{E}_{\mathrm{p}}=1.12 \mathrm{~V}\right)$, indicating an inferior charge transport compared to $\mathrm{TiO}_{\mathrm{x}}\left(\Delta \mathrm{E}_{\mathrm{p}}=0.58 \mathrm{~V}\right)$. The results are qualitatively in agreement with EIS measurements (Figure 5.1b), revealing a resistance of $525+/-118 \Omega$ for $\mathrm{TiO}_{\mathrm{x}}: \mathrm{Nb}$, that is approximately ten times larger than for $\mathrm{TiO}_{\mathrm{x}}$ $(50+/-6 \Omega$ ). In order to exclude an effect of differences in the electrochemical active surface area (ECSA) the double layer capacitance $\left(\mathrm{c}_{\mathrm{dl}}\right)$ has been determined (see Figure A5.2 for more information) and ECSA corrected CVs are shown in Figure A5.3.

a)

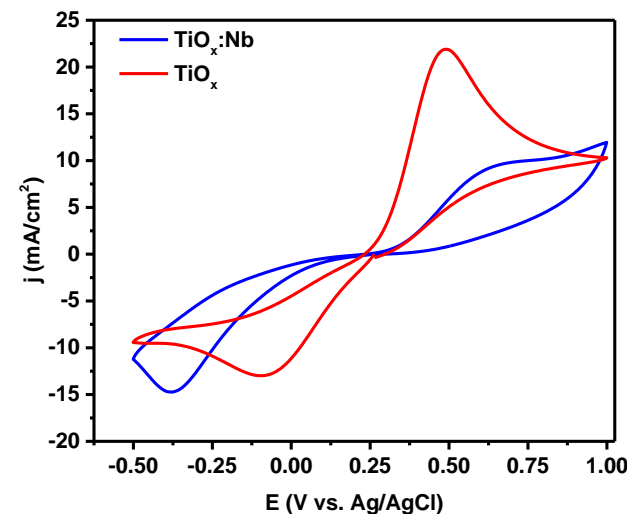

b)

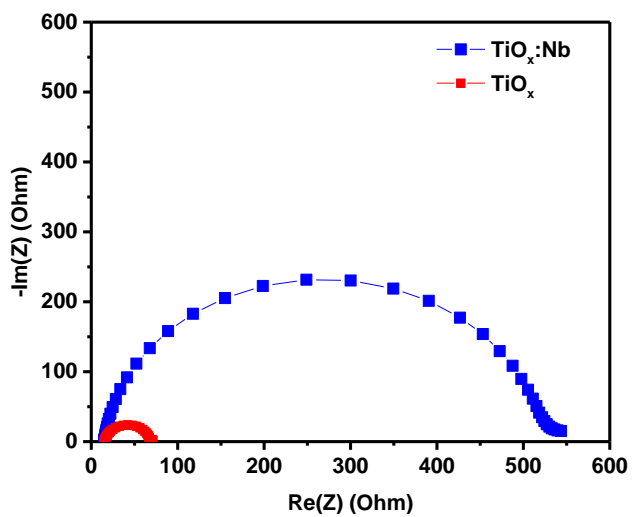

Figure 5.1. CT measurements of $\mathrm{TiO}_{x}$ (red) and $\mathrm{TiO}_{\mathrm{x}}: \mathrm{Nb}$ (blue) after $180 \mathrm{~min}$ cathodization. a) $\mathrm{CV}$ of $\mathrm{Fe}^{2+/ 3+}$ oxidation and reduction; b) EIS measurements 
Nevertheless, the cathodization significantly improves the CT properties of $\mathrm{TiO}_{2}: \mathrm{Nb}$ substrates (see Figure A5.4). Moreover, it is interesting to notice, that the initial resistance of $\mathrm{TiO}_{2}$ is approx. 2.5 times larger than for $\mathrm{TiO}_{2}: \mathrm{Nb}$, highlighting enhanced electrical conductivity of $\mathrm{TiO}_{2}: \mathrm{Nb}$ compared to $\mathrm{TiO}_{2}{ }^{4,7}$ The observations obtained after cathodization are interesting, because $\mathrm{Nb}$ doping has been shown to cause lattice expansion ${ }^{24,29}$ and thus cause a lower migration barrier for small ion intercalation into the host; ${ }^{29}$ however, this effect did not result into superior charge transfer properties of the $\mathrm{TiO}_{2}: \mathrm{Nb}$ prepared under the conditions of this study.

a)

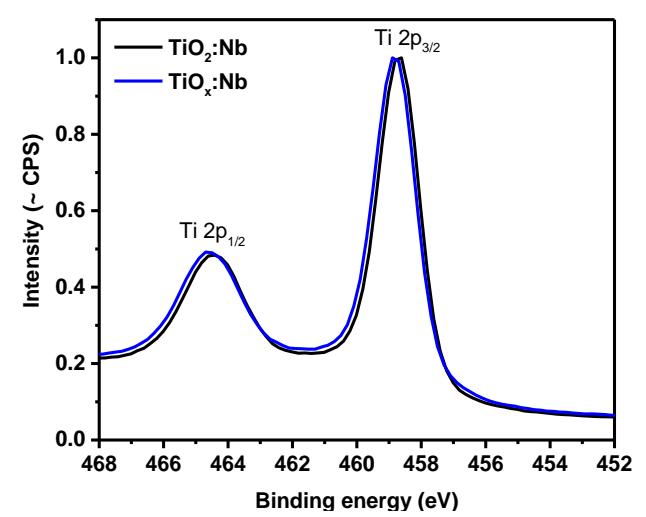

b)

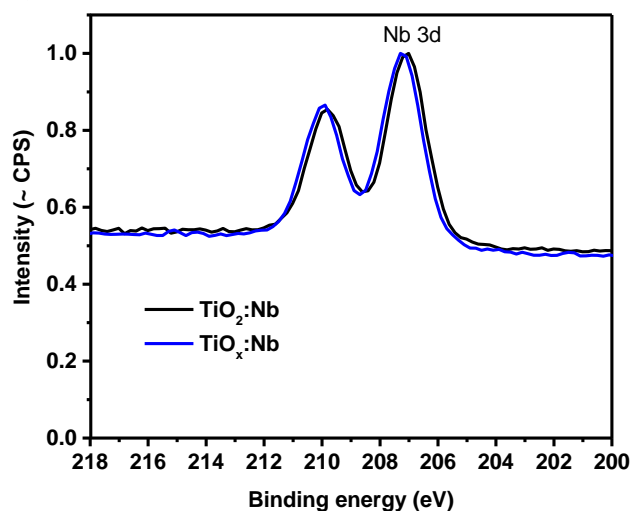

Figure 5.2. $\mathrm{X}$-ray photoelectron spectra of initial $\mathrm{TiO}_{2}: \mathrm{Nb}\left(\mathrm{t}_{\mathrm{c}}=0\right.$ min; black) and $\mathrm{TiO}_{\mathrm{x}}: \mathrm{Nb}$ $\left(t_{\mathrm{c}}=180 \mathrm{~min}\right.$, blue $\left.), \mathrm{a}\right) \mathrm{Ti}$ core spectra, $\left.\mathrm{b}\right) \mathrm{Nb}$ core spectra

As mentioned, various charge compensation mechanisms are described in the literature. Here XPS was used to reveal the $\mathrm{Ti}$ and $\mathrm{Nb}$ oxidation states after cathodization. XPS survey spectra indicate a similar chemical surface composition of $\mathrm{TiO}_{2}: \mathrm{Nb}$ and $\mathrm{TiO}_{\mathrm{x}}: \mathrm{Nb}$ with a $\mathrm{Ti} / \mathrm{O}$ ratio of approximately $0.41-0.42$, similar to $\mathrm{TiO}_{\mathrm{x}}(0.42$; see Figure A5.5 for survey spectra). In addition, a $\mathrm{Nb}$ surface concentration of 2 at $\%$ was determined, in agreement with data obtained from SEMEDX mapping, revealing a homogeneous $\mathrm{Nb}$ distribution (Figure A5.6). XPS core spectra of $\mathrm{Ti}$ (Figure 5.2a) and $\mathrm{Nb}$ (Figure 5.2b) indicate that $\mathrm{Nb}(+\mathrm{V})$ and $\mathrm{Ti}(+\mathrm{IV}$ ) are the predominant oxidation states. ${ }^{25,31,32}$ Moreover, no difference to $\mathrm{TiO}_{\mathrm{x}}$ samples is present (Figure A5.7). Thus the dominant charge compensation mechanism in the $\mathrm{Nb}$ doped samples is likely due to formation of Ti vacancies, which is in accordance to other studies of air annealed $\mathrm{TiO}_{2}: \mathrm{Nb}^{23,26}$ Although feasible according to the standard redox potentials, ${ }^{33}$ no reduction of $\mathrm{Nb}$ according to equation 5.4 and 5.5 was observed. 


$$
\begin{array}{ll}
\mathrm{NbO}_{2}+2 \mathrm{H}^{+}+2 \mathrm{e}^{-} \leftrightarrow \mathrm{NbO}+\mathrm{H}_{2} \mathrm{O} & \left(\mathrm{E}^{0}=-0.646 \mathrm{~V}\right) \\
\mathrm{Nb}_{2} \mathrm{O}_{5}+10 \mathrm{H}^{+}+10 \mathrm{e}^{-} \leftrightarrow 2 \mathrm{Nb}+5 \mathrm{H}_{2} \mathrm{O} & \left(\mathrm{E}^{0}=-0.644 \mathrm{~V}\right)
\end{array}
$$

This might be explained by the higher driving force necessary to reduce the crystalline substrate compared to amorphous substrates, ${ }^{34,35}$ as observed for $\mathrm{TiO}_{\mathrm{x}}$ in Chapter 4. The absence of $\mathrm{Nb}^{<5+}$ and $\mathrm{Ti}^{<4+}$ (at least at the sub-/surface) indicates that the doping induced by cathodization and the resulting CT properties are mainly attributed to $\mathrm{H}$-doping ${ }^{1,29,36,37}$ and not to $\mathrm{Nb}$ reduction, in agreement with observations for $\mathrm{Nb}$ free $\mathrm{TiO}_{\mathrm{x}}$ (Chapter 4). The slight shift of $\mathrm{TiO}_{\mathrm{x}}: \mathrm{Nb}$ to higher binding energies compared to $\mathrm{TiO}_{2}: \mathrm{Nb}$ might be explained by a shift in the fermi level position. ${ }^{23}$

Looking at the cathodization, clear differences in the current-time profiles were observed (Figure 5.3a). Whereas $\mathrm{TiO}_{x}$ follows the typical profile obtained for cathodization using BDD-CE, the $\mathrm{Nb}$ doped substrate shows immediately a higher current density, leading to an approximately three times larger current density at the end of the cathodization compared to $\mathrm{TiO}_{\mathrm{x}}$. CVs of the HER activity of the substrates before cathodization are shown in Figure 5.3b (corrected for the individual ECSA). Clearly, the $\mathrm{TiO}_{2}: \mathrm{Nb}$ substrates show a higher HER activity compared to $\mathrm{TiO}_{2}$, explaining the higher cathodization currents observed. The findings are in analogy to Chapter 4, where trace Ir contaminations are proposed to favor HER over the Hdoping. Here, the $\mathrm{Nb}$ in the oxide lattice has likely a similar effect by favoring the HER (compared to the bare $\mathrm{TiO}_{2}$ ). The HER leads to proton scavenging and results in inferior doping and thus inferior CT properties, despite the lattice expansion described for $\mathrm{TiO}_{2}: \mathrm{Nb}^{24,29}$ In addition, cathodization experiments have been carried out at $-0.5 \mathrm{~V}$ vs. RHE to prevent proton scavenging by HER (Figure A5.8). Only minor improvement of CT properties was obtained, which can be explained by the absence of HER (less $\mathrm{H}$ diffusion into $\mathrm{TiO}_{2}$ ) and/or the lower applied potential (less proton intercalation). Nevertheless, the relative improvement of the resistance determined by EIS was superior for $\mathrm{TiO}_{\mathrm{x}}$ (Figure A5.8, Table A5.1), revealing the negative effect of $\mathrm{Nb}$ on the $\mathrm{H}$-doping. Overall, cathodization at this potential was not sufficient to obtain superior CT properties. 
a)

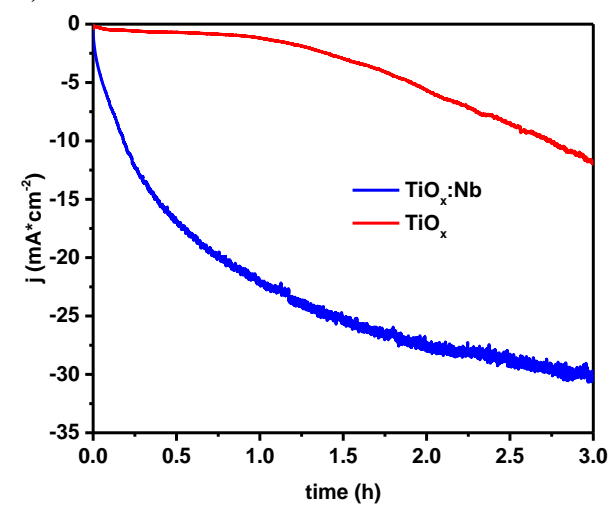

b)

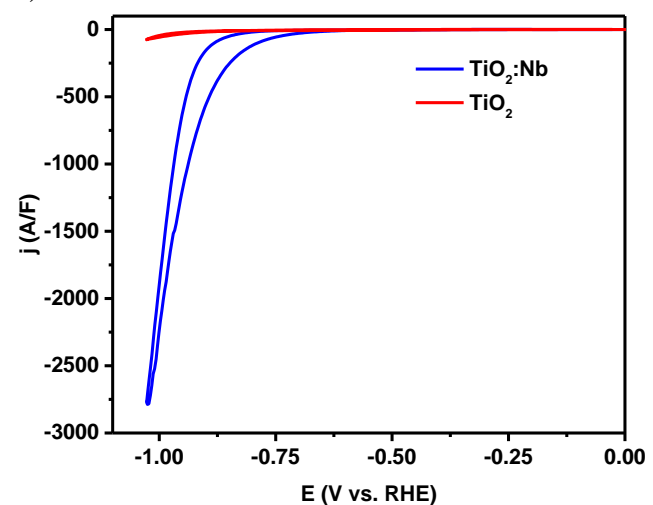

Figure 5.3. a) Cathodization currents obtained for $\mathrm{TiO}_{\mathrm{x}}$ (red) and $\mathrm{TiO}_{\mathrm{x}}: \mathrm{Nb}$ preparation (blue); b) $\mathrm{HER}-\mathrm{CV}$ of $\mathrm{TiO}_{2}$ and $\mathrm{TiO}_{2}$ : $\mathrm{Nb}$ substrates (ECSA corrected). All curves were recorded in $1 \mathrm{~mol} \mathrm{~L}^{-1} \mathrm{H}_{2} \mathrm{SO}_{4}$.

\subsubsection{Stability and recovery}

The stability of cathodized $\mathrm{TiO}_{\mathrm{x}}$ and $\mathrm{TiO}_{\mathrm{x}}: \mathrm{Nb}$ under oxidative conditions was characterized by chronoamperometric measurements at $5 \mathrm{~mA} \mathrm{~cm}{ }^{-2}$ in $\mathrm{Na}_{2} \mathrm{SO}_{4}$ electrolyte as shown in Figure 5.4. The stability or lifetime was determined as time under anodic polarization until potentiostat overload was reached. Although both materials suffer from fast passivation, which was already observed during subsequent cycles of the $\mathrm{Fe}^{2+/ 3+} \mathrm{CV}$ (Figure A5.9), $\mathrm{TiO}_{\mathrm{x}}: \mathrm{Nb}$ shows a $2.75 \mathrm{x}$ better stability $\left(\approx 370 \mathrm{~s}\right.$ ) compared to $\mathrm{TiO}_{\mathrm{x}}(\approx 135 \mathrm{~s})$. Since the ECSA $\left(\mathrm{c}_{\mathrm{dl}}\right)$ of $\mathrm{TiO}_{\mathrm{x}}: \mathrm{Nb}$ is only $3 / 4$ of $\mathrm{TiO}_{\mathrm{x}}$, a higher current density per active site was present for $\mathrm{TiO}_{\mathrm{x}}: \mathrm{Nb}$ compared to $\mathrm{TiO}_{x}$, confirming $\mathrm{TiO}_{\mathrm{x}}: \mathrm{Nb}$ has a better stability. Therefore, it is likely that $\mathrm{Nb}$ doping has a beneficial effect on the oxidative stability of the electrodes, which is in agreement with observations by Chen et al. ${ }^{10,16}$ 


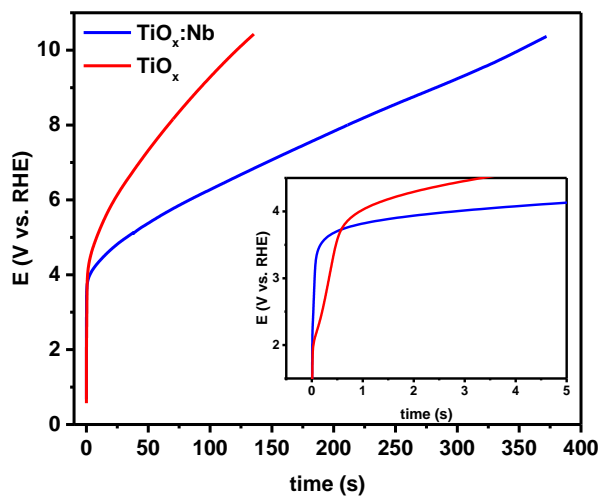

Figure 5.4. Chronopotentiometry of $\mathrm{TiO}_{x}$ and $\mathrm{TiO}_{x}: \mathrm{Nb}$ recorded at $5 \mathrm{~mA} \mathrm{~cm}{ }^{-2}$ in $\mathrm{Na}_{2} \mathrm{SO}_{4}$ electrolyte $\left[0.5 \mathrm{~mol} \mathrm{~L}^{-1}\right]$. The inset shows an enlarged section of the initial polarization.

After passivation (oxidation at $5 \mathrm{~mA} \mathrm{~cm}^{-2}$ in $0.5 \mathrm{~mol} \mathrm{~L}^{-1} \mathrm{Na}_{2} \mathrm{SO}_{4}$ ) the samples were cathodized for $15 \mathrm{~min}$ at $-5 \mathrm{~mA} \mathrm{~cm}^{-2}$ to study the recovery of the CT properties under neutral conditions $\left(0.5 \mathrm{~mol} \mathrm{~L}{ }^{-1} \mathrm{Na}_{2} \mathrm{SO}_{4}\right.$; longer recovery times were not studied due to the short time of oxidative stability and the desired match between time of operation in oxidation and reduction mode). During the recovery step a lower potential $\left(\Delta \mathrm{E}_{\mathrm{c}} \approx 150 \mathrm{mV}\right.$ ) was observed for $\mathrm{TiO}_{\mathrm{x}}: \mathrm{Nb}$ (Figure A5.10a), in agreement with the superior HER performance compared to $\mathrm{TiO}_{\mathrm{x}}$ (Figure 5.3b). Figure 5.5 shows the CT properties ( $\mathrm{Fe}^{2+/ 3+} \mathrm{CV}$ and EIS measurements) of cathodized samples after passivation and after the recovery treatment (for initial samples before passivation see Figure 5.1). After passivation, oxidative CT was absent, in agreement with a huge resistance of the electrodes. However, after the recovery step, both electrodes clearly show improved CT properties. Although the initial properties were not fully recovered, the recovery of charge transfer of $\mathrm{TiO}_{\mathrm{x}}$ is superior $(97 \%$ reduction of CT resistance) compared to $\mathrm{TiO}_{\mathrm{x}}: \mathrm{Nb}$ (only 50\%; see Table 5.1). Similar observations were made for pristine substrates $\left(\mathrm{TiO}_{2}\right.$ and $\left.\mathrm{TiO}_{2}: \mathrm{Nb}\right)$ treated under the same conditions $\left(15 \mathrm{~min}\right.$ at $-5 \mathrm{~mA} \mathrm{~cm}{ }^{-2}$ in $0.5 \mathrm{~mol} \mathrm{~L}^{-1} \mathrm{Na}_{2} \mathrm{SO}_{4}$ : see Figure A5.10, Table A5.2). The enhanced recovery for $\mathrm{TiO}_{\mathrm{x}}$ is in good agreement with the superior doping due to the absence of $\mathrm{Nb}$ favouring the HER as discussed (Figure 5.1, Figure 5.3). The observed reversibility for both electrode materials is in disagreement with Chen et al. ${ }^{16}$ who did not observe a reversibility for substoichiometric $\mathrm{TiO}_{2}$ electrodes, but this can be explained by a more negative polarization applied for recovery in this study and general differences in electrode preparation between the studies (vacuum or $\mathrm{H}_{2}$ annealing vs. cathodization applied 
in this study). In general, the observed reversibility of $\mathrm{TiO}_{\mathrm{x}}$ is in agreement with various $\mathrm{TiO}_{\mathrm{x}}$ types described in literature. ${ }^{1,2,28}$

a)

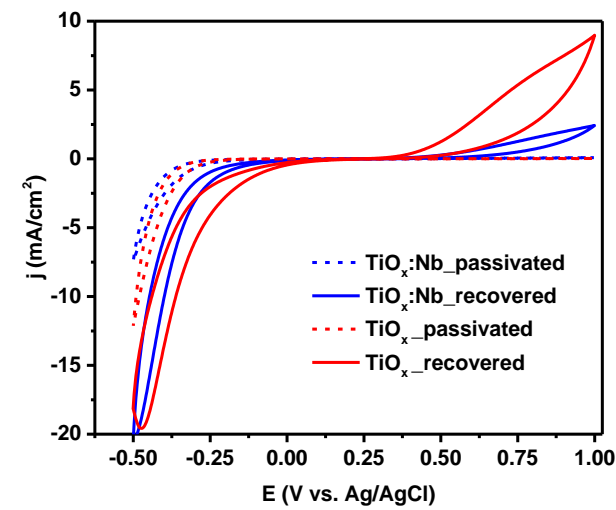

b)

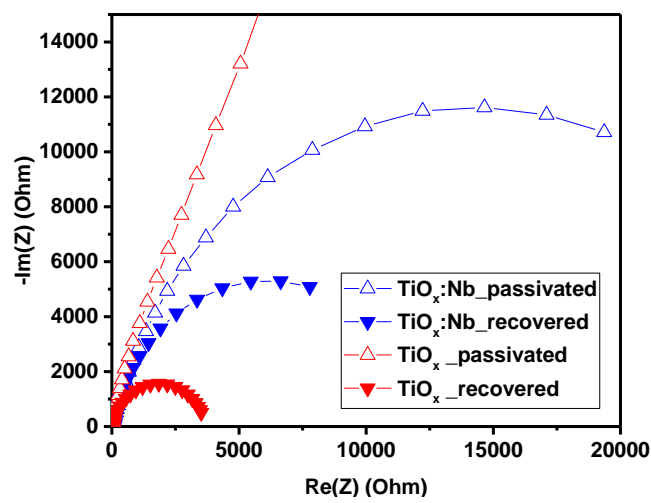

Figure 5.5. $\mathrm{CT}$ measurements of passivated $\mathrm{Nb}$-doped and undoped $\mathrm{TiO}_{\mathrm{x}}$ before and after recovery step $\left(-5 \mathrm{~mA} \mathrm{~cm}^{2}\right.$ in $\left.0.5 \mathrm{~mol} \mathrm{~L}^{-1} \mathrm{Na}_{2} \mathrm{SO}_{4}\right)$; a) $\mathrm{CV}$ of Fe${ }^{2+/ 3+}$ oxidation and reduction; b) EIS.

Table 5.1: Resistance of initial as well as passivated $\mathrm{Nb}$ doped and undoped $\mathrm{TiO}_{\mathrm{x}}$ before and after recovery. Additionally, the ratio between the resistance of recovered and passivated samples is shown to calculate the recovery based on the CT resistance.

\begin{tabular}{|c|c|c|c|c|c|}
\hline$\#$ & $\begin{array}{c}\mathbf{R}_{\text {initial }} \\
{[\mathbf{\Omega}]}\end{array}$ & $\begin{array}{c}\mathbf{R}_{\text {passivated }} \\
{[\mathbf{\Omega}]}\end{array}$ & $\begin{array}{c}\mathbf{R}_{\text {recovered }} \\
{[\mathbf{\Omega}]}\end{array}$ & $\begin{array}{c}\mathbf{R}_{\text {recovered/ }} \\
\mathbf{R} \text { passivated } \\
{[\%]}\end{array}$ & $\begin{array}{c}\text { Recovery } \\
{[\%]}\end{array}$ \\
\hline $\mathbf{T i O}_{\mathbf{x}}$ & 53 & $1.21 \mathrm{E} 5$ & $3.74 \mathrm{E} 3$ & $3 \%$ & $97 \%$ \\
\hline $\mathbf{T i O}_{\mathbf{x}}: \mathbf{N b}$ & 510 & $2.99 \mathrm{E} 4$ & $1.46 \mathrm{E} 4$ & $50 \%$ & $50 \%$ \\
\hline
\end{tabular}

For both materials a fast passivation under anodic polarization was observed and after subsequent cathodic polarization of passivated samples, a partial recovery of CT was achieved. Therefore, shorter polarization cycles were applied to avoid full passivation and allow for recovery between anodic polarization steps. Figure 5.6 shows consecutive cycles of $15 \mathrm{~s}$ at $5 \mathrm{~mA} \mathrm{~cm}$ followed by $15 \mathrm{~s}$ at $-5 \mathrm{~mA} \mathrm{~cm}{ }^{-2}$. Clearly, for both electrode materials the passivation was suppressed compared to the continued polarization experiments, likely due to the short time of oxidative polarization followed by an immediate recovery step. Therefore, the operation time could be significantly extended and both electrodes operated in total for $1800 \mathrm{~s}$; equal to $900 \mathrm{~s}$ of oxidative conditions, which is 2.5 times longer for the 
$\mathrm{TiO}_{\mathrm{x}}: \mathrm{Nb}$ and 6.5 times longer for the $\mathrm{TiO}_{\mathrm{x}}$ electrode. The superior enhancement of operation time for $\mathrm{TiO}_{\mathrm{x}}$ compared to $\mathrm{TiO}_{\mathrm{x}}: \mathrm{Nb}$ can be explained by the enhanced recovery for $\mathrm{TiO}_{\mathrm{x}}$ (see Figure 5.5, Table 5.1). In general, the enhancement in lifetime for $\mathrm{TiO}_{\mathrm{x}}$ during polarization cycling is in agreement with observations for cathodized titanium nanotubes. ${ }^{2} \mathrm{By} \mathrm{Nb}$ doping of the $\mathrm{TiO}_{x}$ a less steep increase in potential compared to undoped $\mathrm{TiO}_{\mathrm{x}}$ was achieved, which is in agreement with the results at constant current conditions (Figure 5.4). However, the observed passivation of the electrodes during oxidative polarization is still dominating, and the recovery of CT is so far inferior under the studied conditions.

a)

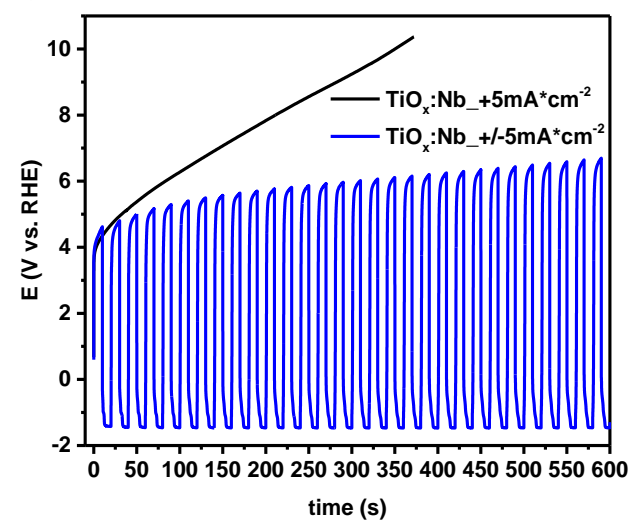

c)

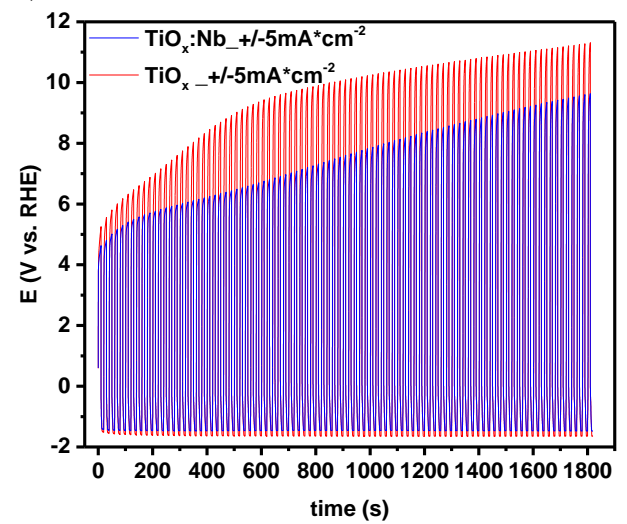

b)

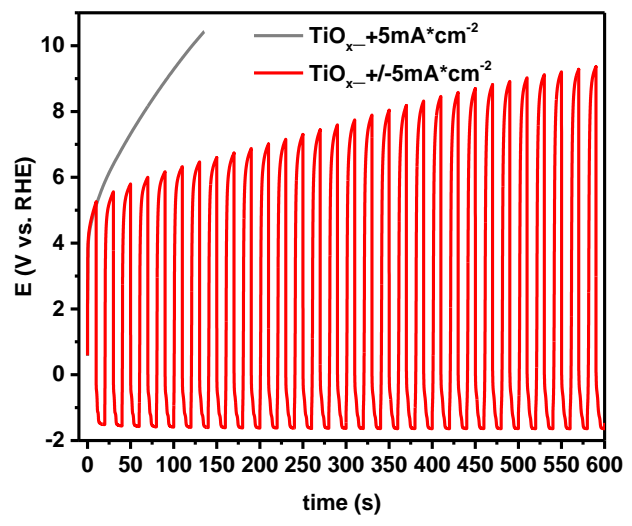

Figure 5.6. Fast polarization switch measurements between $+5 \mathrm{~mA} \mathrm{~cm}^{-2}(15 \mathrm{~s})$ and $-5 \mathrm{~mA} \mathrm{~cm}^{-2}(15 \mathrm{~s})$ in $0.5 \mathrm{~mol} \mathrm{~L}^{-1} \mathrm{Na}_{2} \mathrm{SO}_{4}$ for enhanced lifetime experiments. a) $\mathrm{TiO}_{\mathrm{x}} \mathrm{Nb}$ (blue: fast polarization switch, black line: constant current at $+5 \mathrm{~mA} \mathrm{~cm}^{-2}$ ); b) $\mathrm{TiO}_{\mathrm{x}}$ (red: fast polarization switch, grey line: constant current at $\left.+5 \mathrm{~mA} \mathrm{~cm}^{-2}\right)$; c) overlay of fast polarization switch graphs for the full time of the experiment $(t=30 \mathrm{~min})$ 
The overall poor oxidative stability observed here for $\mathrm{Nb}$ doped and $\mathrm{Nb}$ free $\mathrm{TiO}_{\mathrm{x}}$ as compared to literature might be attributed to several reasons or even combinations of them. For example, materials reported were prepared by different preparation methods (e.g. reductively annealed samples; high temperature annealing for formation of ceramic materials). Moreover, different structures or morphologies were studied (e.g. nanotubes with large surface areas). In addition, the absence of catalytic particles in this study (e.g. favoring OER instead of substrate oxidation) or in general variations of conditions such as applied current densities and real surface areas, likely contribute to different material performances. Due to hydrogen embrittlement and poor reproducibility during material preparation by annealing in hydrogen atmosphere, a comparison between cathodized and hydrogen annealed $\mathrm{TiO}_{\mathrm{x}}$ and $\mathrm{TiO}_{\mathrm{x}}: \mathrm{Nb}$ was not possible. Nevertheless, $\mathrm{Nb}$ doping and application of reversible polarization is promising to enhance the lifetime of cathodized $\mathrm{TiO}_{\mathrm{x}}$ electrodes. Further optimization of the preparation (e.g. a combination of $\mathrm{H}_{2}$ annealing with cathodic doping), along with optimizing conditions during polarization cycling will likely result in further lifetime improvements of the electrode materials.

\subsection{Conclusions}

Electrochemical reduction of $\mathrm{Nb}$ doped and undoped $\mathrm{TiO}_{2}$ resulted in superior $\mathrm{CT}$ properties for $\mathrm{TiO}_{\mathrm{x}}$ compared to $\mathrm{TiO}_{\mathrm{x}}: \mathrm{Nb}$ (under the tested conditions of this study). Using X-ray photoelectron spectroscopy, pentavalent $\mathrm{Nb}$ and tetravalent Ti were identified as main valence states at the (sub-)surface of the materials before and after cathodization. The $\mathrm{TiO}_{2}: \mathrm{Nb}$ substrates show a higher HER activity compared to $\mathrm{TiO}_{2}$, likely leading to inferior H-doping during cathodization, thus explaining the inferior CT properties obtained for $\mathrm{TiO}_{\mathrm{x}}: \mathrm{Nb}$. However, the $\mathrm{Nb}$ has a positive influence on the oxidative stability of $\mathrm{TiO}_{\mathrm{x}}: \mathrm{Nb}$; unfortunately, fast passivation was observed under oxidative conditions. For both materials, Nb-doped and undoped $\mathrm{TiO}_{\mathrm{x}}$, recovery of CT properties after passivation by polarization switch in neutral media is promising, whereas $\mathrm{TiO}_{\mathrm{x}}$ shows superior recovery due to the absence of $\mathrm{Nb}$. Fast polarization cycling clearly extended the lifetime of the electrodes due to the inbetween recovery steps; however, the recovery rate was inferior compared to the fast passivation under oxidative conditions observed in this study. 


\subsection{Acknowledgements}

We would like to thank Magneto special anodes B.V. for providing Ti substrates and the BDD electrode.

\subsection{References}

(1) Jing, Y.; Almassi, S.; Mehraeen, S.; LeSuer, R. J.; Chaplin, B. P. The Roles of Oxygen Vacancies, Electrolyte Composition, Lattice Structure, and Doping Density on the Electrochemical Reactivity of Magnéli Phase $\mathrm{TiO}_{2}$ Anodes. J. Mater. Chem. A 2018, 6 (46), 23828-23839. https://doi.org/10.1039/C8TA03719A.

(2) Yang, Y.; Hoffmann, M. R. Synthesis and Stabilization of Blue-Black $\mathrm{TiO}_{2}$ Nanotube Arrays for Electrochemical Oxidant Generation and Wastewater Treatment. Environ. Sci. Technol. 2016, 50 (21), 11888-11894. https://doi.org/10.1021/acs.est.6b03540.

(3) Nowotny, J.; Alim, M. A.; Bak, T.; Idris, M. A.; Ionescu, M.; Prince, K.; Sahdan, M. Z.; Sopian, K.; Mat Teridi, M. A.; Sigmund, W. Defect Chemistry and Defect Engineering of $\mathrm{TiO}_{2}$-Based Semiconductors for Solar Energy Conversion. Chem. Soc. Rev. 2015, 44 (23), 8424-8442. https://doi.org/10.1039/C4CS00469H.

(4) Furubayashi, Y.; Hitosugi, T.; Yamamoto, Y.; Inaba, K.; Kinoda, G.; Hirose, Y.; Shimada, T.; Hasegawa, T. A Transparent Metal: Nb-Doped Anatase $\mathrm{TiO}_{2}$. Appl. Phys. Lett. 2005, 86 (25), 252101. https://doi.org/10.1063/1.1949728.

(5) Sheppard, L. R.; Bak, T.; Nowotny, J. Electrical Properties of NiobiumDoped Titanium Dioxide. 1. Defect Disorder. J. Phys. Chem. B 2006, 110 (45), 22447-22454. https://doi.org/10.1021/jp0637025.

(6) Saha, M.; Ghosh, S.; Paul, S.; Dalal, B.; De, S. K. Nb-Dopant-Induced Tuning of Optical and Electrical Property of Anatase $\mathrm{TiO}_{2}$ Nanocrystals. ChemistrySelect 2018, 3 (23), 6654-6664. https://doi.org/10.1002/slct.201800434.

(7) Hitosugi, T.; Yamada, N.; Nakao, S.; Hirose, Y.; Hasegawa, T. Properties of $\mathrm{TiO}_{2}$-Based Transparent Conducting Oxides. Phys. status solidi 2010, 207 (7), 1529-1537. https://doi.org/10.1002/pssa.200983774.

(8) Lee, S.; Noh, J. H.; Han, H. S.; Yim, D. K.; Kim, D. H.; Lee, J.-K.; Kim, J. Y.; Jung, H. S.; Hong, K. S. Nb-Doped $\mathrm{TiO}_{2}$ : A New Compact Layer 
Material for $\mathrm{TiO}_{2}$ Dye-Sensitized Solar Cells. J. Phys. Chem. C 2009, 113 (16), 6878-6882. https://doi.org/10.1021/jp9002017.

(9) Kim, S. G.; Ju, M. J.; Choi, I. T.; Choi, W. S.; Choi, H.-J.; Baek, J.-B.; Kim, H. K. Nb-Doped $\mathrm{TiO}_{2}$ Nanoparticles for Organic Dye-Sensitized Solar Cells. RSC Adv. 2013, 3 (37), 16380. https://doi.org/10.1039/c3ra42081g.

(10) Chen, G.; Bare, S. R.; Mallouk, T. E. Development of Supported Bifunctional Electrocatalysts for Unitized Regenerative Fuel Cells. $J$. Electrochem. Soc. 2002, 149 (8), A1092-A1099. https://doi.org/10.1149/1.1491237.

(11) Chhina, H.; Campbell, S.; Kesler, O. Characterization of Nb and W Doped Titania as Catalyst Supports for Proton Exchange Membrane Fuel Cells. $J$. New Mater. Electrochem. Syst. 2009, 12 (4), 177-185.

(12) Hao, C.; Lv, H.; Mi, C.; Song, Y.; Ma, J. Investigation of Mesoporous Niobium-Doped $\mathrm{TiO}_{2}$ as an Oxygen Evolution Catalyst Support in an SPE Water Electrolyzer. ACS Sustain. Chem. Eng. 2016, 4 (3), 746-756. https://doi.org/10.1021/acssuschemeng.5b00531.

(13) Das, C.; Roy, P.; Yang, M.; Jha, H.; Schmuki, P. Nb Doped $\mathrm{TiO}_{2}$ Nanotubes for Enhanced Photoelectrochemical Water-Splitting. Nanoscale 2011, 3 (8), 3094. https://doi.org/10.1039/c1nr10539f.

(14) Mei, B.; Byford, H.; Bledowski, M.; Wang, L.; Strunk, J.; Muhler, M.; Beranek, R. Beneficial Effect of Nb Doping on the Photoelectrochemical Properties of $\mathrm{TiO}_{2}$ and $\mathrm{TiO}_{2}$-Polyheptazine Hybrids. Sol. Energy Mater. Sol. Cells 2013, 117, 48-53. https://doi.org/10.1016/j.solmat.2013.05.024.

(15) Saleh, A. A.; Farag, M.; Allam, N. K. Correlation between Microstructural Defects and Photoelectrochemical Performance of 1D Ti e Nb Composite Oxide Photoanodes for Solar Water Splitting. Int. J. Hydrogen Energy 2019, 44 (45), 24418-24429. https://doi.org/10.1016/j.ijhydene.2019.07.219.

(16) Chen, G.; Waraksa, C. C.; Cho, H.; Macdonald, D. D.; Mallouka, T. E. EIS Studies of Porous Oxygen Electrodes with Discrete Particles: I. Impedance of Oxide Catalyst Supports. J. Electrochem. Soc. 2003, 150 (9), E423E428. https://doi.org/10.1149/1.1594729.

(17) Gojković, S. L.; Babić, B. M.; Radmilović, V. R.; Krstajić, N. V. Nb-Doped $\mathrm{TiO}_{2}$ as a Support of Pt and Pt-Ru Anode Catalyst for PEMFCs.

J. Electroanal. Chem. 2010, 639 (1-2), 161-166. https://doi.org/10.1016/j.jelechem.2009.12.004. 
(18) Xu, L.; Liang, G.; Yin, M. A Promising Electrode Material Modified by $\mathrm{Nb}$-Doped $\mathrm{TiO}_{2}$ Nanotubes for Electrochemical Degradation of AR 73. Chemosphere 2017, 173 (Supplement C), 425-434. https://doi.org/https://doi.org/10.1016/j.chemosphere.2017.01.077.

(19) Weres, O.; Hoffmann, M. R. Electrode, Electrode Manufacturing Process and Electrochemical Cell. US005419824A, 1995.

(20) Kesselman, J. M.; Weres, O.; Lewis, N. S.; Hoffmann, M. R. Electrochemical Production of Hydroxyl Radical at Polycrystalline NbDoped $\mathrm{TiO}_{2}$ Electrodes and Estimation of the Partitioning between Hydroxyl Radical and Direct Hole Oxidation Pathways. J. Phys. Chem. B 1997, 101 (14), 2637-2643. https://doi.org/10.1021/jp962669r.

(21) Weres, O.; Hoffmann, M. R. Electrochemical Method and Device for Generating Hydroxyl Free Radicals and Oxidizing Chemical Substances Dissolved in Water. US005364508A, 1994.

(22) Chaplin, B. P. Advantages, Disadvantages, and Future Challenges of the Use of Electrochemical Technologies for Water and Wastewater Treatment; Elsevier Inc., 2018. https://doi.org/10.1016/B978-0-12-813160-2.00017-1.

(23) Ruiz, A. M.; Dezanneau, G.; Arbiol, J.; Cornet, A.; Morante, J. R. Insights into the Structural and Chemical Modifications of $\mathrm{Nb}$ Additive on $\mathrm{TiO}_{2}$ Nanoparticles. Chem. Mater. 2004, 16 (5), 862-871. https://doi.org/10.1021/cm0351238.

(24) Dy, E.; Hui, R.; Zhang, J.; Liu, Z. S.; Shi, Z. Electronic Conductivity and Stability of Doped Titania $\left(\mathrm{Ti}_{1-\mathrm{x}} \mathrm{M}_{\mathrm{x}} \mathrm{O}_{2}, \mathrm{M}=\mathrm{Nb}, \mathrm{Ru}\right.$, and Ta)- A Density Functional Theory-Based Comparison. J. Phys. Chem. C 2010, 114 (31), 13162-13167. https://doi.org/10.1021/jp100826g.

(25) Morris, D.; Dou, Y.; Rebane, J.; Mitchell, C. E. J.; Egdell, R. G.; Law, D. S. L.; Vittadini, A.; Casarin, M. Photoemission and STM Study of the Electronic Structure of Nb-Doped $\mathrm{TiO}_{2}$. Phys. Rev. B 2000, 61 (20), 1344513457. https://doi.org/10.1103/PhysRevB.61.13445.

(26) Mei, B.; Sánchez, M. D.; Reinecke, T.; Kaluza, S.; Xia, W.; Muhler, M. The Synthesis of $\mathrm{Nb}$-Doped $\mathrm{TiO}_{2}$ Nanoparticles by Spray Drying: An Efficient and Scalable Method. J. Mater. Chem. 2011, 21 (32), 1178111790. https://doi.org/10.1039/c1jm11431j.

(27) Yue, J.; Suchomski, C.; Voepel, P.; Ellinghaus, R.; Rohnke, M.;

Leichtweiss, T.; Elm, M. T.; Smarsly, B. M. Mesoporous Niobium-Doped Titanium Dioxide Films from the Assembly of Crystalline Nanoparticles: Study on the Relationship between the Band Structure, Conductivity and Charge Storage Mechanism. J. Mater. Chem. A 2017, 5 (5), 1978-1988. 
https://doi.org/10.1039/C6TA06840E.

(28) Wu, H.; Li, D.; Zhu, X.; Yang, C.; Liu, D.; Chen, X.; Song, Y.; Lu, L. High-Performance and Renewable Supercapacitors Based on $\mathrm{TiO}_{2}$ Nanotube Array Electrodes Treated by an Electrochemical Doping Approach. Electrochim. Acta 2014, 116, 129-136.

https://doi.org/10.1016/j.electacta.2013.10.092.

(29) Ghicov, A.; Yamamoto, M.; Schmuki, P. Lattice Widening in NiobiumDoped $\mathrm{TiO}_{2}$ Nanotubes: Efficient Ion Intercalation and Swift

Electrochromic Contrast. Angew. Chemie - Int. Ed. 2008, 47 (41), 79347937. https://doi.org/10.1002/anie.200802598.

(30) Jha, H.; Hahn, R.; Schmuki, P. Ultrafast Oxide Nanotube Formation on $\mathrm{TiNb}, \mathrm{TiZr}$ and TiTa Alloys by Rapid Breakdown Anodization.

Electrochim. Acta 2010, 55 (28), 8883-8887.

https://doi.org/10.1016/j.electacta.2010.07.098.

(31) Grundner, M.; Halbritter, J. XPS and AES Studies on Oxide Growth and Oxide Coatings on Niobium. J. Appl. Phys. 1980, 51 (1), 397-405. https://doi.org/10.1063/1.327386.

(32) Moulder, J. F.; Stickle, W. F.; Sobol, P. E.; Bomben, K. D. Handbook of XRay Photoelectron Spectroscopy; Chastain, J., Ed.; Perkin-Elmer Corporation, 1992.

(33) Vanýsek, P. Electrochemical Series. In CRC Handbook of Chemistry \& Physics; Haynes, W. M., Ed.; CRC Press LLC: London, New York; pp 580-5-89.

(34) Pham, H. H.; Wang, L.-W. Oxygen Vacancy and Hole Conduction in Amorphous $\mathrm{TiO}_{2}$. Phys. Chem. Chem. Phys. 2015, 17 (1), 541-550. https://doi.org/10.1039/C4CP04209C.

(35) Deskins, N. A.; Du, J.; Rao, P. The Structural and Electronic Properties of Reduced Amorphous Titania. Phys. Chem. Chem. Phys. 2017, 19 (28), 18671-18684. https://doi.org/10.1039/C7CP02940C.

(36) Fabregat-Santiago, F.; Barea, E. M.; Bisquert, J.; Mor, G. K.; Shankar, K.; Grimes, C. A. High Carrier Density and Capacitance in $\mathrm{TiO}_{2}$ Nanotube Arrays Induced by Electrochemical Doping. J. Am. Chem. Soc. 2008, 130 (34), 11312-11316. https://doi.org/10.1021/ja710899q.

(37) Berger, T.; Lana-Villarreal, T.; Monllor-Satoca, D.; Gómez, R. Charge Transfer Reductive Doping of Nanostructured $\mathrm{TiO}_{2}$ thin Films as a Way to Improve Their Photoelectrocatalytic Performance. Electrochem. commun. 2006, 8 (11), 1713-1718. https://doi.org/10.1016/j.elecom.2006.08.006. 


\subsection{Appendix}

a)

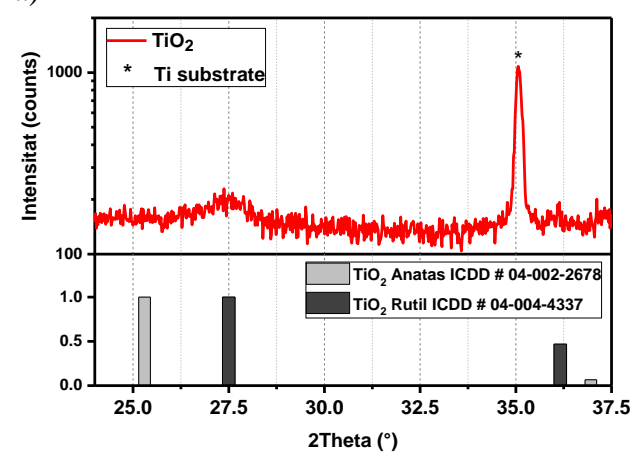

b)

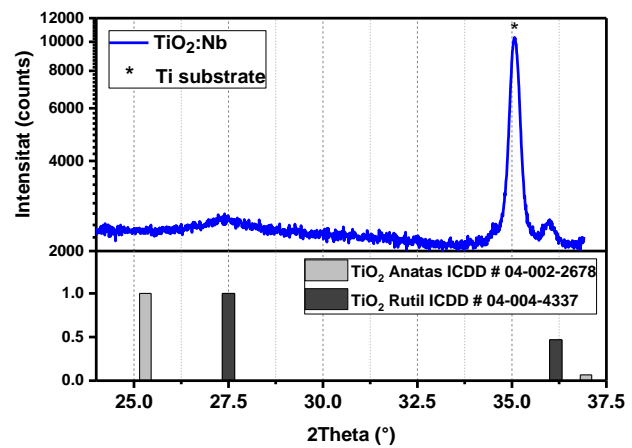

Figure A5.1. XRD of a) $\mathrm{TiO}_{2}$ and b) $\mathrm{TiO}_{2}: \mathrm{Nb}$ substrates after annealing at $450^{\circ} \mathrm{C}$. For both substrates, $\mathrm{Nb}$-doped and undoped $\mathrm{TiO}_{2}$ are present in Rutile phase. 
a)

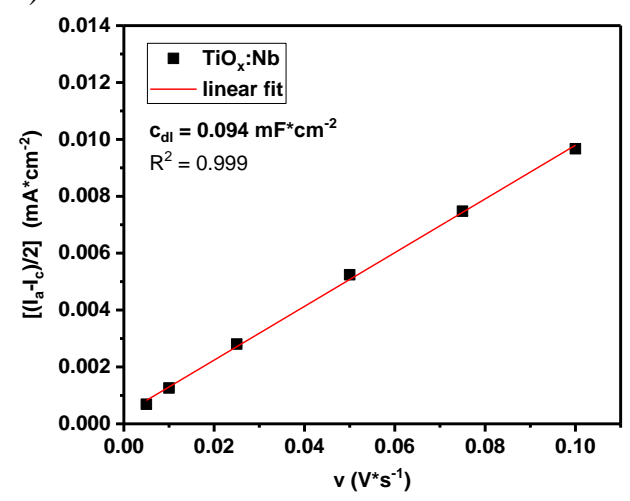

c)

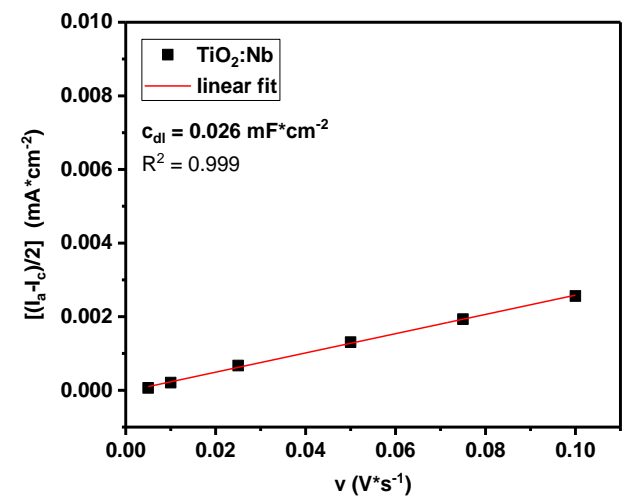

b)

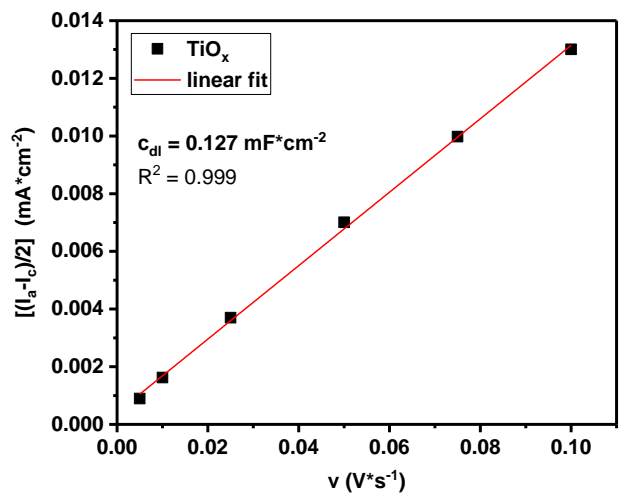

d)

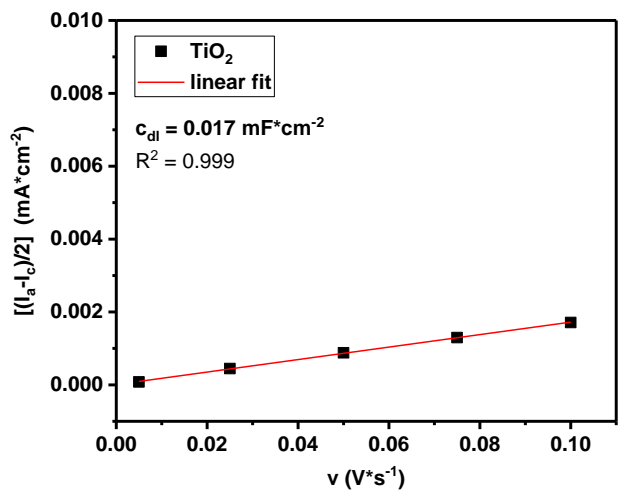

Figure A5.2. Determination of the electrochemical active surface area (ECSA) via double layer capacitance $\left(\mathrm{c}_{\mathrm{dl}}\right)$. CVs in a non-faradaic potential region were recorded in background electrolyte $\left[0.5 \mathrm{~mol} \mathrm{~L}^{-1} \mathrm{Na}_{2} \mathrm{SO}_{4}\right]$ at various scan rates $(5,10,25,50,75$, $\left.100 \mathrm{mV} \mathrm{s}^{-1}\right)$. The linear correlation between $\left(\mathrm{I}_{\mathrm{a}}-\mathrm{I}_{\mathrm{c}}\right) / 2$ vs. scan rate is shown for a) $\mathrm{TiO}_{\mathrm{x}}: \mathrm{Nb}$; b) $\mathrm{TiO}_{\mathrm{x}}$; c) $\mathrm{TiO}_{2}: \mathrm{Nb}$ and d) $\mathrm{TiO}_{2}$. The slope is giving the $\mathrm{c}_{\mathrm{dl}}$ representative for the ECSA. 


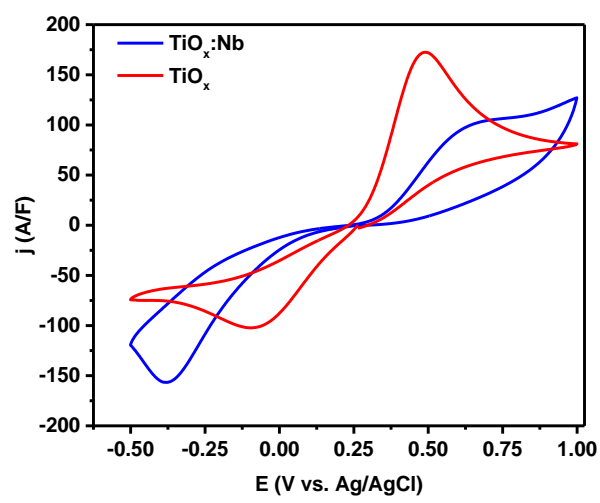

Figure A5.3. ECSA $\left(\mathrm{c}_{\mathrm{dl}}\right)$ corrected $\mathrm{CV}$ of $\mathrm{Fe}^{2+/ 3+}$ oxidation and reduction. $\mathrm{CT}$ of $\mathrm{TiO}_{\mathrm{x}}$ is superior than for $\mathrm{TiO}_{\mathrm{x}}: \mathrm{Nb}$

a)

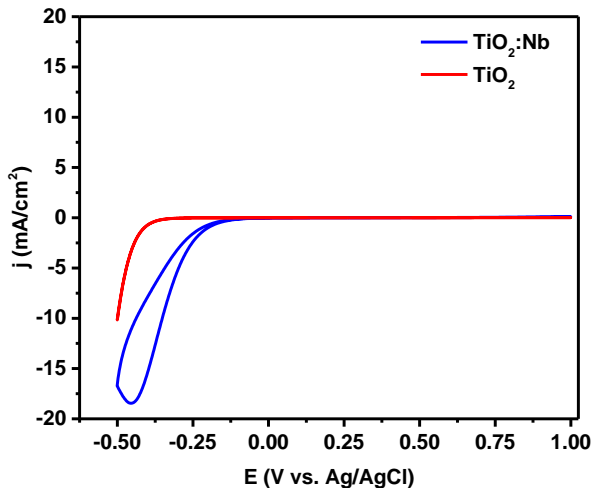

b)

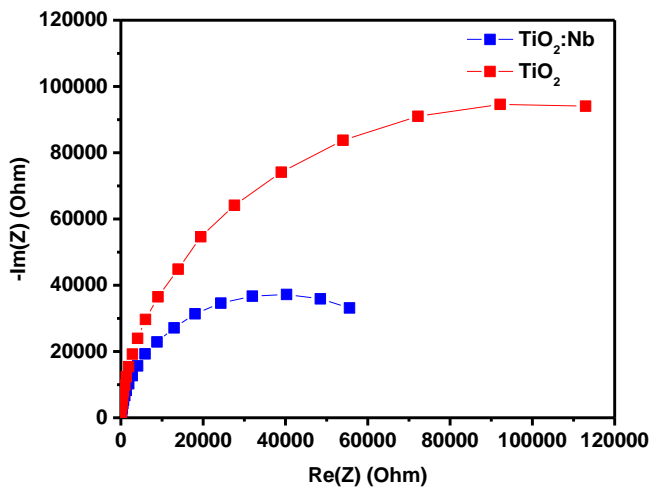

Figure A5.4. CT measurements of initial $\mathrm{TiO}_{2}$ and $\mathrm{TiO}_{2}: \mathrm{Nb}\left(\mathrm{t}_{\mathrm{c}}=0 \mathrm{~min}\right)$; a) $\mathrm{CV}$ of $\mathrm{Fe}^{2+/ 3+}$ oxidation and reduction; b) EIS $\left(\mathrm{TiO}_{2} 2 \times 10^{5} \Omega, \mathrm{TiO}_{2}: \mathrm{Nb}_{8} \times 10^{4} \Omega\right)$ 
a)

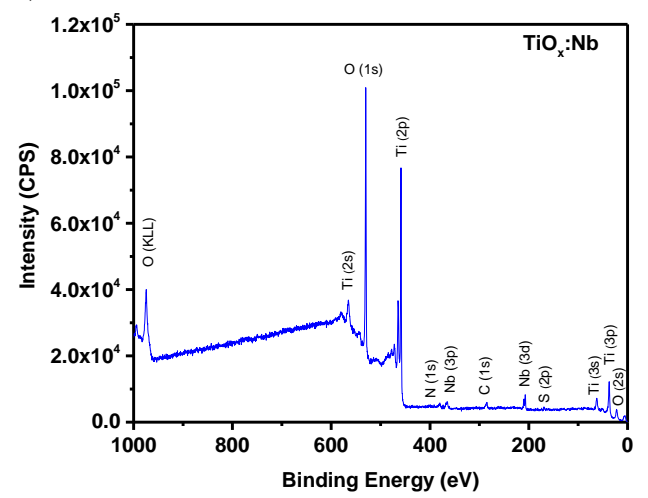

c)

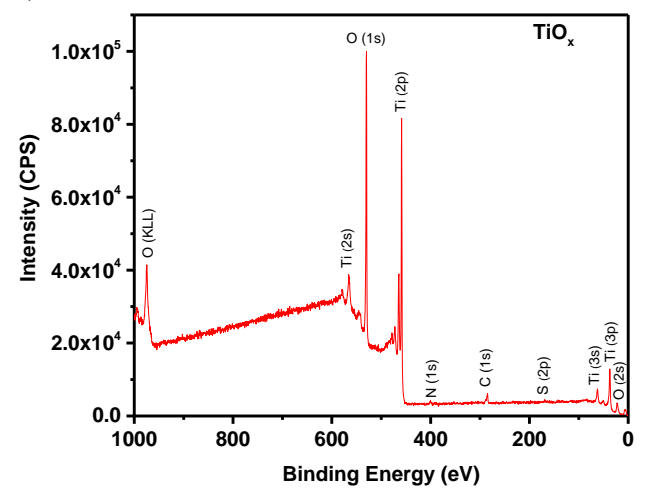

b)

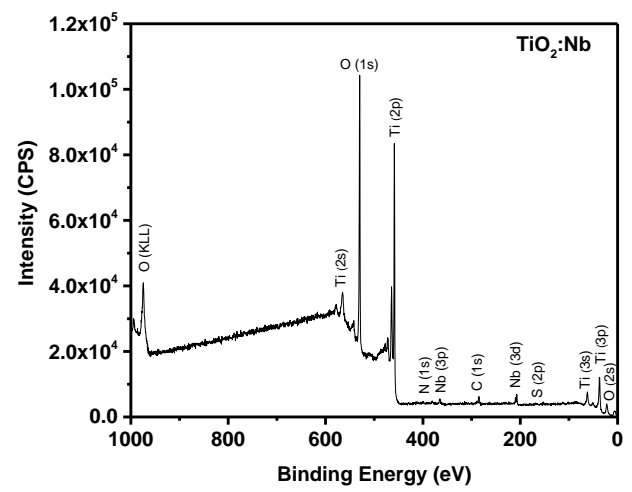

Figure A5.5. XPS survey spectra of a) $\mathrm{TiO}_{\mathrm{x}}: \mathrm{Nb}\left(\mathrm{t}_{\mathrm{c}}=180 \mathrm{~min}\right)$, b) $\mathrm{TiO}_{2}: \mathrm{Nb}\left(\mathrm{t}_{\mathrm{c}}=0 \mathrm{~min}\right)$ and c) $\mathrm{TiO}_{\mathrm{x}}\left(\mathrm{t}_{\mathrm{c}}=180 \mathrm{~min}\right)$. Except $\mathrm{Nb}$, no difference between doped and undoped $\mathrm{TiO}_{\mathrm{x}}$ is observed. For all samples a $\mathrm{Ti} / \mathrm{O}$ ratio of $\approx 0.41-0.42$ is determined. 
a)

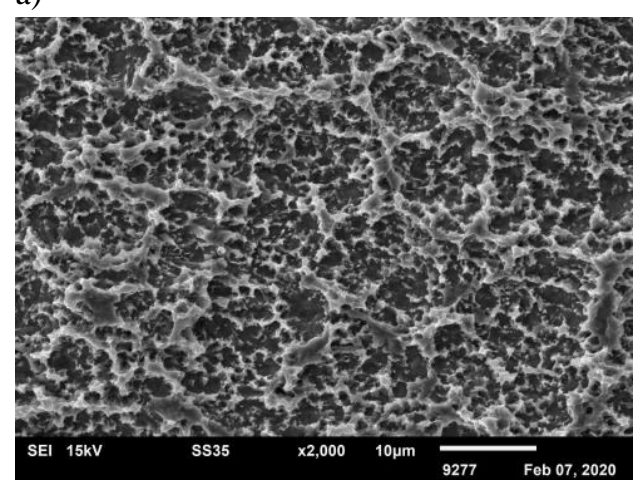

c)

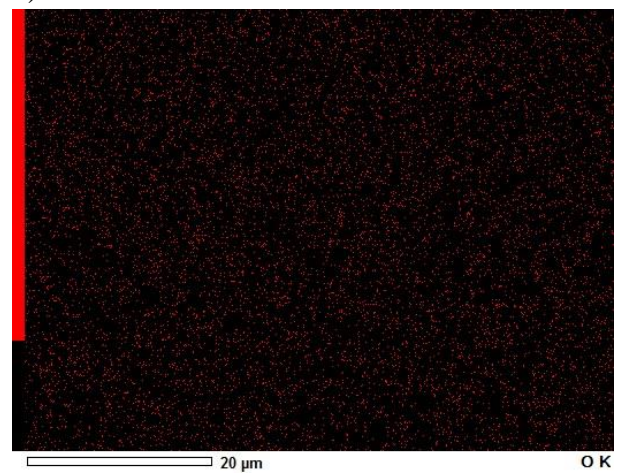

b)

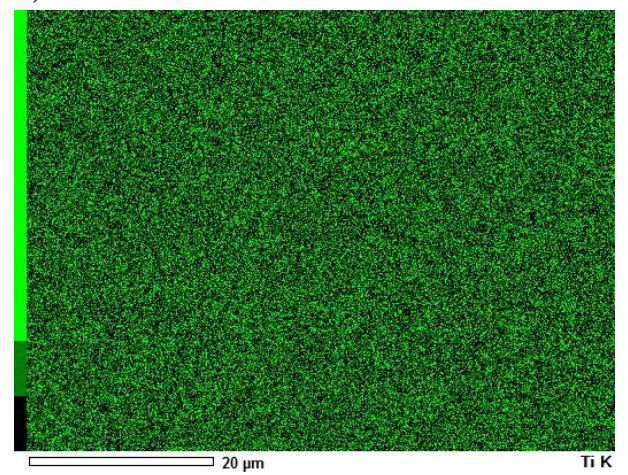

d)

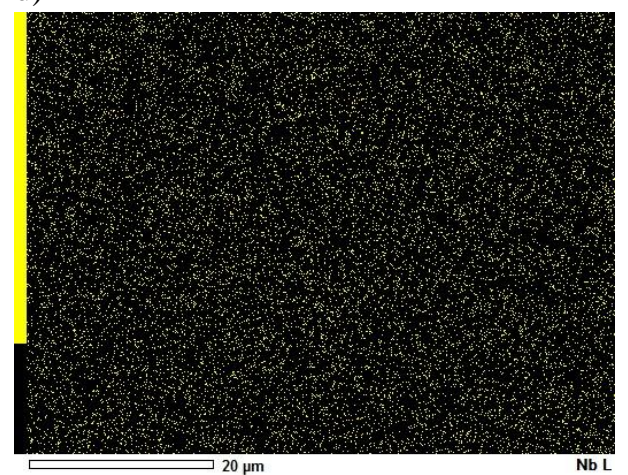

Figure A5.6. [a - d] SEM-EDX mapping analysis: a) SEM image of $\mathrm{TiO}_{\mathrm{x}}: \mathrm{Nb}$ with b) $\mathrm{Ti}$ distribution, c) oxygen distribution, d) $\mathrm{Nb}$ distribution. Images were taken after $\mathrm{CT}$ characterization. No difference for the $\mathrm{TiO}_{\mathrm{x}}: \mathrm{Nb}$ sample compared to non-cathodized $\mathrm{TiO}_{2}: \mathrm{Nb}$ was observed 
e)

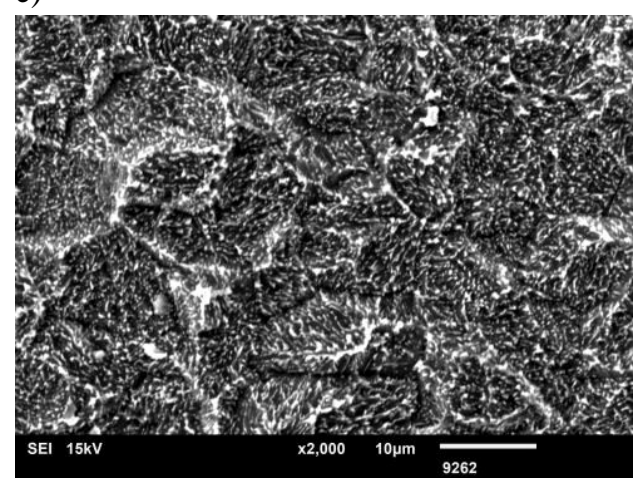

f)

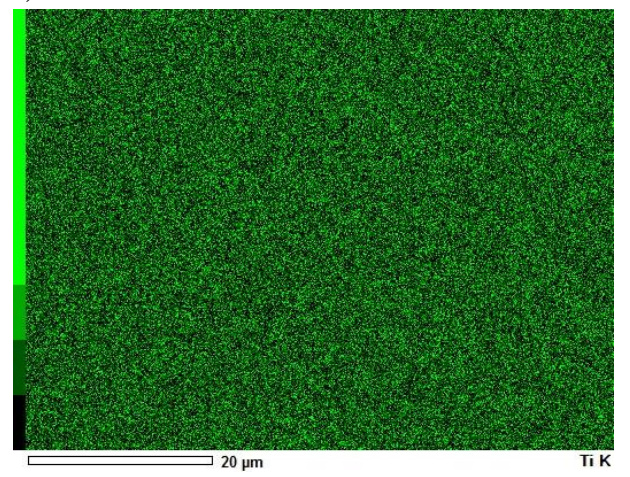

g)

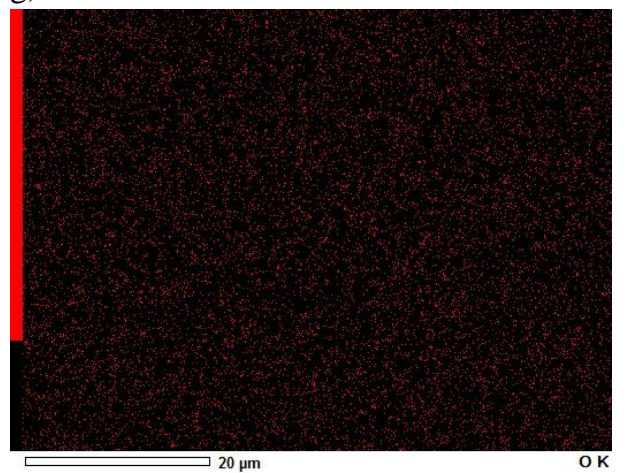

Figure A5.6. [e - g] e) SEM image of $\mathrm{TiO}_{\mathrm{x}}$ with f) Ti distribution, g) oxygen distribution. Images were taken after $\mathrm{CT}$ characterization. 
a)

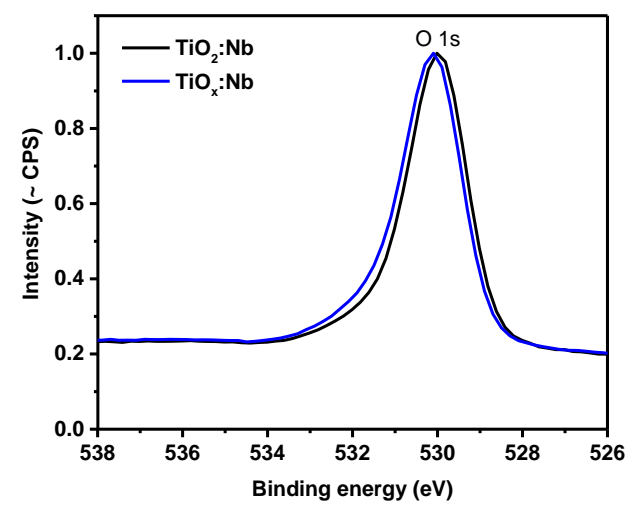

c)

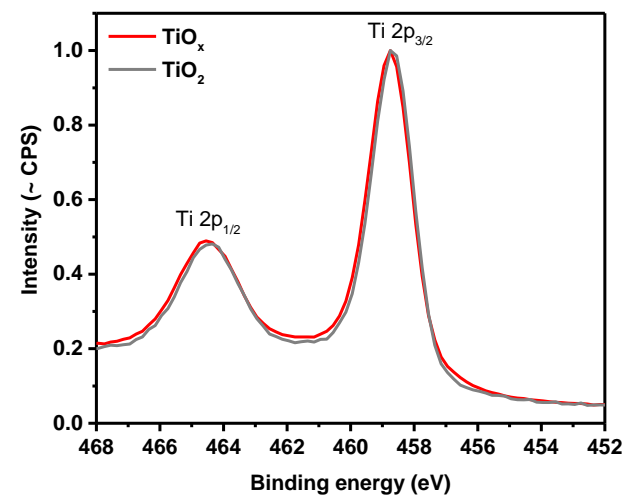

b)

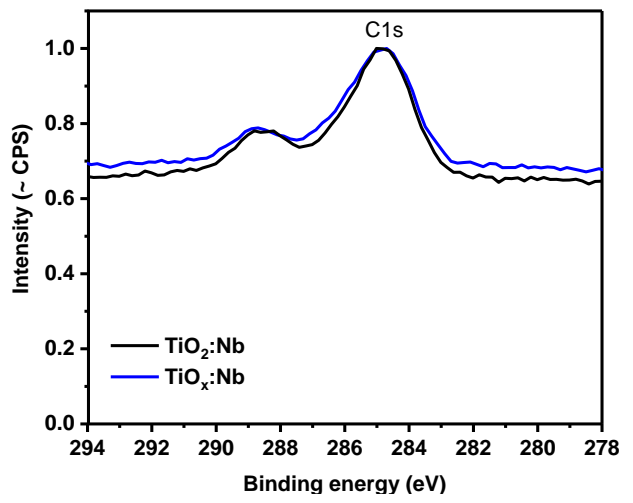

d)

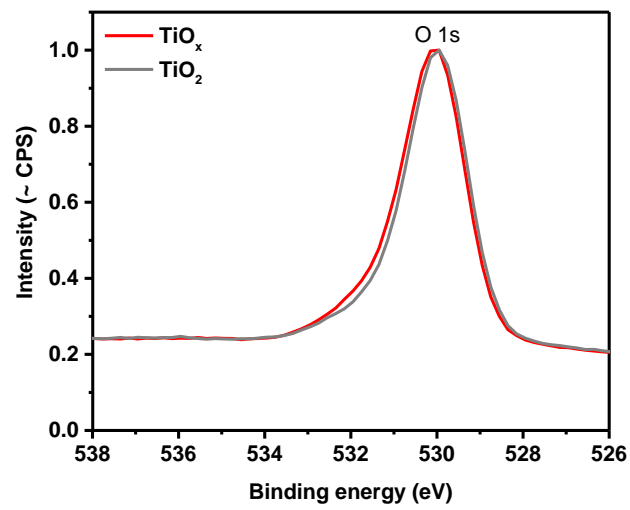

Figure A5.7. XPS core spectra of $\mathrm{Nb}$ doped and $\mathrm{Nb}$ free $\mathrm{TiO}_{2}$ and $\mathrm{TiO}_{\mathrm{x}}$. a) $\mathrm{O}$ 1s and b) $\mathrm{C} 1 \mathrm{~s}$ for $\mathrm{Nb}$ doped $\mathrm{TiO}_{2}$ before and after cathodization; c) $\mathrm{Ti} 2 \mathrm{p}$ and c) $\mathrm{O} 1 \mathrm{~s}$ of $\mathrm{Nb}$ free $\mathrm{TiO}_{2}$ and $\mathrm{TiO}_{x}$ 
a)

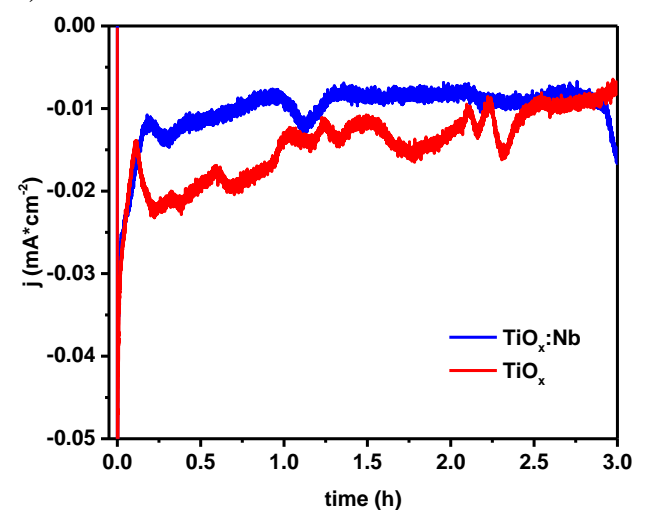

c)

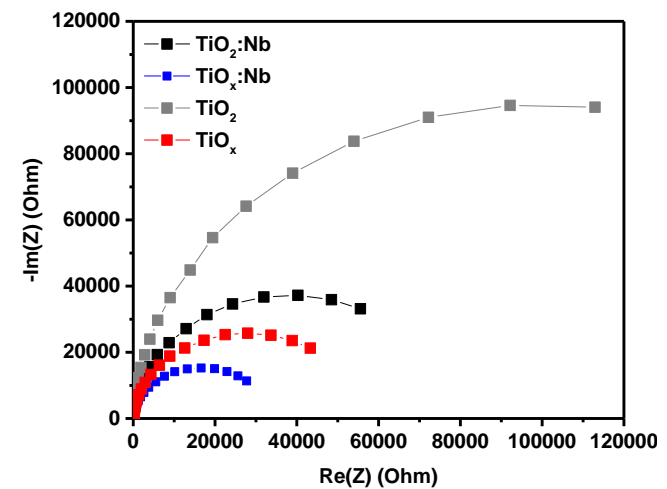

b)

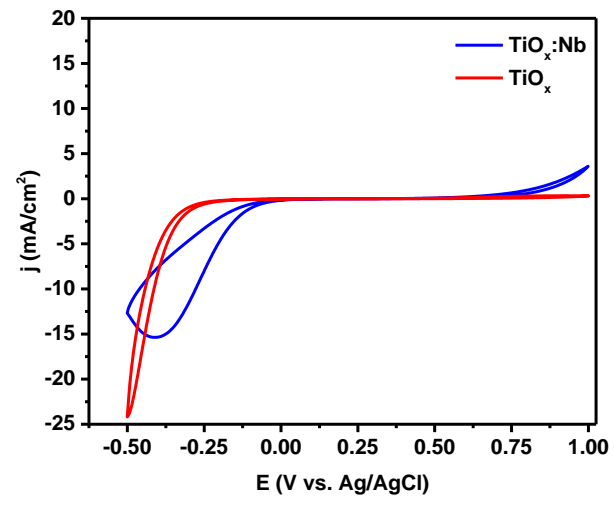

Figure A5.8. a) Cathodization current densities of $\mathrm{TiO}_{\mathrm{x}}$ and $\mathrm{TiO}_{\mathrm{x}}: \mathrm{Nb}$ at $-0.5 \mathrm{~V}$ vs. RHE in $1 \mathrm{~mol} \mathrm{~L}^{-1} \mathrm{H}_{2} \mathrm{SO}_{4}$ (no significant $\mathrm{HER}$ ); b) $\mathrm{Fe}^{2+/ 3+}$ redox couple $\mathrm{CV}$ and c) EIS measurements after cathodization. Although $\mathrm{TiO}_{\mathrm{x}}: \mathrm{Nb}$ shows superior $\mathrm{CT}$ properties after cathodization, $\mathrm{TiO}_{\mathrm{x}}$ shows a higher relative improvement in CT resistance (Table A5.1).

Table A5.1. Resistance of initial $\mathrm{Nb}$ doped and undoped $\mathrm{TiO}_{2}$ and after cathodization at $-0.5 \mathrm{~V}$ vs. RHE or $-0.8 \mathrm{~V}$ vs. RHE in $1 \mathrm{~mol} \mathrm{~L}^{-1} \mathrm{H}_{2} \mathrm{SO}_{4}$.

\begin{tabular}{|c|c|c|c|c|c|}
\hline$\#$ & $\begin{array}{c}\mathrm{R}_{\text {initial }} \\
{[\Omega]}\end{array}$ & $\begin{array}{c}\mathrm{R}_{\text {reduced }} \\
{[\Omega]}\end{array}$ & $\begin{array}{c}\mathrm{R}_{\text {reduced }} / \\
\mathrm{R}_{\text {initial }} \\
{[\%]}\end{array}$ & $\begin{array}{c}\text { Reduction } \\
{[\%]}\end{array}$ & $\begin{array}{c}\mathrm{R}_{\text {reduced }} \\
{[\Omega]}\end{array}$ \\
\hline & $\begin{array}{c}\text { Initial } \\
\left(\mathrm{t}_{\mathrm{c}}=0 \mathrm{~min}\right)\end{array}$ & $\begin{array}{c}\text { cathodization } \\
@-0.5 \mathrm{~V}_{\mathrm{RHE}} \\
\left(\mathrm{t}_{\mathrm{c}}=180 \mathrm{~min}\right)\end{array}$ & & $\begin{array}{c}\text { cathodization } \\
@-0.8 \mathrm{~V}_{\mathrm{RHE}} \\
\left(\mathrm{t}_{\mathrm{c}}=180 \mathrm{~min}\right)\end{array}$ \\
\hline $\mathrm{TiO}_{2 \text { or } \mathrm{x}}$ & $1.98 \mathrm{E} 5$ & $5.43 \mathrm{E} 4$ & 27 & 73 & 50 \\
\hline $\mathrm{TiO}_{2 \text { or } x}: \mathrm{Nb}$ & $7.94 \mathrm{E} 4$ & $3.23 \mathrm{E} 4$ & 41 & 59 & 525 \\
\hline
\end{tabular}




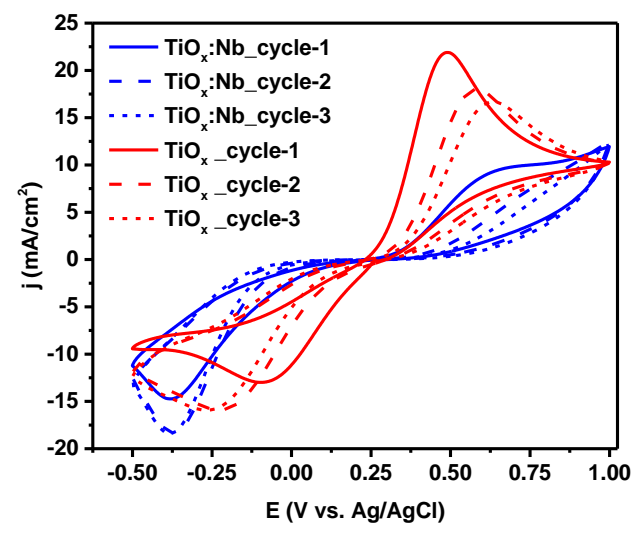

Figure A5.9. CT characterization of $\mathrm{TiO}_{\mathrm{x}}$ and $\mathrm{TiO}_{\mathrm{x}}: \mathrm{Nb}\left(\mathrm{t}_{\mathrm{c}}=180 \mathrm{~min}\right)$. The $\mathrm{CV}$ of $\mathrm{Fe}^{2+/ 3+}$ oxidation and reduction showing passivation already in the $1^{\text {st }}$ cycle

Table A5.2. Resistance of $\mathrm{Nb}$ doped and undoped $\mathrm{TiO}_{2}$ before and after cathodization in $0.5 \mathrm{~mol} \mathrm{~L}^{-1} \mathrm{Na}_{2} \mathrm{SO}_{4}$ for $15 \mathrm{~min}$ at $-5 \mathrm{~mA} \mathrm{~cm}^{-2}$

\begin{tabular}{|c|c|c|c|c|}
\hline$\#$ & $\begin{array}{c}\mathrm{R}_{\text {initial }} \\
{[\Omega]}\end{array}$ & $\begin{array}{c}\mathrm{R}_{\text {reduced }} \\
{[\Omega]}\end{array}$ & $\begin{array}{c}\mathrm{R}_{\text {reduced }} / \\
\mathrm{R}_{\text {initial }} \\
{[\%]}\end{array}$ & $\begin{array}{c}\text { Reduction } \\
{[\%]}\end{array}$ \\
\hline- & $\begin{array}{c}\text { initial } \\
\left(\mathrm{t}_{\mathrm{c}}=0 \mathrm{~min}\right)\end{array}$ & $\begin{array}{c}15 \mathrm{~min} \mathrm{@} \\
-5 \mathrm{~mA} \mathrm{~cm}{ }^{-2} \\
\left(0.5 \mathrm{~mol} \mathrm{~L}^{-1}\right)\end{array}$ & - & - \\
\hline $\mathrm{TiO}_{2}$ or x & $1.98 \mathrm{E} 5$ & $4.87 \mathrm{E} 3$ & 3 & 97 \\
\hline $\mathrm{TiO}_{2}$ or $\mathrm{x}: \mathrm{Nb}$ & $7.94 \mathrm{E} 4$ & $2.70 \mathrm{E} 4$ & 34 & 66 \\
\hline
\end{tabular}


a)

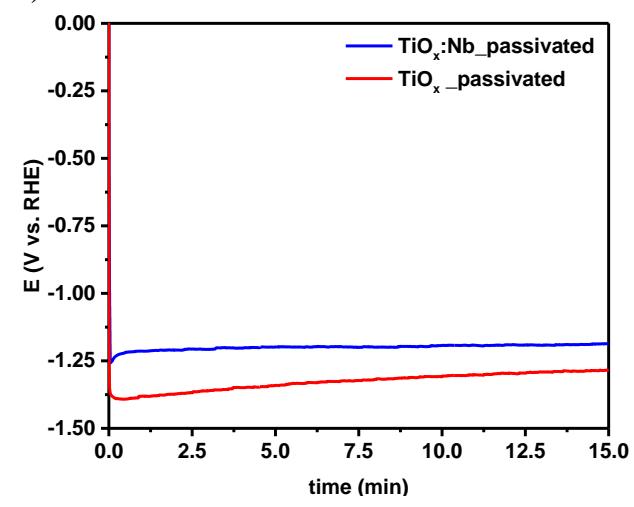

c)

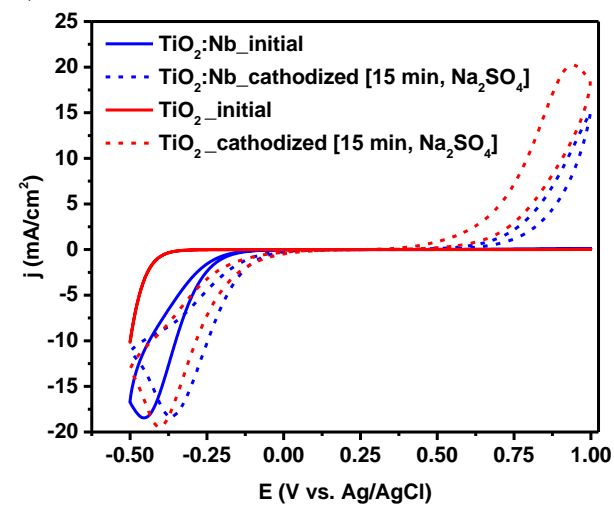

b)

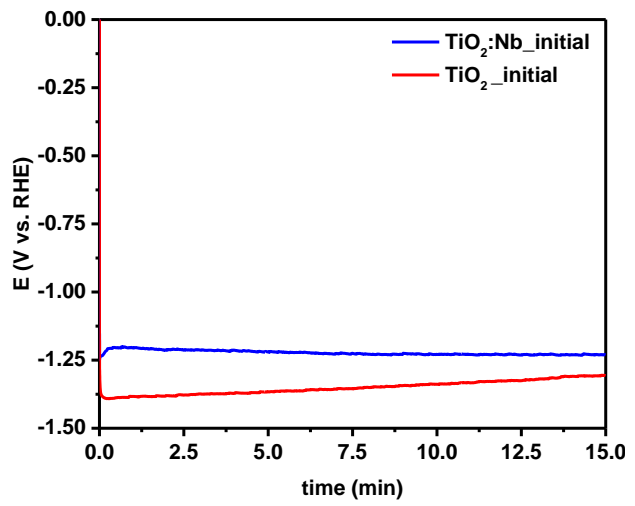

d)

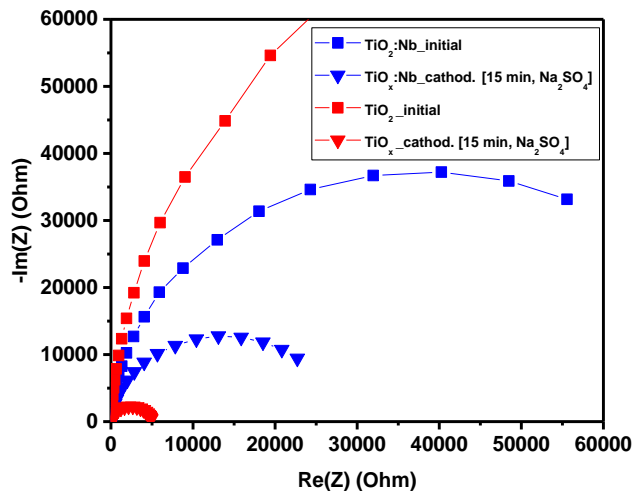

Figure A5.10. Cathodization at $-5 \mathrm{~mA} \mathrm{~cm}^{-2}$ in $\mathrm{Na}_{2} \mathrm{SO}_{4}$ electrolyte $\left[0.5 \mathrm{~mol} \mathrm{~L}^{-1}\right]$ of a) passivated $\mathrm{Nb}$ doped and $\mathrm{Nb}$ free $\mathrm{TiO}_{\mathrm{x}}$ and b) pristine $\mathrm{TiO}_{2}: \mathrm{Nb}$ and $\mathrm{TiO}_{2}$. In both cases, for the $\mathrm{Nb}$ doped material a lower potential is necessary, in agreement with the superior HER; c) $\mathrm{Fe}^{2+/ 3+}$ redox couple $\mathrm{CV}$ and d) EIS measurements after cathodization of pristine $\mathrm{TiO}_{2}: \mathrm{Nb}$ or $\mathrm{TiO}_{2}$. $\mathrm{TiO}_{\mathrm{x}}$ shows better CT properties after cathodization and a higher degree of CT-R reduction (see also Table A5.2) 


\section{Chapter 6}

\section{Cathodic reduction of oxychlorides in electrooxidized saline water}

The formation of toxic oxychlorides, such as hypochlorite and chlorate, is a crucial drawback in electrochemical advanced oxidation processes for saline wastewater treatment. The oxidation of ubiquitous chloride is difficult to avoid at potentials required for hydroxyl radical formation, and a reductive post-treatment step for electrooxidized saline water to minimize the oxychloride concentration and thereby the toxicity of the water is required. In this study, various electrode materials, namely $\mathrm{Ti}$, platinized $\mathrm{Ti}$, electrochemically reduced $\mathrm{TiO}_{\mathrm{x}}$ and $\mathrm{Ir}$ and/or Ru-mixed metal oxide electrodes were evaluated for their performance in reduction of low concentrations of hypochlorite and chlorate. Faradaic efficiencies, kinetic rate constants and energy consumption were analyzed. None of the electrodes showed reduction of chlorate under the conditions studied. However, significant removal of hypochlorite was observed, with Ti electrodes being most effective. RDE experiments revealed that hypochlorite reduction on $\mathrm{Ti}$ and Pt electrodes is mass transport limited. On the contrary, Ir and Ru mixed metal oxide electrodes showed low activity. Application of novel porous Ti based hollow-fibre electrodes, using inert gas purging through the fibre, leads to significant improvements in the rates of hypochlorite reduction, confirming mass transport limitations apply for Ti. Toxicity tests confirm the enhanced removal using the fibre electrodes, showing a reduction in toxicity of more than 30 times (based on the half maximal effective concentration) within $24 \mathrm{~h}$ of reductive treatment, in comparison to non-treated water.

This chapter is based on R. Brüninghoff, P. Saha, P. M. Krzywda, A.W. Jeremiasse, G. Mul, B. Mei, Cathodic reduction of oxychlorides in electrooxidized saline water; in preparation 


\subsection{Introduction}

During electrochemical advanced oxidation process (EAOP) the oxidation of chloride (ubiquitous for many industrial wastewaters ${ }^{1}$ ) is difficult to avoid because of the high anodic potentials necessary for hydroxyl radical formation $\left(\mathrm{E}^{0}=2.7 \mathrm{~V}\right){ }^{2}$ This is due to the fact that the chlorine evolution reaction (CIER) has a lower standard potential of formation $\left(\mathrm{E}^{0}=1.36 \mathrm{~V}\right)$ and favorable kinetics. ${ }^{3,4}$ Thus, besides the formation of chlorinated organics significant amounts of hypochlorite, chlorate and sometimes even perchlorate are generated during the treatment of saline wastewater. ${ }^{5-9}$ For example concentrations up to $100 \mathrm{mg} \mathrm{L}^{-1}$ free chlorine (FC = $\mathrm{Cl}_{2 \text { (dissolved) }}+\mathrm{HOCl}+\mathrm{OCl}^{-}$) have been observed ${ }^{6,10-12}$ along with similar amounts for chlorate $^{7,13}$ (see also Chapter 3). Sometimes even higher values have been reported. For example Jasper et al. observed up to $\approx 2.8 \mathrm{~g} \mathrm{~L}^{-1} \mathrm{FC}$ and $\approx 6.3 \mathrm{~g} \mathrm{~L}^{-1}$ of $\mathrm{ClO}_{3}{ }^{-8}$. The formation of oxychlorides is problematic, not only due to the hypochlorite induced chlorination of organic compounds (as discussed in Chapter 2),${ }^{10}$ but also because of the increase in toxicity of the treated water. ${ }^{14}$ Both, hypochlorite and chlorate are listed in the globally harmonized system (GHS) as (very) toxic to aquatic life causing long lasting effects and are thus detrimental for the environment. ${ }^{14-16}$ Moreover, because of the toxicity, the world's health organization (WHO) recommends drinking water not to exceed $0.7 \mathrm{mg} \mathrm{L}^{-1}$ of chlorate. ${ }^{17}$ Therefore, discharging of high concentrations of oxychlorides in surface water must be avoided.

As a potential solution, a reductive treatment of oxychlorides in combination with the EAOP has been suggested by Garcia-Segura et al. ${ }^{13}$ and was first demonstrated by Drennan et al. ${ }^{12}$ A reduction of free chlorine of about $50 \%$ during a post-treatment using BDD, graphite or stainless-steel cathodes has been reported. Looking at the EAOP, in general the $\mathrm{CE}$ is used to produce hydrogen (as side product). Alternatively, the CE can be used for the reduction of oxychlorides or chlorine containing organic molecules, thus to reduce the overall toxicity. ${ }^{12}$ The overall principle is shown in Scheme 6.1. For the electrochemical process the oxidation and reduction reaction are spatially separated. A cathode needs to be developed, to achieve high removal rates and low kinetic barriers. In addition, the reductive posttreatment step can have a beneficial effect on the reductive dehalogenation of halocarbons. ${ }^{12,18-21}$ 


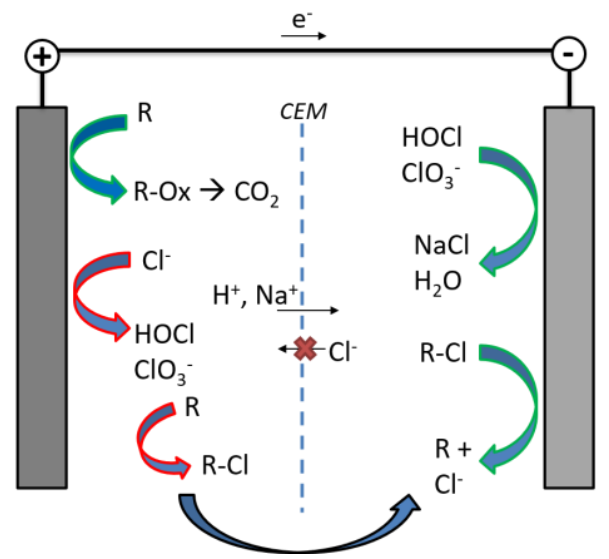

Scheme 6.1. Post-treatment step of electrooxidized saline water to reduce oxychlorides and lower the overall toxicity.

The electrochemical reduction of oxychlorides is well known and should be prevented in the industrial electrochemical production of chlorate, which is performed at elevated temperatures, high electrolyte concentrations and high current densities. ${ }^{3,22-27}$ In general, the electrochemical reduction of hypochlorite and chlorate occurs following the reactions shown in Eq. 6.1-6.3:28

$$
\begin{array}{lll}
\mathrm{HClO}+\mathrm{H}^{+}+2 \mathrm{e}^{-} \leftrightarrow \mathrm{Cl}^{-}+2 \mathrm{OH}^{-} & 1.482 \mathrm{~V} & \text { (Eq. 6.1) } \\
\mathrm{ClO}^{-}+\mathrm{H}_{2} \mathrm{O}+2 \mathrm{e}^{-} \leftrightarrow \mathrm{Cl}^{-}+2 \mathrm{OH}^{-} & 0.81 \mathrm{~V} & \text { (Eq. 6.2) } \\
\mathrm{ClO}_{3}^{-}+3 \mathrm{H}_{2} \mathrm{O}+6 \mathrm{e}^{-} \leftrightarrow \mathrm{Cl}^{-}+6 \mathrm{OH}^{-} & 0.62 \mathrm{~V}
\end{array}
$$

The reduction of hypochlorite (Eq. 6.1 and Eq. 6.2) is a fast reaction, often limited by diffusion. ${ }^{24,27,29-34}$ The reaction follows first order kinetics proceeding in two steps (Eq. 6.4 and Eq. 6.5), where the adsorption of hypochlorite on the electrode surface (Eq. 6.4) is the rate limiting step: $:^{29,30,35}$

$$
\begin{aligned}
& \mathrm{ClO}^{-}+\mathrm{H}_{2} \mathrm{O}+\mathrm{e}^{-} \leftrightarrow \mathrm{Cl}_{\mathrm{ad}}+2 \mathrm{OH}^{-} \\
& \mathrm{Cl}_{\mathrm{ad}}+\mathrm{e}^{-} \leftrightarrow \mathrm{Cl}^{-}
\end{aligned}
$$

In contrast, the reduction of chlorate to chloride is more complex involving eight electrons and depends strongly on the electrode material. ${ }^{24,27,36,37}$ Tilak et al. ${ }^{36}$ did not observe any chlorate reduction for $\mathrm{Ni}, \mathrm{Co}, \mathrm{Mo}, \mathrm{Ti}, \mathrm{Hg}$ and graphite electrodes. 
Only iron and iron oxide electrodes showed chlorate reduction at $95{ }^{\circ} \mathrm{C}$. Hine et al..$^{31}$ did not observe chlorate reduction for Pt electrodes at room temperature. In contrast, Cornell et al..$^{33}$ observed $\mathrm{ClO}_{3}{ }^{-}$reduction on Pt electrodes at $70{ }^{\circ} \mathrm{C}$; however, the reduction rates observed for $\mathrm{Pt}$ were inferior compared to iron electrodes. For $\mathrm{RuO}_{2}$ electrodes the chlorate reduction was described to be very effective (studied at $70{ }^{\circ} \mathrm{C}$; current efficiency for hydrogen evolution reaction (HER) was only 5\%) ${ }^{38}$ Moreover, Brown et al. observed reduction of chlorate on $\mathrm{Ti}$ electrodes at $30{ }^{\circ} \mathrm{C}$ proposing a stepwise reduction of chlorate via formation of intermediates. ${ }^{39} \mathrm{In}$ addition, for $\mathrm{TiO}_{\mathrm{x}}$ nanotubes the reduction of $\mathrm{ClO}_{3}{ }^{-}$was observed leading to a lower degree of chlorate (and also hypochlorite) formation during EAOP, when the cell was operated in a polarization switch mode. ${ }^{40}$

The diffusion limitation of the oxychloride reduction reactions is problematic in order to achieve a high removal rate, especially for lower concentrations. Thus, the electrode and process conditions need to be designed to minimize mass transport limitations. Recently, Jong et al. developed porous Ti hollow fibre electrodes with a rough and large surface area due to the morphology of the electrodes consisting out of sintered Ti particles. ${ }^{41}$ Moreover, the application of a gas flow through the fibre (inside-out flow) introduces a vigorous mixing of the electrolyte close to the electrode-electrolyte interface because of gas bubbles, thus inducing favorable mass transport conditions.

In this study the removal of hypochlorite and chlorate by electrochemical reduction is studied in a two-compartment cell under conditions resembling electrooxidized water after anodic treatment (i.e. room temperature, relatively low oxychloride and electrolyte concentrations). Various electrode materials, namely $\mathrm{Ti}, \mathrm{Pt}$ and commercially available mixed metal oxide electrodes (MMO) based on $\mathrm{IrO}_{2}$ and/or $\mathrm{RuO}_{2}$ (mixed with $\mathrm{TiO}_{2}$ ) are evaluated, since their activity for oxychloride reduction has been proposed in literature and the materials are either a suited base material for the fibre or could serve for their modification (e.g. deposited as electrocatalyst). Additionally, home-made $\mathrm{TiO}_{\mathrm{x}}$ electrodes (see Chapter 4) are characterized for their activity to reduce hypochlorite and chlorate. In particular, the activity of $\mathrm{TiO}_{\mathrm{x}}$ is of interest, since the cathodic reduction of oxychlorides could be combined with lifetime enhancement during polarization cycling, as discussed in Chapter 5. The suitability of the various electrode materials is evaluated from several points of view, i.e. removal of hypochlorite and chlorate, kinetics, Faradaic efficiency (FE), energy 
consumption, and mass transport limitations. In addition, the effect of the reductive treatment on the toxicity of the water is discussed.

\subsection{Materials and methods}

\subsubsection{Chemicals, materials and equipment}

The following chemicals, materials and equipment were used in this study: $\mathrm{Na}_{2} \mathrm{SO}_{4}$ (> 99.0\%, Sigma Aldrich), $\mathrm{NaCl}$ ( $\geq 99 \%$, Sigma Aldrich); demineralized water (MQ water; Merck MilliQ system, resistivity > 18M $\Omega \mathrm{cm}$ ), $\mathrm{NaClO}$ solution (11$14 \%$ available chlorine, Alfa Aeasar), $\mathrm{NaClO}_{3}$ purified (recrystallized grade; Nouryon Pulp and Performance Chemicals AB Bohus, Sweden).

Ti plates $(2.5 \times 2.5 \mathrm{~cm}, 1 \mathrm{~mm}$ thickness, Ti grade 1 [>99.7\%], $\mathrm{P} / \mathrm{N}$ “ $\mathrm{C} 1148$ ”), platinized Ti electrodes (Ti/Pt), IrMMO electrodes (P/N "CHH”), RuIrMMO (P/N "INS") and RuMMO (P/N "DFG”) were provided by Magneto special anodes B.V. $\mathrm{TiO}_{\mathrm{x}}$ electrodes were prepared as described in Chapter 4 (deviation: cathodized geometric surface was $3.14 \mathrm{~cm}^{2}$ ). Ti fibre electrodes were prepared according to a method described in the literature. ${ }^{41}$

$\mathrm{Ti}$ and Pt RDE (5 mm outer diameter $\mathrm{x} 4 \mathrm{~mm}$ thickness) were purchased from Equilabrium (Lyon, France). MMO coatings were applied on Ti disk electrodes by Magneto special anodes B.V.

Electrochemical experiments were carried out using a polytetrafluoroethylene based custom-made two-compartment reactor with glass walls. A Nafion N115 cation exchange membrane (Ion Power, Germany) was used to separate the two compartments. An IrMMO coated mesh (Magneto special anodes B.V.) was used as counter electrode (CE). The cell volume of the working electrode (WE) compartment was approx. $100 \mathrm{~mL}$. All plate electrodes had a geometric surface area of $3.14 \mathrm{~cm}^{2}$. A Biologic SP-300 or VSP-9 potentiostat, controlled by EC-lab software was used. Experiments were performed in a three-electrode set-up using a $\mathrm{Ag} / \mathrm{AgCl}$ electrode (3 $\mathrm{M} \mathrm{NaCl}, \mathrm{BASi}$ ) as reference electrode (RE), except for the Ti-fibre experiments, which were carried out in a two-electrode set-up. The stability of the RE was monitored using a master-RE (Ag/AgCl; $3 \mathrm{M} \mathrm{NaCl}, \mathrm{BASi})$.

RDE studies were carried out with a Waver Vortex electrode rotator and a RDE glass cell $[\mathrm{V}=150 \mathrm{~mL}]$ (both Pine Research, USA). A Pt-CE was used in a CE compartment separated by a glass frit. 


\subsubsection{Degradation experiments}

Solutions with a starting concentration of $\mathrm{c}_{0} \approx 100 \mathrm{mg} \mathrm{L}^{-1} \mathrm{FC}$ or chlorate were prepared in $\mathrm{Na}_{2} \mathrm{SO}_{4}\left[4 \mathrm{~g} \mathrm{~L}^{-1}\right]+\mathrm{NaCl}\left[0.5 \mathrm{~g} \mathrm{~L}^{-1}\right]$ background electrolyte, to mimic electrooxidized wastewater (related to the Water Nexus project). The solution for hypochlorite experiments were always directly prepared before the experiments. A volume of $100 \mathrm{~mL}$ solution was filled in the WE compartment. The CE compartment was filled with only $\mathrm{Na}_{2} \mathrm{SO}_{4}$ electrolyte $\left[4 \mathrm{~g} \mathrm{~L}^{-1}\right]$. A current density of $2.5,5.0$ or $10.0 \mathrm{~mA} \mathrm{~cm}{ }^{-2}$ was applied. The reactor was continuously stirred using a magnetic stir bar (350 rpm). During the experiments samples for analysis were taken every hour (if not otherwise stated) using a syringe.

Hypochlorite reduction experiments using a Ti hollow fibre were carried out in the same reactor. The fibre were connected to a Swagelok tube (using epoxy-resin). An inert Argon flow of $20 \mathrm{~mL} \mathrm{~min}{ }^{-1}$ was applied, since this typically yields optimized mass transfer behavior. ${ }^{42}$ The electrolyte was pre-purged for $45 \mathrm{~min}$ before a current was applied (the $\mathrm{c}_{0}$ measurement was performed after $30 \mathrm{~min}$ ). For reference, degradation rates were also determined for a fibre without Ar-purge, while maintaining an Ar blanket above the solution after the pre-purge.

\subsubsection{Analysis}

The FC concentration was determined using a Hanna Instruments Free Chlorine photometer (HI 96711) and reagents (HI-93701) based on the DPD-method (using $\mathrm{N}, \mathrm{N}$-diethyl-p-phenylenediamine reagent). Samples were measured directly or after dilution (dilution factor $=25$; concentration rage of measurement $0.00-$ $5.00 \mathrm{mg} \mathrm{L}^{-1}$ ). Measurements were carried out in duplicate. The relative standard deviation of the measurements was determined as $2 \%$ (based on seven measurements at $\mathrm{c}_{0} \approx 100 \mathrm{mg} \mathrm{L}^{-1}$ ). CAL Check ${ }^{\mathrm{TM}}$ standards (HI-96771-11) of Hanna Instruments were used for photometer validation.

The chlorate and chloride concentrations were determined using a Thermo Scientific Dionex Ultimate 3000 ion chromatograph (IC) equipped with an autosampler and a Dionex Ion Pac AS14A analytical column using a hydroxide gradient. Samples were diluted (1:10), filtered with a Phenex RC membrane filter $(0.2 \mu \mathrm{m}$; Phenomenex) and measured in duplicate. The retention time of $\mathrm{Cl}^{-}$was $6.5 \mathrm{~min}$, and for $\mathrm{ClO}_{3}^{-} 7.6 \mathrm{~min}$. 
The acute toxicity of the samples was measured by a Microtox ${ }^{\circledR}$ toxicity test kit (model 500). Vibrio fischeri bacteria, purchased from Hach Lange France SAS, were diluted with the sample and exposed for $15 \mathrm{~min}$. Afterwards, the toxicity was determined by measuring the toxicity induced reduction in light emission of the bacteria. $\mathrm{CuSO}_{4}$ was used as a toxic control sample and $\mathrm{MQ}$ water was used as blank control to verify the analytical method. Measurements were carried out in triplicate.

\subsubsection{RDE experiments}

For RDE experiments the same solutions were used as described for the degradation experiments. The solutions were purged with $\mathrm{N}_{2}$ before $(\geq 30 \mathrm{~min}$ ) and during the $\mathrm{CV}$ measurements. The $\mathrm{CV}$ were recorded in the potential range of interest with a scan speed of $100 \mathrm{mV} \mathrm{s}^{-1}$. All CV are iR drop corrected (electrical impedance spectroscopy was used to determine the $\mathrm{iR}$ drop). Three consecutive $\mathrm{CV}$ cycles were recorded at 0, 100, 400, 900, 1600 and $2500 \mathrm{rpm}$ for each experiment. The third cycle resulted in reproducible $\mathrm{CV}$ (compared to $2^{\text {nd }}$ cycle) and was used for analysis.

\subsection{Results and discussion}

\subsubsection{Reduction of hypochlorite at various electrodes}

The reduction of hypochlorite was monitored as FC concentration (the sum of dissolved chlorine, hypochlorous acid and the hypochlorite ion). Since the $\mathrm{pH}$ of the hypochlorite solution was $\approx 10$, the hypochlorite ion is the dominating species in the solution ${ }^{43}$ and can be directly correlated to the FC measurements. In Figure 6.1 the removal of hypochlorite at $-2.5 \mathrm{~mA} \mathrm{~cm}^{-2}$ is shown (for $\left(\mathrm{c} / \mathrm{c}_{0}\right)$ vs. time plot see Figure A6.1a). After $7 \mathrm{~h}$ of reductive treatment Ti, Ti/Pt, IrRuMMO and RuMMO showed a removal of $\geq 50 \%$, whereas Ti showed the highest removal of $59 \%$. In contrast, for IrMMO and $\mathrm{TiO}_{x}$ electrodes a removal of only $38 \%$ or $41 \%$ was achieved respectively. Removal due to non-electrochemically induced reduction (e.g. by light) was determined to be $\leq 5 \%$ and can be neglected (Figure A6.1b). The removal was corrected for membrane cross-over losses, which were in general small $(<5 \%)$. For all electrodes apparent first order kinetics were observed as shown in Figure 6.1b, in agreement with studies of $\mathrm{OCl}^{-}$reduction on Pt electrodes. ${ }^{30,35} \mathrm{For} \mathrm{Ti}$, Ti/Pt, IrRuMMO and RuMMO, reduction rate constants of $\geq 0.1 \mathrm{~h}^{-1}$ were obtained with Ti showing the highest reduction rate constant $\left(0.13 \mathrm{~h}^{-1}\right)$ and $\operatorname{IrMMO}\left(0.07 \mathrm{~h}^{-1}\right)$ and $\mathrm{TiO}_{\mathrm{x}}\left(0.08 \mathrm{~h}^{-1}\right)$ the lowest as expected by the determined overall removal. 
a)

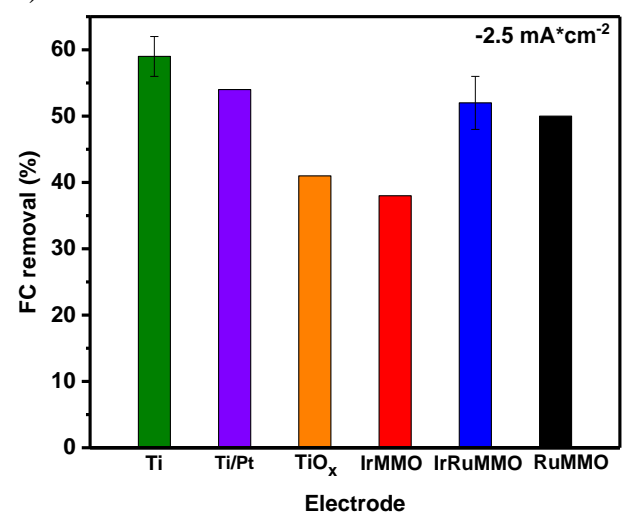

b)

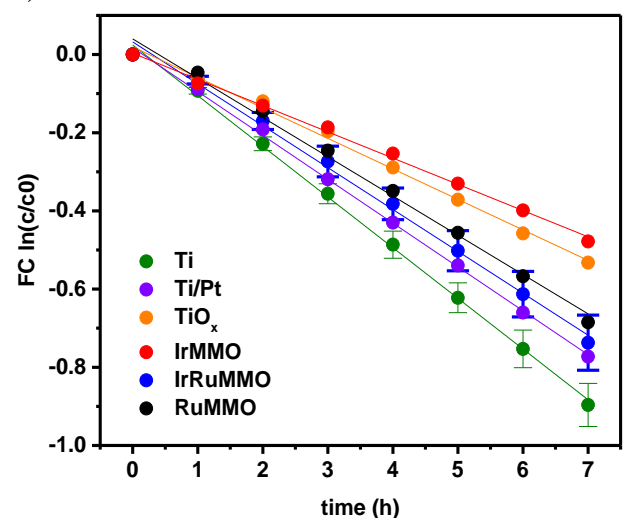

Figure 6.1. Reduction of hypochlorite [measured as FC (free chlorine), $\mathrm{c}_{0} \approx 100 \mathrm{mg} \mathrm{L}^{-1}$ ] using various electrodes ( $\mathrm{Ti}, \mathrm{Ti} / \mathrm{Pt}, \mathrm{TiO}_{\mathrm{x}}, \mathrm{IrMMO}, \mathrm{IrRuMMO}$ and $\mathrm{RuMMO}$ ) at a constant current of $-2.5 \mathrm{~mA} \mathrm{~cm}^{-2}$; a) removal of $\mathrm{FC}$ after $7 \mathrm{~h}$ of treatment; b) $1^{\text {st }}$ order degradation plots for the various electrodes tested. [See color codes for electrode composition]

Figure 6.2 provides an overview of the obtained FE for FC removal as a function of the determined rate constants for hypochlorite reduction (Figure 6.2a) and applied current densities (Figure 6.2b). Values for FC removal, FC reduction rate constants, Faradaic efficiencies and double layer capacitance $\left(c_{d l}\right.$; corresponding to the electrochemical active surface area; see Figure A6.2 for $\mathrm{c}_{\mathrm{dl}}$ determination) of the electrodes are summarized in Table A6.1. Further hypochlorite removal curves along with first order degradation plots and kinetic rate constants along with FE are provided in the appendix (Figure A6.3; Figure A6.4; Table A6.2). A general trend for decreasing FE with increasing current density can be observed. Increased current densities resulted in higher rate constants for the hypochlorite removal. Nevertheless, at higher current densities the competitive reaction, i.e. the hydrogen evolution reaction (HER), limits hypochlorite reduction. ${ }^{24,30,33,34}$ Given the fact that only at low current densities, i.e. at $-2.5 \mathrm{~mA} \mathrm{~cm}^{-2}$ the most significant differences between the electrodes compositions were resolved, $-2.5 \mathrm{~mA} \mathrm{~cm}^{-2}$ was considered as optimum current density (of the experimental set-up) for further evaluation. At this current density, the following trend in FE was observed $\mathrm{Ti}(11.2 \%)>\mathrm{Ti} / \mathrm{Pt}(10.2 \%) \approx$ $\operatorname{IrRuMMO}(9.7 \%) \approx \operatorname{RuMMO}(9.5 \%)>\mathrm{TiO}_{\mathrm{x}}(7.7 \%)>\operatorname{IrMMO}(7.2 \%)$, obviously in agreement with the trend for the rate constants determined. Considering the strong variations in the ECSA (Table A6.1), it can be concluded that Ti (and to a lesser extend also $\mathrm{TiO}_{\mathrm{x}}$ ) have the highest activities per electrochemical active site for 
hypochlorite reduction (see also Figure A6.5). The noble metal catalysts investigated are less effective due to the excessive formation of hydrogen.

a)

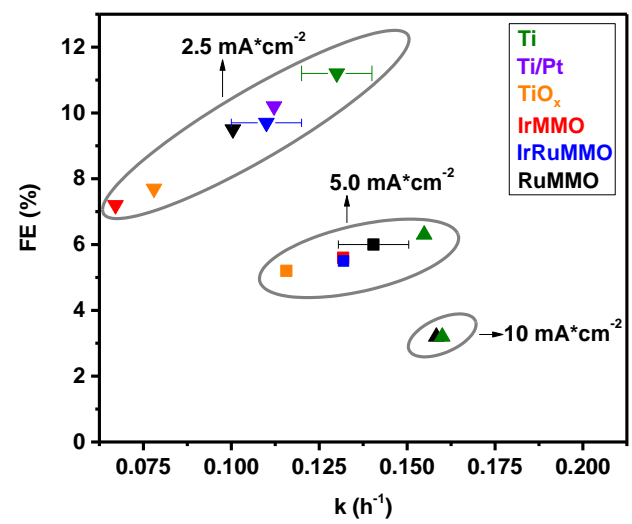

b)

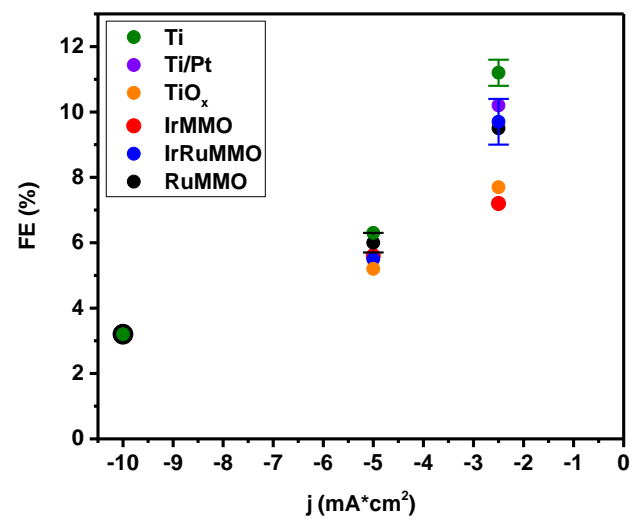

Figure 6.2. Faradaic efficiency of hypochlorite reduction (measured as FC, $\mathrm{c}_{0} \approx 100 \mathrm{mg} \mathrm{L}^{-1}$ ) for various electrodes ( $\mathrm{Ti}, \mathrm{Ti} / \mathrm{Pt}, \mathrm{TiO}_{\mathrm{x}}, \mathrm{IrMMO}_{\mathrm{IrRuMMO}}$ and $\mathrm{RuMMO}$ ) and various current densities $\left(-2.5 \mathrm{~mA} \mathrm{~cm} \mathrm{~cm}^{-2},-5 \mathrm{~mA} \mathrm{~cm}^{-2}\right.$ and $-10 \mathrm{~mA} \mathrm{~cm}$ ) are shown in a) vs. reduction rate constants; b) vs. applied current density.

In addition, rotating disc electrode (RDE) experiments were performed for all electrodes except $\mathrm{TiO}_{\mathrm{x}}$ (not available in the electrode configuration required) to characterize the electrochemical reduction of hypochlorite in more detail. The CVs recorded for the sulfate electrolyte in the absence or presence of hypochlorite are shown in the appendix (Figure A6.8 shows the overlay of CV recorded at $2500 \mathrm{rpm}$, Figure A6.9 shows the CV recorded at various scan speeds for the hypochlorite reduction). The hypochlorite reduction on Pt occurred at $<1.3 \mathrm{~V}$ vs. RHE, which is in good agreement with literature. ${ }^{32,44}$ For Ti a more negative potential was necessary $\left(<0.2 \mathrm{~V}\right.$ vs. RHE) indicating a higher overpotential for the hypochlorite reduction. ${ }^{34}$ For both electrodes a mass transport limited region was observed, confirmed by the straight correlation between the current densities and square root of the angular velocity $\left(R^{2} \geq 0.995\right)$ in the Levich analysis shown in Figure 6.3, which is in agreement with literature. ${ }^{30,32-34}$ For the MMO coated RDE hypochlorite reduction was observed $<0.75 \mathrm{~V}$ vs. RHE for IrMMO or $<0.5 \mathrm{~V}$ vs. RHE for RuMMO and IrRuMMO respectively, in agreement with literature confirming a higher overpotential necessary compared to $\mathrm{Pt} .{ }^{38} \mathrm{In}$ contrast to $\mathrm{Pt}$ or Ti, plateaus in the $\mathrm{CV}$ were absent. Therefore, a Koutecký-Levich plot was used for analysis and is shown in Figure $6.3 \mathrm{~b}$. The extrapolated $y$-axis intercept $\neq 0$ is a clear indication, that the 
MMO electrodes have a low activity for the hypochlorite reduction. Thus, further improvements require catalyst modification. In contrast, for $\mathrm{Ti}$ and $\mathrm{Pt}$ the removal efficiency can be improved by enhancing mass transport. Therefore, a smart electrode design e.g. by hollow fibre based on abundant Ti, would allow for a large number of active sites and mitigation of mass transport limitations. Moreover, a high surface roughness of electrodes has been reported being beneficial for the reduction of hypochlorite. ${ }^{27,34,45}$

a)

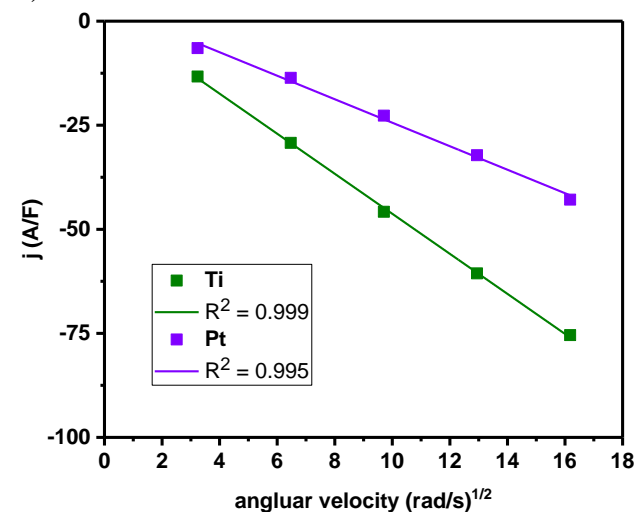

b)

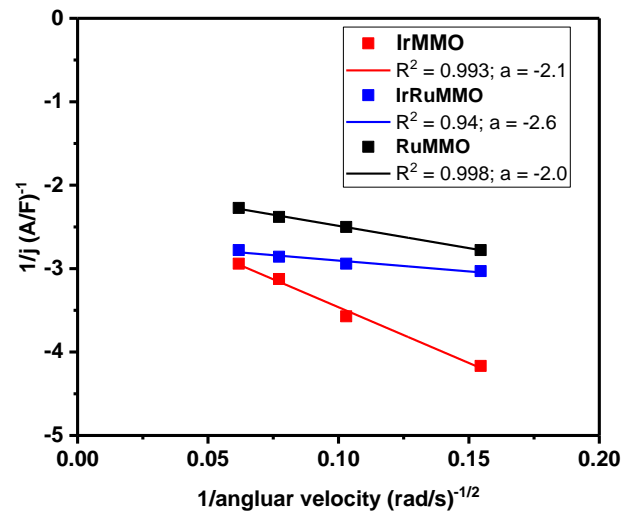

Figure 6.3. Analysis of mass transfer limitations for hypochlorite reduction $\left[\mathrm{c} \approx 100 \mathrm{mg} \mathrm{L}^{-1} \mathrm{FC}\right]$ using RDE. a) Levich analysis for hypochlorite reduction at $\mathrm{Ti}$ and $\mathrm{Pt}$ indicating a mass transport limited reaction; b) Koutecký-Levich analysis for IrMMO/Ti, IrRuMMO/Ti, RuMMO/Ti indicating a low activity for the reaction. [Current densities were normalized by $c_{\mathrm{dl}}$ to correct for differences in the ECSA (see Figure A6.6 for $\mathrm{c}_{\mathrm{dl}}$ determination); Koutecký-Levich analysis for Ti and $\mathrm{Pt}$ as well as Levich analysis for MMO electrodes is shown in Figure A6.7]

In Table A6.3, to underline that $\mathrm{Ti}$ is a beneficial electrode material, the energy consumption (based on the overall cell potential) is shown. The following trend was observed: $\mathrm{Pt} \approx \mathrm{IrMMO}<\mathrm{IrRuMMO} \approx \mathrm{RuMMO}<\mathrm{Ti}<\mathrm{TiO}_{\mathrm{x}}$, which is in agreement for the HER overpotential of the individual electrodes. However, for the energy consumption per removal of hypochlorite, the trend changed according to the following order: $\mathrm{Pt}<\mathrm{Ti}<\mathrm{IrRuMMO}<\mathrm{RuMMO}<\mathrm{IrMMO}<\mathrm{TiO}_{\mathrm{x}}$. Here, $\mathrm{Pt}$ and $\mathrm{Ti}$ show the lowest energy consumption, in accordance with the determined FE. Furthermore, for $\mathrm{IrMMO}_{\mathrm{M}} \mathrm{TiO}_{\mathrm{x}}$ the highest energy consumption per hypochlorite removal was determined. Consequently, these materials are less suited for hypochlorite reduction. 


\subsubsection{Reduction of chlorate at various electrodes}

In addition to the reduction of hypochlorite, the reduction of chlorate was studied. Due to the severe mass transfer limitations observed for hypochlorite reduction similar conditions as for the hypochlorite reduction were used (i.e. $-2.5 \mathrm{~mA} \mathrm{~cm}{ }^{-2}$, $\mathrm{c}_{0}=100 \mathrm{mg} \mathrm{L}^{-1} \mathrm{ClO}_{3}{ }^{-}, \mathrm{Na}_{2} \mathrm{SO}_{4}+\mathrm{NaCl}$ as supporting electrolyte). In Table 6.1 the chlorate concentrations after $7 \mathrm{~h}$ of continuous reductive treatment are summarized. For all electrodes studied, chlorate reduction was negligible and within the error of the measurement. Moreover, the chloride concentration kept constant during the experiments and no formation of FC (as potential intermediate) was observed. The results are interesting, because several reports in literature propose or show the electrochemical reduction of chlorate as described in the introduction. ${ }^{33,36,38,39} \mathrm{An}$ explanation might be the different conditions applied in this study. For example, the reduction of chlorate is in particular studied in the context of the chlorate process at elevated temperatures (e.g. $\geq 70^{\circ} \mathrm{C}$ ) and higher concentrations applied in the present study. ${ }^{33,36,38}$ Moreover, Cornell et al. ${ }^{38}$ observed an increased gas evolution (HER) at lower temperatures using $\mathrm{RuO}_{2}$ electrodes. In addition, Hine et al. ${ }^{31}$ did not observe any activity for chlorate reduction at Pt electrodes at room temperature. Therefore, it is likely that the elevated temperature reduces the kinetic barrier for chlorate reduction. The explanation is in agreement with Bancroft et al. ${ }^{46}$ reporting higher stability of chlorate against reduction compared to hypochlorite. Moreover, Booth et al. ${ }^{37}$ described the chlorate reduction as being activation controlled. Another explanation could be a (self-)inhibiting effect of (formed) $\mathrm{Cl}^{-}$ions adsorbed on active sites blocking further reduction reactions as proposed for perchlorate reduction; ${ }^{39,47}$ however, since the hypochlorite reduction proceeds easily in chloride containing solution this explanation seems less likely. The absence of electrochemical activity for chlorate reduction has been confirmed by CV (Figure A6.8). Thus, the electrochemical reduction of chlorate is not feasible under the conditions applied in this study. 
Table 6.1. Chlorate, chloride and FC concentration after $7 \mathrm{~h}$ of reduction for various electrodes ( $\mathrm{Ti}, \mathrm{Ti} / \mathrm{Pt}, \mathrm{TiO}_{\mathrm{x}}, \mathrm{IrMMO}, \mathrm{IrRuMMO}$ and RuMMO) at $-2.5 \mathrm{~mA} \mathrm{~cm}^{-2}$ $\left[\mathrm{c}_{0}=100 \mathrm{mg} \mathrm{L}^{-1}\right]$

\begin{tabular}{|c|c|c|c|}
\hline Electrode & $\begin{array}{c}\mathrm{ClO}_{3}{ }^{-} \mathrm{c}\left(\mathrm{t}_{7}\right) / \mathrm{c}\left(\mathrm{t}_{0}\right) \\
{[\%]}\end{array}$ & $\begin{array}{c}\mathrm{Cl}^{-} \mathrm{c}\left(\mathrm{t}_{7}\right) / \mathrm{c}\left(\mathrm{t}_{0}\right) \\
{[\%]}\end{array}$ & $\begin{array}{c}\mathrm{FC}\left(\mathrm{t}_{7}\right) \\
{\left[\mathrm{mg} \mathrm{L}^{-1}\right]}\end{array}$ \\
\hline $\mathrm{Ti}$ & 99 & 103 & 0 \\
\hline $\mathrm{TiPt}$ & 101 & 102 & 0 \\
\hline $\mathrm{TiO}$ & 99 & 101 & 0 \\
\hline IrMMO & 99 & 99 & 0 \\
\hline IrRuMMO & 99 & 98 & 0 \\
\hline RuMMO & 100 & 100 & 0 \\
\hline
\end{tabular}

\subsubsection{Hypochlorite reduction for toxicity removal using Ti hollow}

\section{fibre electrodes}

Ti hollow fibre were tested for hypochlorite reduction. A SEM cross-sectional image of the electrodes and the hypochlorite removal experiments, along with toxicity tests are shown in Figure 6.4. The SEM image (Figure 6.4a) shows a highly porous fibre (pore sizes $1.3-2.9 \mu \mathrm{m}$; outer diameter $1.9 \mathrm{~mm}$ ) with a rough surface. ${ }^{41}$ The reduction of hypochlorite is shown in Figure 6.4b. Under Ar purge conditions a clearly improved FC removal is observed. Already after $7 \mathrm{~h}$ a removal of $91 \%$ was obtained, corresponding to a rate constant of $0.35 \mathrm{~h}^{-1}$ leading to a $\mathrm{FE}$ of $31.5 \%$, whereas under non-purge conditions only $43 \%$ was removed $\left(0.08 \mathrm{~h}^{-1} ; 16.4 \% \mathrm{FE}\right)$. After 24 h 99\% removal was achieved (86\% for non-purge conditions). Since the $\mathrm{Ar}$ purge itself did not influence the FC concentration, the enhanced FC removal is solely attributed to the favorable mass transport conditions. The remarkable improvement in FE obtained, with Ar purge (approx. 3 - 5 times higher) and even without Ar purge (approx. 1.5 - 2.5 times higher), compared to the flat Ti plate electrodes (Figure 6.2; having a 3.5x larger geometric surface area $\left[0.15 \mathrm{~h}^{-1}\right.$ at $\left.-5 \mathrm{~mA}^{*} \mathrm{~cm}^{-2}\right]$ ), indicate that a larger active surface area of the fibre electrodes due to their surface morphology contributed additionally to the enhanced removal. Overall, the results show that the application of $\mathrm{Ti}$ hollow fibre for hypochlorite reduction improves the removal tremendously. 
a)

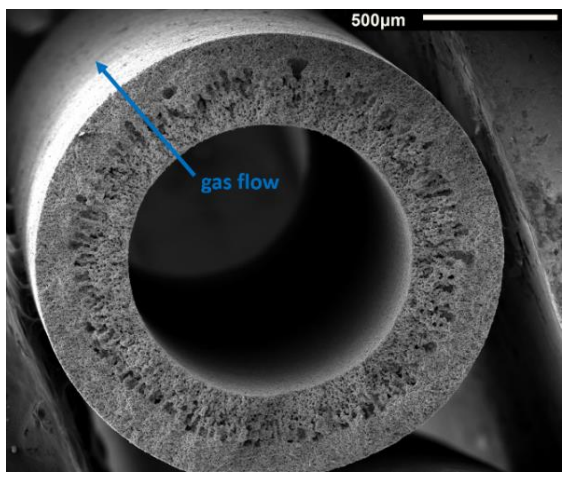

c)

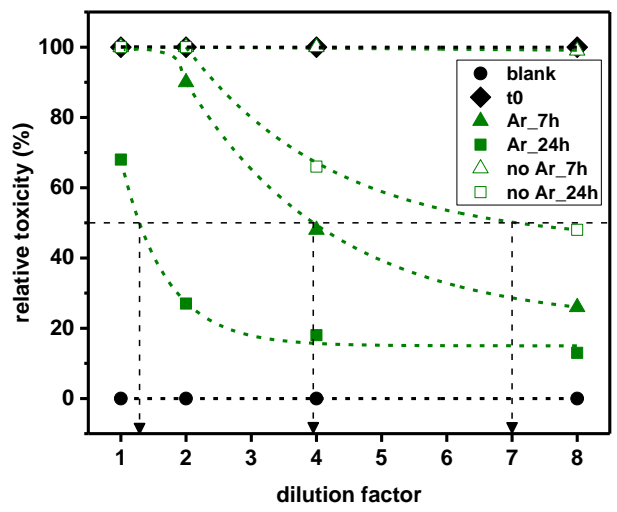

b)

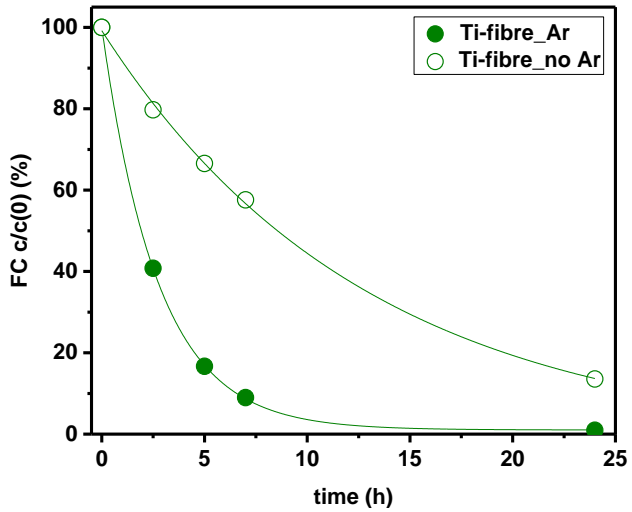

Figure 6.4. a) SEM cross sectional image of a Ti hollow fibre electrode showing a highly porous structure. The gas flow is inside-out, inducing strong electrolyte mixing at the electrode-electrolyte interface enhancing mass-transport. b) removal of hypochlorite $\left[\mathrm{c}_{0} \approx 100 \mathrm{mg} \mathrm{L}^{-1} \mathrm{FC}\right.$ ] at $-4.5 \mathrm{~mA} \mathrm{~cm}^{-2}$ for $24 \mathrm{~h}$ using porous Ti hollow fibre electrodes with and without Ar purge $\left(20 \mathrm{~mL} \mathrm{~min}^{-1}\right)$ for enhanced mass transport. c) Toxicity of water samples containing hypochlorite before $\left(\mathrm{t}_{0}\right)$ and after $7 \mathrm{~h}$ and $24 \mathrm{~h}$ of reductive treatment with and without Ar purge shown as a function of dilution for toxicity measurements. The vertical dashed lines indicate the dilution factor necessary to reach a relative toxicity level of $50 \%$ corresponding to the half maximal effective concentration $\left(\mathrm{EC}_{50}\right)$.

Finally, toxicity measurements have been carried out to assess the toxicity of the water before and after reductive treatment. Figure $6.4 \mathrm{c}$ shows the relative toxicity, determined by the inhibition of light emission from Vibrio fischeri bacteria (see experimental part for more information), as a function of dilution factor (f) of the water. After $24 \mathrm{~h}$ of reductive treatment under enhanced mass transport conditions (Ar purge) the relative toxicity was reduced to $68 \%$, whereas for $7 \mathrm{~h}$ or non-Ar-purge 
conditions higher dilution was necessary to observe a reduction in the relative toxicity. For the stock solution and the water treated for only $7 \mathrm{~h}$ without Ar purge, the toxicity was for all dilutions $100 \%$, due to the high initial or residual hypochlorite concentration respectively. In order to compare the reduction of the relative toxicity before and after the treatment, the dilution factor necessary to reach the half maximal effective concentration $\left(\mathrm{EC}_{50}\right.$; corresponding to a relative toxicity of $50 \%$ ) was determined. For the water treated for $24 \mathrm{~h}$ (under Ar purge) a dilution of only $\approx 1.3$ was necessary (Figure 6.4c), whereas for the non-treated water $\left(\mathrm{t}_{0}\right)$ a dilution of more than 40 times was necessary (Figure A6.10). Thus, the relative toxicity of the treated water could be lowered by a factor of $\approx 31$ (based on the dilution factors necessary to reach $\mathrm{EC}_{50}$ ).

Overall, an effective hypochlorite removal during the reductive treatment, as achieved under Ar-purge conditions, is most beneficial to obtain low toxicities. Still, residual hypochlorite results in significant relative toxicities, thus an even more effective hypochlorite removal is necessary. Further electrode as well as reactor and process optimization likely result in improved hypochlorite removal.

\subsection{Conclusions}

In this study the removal of toxic hypochlorite and chlorate by electrochemical reduction was investigated to reduce the overall toxicity of electrooxidized water. Various electrode materials, namely $\mathrm{Ti}$, platinized $\mathrm{Ti}$, Ir and $\mathrm{Ru}$ based mixed metal oxides and self-made $\mathrm{TiO}_{x}$ were evaluated. For all electrodes removal of hypochlorite followed apparent first order kinetics at the lowest current densities applied. The highest removal along with highest FE were obtained for Ti electrodes. The reduction of hypochlorite is mass transport limited on Ti and Pt electrodes, whereas the Ir and Ru-MMO based electrodes showed low activity as verified by RDE experiments. In contrast to the reduction of hypochlorite, no reduction of chlorate was observed for all studied electrodes, which can be likely attributed to the conditions of this study (i.e. reduction was studied only at room temperature). The application of novel Ti based hollow fibre electrodes and inert gas flow (inside-out) induced vigorous mixing of the electrolyte close to the liquid-solid interface resulting in favorable mass transport. As a consequence, clearly improved hypochlorite removal was achieved leading to $99 \%$ removal within $24 \mathrm{~h} \mathrm{(>90 \%}$ within first $7 \mathrm{~h}$ ). The experiments show that a smart electrode design is beneficial to 
achieve high hypochlorite removal rates. Finally, toxicity measurements before and after the reductive treatment showed a clear reduction in the toxicity of the water, confirming the suitability of the reductive post-treatment approach for remediation of electrooxidized wastewater. Electrode and process optimization will likely result in further improvements. For example, modification of Ti fibre by deposited $\mathrm{Pt}$ particles could reduce the overall overpotential, thus lowering the cell potential being beneficial for the energy consumption.

\subsection{Acknowledgements}

We would like to thank Magneto special anodes B.V. for coating the Ti disk substrates with mixed metal oxides and electrode supply. Ronald Jong is acknowledged for the support with Ti-fibers and discussions. Pengyu $\mathrm{Xu}$ is acknowledged for supporting the IC measurements. Elmar Boorsma is acknowledged for initial experiments. Robert Meijer is acknowledged for technical support. Nouryon Pulp and Performance Chemicals AB (Bohus, Sweden) is acknowledged for providing recrystallized sodium chlorate

\subsection{References}

(1) Lefebvre, O.; Moletta, R. Treatment of Organic Pollution in Industrial Saline Wastewater: A Literature Review. Water Res. 2006, 40 (20), 36713682. https://doi.org/http://dx.doi.org/10.1016/j.watres.2006.08.027.

(2) Armstronga, D. A.; Huie, R. E.; Lymar, S.; Koppenol, W. H.; Merényi, G.; Neta, P.; Stanbury, D. M.; Steenken, S.; Wardman, P. Standard Electrode Potentials Involving Radicals in Aqueous Solution: Inorganic Radicals. Bioinorg. React. Mech. 2013, 9 (1-4), 59-61. https://doi.org/10.1515/irm2013-0005.

(3) Karlsson, R. K. B.; Cornell, A. Selectivity between Oxygen and Chlorine Evolution in the Chlor-Alkali and Chlorate Processes. Chem. Rev. 2016, 116 (5), 2982-3028. https://doi.org/10.1021/acs.chemrev.5b00389.

(4) Fukuzumi, S.; Lee, Y.-M.; Nam, W. Fuel Production from Seawater and Fuel Cells Using Seawater. ChemSusChem 2017, 10 (22), 4264-4276. https://doi.org/10.1002/cssc.201701381.

(5) Bergmann, M. E. H.; Koparal, A. S.; Iourtchouk, T. Electrochemical Advanced Oxidation Processes, Formation of Halogenate and Perhalogenate Species: A Critical Review. Crit. Rev. Environ. Sci. Technol. 
2014, 44 (4), 348-390. https://doi.org/10.1080/10643389.2012.718948.

(6) Yoon, Y.; Cho, E.; Jung, Y.; Kwon, M.; Yoon, J.; Kang, J. W. Evaluation of the Formation of Oxidants and By-Products Using Pt/Ti, $\mathrm{RuO}_{2} / \mathrm{Ti}$, and $\mathrm{IrO}_{2} / \mathrm{Ti}$ Electrodes in the Electrochemical Process. Environ. Technol. (United Kingdom) 2015, 36 (3), 317-326. https://doi.org/10.1080/09593330.2014.946098.

(7) Farhat, A.; Keller, J.; Tait, S.; Radjenovic, J. Assessment of the Impact of Chloride on the Formation of Chlorinated By-Products in the Presence and Absence of Electrochemically Activated Sulfate. Chem. Eng. J. 2017, 330 (August), 1265-1271. https://doi.org/10.1016/j.cej.2017.08.033.

(8) Jasper, J. T.; Yang, Y.; Hoffmann, M. R. Toxic Byproduct Formation during Electrochemical Treatment of Latrine Wastewater. Environ. Sci. Technol. 2017, 51 (12), 7111-7119. https://doi.org/10.1021/acs.est.7b01002.

(9) Chaplin, B. P. Advantages, Disadvantages, and Future Challenges of the Use of Electrochemical Technologies for Water and Wastewater Treatment; Elsevier Inc., 2018. https://doi.org/10.1016/B978-0-12-813160-2.00017-1.

(10) Brüninghoff, R.; van Duijne, A. K.; Braakhuis, L.; Saha, P.; Jeremiasse, A. W.; Mei, B.; Mul, G. Comparative Analysis of Photocatalytic and Electrochemical Degradation of 4-Ethylphenol in Saline Conditions. Environ. Sci. Technol. 2019, 53 (15), 8725-8735. https://doi.org/10.1021/acs.est.9b01244.

(11) Kraft, A. Electrochemical Water Disinfection: A Short Review. Platin. Met. Rev. 2008, 52 (3), 177-185. https://doi.org/10.1595/147106708X329273.

(12) Drennan, D. M.; Koshy, R. E.; Gent, D. B.; Schaefer, C. E. Electrochemical Treatment for Greywater Reuse: Effects of Cell Configuration on COD Reduction and Disinfection Byproduct Formation and Removal. Water Supply 2019, 19 (3), 891-898. https://doi.org/10.2166/ws.2018.138.

(13) Garcia-Segura, S.; Keller, J.; Brillas, E.; Radjenovic, J. Removal of Organic Contaminants from Secondary Effluent by Anodic Oxidation with a BoronDoped Diamond Anode as Tertiary Treatment. J. Hazard. Mater. 2015, 283, 551-557. https://doi.org/10.1016/j.jhazmat.2014.10.003.

(14) García-Espinoza, J. D.; Mijaylova-Nacheva, P.; Avilés-Flores, M. Electrochemical Carbamazepine Degradation: Effect of the Generated Active Chlorine, Transformation Pathways and Toxicity. Chemosphere 2018, 192, 142-151. https://doi.org/10.1016/j.chemosphere.2017.10.147. 
(15) Emmanuel, E.; Keck, G.; Blanchard, J.-M.; Vermande, P.; Perrodin, Y. Toxicological Effects of Disinfections Using Sodium Hypochlorite on Aquatic Organisms and Its Contribution to AOX Formation in Hospital Wastewater. Environ. Int. 2004, 30 (7), 891-900.

https://doi.org/10.1016/j.envint.2004.02.004.

(16) Gül, S.; Savsar, A.; Tayfa, Z. Cytotoxic and Genotoxic Effects of Sodium Hypochlorite on Human Peripheral Lymphocytes in Vitro. Cytotechnology 2009, 59 (2), 113-119. https://doi.org/10.1007/s10616-009-9201-4.

(17) Word Healt Organization; Chlorine Dioxide, Chlorite and Chlorate in Drinking-water https://www.who.int/water_sanitation_health/waterquality/guidelines/chemicals/chlorine-chlorate-chlorite/en/ (accessed Feb $21,2020)$.

(18) Peters, D. G.; McGuire, C. M.; Pasciak, E. M.; Peverly, A. A.; Strawsine, L. M.; Wagoner, E. R.; Tyler Barnes, J. Electrochemical Dehalogenation of Organic Pollutants. J. Mex. Chem. Soc. 2014, 58, 287-302.

(19) Martínez-Huitle, C. A.; Rodrigo, M. A.; Sirés, I.; Scialdone, O. Single and Coupled Electrochemical Processes and Reactors for the Abatement of Organic Water Pollutants: A Critical Review. Chem. Rev. 2015, 115 (24), 13362-13407. https://doi.org/10.1021/acs.chemrev.5b00361.

(20) Chen, Z.; Liu, Y.; Wei, W.; Ni, B. J. Recent Advances in Electrocatalysts for Halogenated Organic Pollutant Degradation. Environmental Science: Nano. Royal Society of Chemistry 2019, pp 2332-2366. https://doi.org/10.1039/c9en00411d.

(21) Martin, E. T.; McGuire, C. M.; Mubarak, M. S.; Peters, D. G. Electroreductive Remediation of Halogenated Environmental Pollutants. Chem. Rev. 2016, 116 (24), 15198-15234. https://doi.org/10.1021/acs.chemrev.6b00531.

(22) Hammar, L.; Wranglén, G. Cathodic and Anodic Efficiency Losses in Chlorate Electrolysis. Electrochim. Acta 1964, 9 (1), 1-16. https://doi.org/10.1016/0013-4686(64)80001-3.

(23) Viswanathan, K.; Tilak, B. V. Chemical, Electrochemical, and Technological Aspects of Sodium Chlorate Manufacture. J. Electrochem. Soc. 1984, 131 (7), 1551-1559. https://doi.org/10.1149/1.2115908.

(24) Wulff, J.; Cornell, A. Cathodic Current Efficiency in the Chlorate Process. J. Appl. Electrochem. 2007, 37 (1), 181-186. https://doi.org/10.1007/s10800-006-9263-3. 
(25) Hedenstedt, K.; Gomes, A. S. O.; Busch, M.; Ahlberg, E. Study of Hypochlorite Reduction Related to the Sodium Chlorate Process. Electrocatalysis 2016, 7 (4), 326-335. https://doi.org/10.1007/s12678-0160310-5.

(26) Gustavsson, J.; Li, G.; Hummelgard, C.; Backstrom, J.; Cornell, A. On the Suppression of Cathodic Hypochlorite Reduction by Electrolyte Additions of Molybdate and Chromate Ions. J. Electrochem. Sci. Eng. 2012, 2, 185198. https://doi.org/10.5599/jese.2012.0021.

(27) Vogt, H.; Balej, J.; Bennett, J. E.; Wintzer, P.; Sheikh, S. A.; Gallone, P.; Vasudevan, S.; Pelin, K. Chlorine Oxides and Chlorine Oxygen Acids. In Ullmann's Encyclopedia of Industrial Chemistry; Wiley-VCH Verlag GmbH \& Co. KGaA: Weinheim, Germany, 2010. https://doi.org/10.1002/14356007.a06_483.pub2.

(28) Vanýsek, P. Electrochemical Series. In CRC Handbook of Chemistry \& Physics; Haynes, W. M., Ed.; CRC Press LLC: London, New York; pp 580-5-89.

(29) Harrison, J. A.; Khan, Z. A. The Reduction of Chlorine in Alkaline Solution. J. Electroanal. Chem. 1971, 30 (1), 87-92. https://doi.org/10.1016/0368-1874(71)85036-0.

(30) Hine, F.; Yasuda, M. Studies on the Cathodic Reaction in the DiaphragmType Chlorine Cell. J. Electrochem. Soc. 1971, 118 (1), 170-173. https://doi.org/10.1149/1.2407938.

(31) Hine, F.; Yasuda, M. On the Cathode Reaction in Solutions Containing $\mathrm{ClO}_{3}{ }^{-}$. J. Electrochem. Soc. 1971, 118 (1), 182-183. https://doi.org/10.1149/1.2407941.

(32) Lindbergh, G.; Simonsson, D. The Effect of Chromate Addition on Cathodic Reduction of Hypochlorite in Hydroxide and Chlorate Solutions. J. Electrochem. Soc. 1990, 137 (10), 3094. https://doi.org/10.1149/1.2086165.

(33) Cornell, A.; Lindbergh, G.; Simonsson, D. The Effect of Addition of Chromate on the Hydrogen Evolution Reaction and on Iron Oxidation in Hydroxide and Chlorate Solutions. Electrochim. Acta 1992, 37 (10), 18731881. https://doi.org/10.1016/0013-4686(92)85093-Z.

(34) Girenko, D. V.; Velichenko, A. B. Selection of the Optimal Cathode Material to Synthesize Medical Sodium Hypochlorite Solutions in a Membraneless Electrolyzer. Surf. Eng. Appl. Electrochem. 2018, 54 (1), 88-95. https://doi.org/10.3103/S1068375518010052. 
(35) Wu, J.-K. Kinetics of the Reduction of Hypochlorite Ion. J. Electrochem. Soc. 1987, 134 (6), 1462. https://doi.org/10.1149/1.2100690.

(36) Tilak, B. V.; Tari, K.; Hoover, C. L. Metal Anodes and Hydrogen Cathodes: Their Activity Towards $\mathrm{O}_{2}$ Evolution and $\mathrm{ClO}_{3}{ }^{-}$Reduction Reactions. $J$. Electrochem. Soc. 1988, 135 (6), 1386-1392.

https://doi.org/10.1149/1.2095999.

(37) Booth, J. S.; Hamzah, H.; Kuhn, A. T. Chlorate Formation and Reduction in Undivided Hypochlorite Cells. Electrochim. Acta 1980, 25 (10), 13471350. https://doi.org/10.1016/0013-4686(80)87146-5.

(38) Cornell, A.; Simonsson, D. Ruthenium Dioxide as Cathode Material for Hydrogen Evolution in Hydroxide and Chlorate Solutions. J. Electrochem. Soc. 1993, 140 (11), 3123-3129. https://doi.org/10.1149/1.2220996.

(39) Brown, G. M. The Reduction of Chlorate and Perchlorate Ions at an Active Titanium Electrode. J. Electroanal. Chem. 1986, 198 (2), 319-330. https://doi.org/10.1016/0022-0728(86)90008-2.

(40) Yang, Y.; Hoffmann, M. R. Synthesis and Stabilization of Blue-Black $\mathrm{TiO}_{2}$ Nanotube Arrays for Electrochemical Oxidant Generation and Wastewater Treatment. Environ. Sci. Technol. 2016, 50 (21), 11888-11894. https://doi.org/10.1021/acs.est.6b03540.

(41) Jong, R. P. H.; Krzywda, P. M.; Benes, N. E.; Mul, G. Preparation of Ti, $\mathrm{Ti} / \mathrm{TiC}$ or Ti/TiN Based Hollow Fibres with Extremely Low Electrical Resistivity; in preparation.

(42) Kas, R.; Hummadi, K. K.; Kortlever, R.; de Wit, P.; Milbrat, A.; LuitenOlieman, M. W. J.; Benes, N. E.; Koper, M. T. M.; Mul, G. ThreeDimensional Porous Hollow Fibre Copper Electrodes for Efficient and High-Rate Electrochemical Carbon Dioxide Reduction. Nat. Commun. 2016, 7 (1), 10748. https://doi.org/10.1038/ncomms 10748.

(43) Weiner, E. R. Applications of Environmental Aquatic Chemistry, 2nd ed.; CRC Press, 2008. https://doi.org/10.1201/9781420008371.

(44) Vos, J. G.; Koper, M. T. M. Measurement of Competition between Oxygen Evolution and Chlorine Evolution Using Rotating Ring-Disk Electrode Voltammetry. J. Electroanal. Chem. 2018, 819 (October 2017), 260-268. https://doi.org/10.1016/j.jelechem.2017.10.058.

(45) Kuhn, A. T.; Hamzah, H. B. H. The Effect of Electrode Roughness and the Ratio of Anode to Cathode Area on the Performance of an Undivided Hypochlorite Cell. Chemie Ing. Tech. 1980, 52 (9), 762-763. https://doi.org/10.1002/cite.330520920. 
(46) Bancroft, W. D.; Magoffin, J. E. Energy Levels in Electrochemistry. J. Am. Chem. Soc. 1935, 57, 2561.

(47) Láng, G. G.; Sas, N. S.; Ujvári, M.; Horányi, G. The Kinetics of the Electrochemical Reduction of Perchlorate Ions on Rhodium. Electrochim. Acta 2008, 53 (25), 7436-7444.

https://doi.org/10.1016/j.electacta.2007.12.007.

\subsection{Appendix}

a)

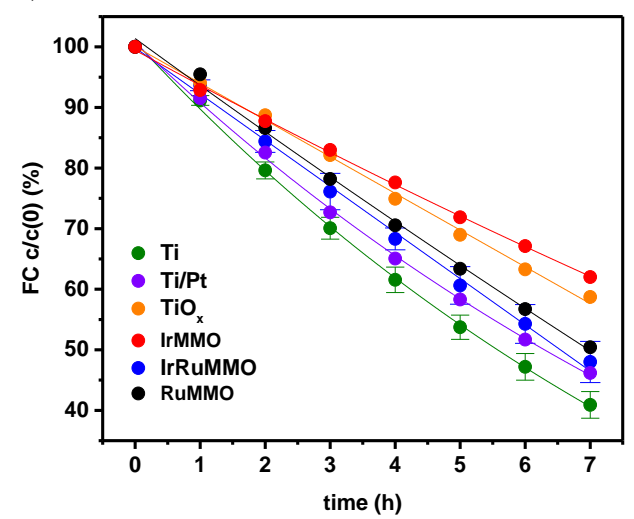

b)

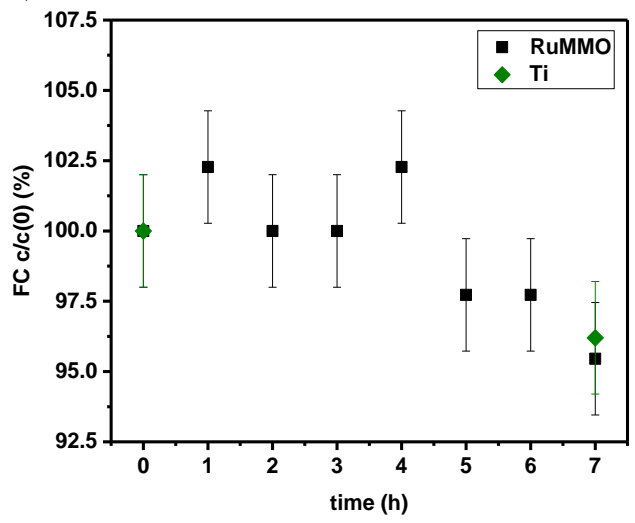

Figure A6.1. a) Reduction of hypochlorite [measured as FC, $\mathrm{c}_{0} \approx 100 \mathrm{mg} \mathrm{L}^{-1}$ ] at various electrodes ( $\mathrm{Ti}, \mathrm{Ti} / \mathrm{Pt}, \mathrm{TiO}_{\mathrm{x}}$, IrMMO, IrRuMMO and RuMMO) at $-2.5 \mathrm{~mA} \mathrm{~cm}^{-2}$ shown as relative $\mathrm{FC}$ concentration over time. The error bars indicate the deviation of the mean for repetitive experiments. b) Removal of hypochlorite in blank experiments (measured as FC, $\mathrm{c}_{0} \approx 100 \mathrm{mg} \mathrm{L}^{-1}$ ) shown for a RuMMO and Ti electrode without applied bias or current respectively (no electrical connection). The blank removal is $\leq 5 \%$. The error bars indicate the relative standard deviation of the analytic procedure. 
Table A6.1. Removal of hypochlorite (measured as FC; $\mathrm{c}_{0} \approx 100 \mathrm{mg} \mathrm{L}^{-1}$ ), FC reduction rate constant and $\mathrm{FE}$ for various electrodes $\left(\mathrm{Ti}, \mathrm{Ti} / \mathrm{Pt}, \mathrm{TiO}_{\mathrm{x}}, \mathrm{IrMMO}, \mathrm{IrRuMMO}\right.$ and RuMMO) at $-2.5 \mathrm{~mA} \mathrm{~cm}^{-2}$

\begin{tabular}{|c|c|c|c|c|}
\hline Electrode & $\begin{array}{c}\text { FC removal } \\
{[\%]}\end{array}$ & $\begin{array}{c}\text { FC reduction rate } \\
\text { constant } \\
{\left[\mathrm{h}^{-1}\right]}\end{array}$ & $\begin{array}{c}\mathrm{FE} \\
{[\%]}\end{array}$ & $\begin{array}{c}\mathrm{c}_{\mathrm{dl}}(\mathrm{ECSA}) \\
{\left[\mathrm{mF} \mathrm{cm}^{-2}\right]}\end{array}$ \\
\hline $\mathrm{Ti}$ & $59[+/-3]$ & $0.13[+/-0.01]$ & $\begin{array}{c}11.2 \\
{[+/-0.4]}\end{array}$ & 0.06 \\
\hline $\mathrm{Ti} / \mathrm{Pt}$ & 54 & 0.11 & 10.2 & 1.46 \\
\hline $\mathrm{TiO}_{\mathrm{x}}$ & 41 & 0.08 & 7.7 & 0.18 \\
\hline $\mathrm{IrMMO}$ & 38 & 0.07 & 7.2 & 12.0 \\
\hline IrRuMMO & $52[+/-4]$ & $0.11[+/-0.01]$ & $9.7[+/-0.7]$ & 7.84 \\
\hline $\mathrm{RuMMO}$ & 50 & 0.10 & 9.5 & 7.45 \\
\hline
\end{tabular}

Table A6.2. FC reduction rate constants $\left(\mathrm{c}_{0} \approx 100 \mathrm{mg} \mathrm{L}^{-1}\right)$ and $\mathrm{FE}$ for various electrodes ( $\mathrm{Ti}$,

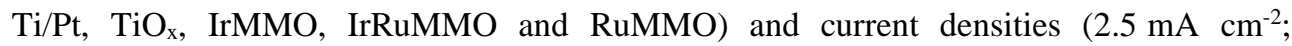
$5 \mathrm{~mA} \mathrm{~cm}^{-2} ; 10 \mathrm{~mA} \mathrm{~cm}^{-2}$ )

\begin{tabular}{|c|c|c|c|}
\hline Electrode & $\begin{array}{c}\text { Current density } \mathrm{j} \\
{\left[\mathrm{mA} \mathrm{cm}^{-2}\right]}\end{array}$ & $\begin{array}{c}\mathrm{k} \\
{\left[\mathrm{h}^{-1}\right]}\end{array}$ & $\begin{array}{c}\mathrm{FE} \\
{[\%]}\end{array}$ \\
\hline $\mathrm{Ti}$ & -2.5 & $0.13[+/-0.01]$ & $11.2[+/-0.4]$ \\
\hline $\mathrm{Ti}$ & -5.0 & 0.15 & 6.3 \\
\hline $\mathrm{Ti}$ & -10.0 & 0.16 & 3.2 \\
\hline $\mathrm{Ti} / \mathrm{Pt}$ & -2.5 & 0.11 & 10.2 \\
\hline $\mathrm{TiO} \mathrm{x}_{\mathrm{n}}$ & -2.5 & 0.08 & 7.7 \\
\hline $\mathrm{TiO} \mathrm{x}_{\mathrm{n}}$ & -5.0 & 0.12 & 5.2 \\
\hline $\mathrm{IrMMO}$ & -2.5 & 0.07 & 7.2 \\
\hline $\mathrm{IrMMO}$ & -5.0 & 0.13 & 5.6 \\
\hline IrRuMMO & -2.5 & $0.11[+/-0.01]$ & $9.7[+/-0.7]$ \\
\hline IrRuMMO & -5.0 & 0.13 & 5.5 \\
\hline RuMMO & -2.5 & 0.10 & 9.5 \\
\hline RuMMO & -5.0 & 0.15 & 6.2 \\
\hline RuMMO & -10.0 & 0.16 & 3.2 \\
\hline
\end{tabular}


a)

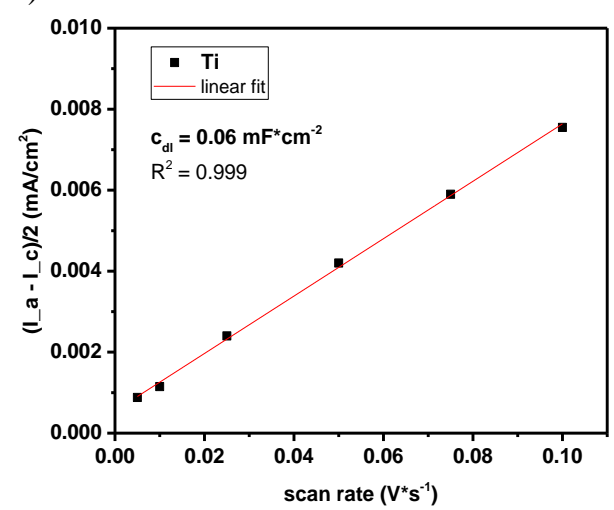

c)

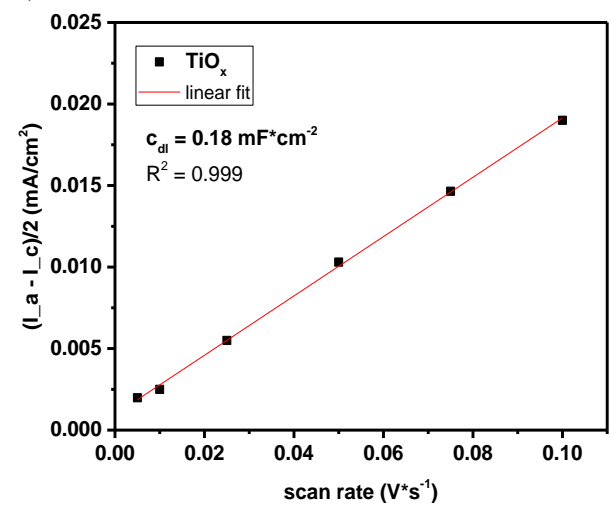

e)

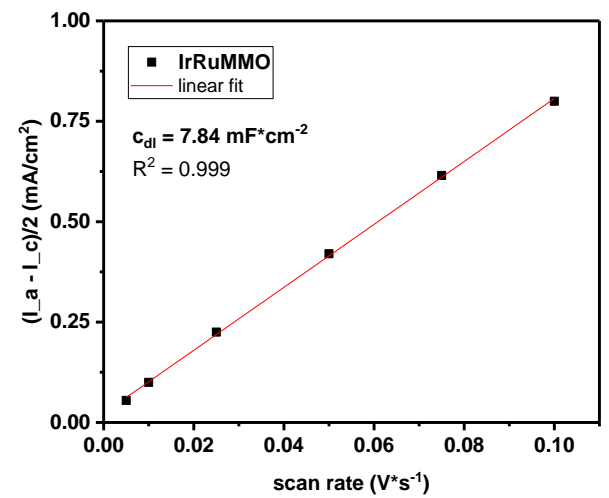

b)

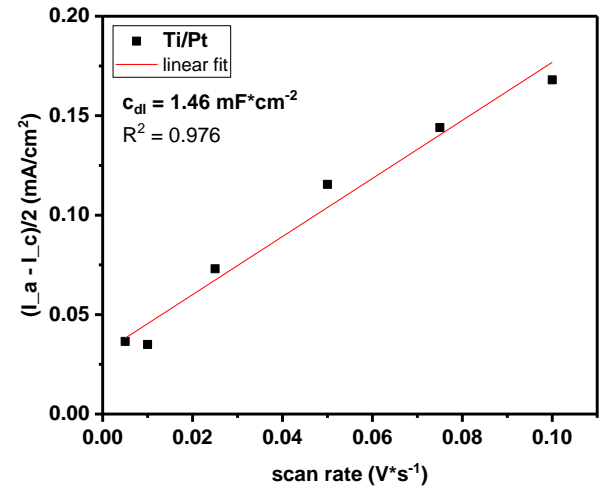

d)

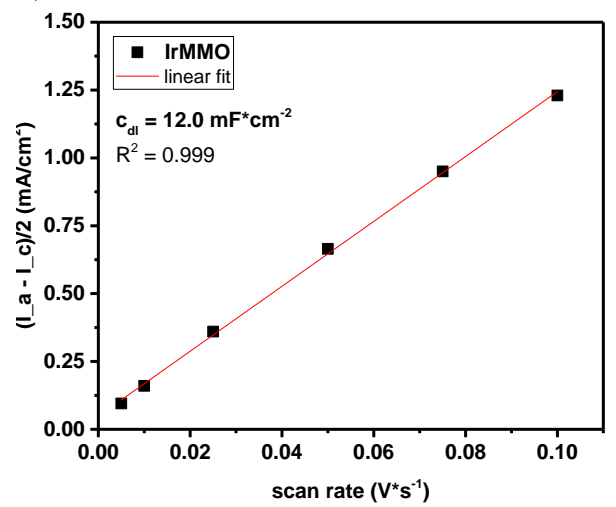

f)

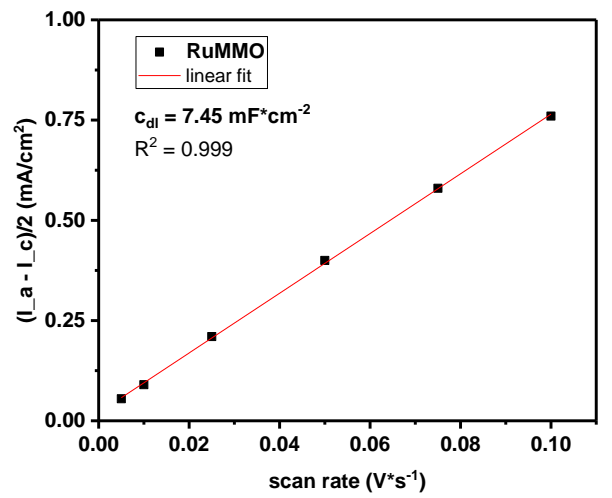

Figure A6.2. Determination of the electrochemical active surface area (ECSA) of various plate electrodes via double layer capacitance $\left(\mathrm{c}_{\mathrm{dl}}\right)$. CVs in a non-faradaic potential region were recorded in background electrolyte $\left[0.5 \mathrm{~mol} \mathrm{~L}^{-1} \mathrm{Na}_{2} \mathrm{SO}_{4}\right]$ at various scan rates $(5,10$, $\left.25,50,75,100 \mathrm{mV} \mathrm{s}^{-1}\right)$. The linear correlation between $\left(\mathrm{I}_{\mathrm{a}}-\mathrm{I}_{\mathrm{c}}\right) / 2$ vs. scan rate is shown for a) $\mathrm{Ti}$; b) Ti/Pt; c) $\mathrm{TiO}_{x}$; d) IrMMO; e) IrRuMMO; f) RuMMO. The slope is giving the $\mathrm{c}_{\mathrm{d} l}$. 
a)

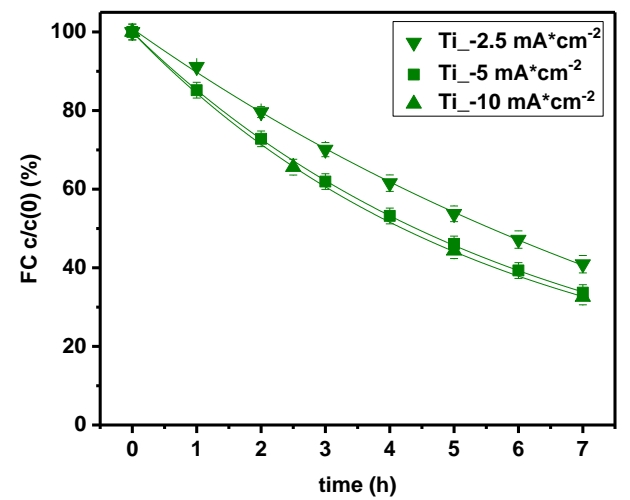

c)

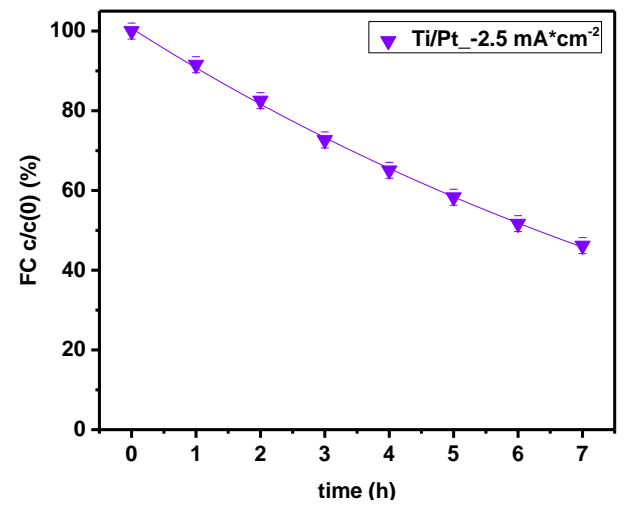

e)

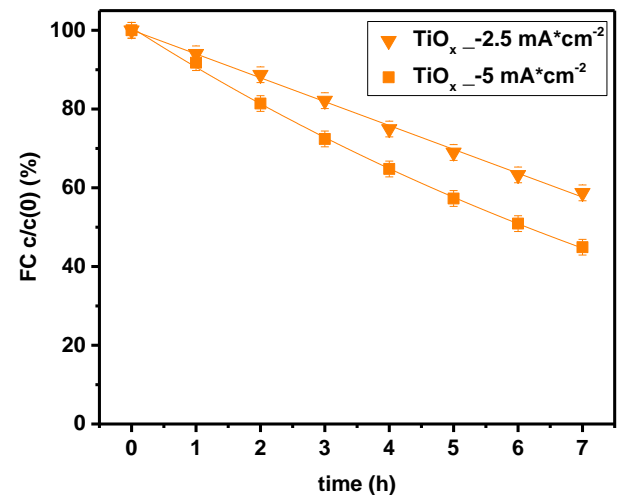

b)

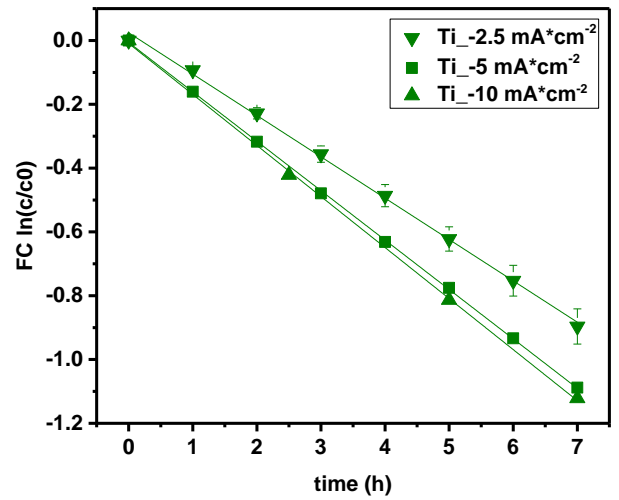

d)

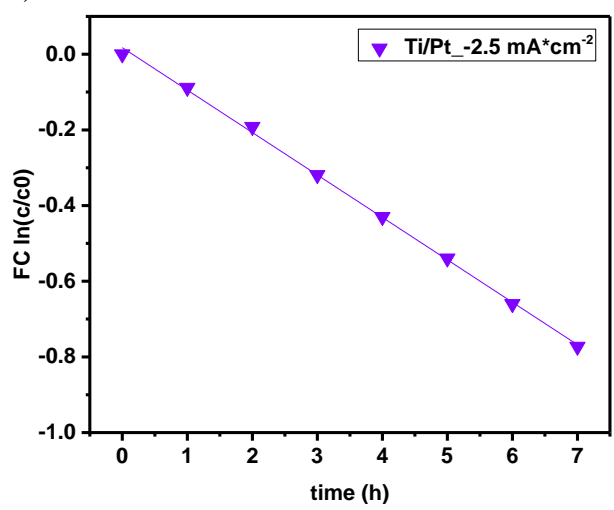

f)

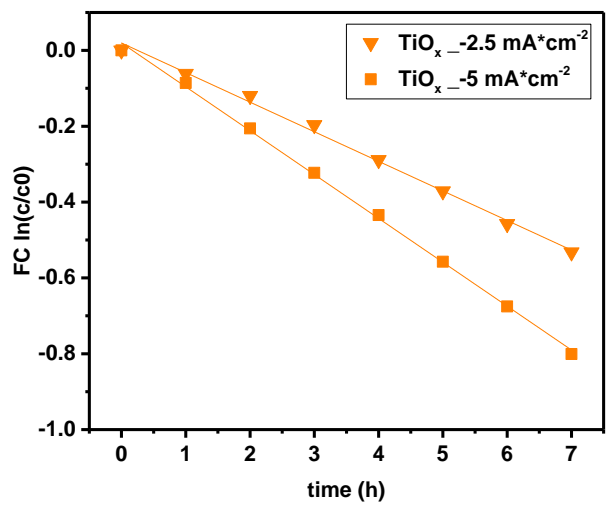

Figure A6.3. Reduction of hypochlorite [measured as $\mathrm{FC}, \mathrm{c}_{0} \approx 100 \mathrm{mg} \mathrm{L}^{-1}$ ] at various electrodes [a) \& b) $\mathrm{Ti}$; c) \& d) $\mathrm{Ti} / \mathrm{Pt}$; e) \& f) $\mathrm{TiO}_{\mathrm{x}}$ ] at $-2.5 \mathrm{~mA} \mathrm{~cm}^{-2}$ and $-5 \mathrm{~mA} \mathrm{~cm}{ }^{-2}$. Left: relative FC concentration over time; right: $1^{\text {st }}$ order degradation plot. Error bars on the left indicate the relative standard deviation of the analytic procedure. Error bars on the right show deviation of the mean based on replicate experiments. 
a)

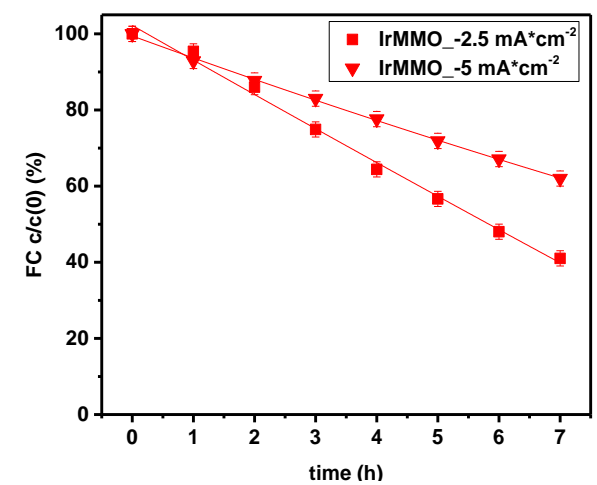

c)

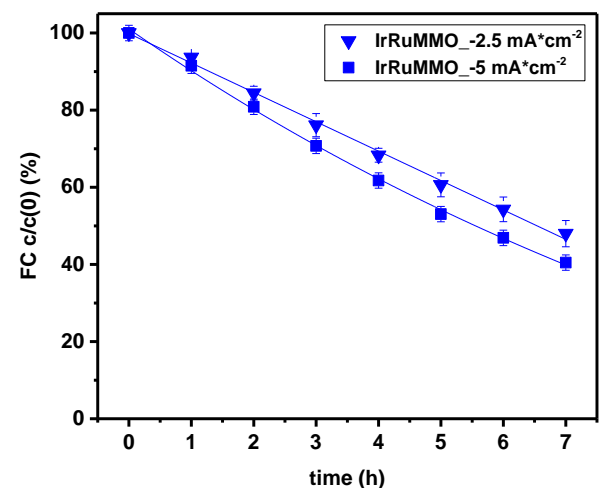

e)

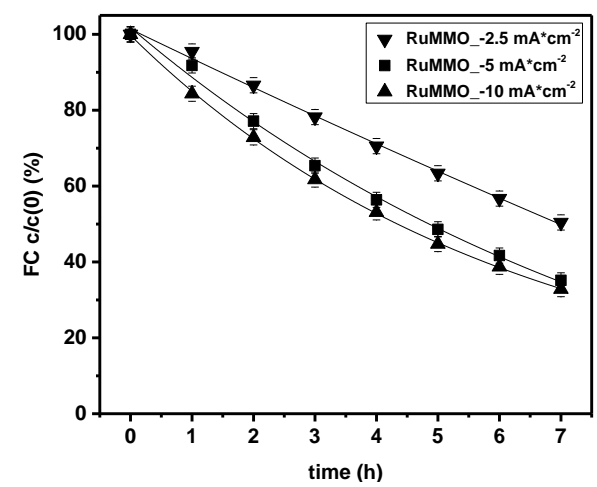

b)

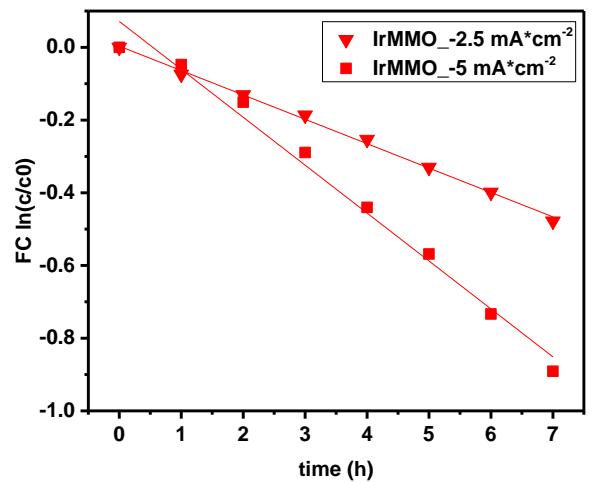

d)

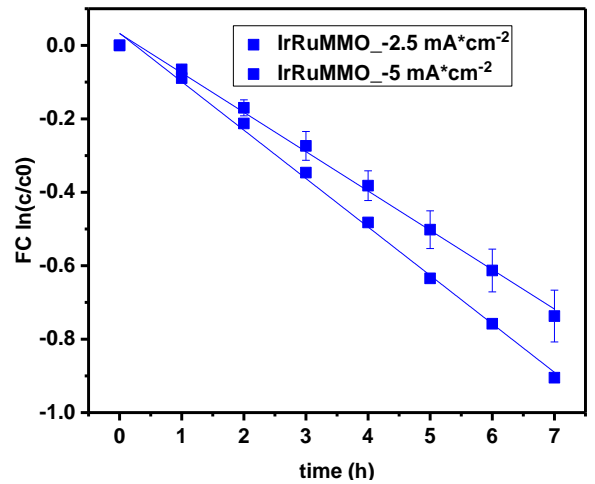

f)

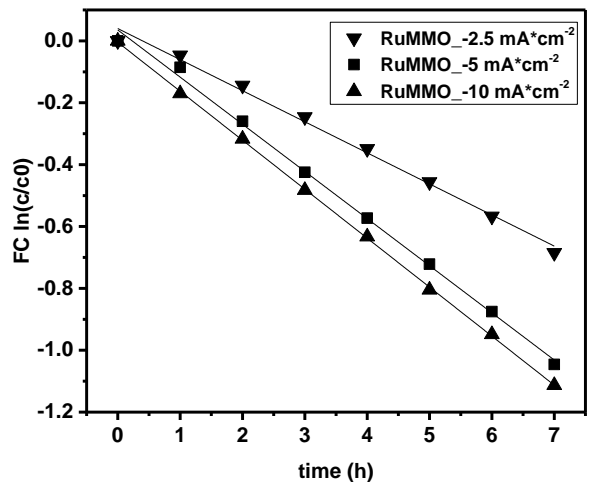

Figure A6.4. Reduction of hypochlorite [measured as $\mathrm{FC}, \mathrm{c}_{0} \approx 100 \mathrm{mg} \mathrm{L}^{-1}$ ] at various electrodes [a) \& b) IrMMO; c) \& d) IrRuMMO; e) \& f) RuMMO] at $-2.5,-5.0$ and $-10 \mathrm{~mA} \mathrm{~cm}{ }^{-2}$. Left: relative FC concentration over time; right: $1^{\text {st }}$ order degradation plot. Error bars on the left indicate the relative standard deviation of the analytic procedure. Error bars on the right show deviation of the mean based on replicate experiments. 


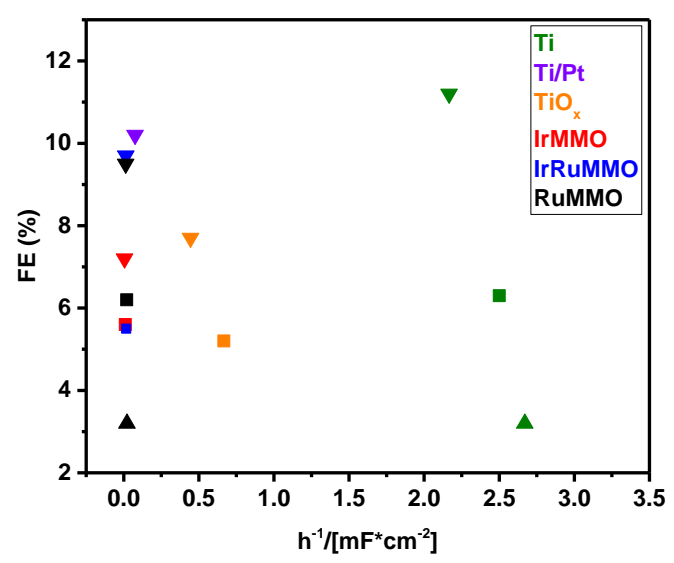

Figure A6.5. Faradaic efficiency of hypochlorite reduction for various electrodes ( $\mathrm{Ti}, \mathrm{Ti} / \mathrm{Pt}$, $\mathrm{TiO}_{\mathrm{x}}$, IrMMO, IrRuMMO and RuMMO) and various current densities $\left(-2.5 \mathrm{~mA} \mathrm{~cm}{ }^{-2}\right.$ [triangle facing downwards], $-5 \mathrm{~mA} \mathrm{~cm} \mathrm{~cm}^{-2}$ [squares] and $-10 \mathrm{~mA} \mathrm{~cm} \mathrm{~cm}^{-2}$ [triangle facing upwards]) shown as a function of rate constant per active site 
a)

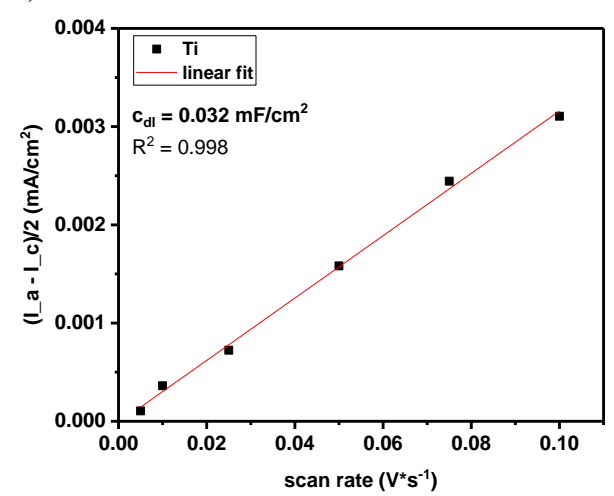

c)

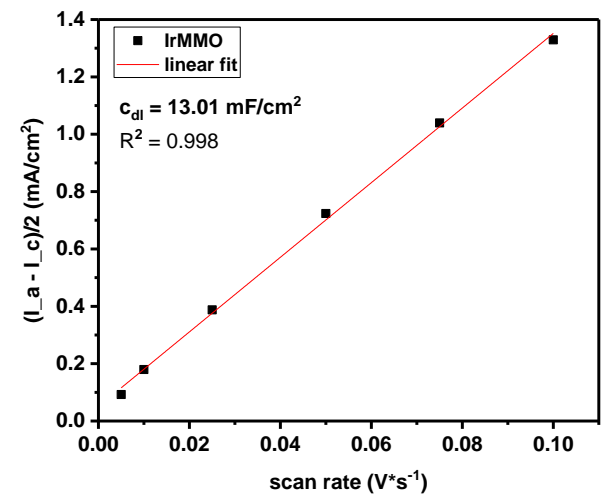

e)

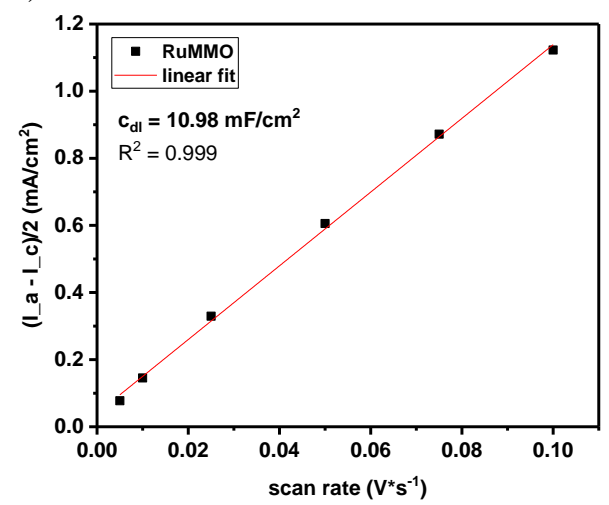

b)

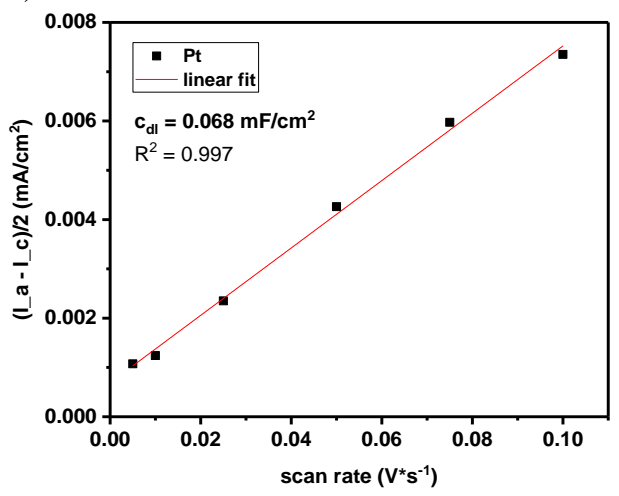

d)

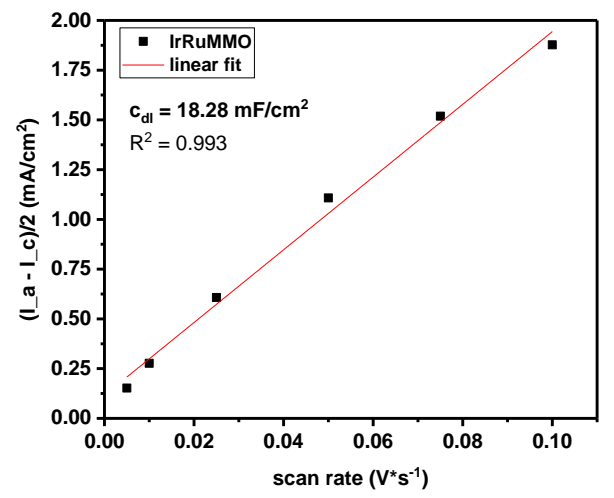

Figure A6.6. Determination of the electrochemical active surface area (ECSA) of RDE via double layer capacitance $\left(\mathrm{c}_{\mathrm{dl}}\right)$. $\mathrm{CVs}$ in a non-faradaic potential region were recorded in background electrolyte $\left[28 \mathrm{mmol} \mathrm{L}^{-1} \mathrm{Na}_{2} \mathrm{SO}_{4}\right]$ at various scan rates $(5,10,25,50,75$, $100 \mathrm{mV} \mathrm{s}^{-1}$ ) for various RDE. The linear correlation between $\left(\mathrm{I}_{\mathrm{a}}-\mathrm{I}_{\mathrm{c}}\right) / 2$ vs. scan rate is shown for a) $\mathrm{Ti}$; b) Pt; c) IrMMO; d) IrRuMMO; e) RuMMO. The slope is giving the $\mathrm{c}_{\mathrm{dl}}$. 
a)

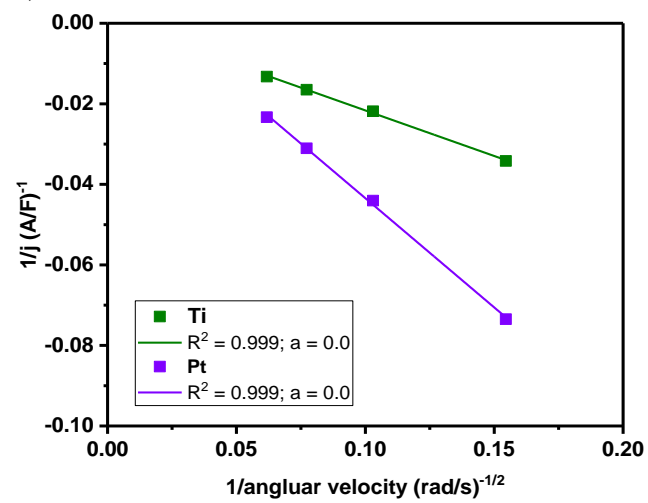

b)

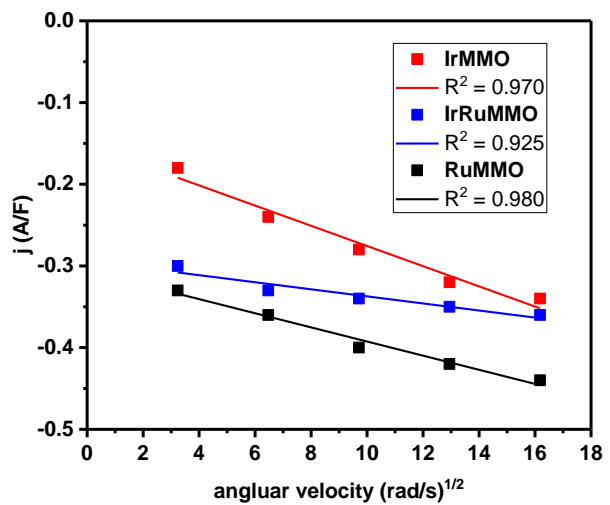

Figure A6.7. Analysis of hypochlorite reduction $\left[\mathrm{c} \approx 100 \mathrm{mg} \mathrm{L}^{-1} \mathrm{FC}\right.$ ] regime from RDE experiments studied for various electrodes. a) Koutecký-Levich analysis of hypochlorite reduction at $\mathrm{Ti}$ and $\mathrm{Pt}$ showing a good linear relation between the inverse square root of angular velocity and the inverse current density with intercept equal 0 indicating a mass transport limited reaction; b) Levich analysis of hypochlorite reduction at IrMMO/Ti, IrRuMMO/Ti, RuMMO/Ti showing a poor linear correlation.

Levich equation:

$$
I_{L}=0.620 n F A D^{2 / 3} v^{-1 / 6} c \omega^{1 / 2}=B \omega^{1 / 2}
$$

Koutecký-Levich equation: $\frac{1}{I_{L}}=\frac{1}{I_{K}}+\left(\frac{1}{0.620 n F A D^{2 / 3} v^{-1 / 6} c}\right) \omega^{-1 / 2}$

limiting current $I_{L}$; number of electrons transferred per mole $n$; Faraday constant $F$; electrode area A; kinematic solution viscosity $v$; diffusion coefficient D; analyte concentration c; angular velocity $\omega$; Levich constant $B$, kinetic current $I_{K}$

Table A6.3. Average cell potential, power and energy consumption for the removal of hypochlorite (measured as $\mathrm{FC} ; \mathrm{c}_{0} \approx 100 \mathrm{mg} \mathrm{L}^{-1}$ ) within $7 \mathrm{~h}$ of degradation for various electrodes (Ti, Ti/Pt, $\mathrm{TiO}_{x}$, IrMMO, IrRuMMO and RuMMO) at $-2.5 \mathrm{~mA} \mathrm{~cm} \mathrm{~cm}^{-2}$

\begin{tabular}{|c|c|c|c|}
\hline Electrode & $\begin{array}{c}\mathrm{E}_{\text {cell(average })} \\
{[\mathrm{V}]}\end{array}$ & $\begin{array}{c}\text { Energy consumption total } \\
{[\mathrm{kJ}] /(7 \mathrm{~h})}\end{array}$ & $\begin{array}{c}\text { Energy consumption } \\
\text { per removal } \\
{\left[\mathrm{kJ}^{\left.-\mathrm{mol} \mathrm{OCl}^{-}\right]}\right.}\end{array}$ \\
\hline $\mathrm{Ti}$ & 3.6 & 0.71 & 620 \\
\hline $\mathrm{Pt}$ & 3.0 & 0.59 & 570 \\
\hline $\mathrm{TiO}$ & 3.7 & 0.73 & 920 \\
\hline $\mathrm{IrMMO}$ & 3.0 & 0.59 & 800 \\
\hline $\mathrm{IrRuMMO}$ & 3.2 & 0.63 & 630 \\
\hline $\mathrm{RuMMO}$ & 3.2 & 0.63 & 650 \\
\hline
\end{tabular}


a)

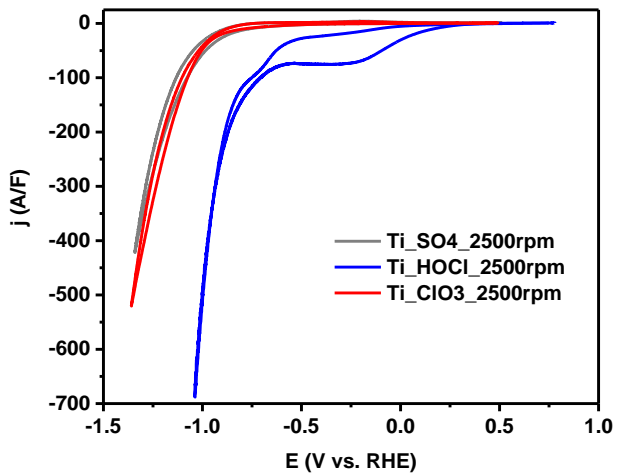

c)

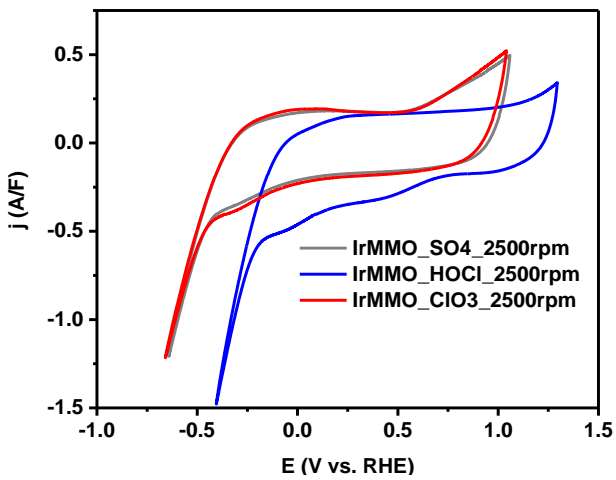

e)

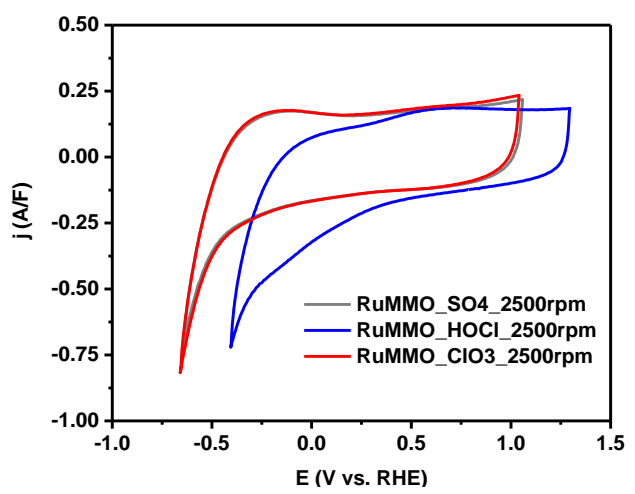

b)

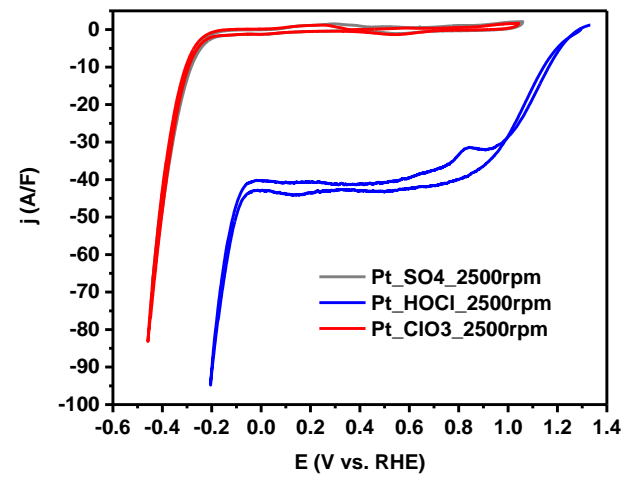

d)

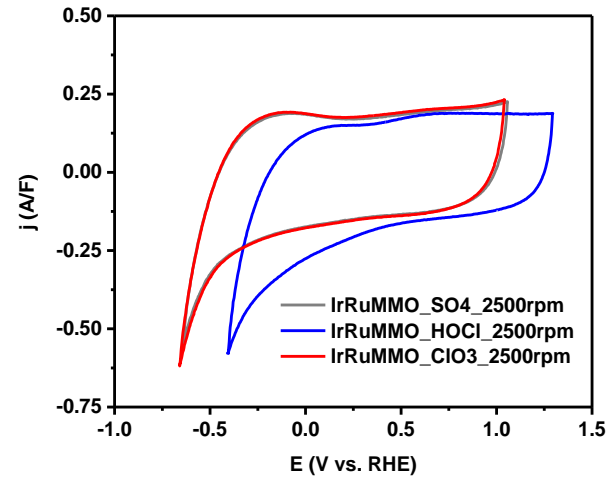

Figure A6.8. Cyclic voltammetry study of hypochlorite reduction [blue graph; $\mathrm{c} \approx 100 \mathrm{mg} \mathrm{L}^{-1} \mathrm{FC}$ ] and chlorate reduction [red graph; $\mathrm{c} \approx 100 \mathrm{mg} \mathrm{L}^{-1} \mathrm{ClO}_{3}^{-}$] at various $\mathrm{RDE}$ a) $\mathrm{Ti}$, b) Pt, c) IMMO/Ti, d) IrRuMMO/Ti, e) RuMMO/Ti shown for $2500 \mathrm{rpm}$ rotation rate. The grey graph shows the $\mathrm{CV}$ in sulphate background electrolyte 
a)

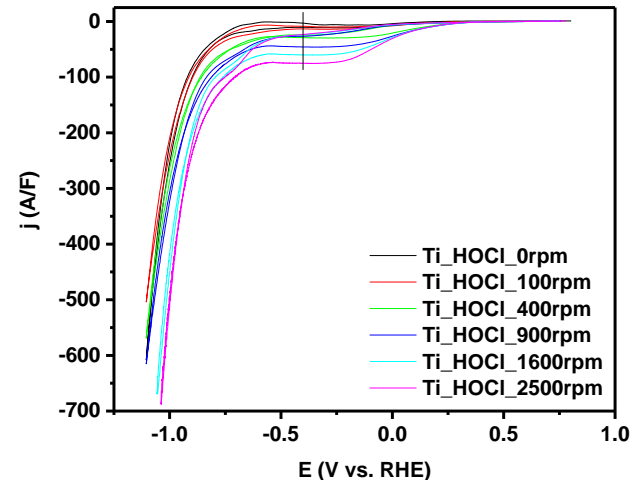

c)

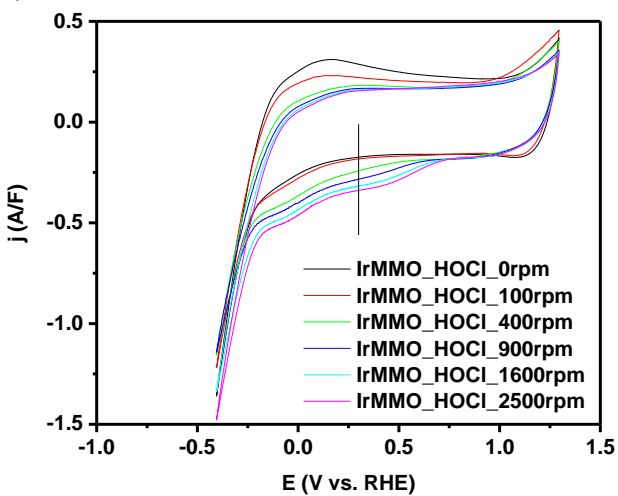

e)

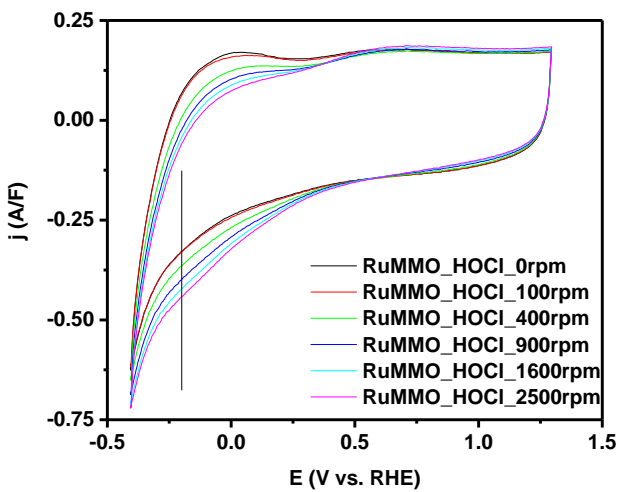

b)

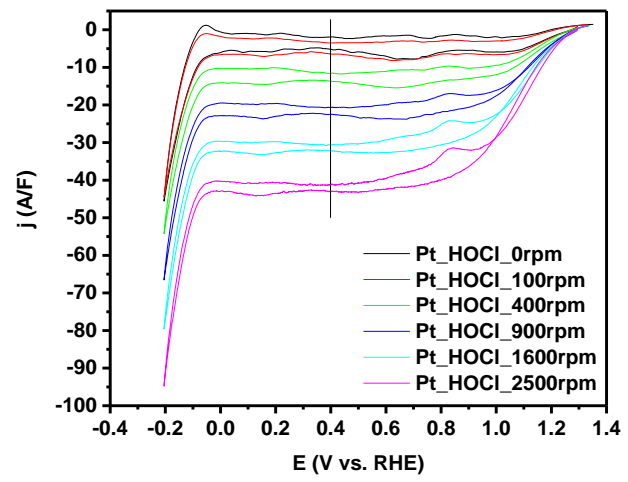

d)

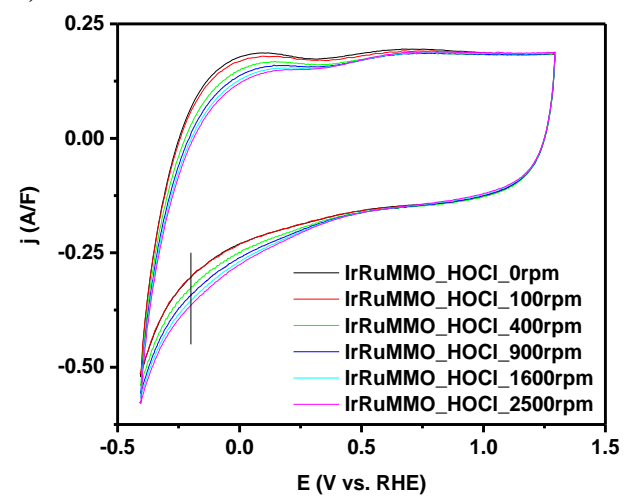

Figure A6.9. Cyclic voltammetry study of hypochlorite reduction $\left[\mathrm{c} \approx 100 \mathrm{mg} \mathrm{L}^{-1} \mathrm{FC}\right]$ at various RDE a) Ti, b) Pt, c) IMMO/Ti, d) IrRuMMO/Ti, e) RuMMO/Ti and various rotation rates $(0,100,400,900,1600$ and $2500 \mathrm{rpm})$. The vertical line indicates the potential chosen for the Levich and Koutecký-Levich analysis. 


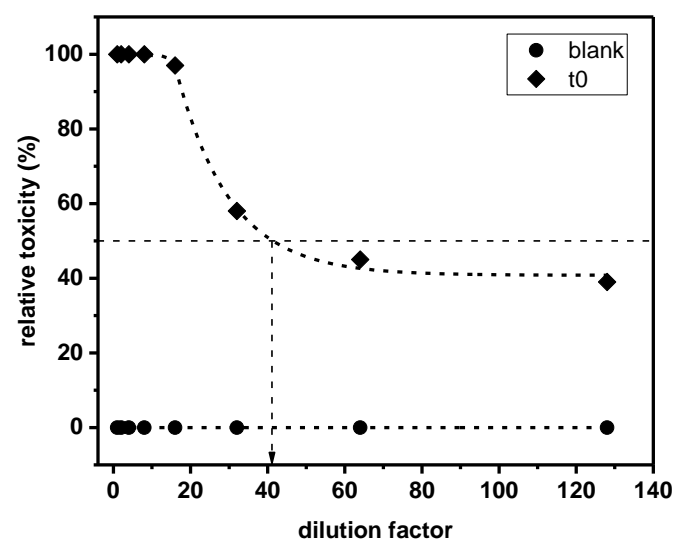

Figure A6.10. Toxicity of the hypochlorite stock solution as a function of dilution for toxicity measurements. The vertical dashed line indicates the dilution factor necessary to reach a relative toxicity level of $50 \%$ corresponding to the half maximal effective concentration $\left(\mathrm{EC}_{50}\right)$. 


\section{Chapter 7}

Summary and perspective 
Fresh water scarcity and water pollution are an enormous challenge for humanity. A sufficient availability of fresh and clean water is crucial for the environment, human health and the economy. The re-use of treated wastewater has a huge potential in the industrial sector. Especially if thereby intake of fresh water can be reduced, contributing to sustainable (process) development. Unfortunately, nonbiodegradable organic compounds are problematic and difficult to remove. Advanced oxidation processes (AOP) are promising technologies and capable to remove such organic compounds, due to their highly oxidative power. Consequently, applying these technologies holds the potential to further improve the quality of treated wastewater. The research project described in this thesis aims at a better understanding and further development of two AOP technologies and related materials for saline wastewater treatment. In particular, photocatalytic degradation treatment of wastewater using UV illuminated $\mathrm{TiO}_{2}$ slurries and electrochemical degradation treatment by anodic formation of oxidizing species, such as $\mathrm{OH}$ and $\mathrm{Cl}$ radicals (also known as electrochemical advanced oxidation process (EAOP)), have been studied in detail. The thesis consists of seven chapters including five chapters describing the main results.

Chapter 1 gives a brief introduction to water pollution and fresh water scarcity. Challenges of water treatment are given and the concept of AOP is introduced. Basic principles of operation, advantages, disadvantages and challenges related to the implementation of photocatalytic degradation and electrochemical degradation have been discussed. Especially, the formation of mostly unknown intermediates represents a major challenge for the implementation of AOP technologies. Partial oxidation and the underlying complex degradation mechanisms, being influenced by the water matrix and the technology applied, result in the manifold formation of intermediates and by-products, including undesired products of high toxicity. Release or discharge of these compounds will likely have effects on the environment and human health. Furthermore, developing appropriate electrodes is needed to facilitate EAOP implementation. Here, $\mathrm{TiO}_{2}$ based electrodes are considered as promising due to their ability to generate reactive hydroxyl radicals. In addition, $\mathrm{TiO}_{2}$ based electrodes are advantageous because of the abundance of the constituents, corrosion resistance as well as non-toxicity.

In Chapter 2 photocatalytic and electrochemical degradation are compared in terms of removal efficiency, energy demand and focus on the formation of chlorinated 
aromatic compounds. Specifically, the removal of the model compound 4-ethylphenol under saline conditions $\left(1.75 \mathrm{~g} \mathrm{~L}^{-1}\right.$ and $\left.35 \mathrm{~g} \mathrm{~L}^{-1} \mathrm{NaCl}\right)$ was investigated to evaluate the two AOP technologies. The analysis revealed electrochemical degradation to be superior in removal of 4-ethylphenol in chloride containing wastewater. However, significant amounts of 2-chloro-4-ethylphenol and 2,6-dichloro-4-ethylphenol were formed in a consecutive degradation mechanism, leading to subsequent formation of unidentified (chlorinated) compounds. The mechanism was observed to be independent of the anode (platinized Ti or boron doped diamond (BDD)). Moreover, the overall mineralization was poor, confirmed by non-purgeable organic carbon measurements revealing a mineralization of $36 \%$ (using a BDD anode) at low salt concentrations. In contrast, photocatalytic degradation appeared to be inhibited in the presence of chloride ions, but only hydroxylated aromatic intermediates were identified as main intermediates even in high salt $(\mathrm{NaCl})$ conditions. Moreover, mineralization of up to $87 \%$ (at low $\mathrm{NaCl}$ concentration) was achieved. Differences in the observed degradation mechanism and the absence of chlorinated intermediates were discussed based on a nanoscale recombination process favoring oxidation and subsequent reduction of reactive chlorine species in the case of photocatalytic degradation. Experimental evidence was obtained by photoelectrochemistry using $\mathrm{TiO}_{2}$ thin films, leading to significantly higher levels of chlorination. Looking at the energy consumption per removal of organic carbon, electrochemical degradation was beneficial compared to photocatalytic degradation; however, the photocatalytic degradation reactor applied had a low illumination efficiency and improvements in the reactor design can likely significantly enhance the energy efficiency of the process.

The study of Chapter 2 was extended to real wastewater and the results have been summarized in Chapter 3. Here, in a case study conducted within the Water Nexus project, cooling tower blowdown (CTBD) water from DOW Benelux B.V. was used as real wastewater matrix. Due to the complexity of the wastewater, the removal of organic compounds was monitored by the total organic carbon (TOC) concentration and the chemical oxygen demand (COD). It is shown that both technologies are capable of removing significant fractions of organic compounds from the CTBD water yielding similar TOC removal of approx. 55\% after $5 \mathrm{~h}$ of continuous treatment. During photocatalytic degradation the oxidation of organic compounds (followed by COD) leads to their mineralization. For the electrochemical degradation treatment, a faster COD removal was observed; however, the superior 
oxidation of the organic compounds did not result in complete mineralization, indicating a different degradation mechanism compared to photocatalytic degradation. Analysis of by-products revealed enhanced formation of adsorbable organic halides (AOX) and oxychlorides during electrochemical degradation, whereas for photocatalytic degradation the formation was negligible. This study highlights that chlorination is a major degradation mechanism during electrochemical degradation treatment of CTBD water.

Based on the results described in Chapter 2 and Chapter 3, photocatalytic degradation treatment appears to be the favorable AOP for the treatment of chloride containing wastewaters. Nevertheless, photocatalytic degradation has major drawbacks. Specifically, photocatalytic degradation is inhibited by anions, is characterized by low efficiencies (due to the recombination of photogenerated charge carriers), and due to the requirement of UV light irradiation scale-up appears to be a major challenge. Regarding the aforementioned points electrochemical degradation treatment is advantageous. In order to implement electrochemical degradation for (saline) wastewater treatment, novel electrode materials are required, which are cost-effective, non-toxic, and stable. Moreover, strategies to limit or prevent the formation or accumulation of (chlorinated) toxic intermediates and byproducts need to be developed. In the following chapters these challenges have been addressed.

As pointed out in the introduction, electrodes based on $\mathrm{TiO}_{2}$ are considered as promising for the mineralization of organic compounds. In Chapter 4 an electrochemical method (cathodization) was developed to create defect-rich, highly conductive $\mathrm{TiO}_{\mathrm{x}}$ electrodes. Specifically, the influence of the applied counter electrode (here as anode) on the properties of $\mathrm{TiO}_{\mathrm{x}}$ was investigated. Pt-anodes were found to induce severe $\mathrm{Pt}$ contamination of the $\mathrm{TiO}_{\mathrm{x}}$ surface, strongly influencing the hydrogen evolution reaction (HER) activity of the material. Iridium mixed metal anodes (MMO; also known as dimensionally stable anode) did not result in measurable $\mathrm{Ir}$ contamination on the $\mathrm{TiO}_{\mathrm{x}}$ surface. However, $\mathrm{TiO}_{\mathrm{x}}$ preparation using BDD anodes lead to superior charge transfer properties of the material, determined by ferrocyanide/ferricyanide redox couple cyclic voltammetry $\left(\mathrm{Fe}^{2+/ 3+} \mathrm{CV}\right)$ and electrochemical impedance spectroscopy (EIS). Using absorption spectroscopy in the VIS/NIR range, and time of flight - secondary ion mass spectrometry (TOFSIMS) the superior properties of $\mathrm{TiO}_{\mathrm{x}}$ prepared with BDD could be correlated to 
incorporation of hydrogen. Electrochemical characterization of the noble metal sensitive HER showed significantly higher activity for $\mathrm{TiO}_{\mathrm{x}}$ prepared using Ir-MMO anodes indicating traces of $\mathrm{Ir}$ contamination on the $\mathrm{TiO}_{\mathrm{x}}$ surface, having a negative impact on the reductive doping of the $\mathrm{TiO}_{\mathrm{x}}$.

Although conductive $\mathrm{TiO}_{x}$ electrodes were successfully prepared in Chapter 4, still stability of the conductive films under anodic polarization was poor. In Chapter 5 $\mathrm{Nb}$ doped $\mathrm{TiO}_{2}$ was treated by cathodization, and the stability of these electrodes in anodic utilization was studied. The cathodization improved the charge transfer properties (determined by $\mathrm{Fe}^{2+/ 3+} \mathrm{CV}$ and EIS) of the substrate and the obtained $\mathrm{TiO}_{\mathrm{x}}: \mathrm{Nb}$ electrodes showed a more than two times improved stability under anodic polarization compared to $\mathrm{TiO}_{\mathrm{x}}$. However, the initial charge transfer properties were inferior to $\mathrm{TiO}_{\mathrm{x}}$, which is explained by an improved HER activity observed for $\mathrm{TiO}_{2}: \mathrm{Nb}$ substrates, negatively influencing the cathodization process. Stability of the $\mathrm{Nb}$-doped $\mathrm{TiO}_{\mathrm{x}}$ could be improved further by using fast polarization switches, which is a promising strategy to extend the lifetime of $\mathrm{TiO}_{\mathrm{x}}$ based electrodes.

Finally, in Chapter 6 electrochemical post-treatment of anodically treated saline wastewater is discussed. Reduction of hypochlorite and chlorate was studied using $\mathrm{Ti}$, platinized $\mathrm{Ti}$, Ir/Ru based MMO, or cathodized $\mathrm{TiO}_{\mathrm{x}}$ (see Chapter 4) at relevant conditions for wastewater treatment. All electrodes were active for the reduction of hypochlorite and superior activity was observed for Ti electrodes. Importantly, the reductive treatment with Ti electrodes was limited by poor mass transport properties in the used batch reactor. Therefore, a novel electrode type based on porous hollow fibre geometry was utilized to achieve enhanced mass transfer properties. Indeed, the Ti hollow fibre electrodes lead to efficient removal of hypochlorite, thus lowering the toxicity of electrooxidized wastewater. Reduction of chlorate was not achieved with any of the tested electrode materials under the conditions studied. Still, electroreductive post-treatment is a promising strategy to reduce the toxicity levels of anodically treated saline wastewater.

This chapter (Chapter 7) summarizes the research carried out in this thesis and provides main conclusions. In addition, it gives an outlook and recommendations for future research. 
Looking at the technologies (electro- or photocatalysis), it can be concluded that, despite many years of research, these technologies cannot be considered as fully understood and developed, especially for saline water treatment. For example, the complexity of degradation pathways, and formation of intermediates and byproducts are manifold, depending on the chemical structure of the compounds, the applied process conditions, and the overall composition of the wastewater matrix. Therefore, it is of special importance to validate the electrodes or photocatalysts in real wastewater applications, to address and verify their suitability. Comparing the results of Chapters 2 and 3 shows that if chlorination is observed in electrochemical treatment of model compounds, this can also be expected in practical conditions. Mitigation of these compounds, including oxychlorides, is thus a necessity.

Despite the advantage of photocatalytic degradation treatment for saline wastewater compared to electrochemical degradation, drawbacks need to be overcome to realize applications on a larger scale, e.g. by optimized reactor design and UV illumination (e.g. by UV-A LEDs) to enhance the degradation rates, illumination efficiency and to reduce the energy consumption and thereby the costs of the treatment. Considering the $D O W$ case study (Chapter 3 ), the treatment of $2.8 \cdot 10^{6} \mathrm{~L}$ per day would require approximately a $10 \mathrm{~h}$ treatment time with $1400 \mathrm{~kg} \mathrm{TiO}_{2}$ in a reactor with dimensions of about $14 \mathrm{~m} \times 14 \mathrm{~m} \times 14 \mathrm{~m}$. Such a scale up would be an enormous engineering challenge, in particular to ensure sufficient illumination of the slurry, likely resulting in high costs. Thus, combinations with other technologies are required, for example as pre-treatment to reduce the amount of water to be treated, and to reduce the TOC content to lower levels, to enable shorter illumination times and smaller reactor volumes. For example, after a membrane treatment the retentate stream (TOC rich but low volume) could be treated biologically (e.g. in wetlands or by saline water resistant microbes) to reduce the biologically degradable TOC content before photocatalytic degradation treatment for the degradation of recalcitrant compounds. In addition, a (mild) desalination step could lower the salinity, thus mitigate the inhibitory effect of anions allowing for a faster removal in the photocatalytic degradation. Furthermore, a biological post-treatment could continue the degradation of partially degraded intermediates from photocatalytic degradation (i.e. hydroxylated aromatics and/or break-down products such as short chained carboxylic acids). 
In addition, the improved understanding of fundamental processes during photocatalysis and photoelectrocatalysis might also open new opportunities and create ideas for further development of novel photocatalysts or application for photoelectrocatalysis. In particular for saline water treatment it is important to fully understand the interaction of ions with photo(electro)catalysts and to develop strategies to mitigate inhibitory effects or oxidation of chloride. Here, electrostatic interactions and/or barriers for anions might play a key role.

For the electrochemical wastewater treatment, the scale up can benefit from experience in industrial electrolysis (e.g. production of chlorine). Moreover, realization of a continuous process is possible, compared to batch processing needed for photocatalytic degradation. However, considering that the treatment of large volumes (e.g. CTBD water) requires large electrode areas, imposes reduction of the electrode costs along with improvements in electrode lifetimes.

In this thesis it was shown that electrochemically reduced $\mathrm{TiO}_{x}$ on cheap $\mathrm{Ti}$ substrates, can be easily prepared. This method can likely also be applied to other substrate geometries (e.g. sponge, fibre etc.) to allow for high electrode surface areas. Moreover, operation using reversed polarization allows for extended lifetimes of the material. Nevertheless, in this thesis stability was only evaluated for operation on short time scale, which should be significantly extended for longer durability tests, to determine if electrochemical degradation is feasible in practice.

Furthermore, for the electrochemical degradation treatment the oxidation of chloride leading to the formation of harmful oxychlorides and chlorinated organic compounds is a critical drawback preventing many applications. Therefore, strategies to lower the chloride concentration in the wastewater (e.g. by desalination), prevent or limit its oxidation (e.g. by advanced electrode development or process design) along with technologies to reduce generated oxychlorides as demonstrated in Chapter 6 (and maybe also even chlorinated organic compounds) are mandatory to bring the technology to application. For example, after mild desalination, wastewater might be treated in a cycled system for short contact times on electrodes with high affinity for TOC removal (rather than chloride oxidation). Subsequently the water can be treated reductively at hollow fibre electrodes with inert gas purge, for the selective reduction of chlorinated intermediates and oxychlorides. Since the scale-up and reactor design for implementing hollow-fibre electrodes is still in its infancy, 
alternative electrode designs, allowing for gas purge at the electrode-electrolyte interface, should be assessed in hypochlorite reduction. In addition, elevated temperatures (e.g. inherent for CTBD water) might be beneficial for the removal of chlorate.

In general, it can be stated that the treatment of complex wastewater streams with high requirements for the effluent is a challenging task, which might require a combination of treatment strategies. The costs of the treatment might increase with increasing complexity of the treatment procedure. Therefore, not only improvements in treatment technologies are required, but also the prevention of water pollution, and limited application (where possible) of harmful and non-biodegradable compounds, is a key element for a sustainable development. 
Samenvatting 
Het tekort aan en de vervuiling van zoet water zijn enorme problemen voor de mensheid. Een toereikende hoeveelheid schoon zoet water is cruciaal voor het milieu, menselijke gezondheid en de economie. Het hergebruik van behandeld afvalwater heeft grote potentie in de industriële sector. In het bijzonder als daardoor de winning van zoet water kan worden verminderd, waarmee wordt bijgedragen aan duurzame (proces)ontwikkeling. Helaas zijn problematische niet-biologisch afbreekbare organische stoffen moeilijk te verwijderen. Geavanceerde oxidatieve processen (AOP) zijn veelbelovende technologieën, die in staat zijn deze organische stoffen te verwijderen door middel van hun sterke oxidatieve kracht. Daardoor heeft de toepassing van deze technieken de potentie tot het verbeteren van de kwaliteit van behandeld afvalwater. Het onderzoeksproject beschreven in dit proefschrift heeft als doel om het begrip en de ontwikkeling te bevorderen van twee AOP technieken alsook van gerelateerde materialen voor de behandeling van zout afvalwater. In het bijzonder is in detail gekeken naar de behandeling van afvalwater door middel van i) fotokatalytische degradatie door UV-bestraalde $\mathrm{TiO}_{2}$ slurries, en ii) elektrochemische degradatie door anodisch gevormde oxidatieve stoffen zoals $\mathrm{OH}$ en $\mathrm{Cl}$ radicalen (ook wel bekend als elektrochemische geavanceerde oxidatieprocessen (EAOP)). Dit proefschrift bestaat uit zeven hoofdstukken, waarvan vijf de hoofdresultaten beschrijven.

Hoofdstuk 1 biedt een beknopte introductie van watervervuiling en zoetwatertekorten. De uitdagingen van waterbehandeling worden genoemd en het concept van AOP wordt genoemd. De basisprincipes van het gebruik, de voor- en nadelen en uitdagingen met betrekking tot het implementeren van elektrochemische degradatie worden toegelicht. In het bijzonder vormt de formatie van voornamelijk onbekende tussenproducten een groot obstakel bij de implementatie van AOP technologieën. Gedeeltelijke oxidatie en de complexe degradatiemechanismen die daaraan ten grondslag liggen, en die beïnvloed worden door de water matrix en de toegepaste techniek, leiden tot de vorming van een scala van tussen- en bijproducten, waaronder ook onwenselijke zeer giftige stoffen. Het vrijkomen of lossen van deze stoffen zal waarschijnlijk consequenties hebben voor het milieu en menselijke gezondheid. Verder vereist de implementatie van EAOP de ontwikkeling van geschikte elektrodes. Hierbij worden elektrodes gebaseerd op $\mathrm{TiO}_{2}$ gezien als veelbelovend vanwege de reactieve hydroxylradicalen die zij kunnen genereren. Daarnaast zijn elektrodes op basis van $\mathrm{TiO}_{2}$ voordelig omdat ze bestaan uit overvloedig beschikbare elementen, en zijn ze corrosiebestendig en niet giftig. 
In Hoofdstuk 2 worden fotokatalytische en elektrochemische degradatie vergeleken op basis van behandelingsefficiëntie, energie benodigdheden en neiging tot de vorming van gechloreerde aromatische stoffen. Concreet wordt de behandeling van de modelstof 4-ethylphenol in zout water $\left(1.75 \mathrm{~g} \mathrm{~L}^{-1}\right.$ en $\left.35 \mathrm{~g} \mathrm{~L}^{-1} \mathrm{NaCl}\right)$ bestudeerd om de twee AOP technologieën te evalueren. Analyse liet zien dat de elektrochemische degradatie de hoeveelheid 4-ethylphenol effectiever verminderde in afvalwater wat chloride bevat. Echter werden significante hoeveelheden 2-chloro4-ethylphenol en 2,6-dichloro-4-ethylphenol gevormd in een meerstaps degradatiemechanisme, waarna ongeïdentificeerde gechloreerde stoffen werden gevormd. Dit mechanisme bleek onafhankelijk van het anodemateriaal (Pt op Ti of met boor gedopeerd diamant (BDD)). Bovendien was de algehele mineralisatie slecht, met een waarde van 36\% (bij gebruik van een BDD anode) niet-vluchtige organische koolstof bij lage zout concentratie. Dit was niet zo bij de fotokatalytische degradatie: deze leek onderdrukt te worden in de aanwezigheid van chloride ionen, maar er werden enkel gehydroxileerde aromatische tussenproducten gevormd zelfs bij een hoge concentratie zout. Bovendien werd mineralisatie bereikt tot $87 \%$ (bij lage zout concentratie). De verschillen tussen de geobserveerde degradatiemechanismen en het gebrek aan gechloreerde tussenproducten werden bediscussieerd op basis van een recombinatieproces op de nano lengteschaal, waarbij oxidatie gevolgd door reductie van reactie chloor stoffen wordt bevoordeeld in het geval van fotokatalytische degradatie. Dit werd experimenteel onderbouwd door fotoelektrochemie uit te voeren op dunne lagen $\mathrm{TiO}_{2}$, waarbij significant meer gechloreerde stoffen gevormd werden. Bij inachtneming van het energiegebruik per verwijderde hoeveel organisch koolstof is elektrochemische degradatie voordeliger dan fotokatalytische degradatie; echter had de fotokatalytische degradatie reactor een lage verlichtingsefficiëntie en kan optimalisatie van het ontwerp hiervan waarschijnlijk leiden tot verbetering van de energetische efficiëntie van het proces.

Het onderzoek van Hoofdstuk 2 werd uitgebreid om ook echt afvalwater te omvatten, en de resultaten hiervan zijn samengevat in Hoofdstuk 3. Een casus binnen het Water Nexus project gebruikte spuiwater van een koeltoren (CTBD water) van $D O W$ Benelux B.V. als echte afvalwater matrix. Vanwege de complexiteit van dit afvalwater werden de totale hoeveelheid organische koolstof (TOC) en het chemisch zuurstofverbruik (COD) gebruikt als maat voor de verwijdering van organische stoffen. Beide technologieën bleken in staat significante hoeveelheden organische stoffen uit het CTBD water te verwijderen en resulteerden in een vergelijkbare TOC 
verwijdering van ongeveer $55 \%$ na 5 uur continue behandeling. Tijdens fotokatalytische degradatie leidde de oxidatie van organische stoffen (gevolgd door COD) tot mineralisatie. Bij elektrochemische degradatie werd een snellere COD verwijdering geobserveerd; echter leidde de superieure oxidatie van de organische stoffen niet tot volledige mineralisatie, wat een verschil in degradatiemechanisme aangeeft ten opzichte van fotokatalytische degradatie. Analyse van bijproducten onthulde een verhoogde vorming van adsorbeerbare organische halogeniden (AOX) en oxychlorides tijdens elektrochemische degradatie, terwijl de vorming hiervan bij fotokatalytische degradatie verwaarloosbaar was. Dit onderzoek geeft aan dat chlorering een primair mechanisme is bij elektrochemische degradatie van CTBD water.

Op basis van de resultaten in hoofdstukken 2 en 3 lijkt fotokatalytische degradatie de voorkeur te hebben als AOP techniek voor het behandelen van zout afvalwater. Echter gaat deze techniek ook gepaard met grote nadelen. Fotokatalytische degradatie wordt gelimiteerd door anionen, gaat gepaard met lage efficiëntie (vanwege de recombinatie van fotogegenereerde ladingsdragers), en de vereiste UV licht bestraling vormt een grote uitdaging om op te schalen. Op de genoemde punten bezit elektrochemische degradatie het voordeel. Om de elektrochemische behandeling van (zout) afvalwater te implementeren zijn nieuwe elektrodematerialen nodig, die kosteneffectief, niet giftig en stabiel zijn. Bovendien moeten strategieën ontwikkeld worden om de vorming of ophoping van (gechloreerde) giftige tussen- en bijproducten te voorkomen. In de volgende hoofdstukken worden deze uitdagingen behandeld.

Zoals beschreven in de introductie zijn elektrodes gebaseerd op $\mathrm{TiO}_{2}$ veelbelovend voor de mineralisatie van organische stoffen. In Hoofdstuk 4 werd een elektrochemische methode (kathodisatie) ontwikkeld om defectrijke en zeer geleidende $\mathrm{TiO}_{x}$ elektrodes te creëren. In het bijzonder werd de invloed van de tegenelektrode (hier als anode) op de eigenschappen van $\mathrm{TiO}_{\mathrm{x}}$ onderzocht. $\mathrm{Pt}$ anodes bleken ernstige Pt vervuiling van het $\mathrm{TiO}_{\mathrm{x}}$ teweeg te brengen, wat een sterke invloed had op de activiteit van de waterstof evolutie reactie (HER) van het materiaal. Anodes van gemengde oxides op basis van iridium (Ir-MMO, ook wel bekend als dimensionally stable anodes) resulteerden niet in meetbare Ir vervuiling op het $\mathrm{TiO}_{\mathrm{x}}$ oppervlak. Gebruik van een BDD anode leidde echter tot superieure ladingsoverdracht van het materiaal, gemeten met het ferro-ferricyanide 
redoxkoppel tijdens cyclische voltammetrie $\left(\mathrm{Fe}^{2+/ 3+} \mathrm{CV}\right)$ en elektrochemische impedantie spectroscopie (EIS). Met behulp van absorptie spectroscopie in de VIS/NIR regio en time-of-flight secundaire ionen massaspectrometrie (TOF-SIMS) konden de superieure eigenschappen van $\mathrm{TiO}_{\mathrm{x}}$ bereid met BDD worden gecorreleerd met de inlijving van waterstof. Elektrochemische karakterisatie van HER, die gevoelig is voor edelmetalen, demonstreerde een significant hogere activiteit voor $\mathrm{TiO}_{\mathrm{x}}$ gekathodiseerd met Ir-MMO anodes, wat duidt op sporen van Ir verontreiniging op het $\mathrm{TiO}_{x}$ oppervlak die een negatief effect hebben op de reductieve doping van het $\mathrm{TiO}_{x}$.

Hoewel in Hoofdstuk 4 met succes geleidende $\mathrm{TiO}_{\mathrm{x}}$ elektrodes zijn gefabriceerd, bleef de stabiliteit van deze geleidende lagen slecht tijdens anodische polarisatie. In Hoofdstuk 5 werd met $\mathrm{Nb}$ gedopeerd $\mathrm{TiO}_{2}$ gekathodiseerd, en werd de stabiliteit van deze elektrodes tijdens gebruik als anode bestudeerd. De kathodisatie verbeterde de ladingsoverdracht (bepaald met $\mathrm{Fe}^{2+/ 3+} \mathrm{CV}$ en EIS) van het substraat en de behaalde $\mathrm{TiO}_{\mathrm{x}}: \mathrm{Nb}$ elektrodes demonstreerden meer dan tweemaal de stabiliteit tijdens anodische polarisatie in vergelijking met $\mathrm{TiO}_{\mathrm{x}}$. Echter was de initiële ladingsoverdracht inferieur aan die van $\mathrm{TiO}_{\mathrm{x}}$, wat werd verklaard door een verbeterde HER activiteit van de $\mathrm{TiO}_{2}: \mathrm{Nb}$ substraten die het kathodisatieproces negatief beïnvloed. De stabiliteit van $\mathrm{Nb}$-gedopeerd $\mathrm{TiO}_{\mathrm{x}}$ kan nog verder worden verbeterd door het gebruik van snelle polarisatiewissels, een veelbelovende strategie om de levensduur van $\mathrm{TiO}_{x}$ elektrodes te verlengen.

Tot slot komt in Hoofdstuk 6 de elektrochemische nabehandeling van anodisch behandeld zout afvalwater aan de orde. Reductie van hypochloriet en chloraat werd bestudeerd door toepassing van een $\mathrm{Ti}, \mathrm{Pt}$ op $\mathrm{Ti}$, Ir/Ru MMO, of gekathodiseerd $\mathrm{TiO}_{\mathrm{x}}$ (zie Hoofdstuk 4) in omstandigheden relevant voor afvalwaterverwerking. Alle elektrodes waren actief in de hypochloriet reductie, en de $\mathrm{TiO}_{\mathrm{x}}$ elektrode vertoonde superieure activiteit. Van belang is dat de reductiebehandeling bij Ti elektrodes werd gelimiteerd door het slechte massatransport in de gebruikte batchreactor. Een innovatieve reactorgeometrie met holle vezel elektrode werd toegepast om het massetransport te verbeteren. De holle vezel Ti elektrodes zorgde inderdaad voor efficiënte verwijdering van hypochloriet, waardoor de giftigheid van het elektrogeoxideerde afvalwater werd verminderd. Reductie van chloraat was door geen van de elektrodematerialen mogelijk in de bestudeerde omstandigheden. 
Desondanks is elektroreductieve nabehandeling een veelbelovende strategie om de giftigheid van anodisch behandeld zout afvalwater te verlagen.

Dit hoofdstuk (Hoofdstuk 7) vat het uitgevoerde onderzoek in deze thesis samen en presenteert de voornaamste conclusies. Daarnaast biedt het een perspectief en aanbevelingen voor toekomstig onderzoek. 


\section{Acknowledgements}

At the end of this thesis and of four years $\mathrm{PhD}$ it is time to express my gratitude to many people who supported me and contributed to this book. It has been a challenging and inspiring time influencing my life. I learned much, had great experiences, many discussions and conversations and I have met many people I will remember.

First of all, I want to thank my supervisor Guido Mul and my co-supervisor Bastian Mei for all your support, enthusiasm and discussions allowing me to carry out this $\mathrm{PhD}$ project and develop myself. Guido, special thanks to you for giving me the opportunity and freedom to do the $\mathrm{PhD}$ in your group and for your positive attitude. Bastian, thank you for all your time, suggestions and motivating words. It has been a great time working with you both.

I want to acknowledge my committee members for reading and evaluating my thesis. Thank you for attending my defence.

Many thanks to Robert Meijer for your technical support and help during my $\mathrm{PhD}$. Dorothy Wold-Deen and Lidy Harryvan-Mug, thanks a lot for your help regarding organizational matters, paper work and always being cheerful. Thanks to Annemarie Huijser for our collaboration. I enjoyed working with you and I learned a lot from you.

Special thanks to my paranymphs Vera and Nakul. I greatly appreciate your help and support, our conversations and your positive vibe. Thanks to my office mates, Piotr, Liniker and Vera. I am very grateful for the good atmosphere I experienced in our office and all the discussions we had. I will certainly miss that nice environment. Moreover, Ronald, Devin, Myles, Kasper, Ainoa, Mozhgan, thank you for being around, for all our discussions and conversations, your help and all the fun and social events we had together. Thanks to all other people of the PCS group and to my 
previous colleagues Alex and Kai. I had a great time in this group, which I will not forget.

I acknowledge the Water Nexus project for the funding and all the project partners. Special thanks to Pradip Saha, Adriaan Jeremiasse, Kitty Nijmeijer and Benjamin Chatillon. I enjoyed our collaborations, meetings and discussions. I am very thankful for all your input.

I want to acknowledge further collaborators and people I worked together with and who helped me during my PhD: Mark Smithers, Gerard Kip, Marko Sturm, Uwe Breuer, Caroline Lievens, Pengyu Xu, Erna Fränzel-Luiten, Andries van Swaaij and Pushkar Marathe. Thank you!

Thanks to all the students I could work together with during their assignments and internships, Alyssa, Ainoa, Sobhan, Lucas, Dyllian, Elmar and Jens. I enjoyed working and discussing with you. Thank you all for your work and input.

Many thanks to Melissa Gile for your help designing the cover of my thesis.

Thanks to all people who supported me during my studies and contributed to my education and development.

Finally, I want to express special thanks to my family and friends, especially to my parents and my partner Nancy. Without your love and support this would not have been possible. Thank you!

Robert Brüninghoff, Mai 2020 


\section{List of Publications}

\section{Journal Articles}

Robert Brüninghoff, Alyssa K. van Duijne, Lucas Braakhuis, Pradip Saha, Adriaan W. Jeremiasse, Bastian Mei, Guido Mul, Comparative analysis of photocatalytic and electrochemical degradation of 4-ethylphenol in saline conditions, Environmental Science \& Technology, 2019, 53, $8725-8735$

Robert Brüninghoff, Kasper Wenderich, Jeroen P. Korterik, Bastian T. Mei, Guido Mul, Annemarie Huijser, Time-dependent photoluminescence of nanostructured anatase $\mathrm{TiO}_{2}$ and the role of bulk and surface processes, Journal of Physical Chemistry C, 2019, 123, 43, 26653-26661

Robert Brüninghoff, Ainoa Paradelo Rodríguez, Ronald P.H. Jong, Jacobus M. Sturm, Uwe Breuer, Caroline Lievens, Adriaan W. Jeremiasse, Guido Mul, Bastian Mei, Electrochemical preparation of defect-engineered titania: bulk doping versus surface contamination; in preparation

Robert Brüninghoff, Pradip Saha, Piotr M. Krzywda, Adriaan W. Jeremiasse, Guido Mul, Bastian Mei, Cathodic reduction of oxychlorides in electrooxidized saline water; in preparation

Pradip Saha, Yicheng Wang, Mahsa Moradia, Robert Brüninghoff, Gholamreza Moussavi, Bastian Mei, Guido Mul, Huub H. M. Rijnaarts, Harry Bruning, Comparison of advanced oxidation processes for cooling tower blowdown organic compounds removal: organic carbon and chlorinated species evaluations; in preparation

\section{International Conference Proceedings}

Robert Brüninghoff, Alyssa K. van Duijne, Lucas Braakhuis, Pradip Saha, Adriaan W. Jeremiasse, Bastian Mei, Guido Mul, Comparative analysis of chlorinated intermediates formed during electrochemical and photo(electro)catalytic degradation of 4-ethylphenol in saline media, $16^{\text {th }}$ International Conference on Environmental Science and Technology, CEST 2019_00206 


\section{Oral Presentations}

$236^{\text {th }}$ Electrochemical Society Meeting, Atlanta, USA, 13. - 17. October 2019, Electrochemical preparation of $\mathrm{TiO}_{\mathrm{x}}$-electrodes: effect of the counter electrode on the charge transfer properties

$16^{\text {th }}$ International Conference on Environmental Science \& Technology, Rhodes, Greece, 4. - 7. September 2019, Comparative analysis of chlorinated intermediates formed during electrochemical and photo(electro)catalytic degradation of 4-ethylphenol in saline media

International Water Conference - Water Science for Impact, Wageningen University, The Netherlands, 16. - 18. October 2018, The influence of sodium chloride on the electrochemical conversion of 4-ethylphenol in water

\section{Poster Presentations}

$20^{\text {th }}$ Netherlands Catalysis \& Chemistry Conference, Noordwijkerhout, The Netherlands, 04. - 06. March 2019, The effect of the applied anode during electrochemical preparation on catalytic properties of $\mathrm{TiO}_{\mathrm{x}}$-electrodes

$19^{\text {th }}$ Netherlands Catalysis \& Chemistry Conference, Noordwijkerhout, The Netherlands, 05. - 07. March 2018, The influence of sodium chloride on the conversion of 4-ethylphenol during the electrochemical advanced oxidation process 


\section{About the Author}

Robert Brüninghoff was born on the $22^{\text {nd }}$ of September 1988 in Stadtlohn, Germany. After a vocational training as chemical laboratory assistant he studied chemical engineering with focus on applied chemistry at Münster University of Applied Sciences (Germany). He received his BSc degree in 2013 after a five-month research internship at Brunel University, London (United Kingdom), where he worked on inorganic phosphor materials. During his master studies (chemical engineering - applied chemistry, Münster

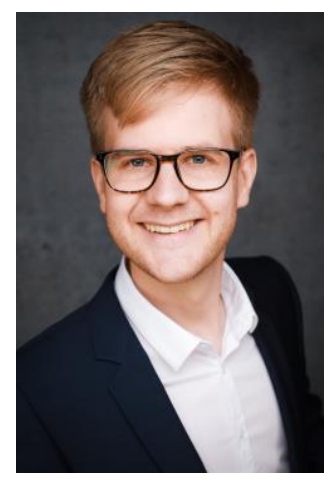
University of Applied Sciences) Robert focussed on analytical chemistry and materials science. He obtained his MSc degree in 2016 after a research internship in the Photocatalytic Synthesis group at the University of Twente (The Netherlands), where he studied the modification of microstructured Si pillars by electrochemical deposition of $\mathrm{TiO}_{2}$ for photocatalytic water purification. After the graduation, he continued his research in the Photocatalytic Synthesis group as $\mathrm{PhD}$ candidate. During his doctoral project Robert worked on Advanced Oxidation Processes for the treatment of saline wastewater. In particular, he focussed on pollutant degradation studies during photo(electro)catalytic and electrochemical oxidation. Moreover, he studied electrochemical doping of $\mathrm{TiO}_{2}$ to achieve electrically conductive electrode materials. The research of his doctoral project is described here in this thesis. 
